\title{
Synthesis of New Composites of Inorganic Polymers (Geopolymers) with Metal Oxide Nanoparticles and their Photodegradation of Organic Pollutants
}

\author{
By \\ Mahroo Falah
}

\begin{abstract}
A thesis
Submitted to Victoria University of Wellington in fulfilment of the requirements for the degree of Doctor of Philosophy in Chemistry
\end{abstract}

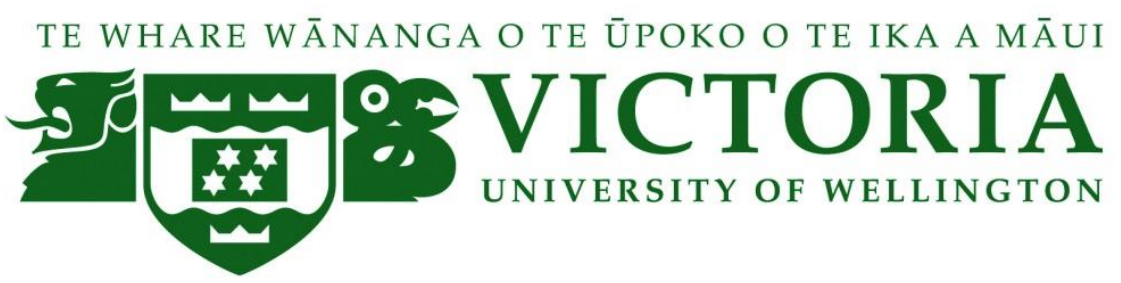

Victoria University of Wellington

2015 



\section{Synthesis of New Composites of Inorganic Polymers (Geopolymers) with Metal Oxide Nanoparticles and their Photodegradation of Organic Pollutants}

\section{Abstract}

This thesis describes the development and performance of novel photocatalytic inorganic polymer (geopolymer) composites for photodegradation of environmentally harmful organic materials. Nanometer-sized cubic cuprous oxide nanoparticles and spherical $\mathrm{Cu}_{2} \mathrm{O} / \mathrm{TiO}_{2}$ nanoheterostructures were synthesized via a precipitation method and then added to a metakaolinite-based geopolymer matrix prior to curing at ambient temperature.

The morphology of the homogeneous oxide nanoparticle dispersion within the geopolymer matrix was demonstrated by SEM/EDS and HRTEM. FTIR spectroscopy confirmed the formation of a well-reacted geopolymer matrix that was unaffected by the insertion of the $\mathrm{Cu}_{2} \mathrm{O}$ and $\mathrm{Cu}_{2} \mathrm{O} / \mathrm{TiO}_{2}$ nanoparticles. The structures of these new composites were determined by ${ }^{27} \mathrm{Al}$ and ${ }^{29} \mathrm{Si}$ MAS NMR spectroscopy. ${ }^{63} \mathrm{Cu}$ NQR spectroscopy and XRD confirmed that the metal oxide nanoparticles are unchanged by their incorporation in the geopolymer composite and after the photodegradation reactions. The nitrogen adsorption-desorption isotherms were determined, providing information about the specific surface areas and total pore volumes of the composites. The action of the composites in the adsorption and photocatalytic destruction of the model organic compound MB was determined under dark and UV illumination conditions. Experiments in dark conditions and under UV irradiation showed that these materials efficiently remove a model organic pollutant (MB dye) from solution by a dual process of adsorption on the geopolymer matrix, and photodecomposition of the dye without destroying the geopolymer structure. The adsorption kinetics of the dye are best described by a pseudo first-order model and the adsorption process by LangmuirFreundlich isotherms.

In a novel extension of this research, the metakaolinite-based geopolymer matrix was modified with a surfactant (cetyltrimethylammonium bromide, CTAB), exploiting the cation exchange capacity of the geopolymers structure. The nano oxide composites were synthesised by adding different amounts of as-prepared metal oxide nanoparticles to the modified geoplymer to produce a hydrophobic photocatalyst composite with improved photocatalytic activity arising from the dispersion of the metal oxide nanoparticles in the external surfaces 
and interlayers of the geopolymer matrix. This method has the advantage of producing geopolymer composites with a stable $\mathrm{pH}$ which are more suitable for dye degradation studies. At concentrations $>20 \mathrm{wt} \%$, the photo-oxide component decreases the adsorption rate by blocking the active adsorption sites of the geopolymer. Under UV radiation, the composites remove the MB by a combination of adsorption and photodegradation, without deterioration of the geopolymer structure or the photoactive metal oxide component.

In addition these studies show that the metal oxide-geopolymer nano composites have significantly improved photocatalytic activity compared with the oxide nanoparticles alone, because of the unique properties of these inorganic polymers. These results demonstrate that composites of nanosized $\mathrm{Cu}_{2} \mathrm{O}$ particles and photoreactive $\mathrm{TiO}_{2}$ in an aluminosilicate inorganic polymer matrix constitute new and novel materials with potential environmental protection applications to efficiently remove organic pollutants from water or the atmosphere. 


\section{Acknowledgements}

My sincere gratitude goes to my supervisor, Professor Kenneth J.D. MacKenzie for the opportunity to do research under his supervision. Thank you for selflessly giving of your knowledge, time and guidance; your patience, and enthusiasm that made this work a reality cannot be quantified. I also express my thanks to Dr. Ruth Knibbe for assistance in interpreting the TEM micrographs. I really was honoured to have the opportunity to work with both of you.

I would also like to express my appreciation to Dr. John V. Hanna, NMR Centre, University of Warwick, UK, for acquiring the ${ }^{63} \mathrm{Cu}$ NQR spectra. The XRF elemental analyses were provided by SpectraChem Services, and the nitrogen adsorption/desorption measurements by Callaghan Innovation.

Many thanks to the MacDiarmid Institute for Advanced Materials and Nanotechnology for the financial support of a PhD Fellowship.

My sincere thanks to all respective staff, technicians, School of Chemical and Physical Sciences and the Callaghan Innovation Centre, for their cooperation and support. Special thanks to David Flynn for assistance with the electron microscopy.

Last but definitely not least, my deepest and most heart-felt gratitude to my beloved mum, and my adored dad, for their endless love and support.

Those who are directly and indirectly involved in this research, your given contribution will not be forgotten. My appreciation to all of you.

Mahroo 


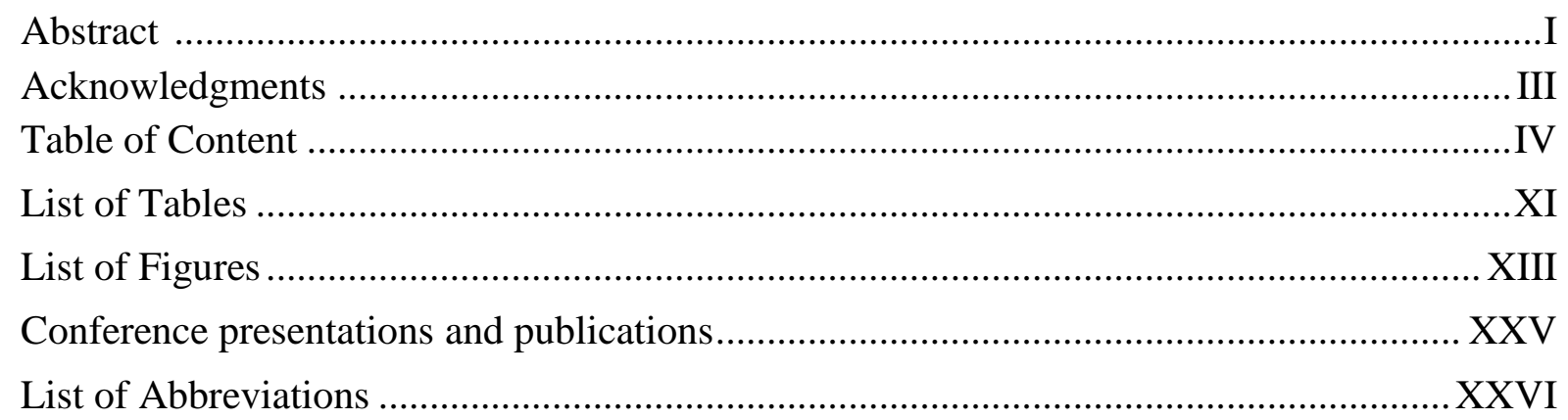

Chapter 1

Introduction 1

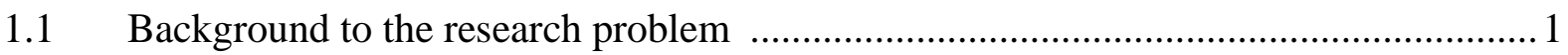

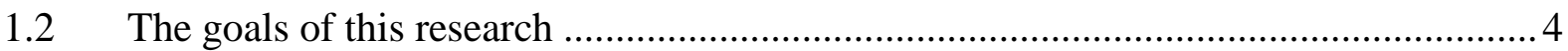

1.3 Dissertation Objectives and Motivation................................................................ 6

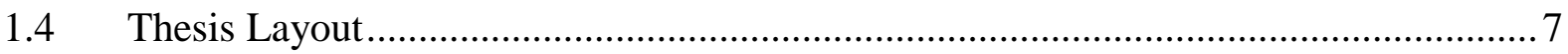

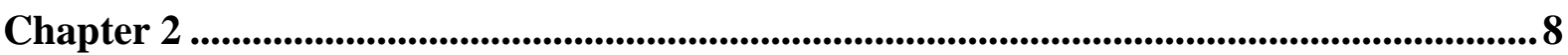

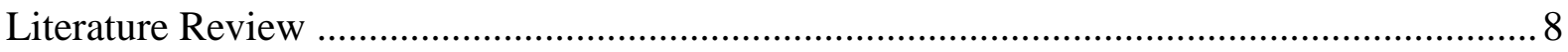

2.1 Fundamentals of the photocatalytic process …................................................... 8

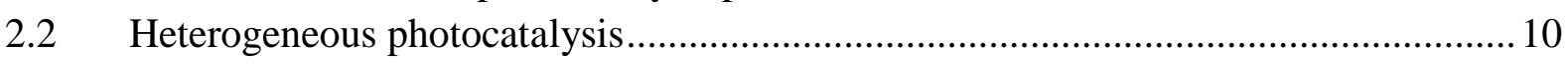

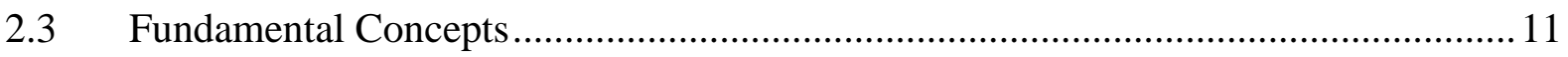

2.3.1 Insulators, conductors, and semiconductors …....................................................... 11

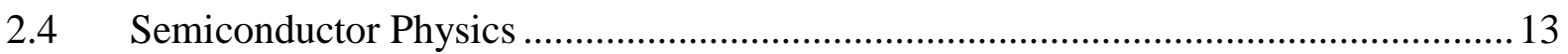

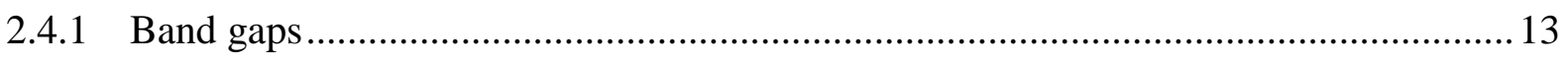

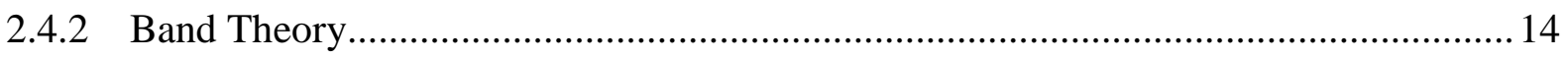

2.5 Basic principles and mechanism for photocatalyzed dye degradation ....................... 15 
2.5.1 Indirect dye degradation mechanism

2.5.2 Direct mechanism for dye degradation

2.6 $\mathrm{Cu}_{2} \mathrm{O}$ Photocatalyst

2.6.1 The mechanism of photo-oxidation in $\mathrm{Cu}_{2} \mathrm{O}$

2.7 The Geopolymer Matrix of the Proposed New Photocatalytic Materials: Raw Materials Used to Make Geopolymers

2.7.1 Metakaolin (dehydroxylated kaolinite)

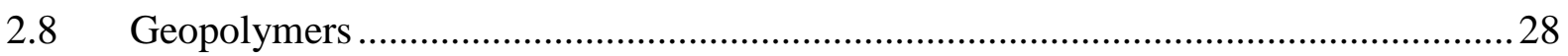

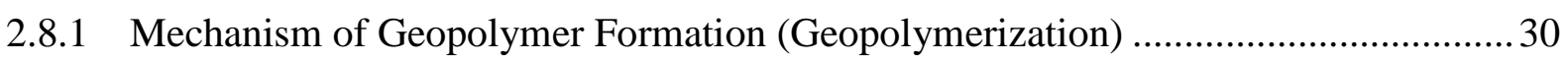

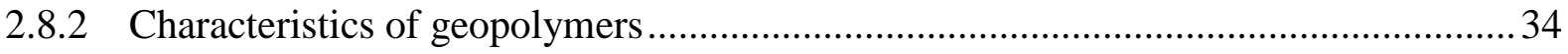

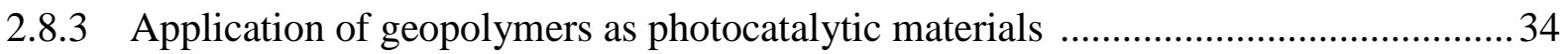

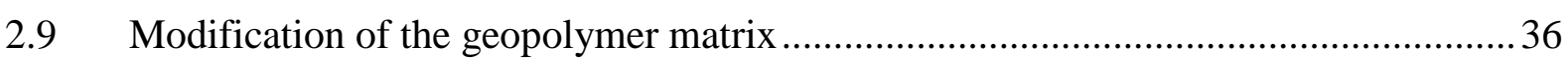

Chapter 3

Methodology

3.1 Preparation of Sodium-Geopolymer (Na-GP) ................................................... 41

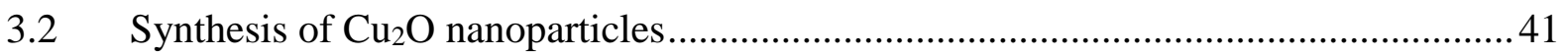

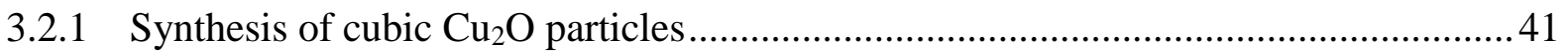

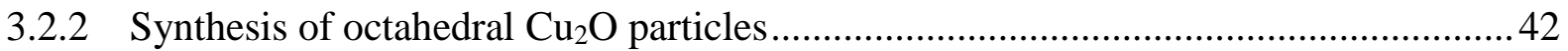

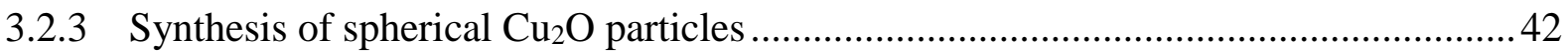

3.2.4 Another Method for Synthesising $\mathrm{Cu}_{2} \mathrm{O}$ Nanoparticles: The Reduction Method ....... 43

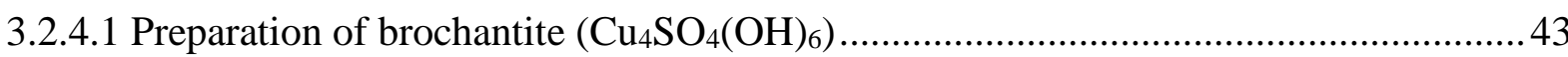

3.2.4.2 One-step synthesis of tenorite $(\mathrm{CuO})$ nanoparticles from $\mathrm{Cu}_{4}\left(\mathrm{SO}_{4}\right)(\mathrm{OH})_{6}$ by a direct

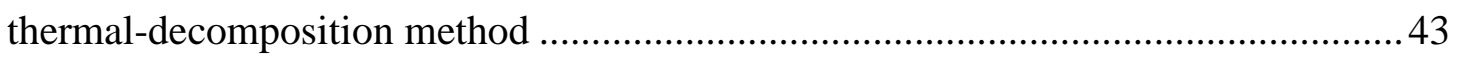

3.2.4.3 Formation of stable $\mathrm{Cu}_{2} \mathrm{O}$ by reduction of $\mathrm{CuO}$ nanoparticles ................................. 43

3.3 Synthesis of spherical $\mathrm{Cu}_{2} \mathrm{O} / \mathrm{TiO}_{2}$ nano-heterostructures ....................................... 44

3.4 Preparation of Na-Geopolymer Composites Containing $\mathrm{Cu}_{2} \mathrm{O}$.................................4 44 
3.6 Preparation of CTAB-Modified Na-Geopolymer Matrix ............................................ 45

3.7 Preparation of CTAB-modified Na-Geopolymer Composites Containing $\mathrm{Cu}_{2} \mathrm{O} \ldots \ldots . . .45$

3.8 Preparation of CTAB-modified GP Composites Containing $\mathrm{Cu}_{2} \mathrm{O} / \mathrm{TiO}_{2} \ldots \ldots \ldots \ldots \ldots \ldots . . . . . . . .46$

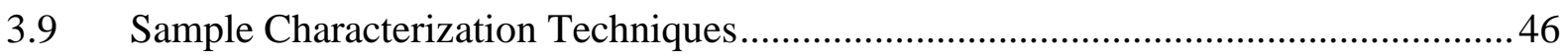

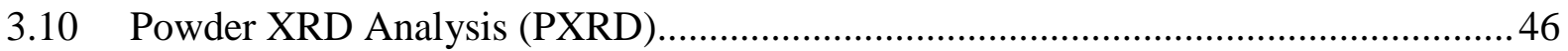

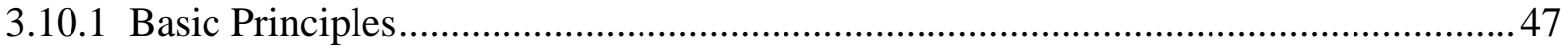

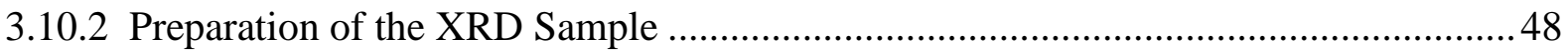

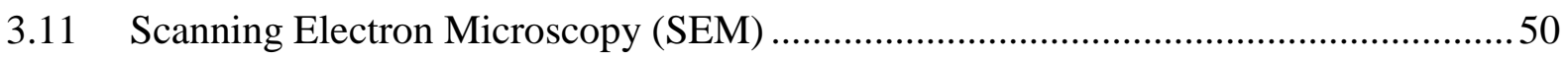

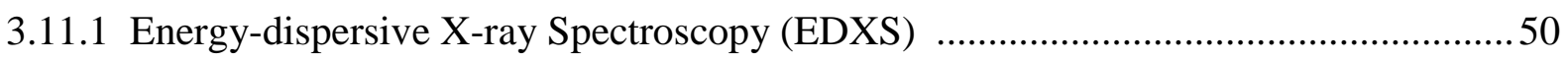

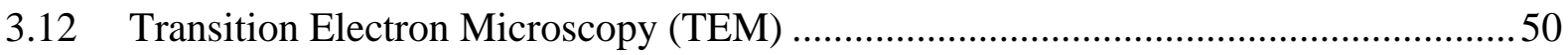

3.13 Fourier Transform Infrared Spectroscopy (FTIR) …............................................. 51

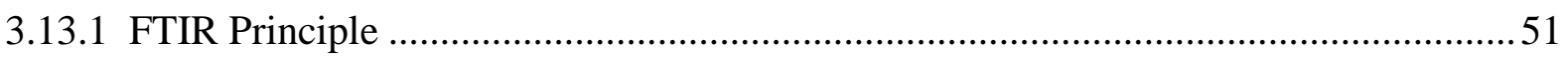

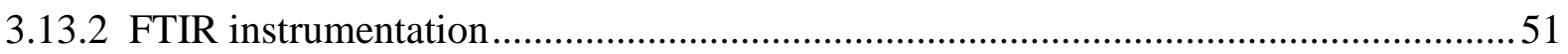

3.14 Nuclear Magnetic Resonance Spectroscopy (MAS NMR) …....................................53

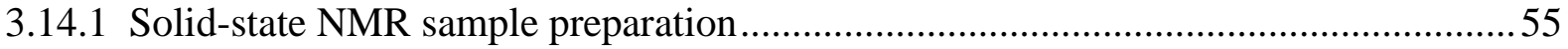

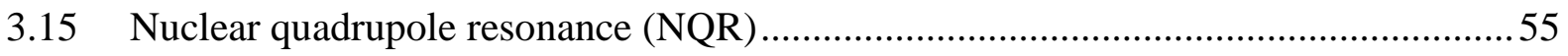

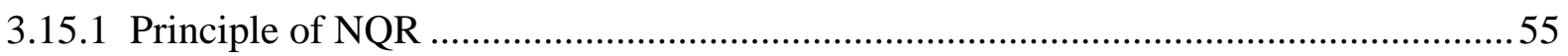

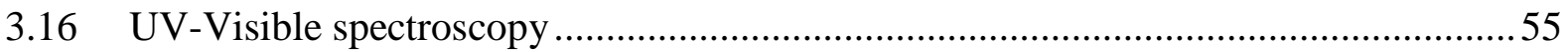

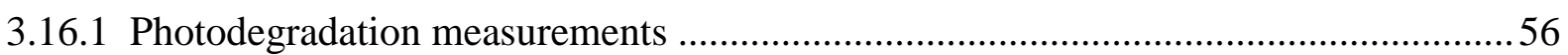

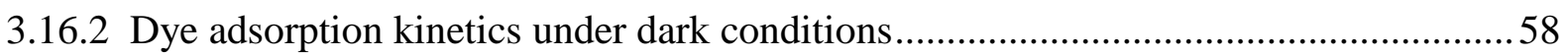

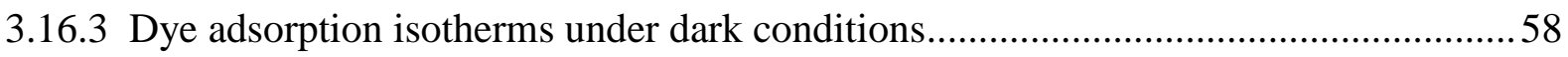




\section{Chapter 4}

Synthesis and characterization of new photoactive geopolymer composites with $\mathrm{Cu}_{2} \mathrm{O}$ nanoparticles

Introduction

4.1 Results and Discussion 60

4.1.1 XRD Analysis 60

4.2 Scanning electron microscopy

4.3 FTIR spectra of these samples .68

4.4 ${ }^{63} \mathrm{Cu}$ NQR Spectroscopy 69

4.5 $\quad{ }^{29} \mathrm{Si}$ and ${ }^{27} \mathrm{Al}$ solid state MAS NMR .70

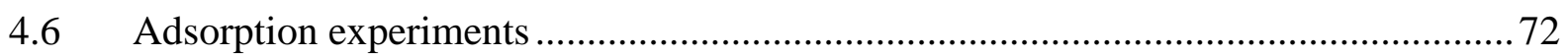

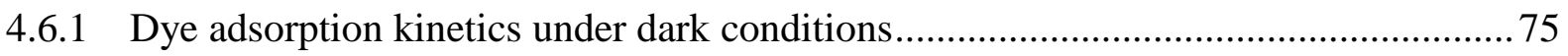

4.6.2 Dye adsorption isotherms under dark conditions................................................... 77

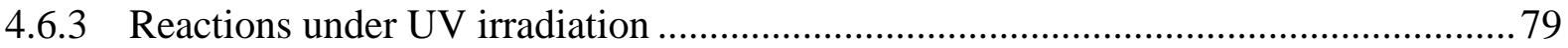

Conclusions

Chapter 5

Synthesis, characterization and photoactive properties of geopolymer composites with $\mathrm{Cu}_{2} \mathrm{O}$ $/ \mathrm{TiO}_{2}$ nano-heterostructures and $\mathrm{P} 25$ titania

Introduction .85

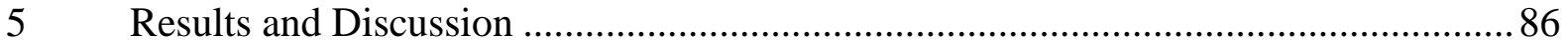

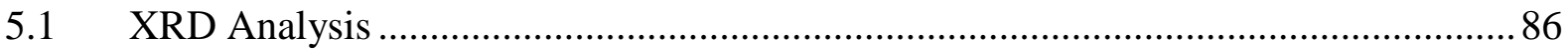


5.2 Scanning electron microscopy

5.3 High-Resolution Transmission Electron Microscopy ............................................... 90

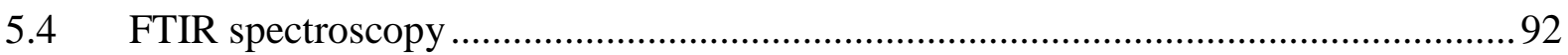

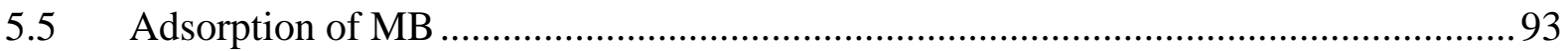

5.5.1 Reactions under dark conditions (adsorption on the matrix) ..................................93

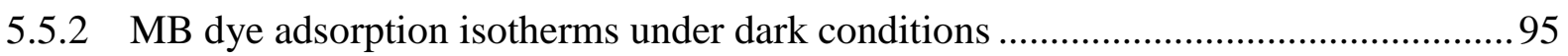

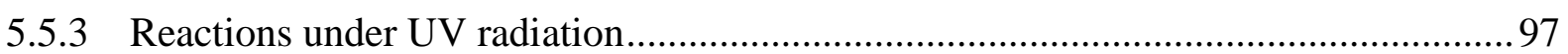

5.5.4 Adsorption and degradation of $\mathrm{MB}$ dye by $\mathrm{P} 25$ titania, $\mathrm{Cu}_{2} \mathrm{O}$ and their geopolymer

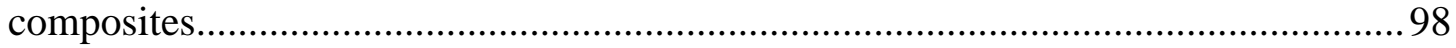

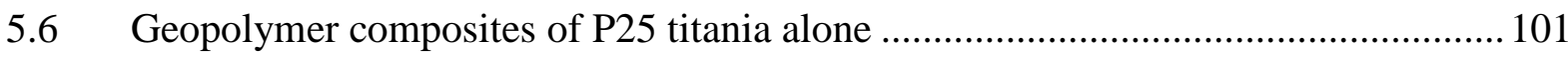

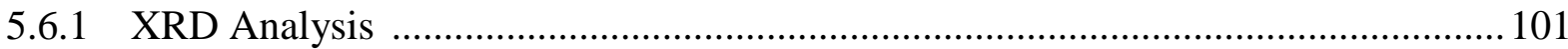

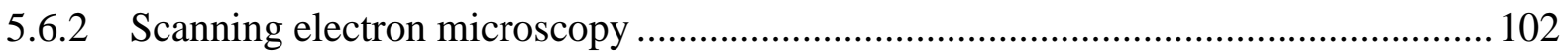

5.6.3 High-Resolution Transmission Electron Microscopy................................................ 104

5.6.4 Nitrogen Adsorption/Desorption Isotherms......................................................... 105

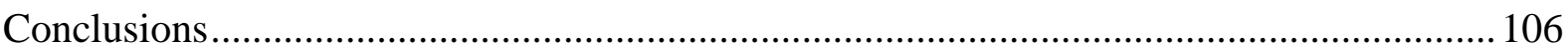

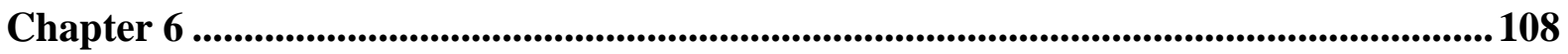

Composites containing $\mathrm{Cu}_{2} \mathrm{O}$ nanoparticles supported on an expanded geopolymer matrix

Introduction

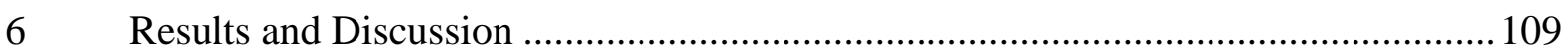

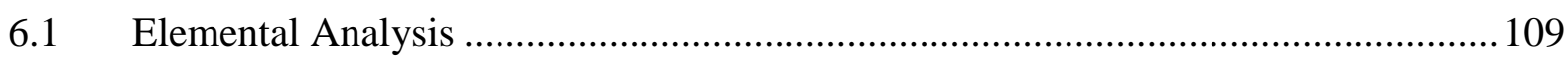

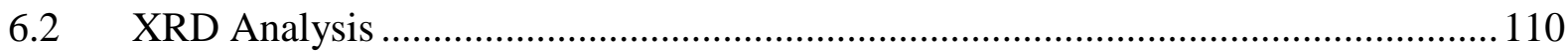

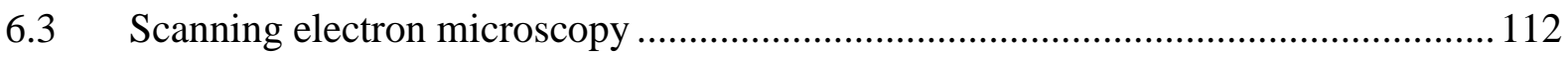

6.4 High-Resolution Transmission Electron Microscopy ................................................ 115

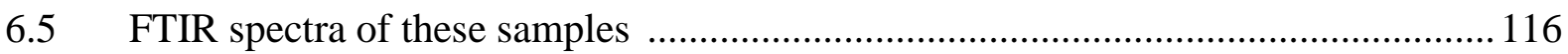

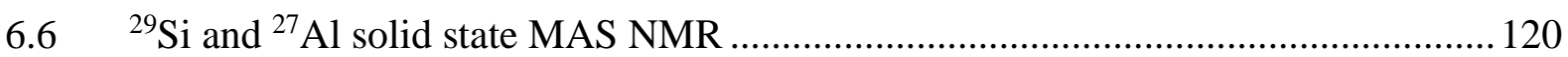


6.7 Adsorption of MB

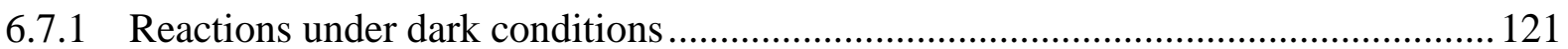

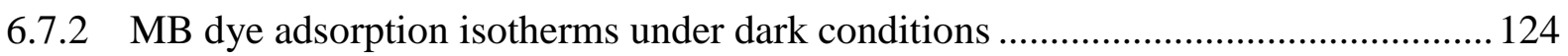

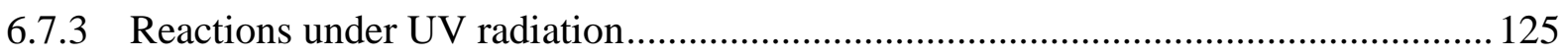

6.7.4 Nitrogen Adsorption/Desorption Isotherms........................................................... 127

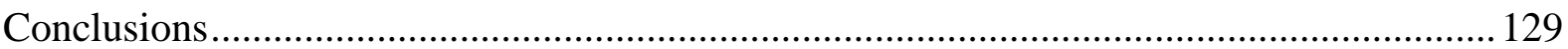

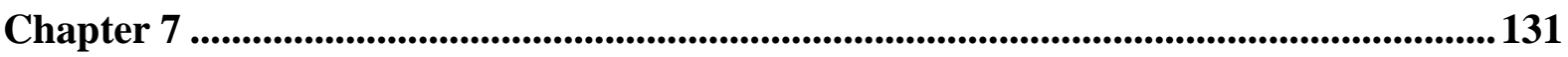

Composites of CTAB-modified geopolymer matrices containing $\mathrm{Cu}_{2} \mathrm{O} / \mathrm{TiO}_{2}$ nanoheterostructures and P25 titania

Introduction

$7 \quad$ Results and Discussion

7.1 Elemental Analysis

7.2 XRD Analysis

7.3 Scanning electron microscopy

7.4 High Resolution Transmission Electron Microscopy 136

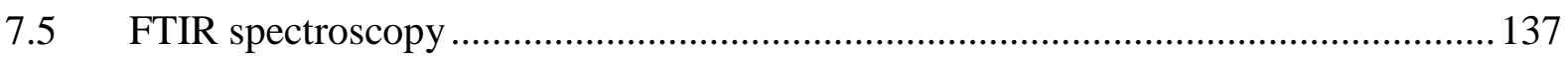

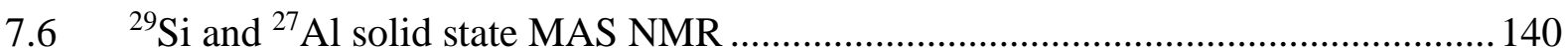

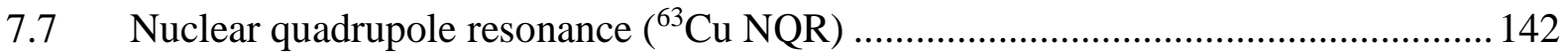

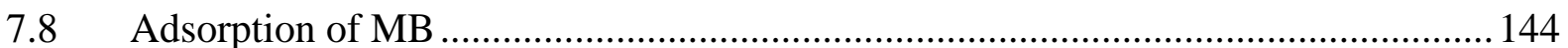

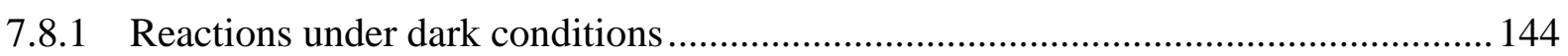

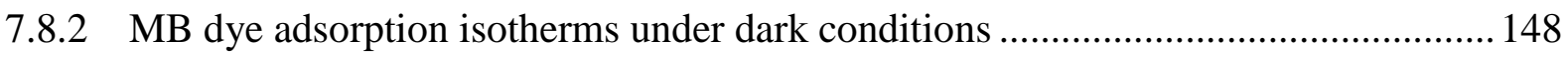




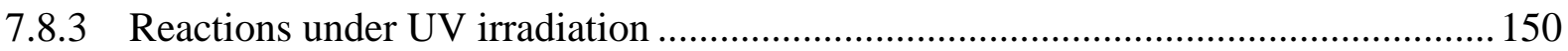

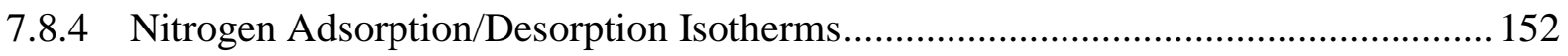

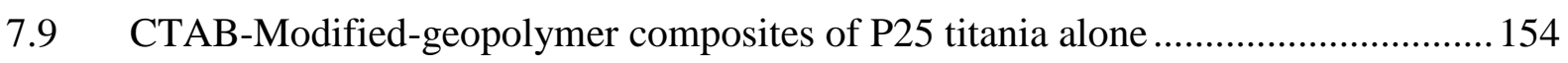

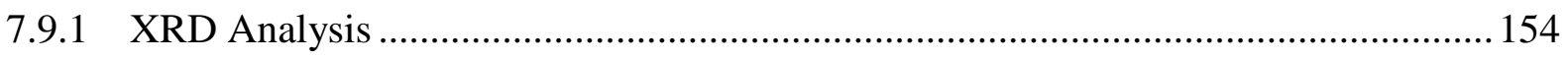

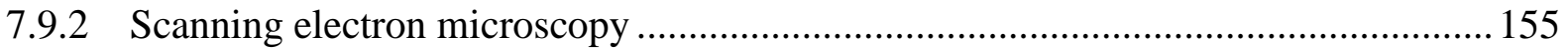

7.9.3 High-Resolution Transmission Electron Microscopy .............................................. 157

7.9.4 Adsorption and degradation of $\mathrm{MB}$ dye by $\mathrm{P} 25$ titania, $\mathrm{Cu}_{2} \mathrm{O}, \mathrm{Cu}_{2} \mathrm{O} / \mathrm{TiO}_{2}$ and their

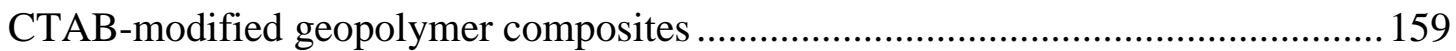

7.9.5 Nitrogen Adsorption/Desorption Isotherms.......................................................... 161

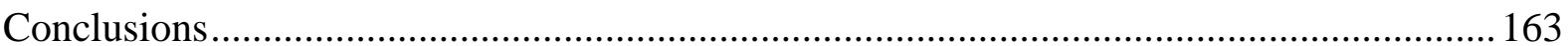

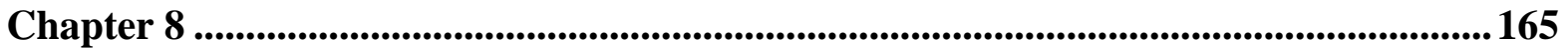

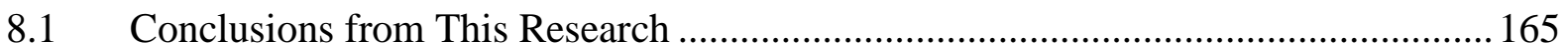

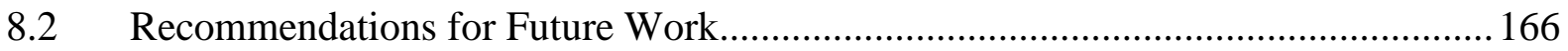

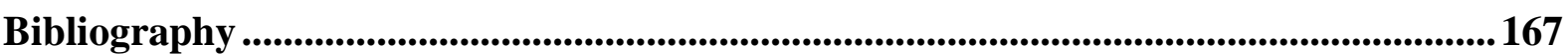




\section{List of Tables}

$\underline{\text { Table }}$

$\underline{\text { Page }}$

2.1 Comparison of main advantages/disadvantages of heterogeneous and homogenous photocatalysis

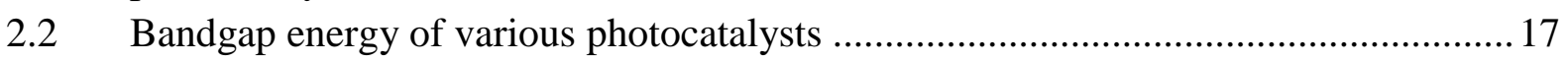

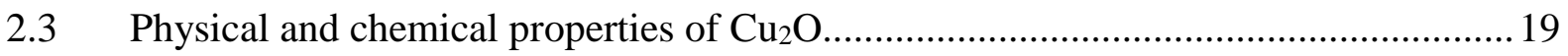

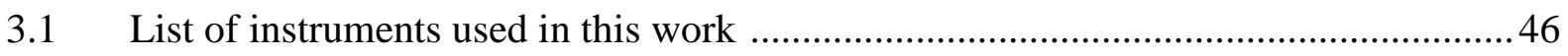

3.2 Assigned crystalline phases and measured reflections ..............................................49

3.3 IR characteristic bands and corresponding species of metakaolin and GPs ...............53

4.1 Parameters for kinetic models of MB adsorption on samples ....................................77

4.2 Calculated isotherm parameters for MB adsorption on samples .............................. 78

5.1 Calculated parameters for kinetic models of $\mathrm{MB}$ adsorption on samples containing

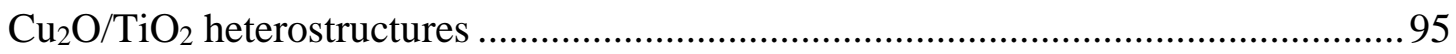

5.2 Specific surface areas and pore parameters of GP and GP composites .................... 106

6.1 XRF analysis (wt\%) of major elements of geopolymer samples with different compositions ................................................................................................ 110

6.2 Positions and assignments of the IR vibration bands observed in the range of 400-

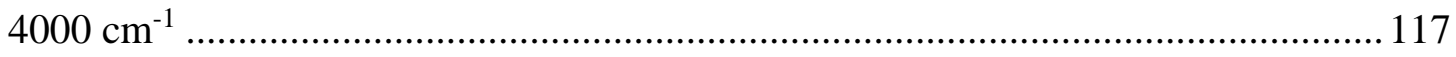

6.3 Parameters for kinetic models of MB adsorption on CTAB-based samples ............ 123

6.4 Specific surface areas and pore parameters of GP and GP composites ................. 129

7.1 XRF analysis (wt\%) of major elements of GP samples with different compositions

7.2 Positions and assignments of the IR vibration bands observed in the range of 400$4000 \mathrm{~cm}^{-1}$

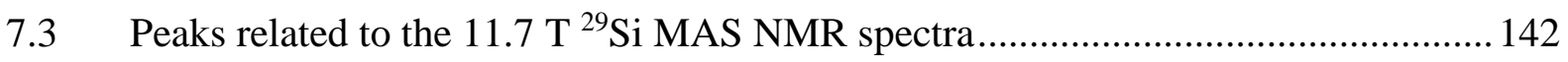

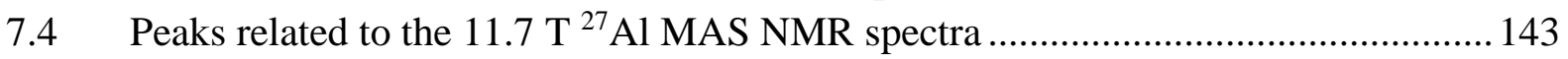

7.5 Parameters for kinetic models of MB adsorption on samples ................................. 147

7.6 Specific surface areas and pore parameters of M-GP matrix and GP composites..... 154

7.7 Specific surface areas and pore parameters of GP, M-GP and their composites containing $\mathrm{TiO}_{2}, \mathrm{Cu}_{2} \mathrm{O}$ and $\mathrm{Cu}_{2} \mathrm{O} / \mathrm{TiO}_{2}$ 


\section{List of Figures}

$\underline{\text { Figure }}$

$\underline{\text { Page }}$

1.1 Inorganic pollutants: $\mathrm{CO}$, VOC (benzene, toluene, etc), methyl mercaptan (gas), organic chlorinated compounds, polycondensed aromatic compounds, acetaldehyde, formaldehyde. Organic pollutant: $\mathrm{NO}_{\mathrm{X}}, \mathrm{SO}_{\mathrm{X}}, \mathrm{NH}_{3}$ (gas)

1.2 Titanium Dioxide nanoparticles used in an environmentally-friendly water purification system with twice the efficiency of current materials 4

2.1 Metal-modified semiconductor photocatalyst particle 9

2.2 Energy band diagrams for (a) Insulators; (b) and (c) conductors, and (d) semiconductors

2.3 Three types of semiconductors: a) intrinsic semiconductors, b) n-type semiconductors, and c) p-type semiconductors

2.4 Photon absorption and charge carrier pair generation

2.5 Formation of bands in a semiconductor

2.6 Pictorial representation of indirect dye degradation process

2.7 The unit cell of the cuprite $\mathrm{Cu}_{2} \mathrm{O}$

2.8 Conventional shapes of face-centered cubic (fcc) metals, surface is enclosed by (100) and (111) facets. Black and gray colors represent the (100) and (111) facets, correspondingly

2.9 SEM images of the $\mathrm{Cu}_{2} \mathrm{O}$ nanocrystals with various morphologies .20 
2.10 Powder XRD patterns of the different morphologies of $\mathrm{Cu}_{2} \mathrm{O}$ nanocrystals. A standard diffraction pattern of $\mathrm{Cu}_{2} \mathrm{O}$ is also given

2.11 Eg values (in $\mathrm{eV}$ ) and position of $\mathrm{CB}$ (blue) and $\mathrm{VB}$ (pink) for various semiconductors at $\mathrm{pH}=0 \mathrm{vs}$. NHE

2.12 SEM images of $\mathrm{Cu}_{2} \mathrm{O}$ samples after irradiation for (a) 0 , (b) 1 , and (c) $16 \mathrm{~h}$ 24

2.13 (Left), XRD patterns of $\mathrm{Cu}_{2} \mathrm{O}$ irradiated for (a) 0, (b) 1, and (c) $16 \mathrm{~h}$ in $\mathrm{MO}$ solution. (Right) schematic diagram showing charge separation among the different crystal faces and regeneration of $\mathrm{Cu}_{2} \mathrm{O}$ nanosheets

2.14 Overview of the redox potentials of the relevant reactions with respect to the estimated position of the $\mathrm{Cu}_{2} \mathrm{O}$ band edges

2.15 Structure of the kaolinite unit .28

2.16 Sketch of the typical reaction mechanism of geopolymerization 32

2.17 (a) Proposed model for the location of the charge balancing $\mathrm{Na}^{+}$cation that assumes the form of a semi attached $\mathrm{Na}$ aluminate species. (b) Proposed model for the site of the charge balancing $\mathrm{Na}^{+}$cation that assumes the form of a modified bridging network. (c) proposed a schematic structural model of AIP structure based on an original model by Barbosa et al. .33

2.18 Typical XRD spectrum of a GP 34

2.19 EDS element quantification of Ti ion-exchanged GPs: (Left) $90{ }^{\circ} \mathrm{C} \mathrm{Na} \mathrm{GP,} \mathrm{(Right)} 90$ ${ }^{\circ} \mathrm{C} \mathrm{NH}$

2.20 (a) XRD pattern of powdered ion-exchanged GPs, (b) UV-Vis reflectance spectra of $90{ }^{\circ} \mathrm{C}$ Na-derived GP and $90{ }^{\circ} \mathrm{C} \mathrm{NH}$-derived GP, (c) Photoactive bleaching of MB by $\mathrm{TiO}_{2}$ particles in Na-derived GP 36

2.21 Schematic for the preparation of $\operatorname{Ti}(x) \mathrm{C}_{16}(y)-\mathrm{Mt}$ 39

2.22 (a,b) TEM images of $\mathrm{Ti}(25) \mathrm{C} 16(1.0)$-MMT sample calcined at $600{ }^{\circ} \mathrm{C}$ 39 
3.1 XRD by lattice planes. Schematic illustration of Bragg's Law ..... 48

3.2 Diagram of an FTIR spectrophotometer. .52

3.3 Fourier transformation of free induction decay (FID) in the time domain to an NMR spectrum in the frequency domain 54

3.4 Illustration of a single beam UV-visible instrument. .56

4.1 Normalized XRD patterns of $\mathrm{GP}$ and $\mathrm{Cu}_{2} \mathrm{O}$ and $\mathrm{Cu}_{2} \mathrm{O}$ supported by GP with different loading contents; (a) GP, (b) GP-10 wt $\% \mathrm{Cu}_{2} \mathrm{O}$, ( (c) GP-20 wt $\% \mathrm{Cu}_{2} \mathrm{O}$, (d) GP-30 wt $\% \mathrm{Cu}_{2} \mathrm{O}$, (e) GP-30 wt $\% \mathrm{Cu}_{2} \mathrm{O}$-under UV with $\mathrm{MB}$, (f) $\mathrm{GP}-20$ wt $\% \mathrm{Cu}_{2} \mathrm{O}$-under $\mathrm{UV}$ with $\mathrm{MB},(\mathrm{g}) \mathrm{Cu}_{2} \mathrm{O}$.

4.2 SEM micrographs of $\mathrm{Cu}_{2} \mathrm{O}$ octahedral (a, b) and spherical (c, d) synthesized via a typical procedure described in the experimental section 3.2.2 and 3.2.3

4.3 (a-d) SEM micrographs of $\mathrm{Cu}_{2} \mathrm{O}$ nanocubes at different magnifications synthesized via a typical procedure described in the experimental section 3.2.1

4.4 (a-c) TEM micrographs of the $\mathrm{Cu}_{2} \mathrm{O}$ nanocubes, (d) SAED pattern, (e) HRTEM image of $\mathrm{Cu}_{2} \mathrm{O}$, (f, $\mathrm{g}$ ) corresponding Fast Fourier Transformation (FFT) patterns of region I and II in panel e 64

4.5 XRD pattern of as-prepared $\mathrm{Cu}_{2} \mathrm{O}$ nanocubes synthesised by the method of Bai et al.

4.6 SEM micrographs of (a) GP matrix, (b) GP-10 wt $\% \mathrm{Cu}_{2} \mathrm{O}$, (c) GP-20 wt $\% \mathrm{Cu}_{2} \mathrm{O}$, (d) GP-30 wt $\% \mathrm{Cu}_{2} \mathrm{O}$

4.7 (a) Backscattered SEM image of ground $\mathrm{GP}-30 \mathrm{wt} \% \mathrm{Cu}_{2} \mathrm{O}$ with corresponding, (b) $\mathrm{Na}$, (c) $\mathrm{Al}$, (d) $\mathrm{Si}$, (e) Cu elemental map

4.8 EDS data of (a) GP, (b) GP- $10 \mathrm{wt} \% \mathrm{Cu}_{2} \mathrm{O}$ (c) GP- $20 \mathrm{wt} \% \mathrm{Cu}_{2} \mathrm{O}$ (d) GP- $30 \mathrm{wt} \%$ $\mathrm{Cu}_{2} \mathrm{O}$

4.9 FTIR spectra of (a) GP, (b) GP- $10 \mathrm{wt} \% \mathrm{Cu}_{2} \mathrm{O}$, (c) GP- $20 \mathrm{wt} \% \mathrm{Cu}_{2} \mathrm{O}$, (d) GP- 30 wt $\% \mathrm{Cu}_{2} \mathrm{O}$, (e) $\mathrm{Cu}_{2} \mathrm{O}$ 68

4.10 ${ }^{63} \mathrm{Cu}$ NQR spectra of nanoparticle $\mathrm{Cu}_{2} \mathrm{O}$ and $\mathrm{Cu}_{2} \mathrm{O} / \mathrm{GP}$ composites. (a) as-synthesized $\mathrm{Cu}_{2} \mathrm{O}$, (b) $\mathrm{Cu}_{2} \mathrm{O}$ after UV irradiation, (c) $\mathrm{Cu}_{2} \mathrm{O} / \mathrm{GP}$ composite before UV irradiation, (d) $\mathrm{Cu}_{2} \mathrm{O} / \mathrm{GP}$ composite after UV irradiation .70

4.11 $11.7 \mathrm{~T}^{29} \mathrm{Si}$ MAS NMR spectra. (a) GP, (b) GP-10 wt $\% \mathrm{Cu}_{2} \mathrm{O}$, (c) GP-20 wt $\% \mathrm{Cu}_{2} \mathrm{O}$, (d) $\mathrm{GP}-30 \mathrm{wt} \% \mathrm{Cu}_{2} \mathrm{O}$ 71

4.12 11.7 $\mathrm{T}^{27} \mathrm{Al}$ MAS NMR spectra. (a) GP, (b) GP-10 wt $\% \mathrm{Cu}_{2} \mathrm{O}$, (c) GP-20 wt $\% \mathrm{Cu}_{2} \mathrm{O}$, (d) $\mathrm{GP}-30 \mathrm{wt} \% \mathrm{Cu}_{2} \mathrm{O}$ 72 
4.13 UV-vis absorption spectra of the MB solution during adsorption in the dark by (a) GP, (b) GP-10 wt $\% \mathrm{Cu}_{2} \mathrm{O}$, (c) GP-20 wt $\% \mathrm{Cu}_{2} \mathrm{O}$, (d) GP-30 wt $\% \mathrm{Cu}_{2} \mathrm{O}$.

4.14 Plots of the residual concentration $\left(\mathrm{C} / \mathrm{C}_{0}\right)$ vs. time $(\mathrm{t})$ onto the GP matrix, GP- $\mathrm{Cu}_{2} \mathrm{O}$ 10,20 , and $30 \mathrm{wt} \%$ (monitored at $664 \mathrm{~nm}$ in the dark)

4.15 (a) Pseudo first-order kinetics, (b) Pseudo second-order kinetics by the nonlinear method and experimental kinetics for the adsorption of MB onto the GP matrix and GP composites 76

4.16 (a) adsorption isotherms for MB adsorption and the corresponding Langmuir, (b-c) adsorption isotherms for $\mathrm{MB}$ adsorption and the corresponding Freundlich and Langmuir-Freundlich models fits (dashed lines).

4.17 The UV-vis absorption spectra of the MB solution during the photocatalytic degradation in the presence of (a) GP, (b) GP-10 wt $\% \mathrm{Cu}_{2} \mathrm{O}$, (c) GP-20 wt $\% \mathrm{Cu}_{2} \mathrm{O}$, (d) $\mathrm{GP}-30 \mathrm{wt} \% \mathrm{Cu}_{2} \mathrm{O}$ under UV light irradiation 80

4.18 Plots of the residual concentration $\left(\mathrm{C} / \mathrm{C}_{0}\right)$ vs. time $(\mathrm{t})$ onto the $\mathrm{GP}, \mathrm{Cu}_{2} \mathrm{O}-\mathrm{GP}-10,20$, $30 \mathrm{wt} \%$ (monitored at $664 \mathrm{~nm}$ under UV)

4.19 Residual concentration $\left(\mathrm{C} / \mathrm{C}_{0}\right)$ of $\mathrm{MB}$ upon exposure to the GP matrix (GP) and the 30 wt $\% \mathrm{Cu}_{2} \mathrm{O}$ GP composite versus time in the dark and under $\mathrm{UV}$ illumination

4.20 Comparison of $\mathrm{MB}$ removal in the dark and under UV irradiation by the GP matrix, GP-10-30 wt $\% \mathrm{Cu}_{2} \mathrm{O}$ composites and $\mathrm{Cu}_{2} \mathrm{O}$ after 60 min. reaction 83

5.1 XRD patterns of GP and GP composites with different loading contents; (a) GP, (b) $\mathrm{Cu}_{2} \mathrm{O} / \mathrm{TiO}_{2}-\mathrm{GP}\left(10\right.$ wt \%), (c) $\mathrm{Cu}_{2} \mathrm{O} / \mathrm{TiO}_{2}-\mathrm{GP}\left(20 \mathrm{wt} \%\right.$ ), (d) $\mathrm{Cu}_{2} \mathrm{O} / \mathrm{TiO}_{2}-\mathrm{GP}$ (30 wt $\%$ ), (e) $\mathrm{Cu}_{2} \mathrm{O} / \mathrm{TiO}_{2}$, (f) $\mathrm{Cu}_{2} \mathrm{O},(\mathrm{g}) \mathrm{TiO}_{2}(\mathrm{P} 25)$.

5.2 (a-c) SEM micrographs of spherical $\mathrm{Cu}_{2} \mathrm{O} / \mathrm{TiO}_{2}$ at different magnifications, synthesized via the procedure described in Chapter 3

5.3 (a) Backscattered image of $\mathrm{Cu}_{2} \mathrm{O} / \mathrm{TiO}_{2}$, (b) $\mathrm{Ti}$, (c) $\mathrm{Cu}$ EDS map..... .88

5.4 XRD pattern of $\mathrm{Cu}_{2} \mathrm{O} / \mathrm{TiO}_{2}$

5.5 Backscattered SEM micrographs of (a) GP-10 wt $\% \mathrm{Cu}_{2} \mathrm{O} / \mathrm{TiO}_{2}$ composite, (b) GP-20 wt $\% \mathrm{Cu}_{2} \mathrm{O} / \mathrm{TiO}_{2}$ composite, (c) GP-30 wt $\% \mathrm{Cu}_{2} \mathrm{O} / \mathrm{TiO}_{2}$ composite, (d) EDS element spectra of the indicated area of image

5.6 (a) Backscattered SEM image of ground $\mathrm{GP}-30 \mathrm{wt} \% \mathrm{Cu}_{2} \mathrm{O} / \mathrm{TiO}_{2}$ and (b) $\mathrm{Ti}$, (c) $\mathrm{Cu}$, EDS maps, (d) EDS element spectra of the indicated area of image 90 
5.7 (a,b) TEM images of GP-10\%-Cu $\mathrm{Cu}_{2} \mathrm{O} / \mathrm{TiO}_{2}$ composite, (c-e) HRTEM image of a single $\mathrm{Cu}_{2} \mathrm{O}$ and $\mathrm{TiO}_{2}$ crystallite and $\mathrm{Cu}_{2} \mathrm{O} / \mathrm{TiO}_{2}$.

5.8 FTIR spectra of (a) GP matrix, (b) GP-10 wt $\% \mathrm{Cu}_{2} \mathrm{O} / \mathrm{TiO}_{2}$, (c) GP-20 wt \% $\mathrm{Cu}_{2} \mathrm{O} / \mathrm{TiO}_{2}$, (d) $\mathrm{GP}-30$ wt \% $\mathrm{Cu}_{2} \mathrm{O} / \mathrm{TiO}_{2}$, (e) $\mathrm{Cu}_{2} \mathrm{O} / \mathrm{TiO}_{2}$...................................... 92

5.9 Plot of the residual concentration $\left(\mathrm{C} / \mathrm{C}_{0}\right)$ vs. time $(\mathrm{t})$ on the $\mathrm{GP}, \mathrm{Cu}_{2} \mathrm{O} / \mathrm{TiO}_{2}-\mathrm{GP} 10,20$, and $30 \mathrm{wt} \%$ (monitored at $664 \mathrm{~nm}$ ) under dark conditions.

5.10 (a) Pseudo first-order kinetics and (b) Pseudo second-order kinetics by the nonlinear method and experimental kinetics for the adsorption of $\mathrm{MB}$ on the geopolymer matrix and geopolymer composites containing $\mathrm{Cu}_{2} \mathrm{O} / \mathrm{TiO}_{2}$ heterostructures .95

5.11 (a-c) Adsorption isotherms for MB adsorption and the corresponding Langmuir, Freundlich and Langmuir-Freundlich models fit (dashed lines). 96

5.12 Plots of the residual concentration $\left(\mathrm{C} / \mathrm{C}_{0}\right)$ vs. time $(\mathrm{t})$ on the GP matrix and $\mathrm{Cu}_{2} \mathrm{O} / \mathrm{TiO}_{2}-\mathrm{GP} 10,20$, and $30 \mathrm{wt} \%$ composites (monitored at $664 \mathrm{~nm}$ ) under UV irradiation 97

5.13 MB removal after $60 \mathrm{~min}$. by the GP matrix, (10-30 wt $\%)$ GP- $\mathrm{Cu}_{2} \mathrm{O} / \mathrm{TiO}_{2}$ composites, and the $\mathrm{Cu}_{2} \mathrm{O} / \mathrm{TiO}_{2}$ nano-heterostructure

5.14 Residual concentration $\left(\mathrm{C} / \mathrm{C}_{0}\right) v s$. time $(\mathrm{t})$ of $\mathrm{MB}$ dye adsorbed and photodegraded on the $\mathrm{TiO}_{2}, \mathrm{Cu}_{2} \mathrm{O}$ and $\mathrm{Cu}_{2} \mathrm{O} / \mathrm{TiO}_{2}$, compared with the $\mathrm{GP}-\mathrm{Cu}_{2} \mathrm{O} / \mathrm{TiO}_{2}$ composites under (a) dark conditions, (b) UV radiation..... 100

5.15 XRD patterns of GP and $\mathrm{TiO}_{2}$ and $\mathrm{TiO}_{2}$ supported by GP with different loading contents; (a) GP, (b) GP-10 wt \% TiO 2 , (c) GP-20 wt \% $\mathrm{TiO}_{2}$, (d) GP-30 wt \% $\mathrm{TiO}_{2}$, (e) $\mathrm{TiO}_{2}$ 101

5.16 SEM micrograph of (a) GP-10 wt $\% \mathrm{TiO}_{2}$, (b) BSE of GP-10 wt $\% \mathrm{TiO}_{2}$, (c) SEM micrograph of GP-20 wt $\% \mathrm{TiO}_{2}$, (d) BSE of GP-20 wt $\% \mathrm{TiO}_{2}$, (e) SEM micrograph of GP-30 wt $\% \mathrm{TiO}_{2}$, (f) BSE of GP-30 wt $\% \mathrm{TiO}_{2}$, showing $\mathrm{TiO}_{2}$ nanoparticles deposited mainly on the GP surface 102

5.17 (a) Backscattered electron image of GP composite containing $30 \mathrm{wt} \% \mathrm{TiO}_{2}$ and (b) sodium, (c) aluminium, (d) silicon, (e) titanium EDS maps, (f) EDS element spectra of the indicated area of image. 103

5.18 (a-c) TEM images of GP-10\%- $\mathrm{TiO}_{2}$ composite, (d,e) HRTEM images of single crystallite of $\mathrm{TiO}_{2}$ 104

5.19 Nitrogen sorption isotherms of the GP matrix ( $\mathbf{\square}$, adsorption $\square$, desorption), GP-10 wt $\% \mathrm{Cu}_{2} \mathrm{O}-(\boldsymbol{O}$, adsorption $\bigcirc$, desorption $)$ and GP-10 wt $\% \mathrm{TiO}_{2^{-}}(\boldsymbol{\Delta}$, adsorption $\triangle$, desorption) 105 
6.1 XRD patterns of (a) $\mathrm{Cu}_{2} \mathrm{O}$, (b) M-GP-50 wt $\% \mathrm{Cu}_{2} \mathrm{O}$, (c) M-GP-30 wt $\% \mathrm{Cu}_{2} \mathrm{O}$, (d) MGP-15 wt $\% \mathrm{Cu}_{2} \mathrm{O}$, (e) M-GP-10 wt $\% \mathrm{Cu}_{2} \mathrm{O}$, (f) M-GP-5 wt $\% \mathrm{Cu}_{2} \mathrm{O}$, (g) M-GP, (h) GP

6.2 (a) Backscattered SEM image of M-GP and elemental maps of (b) Na, (c) Al, (d) si,

(e) EDS element spectrum. Red rectangular areas in the elemental maps correspond to the EDS spectrum (e) 112

6.3 (a,b) M-GP-5 wt $\% \mathrm{Cu}_{2} \mathrm{O}$ composite, (c,d) M-GP-10 wt $\% \mathrm{Cu}_{2} \mathrm{O}$ composite, (e,f) MGP-15 wt $\% \mathrm{Cu}_{2} \mathrm{O}$ composite, (g,h) M-GP-50 wt $\% \mathrm{Cu}_{2} \mathrm{O}$ composite. Micrographs $\mathrm{b}, \mathrm{d}, \mathrm{f}, \mathrm{h}$ are BSE images, micrographs a,c,e,g are SE images

6.4 (a) Backscattered SEM image of ground $\mathrm{M}-\mathrm{GP}-50 \% \mathrm{Cu}_{2} \mathrm{O}$ and elemental maps of (b) $\mathrm{Na}$, (c) $\mathrm{Al}$, (d) $\mathrm{Si}$, (e) $\mathrm{Cu}$, (f) EDS element spectrum of M-GP-50 wt $\% \mathrm{Cu}_{2} \mathrm{O}$

6.5 (a-e) TEM images of GP-CTAB10\%- $\mathrm{Cu}_{2} \mathrm{O}$ composite, (f) HTREM of selected area in (e)

6.6 STEM and EDX elemental mapping images of M-GP-10 wt $\%-\mathrm{Cu}_{2} \mathrm{O}$ composite. Red circled areas in the elemental maps correspond to the EDS spectrum (f) 116

6.7 FTIR spectra of unmodified GP, M-GP, $\mathrm{Cu}_{2} \mathrm{O}$ and $\mathrm{Cu}_{2} \mathrm{O}$ supported by GP matrix with different loading contents; (a) $\mathrm{Cu}_{2} \mathrm{O}$, (b) M-GP-50 wt $\% \mathrm{Cu}_{2} \mathrm{O}$, (c) M-GP-30 wt $\%$ $\mathrm{Cu}_{2} \mathrm{O}$, (d) M-GP-15 wt $\% \mathrm{Cu}_{2} \mathrm{O}$, (e) M-GP-10 wt $\% \mathrm{Cu}_{2} \mathrm{O}$, (f) $\mathrm{M}-\mathrm{GP}-5 \mathrm{wt} \% \mathrm{Cu}_{2} \mathrm{O}$, (g) M-GP, (h) GP, (i) CTAB

6.8 $11.7 \mathrm{~T}{ }^{29} \mathrm{Si}$ MAS NMR spectra (a) GP, (b) M-GP, (c) M-GP-10 wt $\% \mathrm{Cu}_{2} \mathrm{O}$, (d) MGP-30 wt $\% \mathrm{Cu}_{2} \mathrm{O}$, (e) M-GP-50 wt $\% \mathrm{Cu}_{2} \mathrm{O}$ 120

6.9 $11.7 \mathrm{~T}^{27} \mathrm{Al}$ MAS NMR spectra (a) GP, (b) M-GP, (c) M-GP-10 wt\% Cu $2 \mathrm{O}$, (d) MGP-30 wt $\% \mathrm{Cu}_{2} \mathrm{O}$, (e) M-GP-50 wt $\% \mathrm{Cu}_{2} \mathrm{O}$ 121

6.10 Plots of the residual concentration $\left(\mathrm{C} / \mathrm{C}_{0}\right) v s$. time $(\mathrm{t})$ onto the GP matrix, M-GP 5, 10, 15 and $50 \mathrm{wt} \% \mathrm{Cu}_{2} \mathrm{O}$ (monitored at $664 \mathrm{~nm}$ in dark)

6.11 (a) Pseudo first-order kinetics, (b) Pseudo second-order kinetics by the nonlinear method and experimental kinetics for the adsorption of MB onto M-GP and GP composites 123

6.12 (a,b) adsorption isotherms for MB adsorption and the corresponding Freundlich and Langmuir models fit (dashed lines)

6.12 (Continued) (c) adsorption isotherms for MB adsorption and the corresponding Langmuir-Freundlich models fit (dashed lines). 125

6.13 Plots of the residual concentration $\left(\mathrm{C} / \mathrm{C}_{0}\right)$ vs. time ( $\mathrm{t}$ ) onto the $\mathrm{M}-\mathrm{GP}, \mathrm{Cu}_{2} \mathrm{O}$ and $\mathrm{M}-$ GP-5, 10, 15, $50 \mathrm{wt} \% \mathrm{Cu}_{2} \mathrm{O}$ (monitored at $664 \mathrm{~nm}$ ) under different conditions 126 
6.14 MB removal by the M-GP matrix, M-GP composites containing 5, 10, 15 and $50 \mathrm{wt} \%$ $\mathrm{Cu}_{2} \mathrm{O}$ and $\mathrm{Cu}_{2} \mathrm{O}$ alone after $60 \mathrm{~min}$

6.15 Nitrogen sorption isotherms of the M-GP ( $\mathbf{\square}$, adsorption $\square$, desorption), M-GP- 10 wt $\% \mathrm{Cu}_{2} \mathrm{O}\left(\boldsymbol{O}\right.$, adsorption $\bigcirc$, desorption ) and M-GP-15 wt $\% \mathrm{Cu}_{2} \mathrm{O}(\boldsymbol{\Delta}$, adsorption $\triangle$, desorption) 128

7.1 XRD patterns of M-GP, $\mathrm{Cu}_{2} \mathrm{O} / \mathrm{TiO}_{2}$ and $\mathrm{Cu}_{2} \mathrm{O} / \mathrm{TiO}_{2}$ supported by M-GP matrix with different loading contents; (a) $\mathrm{Cu}_{2} \mathrm{O} / \mathrm{TiO}_{2}$, (b) M-GP-50 wt $\% \mathrm{Cu}_{2} \mathrm{O} / \mathrm{TiO}_{2}$, (c) M-GP$15 \mathrm{wt} \% \mathrm{Cu}_{2} \mathrm{O} / \mathrm{TiO}_{2}$, (d) M-GP-10 wt $\% \mathrm{Cu}_{2} \mathrm{O} / \mathrm{TiO}_{2}$ (e) $\mathrm{M}-\mathrm{GP}-5 \mathrm{wt} \% \mathrm{Cu}_{2} \mathrm{O} / \mathrm{TiO}_{2}$, (f) M-GP, (g) GP.

7.2 (a) $\mathrm{BSE}$ image of powdered $\mathrm{M}-\mathrm{GP}-10 \mathrm{wt} \% \mathrm{Cu}_{2} \mathrm{O} / \mathrm{TiO}_{2}$, (b) $\mathrm{Na}$, (c) $\mathrm{Al}$, (d) Si, (e) $\mathrm{Ti}$, (f) $\mathrm{Cu}$. 134

7.3 SEM micrographs of (a,b) M-GP-5 wt $\% \mathrm{Cu}_{2} \mathrm{O} / \mathrm{TiO}_{2}$, (c,d) M-GP-10 wt $\% \mathrm{Cu}_{2} \mathrm{O} / \mathrm{TiO}_{2}$, (e,f) M-GP-15 wt $\% \mathrm{Cu}_{2} \mathrm{O} / \mathrm{TiO}_{2}$, (g,h) M-GP-50 wt $\% \mathrm{Cu}_{2} \mathrm{O} / \mathrm{TiO}_{2}$. Micrographs on lefthand side of figure are SEM, those on the right hand side are BSE 135

7.4 (a,b) TEM images of M-GP-10 wt $\% \mathrm{Cu}_{2} \mathrm{O} / \mathrm{TiO}_{2}$ composite, (c-e) HRTEM images of M-GP-10 wt $\% \mathrm{Cu}_{2} \mathrm{O} / \mathrm{TiO}_{2}$ composite

7.5 (a) STEM image of M-GP-10 wt $\%-\mathrm{Cu}_{2} \mathrm{O} / \mathrm{TiO}_{2}$ composite, (b-f) corresponding EDX elemental maps and (g) EDX spectrum of the area indicated in red. 138

7.6 FTIR spectra of GP, M-GP, $\mathrm{Cu}_{2} \mathrm{O} / \mathrm{TiO}_{2}$ and $\mathrm{Cu}_{2} \mathrm{O} / \mathrm{TiO}_{2}$ supported by GP matrix with different loading contents; (a) $\mathrm{Cu}_{2} \mathrm{O}$, (b) M-GP 50 wt $\% \mathrm{Cu}_{2} \mathrm{O}$, (c) $\mathrm{M}-\mathrm{GP} 30$ wt $\%$ $\mathrm{Cu}_{2} \mathrm{O}$, (d) M-GP 15 wt $\% \mathrm{Cu}_{2} \mathrm{O}$, (e) M-GP 10 wt $\% \mathrm{Cu}_{2} \mathrm{O}$, (f) M-GP 5 wt $\% \mathrm{Cu}_{2} \mathrm{O}$, (g) M- GP, (h) CTAB 139

7.7 $11.7 \mathrm{~T}{ }^{29} \mathrm{Si}$ MAS NMR spectra (a) M-GP $50 \mathrm{wt} \% \mathrm{Cu}_{2} \mathrm{O} / \mathrm{TiO}_{2}$ (b) M-GP 15 wt\% $\mathrm{Cu}_{2} \mathrm{O} / \mathrm{TiO}_{2}$, (c) M-GP $10 \mathrm{wt} \% \mathrm{Cu}_{2} \mathrm{O} / \mathrm{TiO}_{2}$, (d) M-GP, (e) GP

7.8 $11.7 \mathrm{~T}{ }^{27} \mathrm{Al}$ MAS NMR spectra (a) M-GP $50 \mathrm{wt} \% \mathrm{Cu}_{2} \mathrm{O} / \mathrm{TiO}_{2}$ (b) M-GP $15 \mathrm{wt} \%$ $\mathrm{Cu}_{2} \mathrm{O} / \mathrm{TiO}_{2}$, (c) M-GP $10 \mathrm{wt} \% \mathrm{Cu}_{2} \mathrm{O} / \mathrm{TiO}_{2}$, (d) M-GP, (e) GP 143

7.9 ${ }^{63} \mathrm{Cu}$ NQR spectra (a) as-synthesized $\mathrm{Cu}_{2} \mathrm{O}$, (b) $\mathrm{M}-\mathrm{GP}-\mathrm{Cu}_{2} \mathrm{O}$ before UV irradiation, (c) $\mathrm{M}-\mathrm{GP}-\mathrm{Cu}_{2} \mathrm{O}$ after UV irradiation, (d) $\mathrm{M}-\mathrm{GP}-\mathrm{Cu}_{2} \mathrm{O} / \mathrm{TiO}_{2}$ before UV irradiation, (e) $\mathrm{M}-\mathrm{GP}-\mathrm{Cu}_{2} \mathrm{O} / \mathrm{TiO}_{2}$ after UV irradiation 145

7.10 Plots of the residual concentration $\left(\mathrm{C} / \mathrm{C}_{0}\right)$ vs. time (t) onto the M-GP matrix, M-GP $5,10,15$, and $50 \mathrm{wt} \% \mathrm{Cu}_{2} \mathrm{O}$ (monitored at $664 \mathrm{~nm}$ in dark) 146

7.11 Experimental data for the adsorption of MB dye in the dark on to the M-GP matrix and the M-GP- $\mathrm{Cu}_{2} \mathrm{O} / \mathrm{TiO}_{2}$ composites fitted to (a) pseudo first-order kinetic model, (b) pseudo second-order kinetic model 148

7.12 (a-c) Adsorption isotherms for MB adsorption fitted to Freundlich, Langmuir and Langmuir-Freundlich models (dashed lines). 149 
7.13 Plots of the residual concentration $\left(\mathrm{C} / \mathrm{C}_{0}\right) v s$. time $(\mathrm{t})$ onto the M-GP, M-GP-5, 10, 15 and $50 \mathrm{wt} \% \mathrm{Cu}_{2} \mathrm{O}, \mathrm{Cu}_{2} \mathrm{O}, \mathrm{TiO}_{2}, \mathrm{Cu}_{2} \mathrm{O} / \mathrm{TiO}_{2}$ (monitored at $664 \mathrm{~nm}$ )

7.14 MB removal by the M-GP matrix, M-GP composites containing 5,10,15 and $50 \mathrm{wt} \%$ $\mathrm{Cu}_{2} \mathrm{O} / \mathrm{TiO}_{2}, \mathrm{Cu}_{2} \mathrm{O}, \mathrm{TiO}_{2}$, and $\mathrm{Cu}_{2} \mathrm{O} / \mathrm{TiO}_{2}$ alone

7.15 Nitrogen sorption isotherms of the M-GP ( $\mathbf{\square}$, adsorption $\square$, desorption), M-GP-10 wt $\% \mathrm{Cu}_{2} \mathrm{O} / \mathrm{TiO}_{2}\left(O\right.$, adsorption $\bigcirc$, desorption ) and $\mathrm{M}-\mathrm{GP}-15 \mathrm{wt} \% \mathrm{Cu}_{2} \mathrm{O} / \mathrm{TiO}_{2}$ adsorption $\triangle$, desorption) GP $(\diamond$, adsorption $\diamond$, desorption $)$

7.16 XRD patterns of $\mathrm{TiO}_{2}$ and $\mathrm{TiO}_{2}$ supported by M-GP with different loading contents; (a) $\mathrm{TiO}_{2}$, (b-d) M-GP 50, 10 and $5 \mathrm{wt} \% \mathrm{TiO}_{2}$, (e) M- GP 155

7.17 SEM micrographs of (a-f) M-GP composite containing 5, 10, $15 \mathrm{wt} \% \mathrm{TiO}_{2}$. Right hand micrographs are BSE, left hand are SE 156

7.18 (a) Backscattered image, (b) Na, (c) Al, (d) Si, (e) Ti elemental map (f) EDS spectrum of the red-circled area of M-GP-15 wt\% $\mathrm{TiO}_{2}$ 157

7.19 (a-c) TEM images of GP-10\%-TiO 2 composite with, (d-f) HRTEM images of GP$10 \%-\mathrm{TiO}_{2}$ composite 158

7.20 Plots of the residual concentration $\left(\mathrm{C} / \mathrm{C}_{0}\right) v s$. time $(\mathrm{t})$ onto the $\mathrm{M}-\mathrm{GP}, \mathrm{TiO}_{2}$ and $\mathrm{M}-\mathrm{GP}$ $5,10,15$ and $50 \mathrm{wt} \% \mathrm{TiO}_{2}$ (monitored at $664 \mathrm{~nm}$ ).

7.21 Plots of the residual concentration $\left(\mathrm{C} / \mathrm{C}_{0}\right)$ vs. time (t) onto the $\mathrm{M}-\mathrm{GP}, \mathrm{Cu}_{2} \mathrm{O}, \mathrm{TiO}_{2}$, $\mathrm{Cu}_{2} \mathrm{O} / \mathrm{TiO}_{2}, \mathrm{M}-\mathrm{GP}-10 \mathrm{wt} \% \mathrm{Cu}_{2} \mathrm{O}$, M-GP-5 wt $\% \mathrm{Cu}_{2} \mathrm{O} / \mathrm{TiO}_{2}, \mathrm{M}-\mathrm{GP}-10 \mathrm{wt} \% \mathrm{TiO}_{2}$ (monitored at $664 \mathrm{~nm}$ ). 160

7.22 MB removal by the M-GP, M-GP-5,10,15 and $50 \mathrm{wt} \% \mathrm{TiO}_{2}, \mathrm{TiO}_{2}$ alone 161

7.23 Nitrogen sorption isotherms of the GP ( $\diamond$, adsorption $\diamond$, desorption), M-GP adsorption $\square$, desorption), M-GP-15 wt $\% \mathrm{TiO}_{2}$ ( $\boldsymbol{\Delta}$, adsorption $\triangle$, desorption) M-GP$15 \mathrm{wt} \% \mathrm{Cu}_{2} \mathrm{O}(<$, adsorption $\triangleleft$, desorption) 


\section{Publications and conference presentations arising from this work}

M. Fallah, K.J.D. MacKenzie, J.V. Hanna, S.J. Page, Novel photoactive inorganic polymer composites of inorganic polymers with copper (I) oxide nanoparticles. Journal of Materials Science (Published).

M. Falah, K. J.D. MacKenzie. Synthesis and properties of novel photoactive composites of P25 titanium dioxide and copper (I) oxide with inorganic polymers. Ceramics International (Published).

M. Falah, K. J.D. MacKenzie, J. V. Hanna, S. J. Page. Synthesis, structure and photoactivity of new composites of nanoparticle $\mathrm{Cu}$ (I) oxide supported on a novel aluminosilicate inorganic polymer with an expanded structure. (In preparation)

M. Falah, Photoactive inorganic polymer composites with oxide nanoparticles. $13^{\text {th }}$ International Ceramics Congress (CIMTEC 2014), June $8^{\text {th }}-13^{\text {th }} 2014$, Montecatini Terme, Italy. Invited oral presentation.

M. Falah. Novel Photoactive Inorganic Polymer Composites with Metal Oxide Nanoparticles. Asia Nanotechnology camp, (ANC 2014), October $8^{\text {th }}-15^{\text {th }} 2014$, Tehran, Iran. (Poster presentation).

M. Falah, Novel Photoactive Inorganic Polymer Composites with Oxide Nanoparticles. AMN7 Conference, Nelson, New Zealand, February 2015. (Poster presentation).

M. Falah, Incorporation of photoactive $\mathrm{Cu}_{2} \mathrm{O}$ in a metakaolinite inorganic polymer. AMN-6, Auckland, February $11^{\text {th }}-13^{\text {th }} 2013$. (Poster presentation).

M. Falah, K. J. D. MacKenzie, New composites of inorganic polymers (GPs) with $\mathrm{Cu}_{2} \mathrm{O}$ nanoparticles for photodegradation of organic pollutants. International Conference on Traditional and Advanced Ceramics (ICTA2013), Bangkok, Thailand, September $11^{\text {th }}-13^{\text {th }}$, 2013. Invited Presentation. 
BET

BG

$\mathrm{BJH}$

CEC

CB

CTAB

$\mathrm{Cu}_{2} \mathrm{O}$

EDS

FTIR

FFT

GP

HRTEM

MB

M-GP

MMT

MO

Na-GP

NMR

NQR

PVP

SAED

SEM

STEM
Brunauer-Emmett-Teller

Energy Band Gap

Barrett, Joyner, Halenda

Cation Exchange Capacity

Conduction Band

Cetyltrimethylammonium bromide

Cuprous Oxide

Energy Dispersive X-ray Spectroscopy

Fourier Transform Infrared Spectroscopy

Fast Fourier Transformation

Geopolymer

High Resolution Transmission Electron Microscopy

Methylene Blue

Modified geopolymer CTAB

Montmorillinite

Methyl Orange

Sodium Geopolymer

Nuclear Magnetic Resonance Spectroscopy

Nuclear Quadrupole Resonance

polyvinylpyrrolidone

Selected Area Diffraction

Scanning Electron Microscopy

Scanning transmission electron microscopy 
TEM

$\mathrm{TiO}_{2}$

UV

$\mathrm{UV}-\mathrm{Vis}$

VB

XRD

XRF
Transition Electron Microscopy

Titanium Dioxide

Ultraviolet

Ultraviolet-visible Spectroscopy

Valence Band

X-Ray Diffraction

X-Ray Fluorescence Spectroscopy 


\section{Chapter 1 \\ Introduction}

\subsection{Background to the research problem}

Air pollution poses a serious warning to human health and the environment. Pollutants from exhaust systems can cause unsightly blackening and costly degradation of walls and building facades. In most developed areas, the main sources of pollutants are automobile emissions, industrial activities, and heating systems. ${ }^{1}$ These produce a mix of nitrogen oxides $\left(\mathrm{NO}_{\mathrm{X}}\right)$, volatile organic compounds (VOCs), carbon monoxide (CO), sulphur oxides ( $\mathrm{SO}_{\mathrm{X}}$ ), and particulate matter (PM). ${ }^{1}$ The poisonous effects of these pollutants may spread out over the source of emission. ${ }^{2} \mathrm{NO}_{2}$ and VOCs react in the atmosphere and produce secondary pollutants, such as acid rain, smog, and ozone. In order to create a more ecological world, engineers and scientists must develop greener building materials ${ }^{2}$ by selecting suitable construction materials to reduce the negative impact of air pollution. Concrete is one of the most popular structural construction materials with a verified history over many years; it has an ability to produce strong creative and cost effective systems. The main ingredient in concrete is Portland cement, consisting of limestone (calcium carbonate, $\mathrm{CaCO}_{3}$ ) and kaolinite clay which must be heated up to $1450{ }^{\circ} \mathrm{C} .{ }^{3}$ Currently the contribution of Portland cement production worldwide to the greenhouse gas problem is about 1.35 billion tons of $\mathrm{CO}_{2}$ annually or about $7 \%$ of the total greenhouse gas emissions into the earth's atmosphere. ${ }^{4}$ Photocatalytic reactions can remove the air pollutants that are typically results in discoloration of exposed surfaces from the atmosphere. The basic photocatalyst reactions oxidize both organic and inorganic compounds by using the energy from ultraviolet (UV) rays through the photocatalytic materials. ${ }^{2}$ New photocatalytic cements containing a photoactive oxide like $\mathrm{TiO}_{2}$ have been produced, saving on maintenance costs and providing a cleaner environment. ${ }^{2}$ The organic and inorganic pollutants produce staining on the surface of concrete. Novel self-cleaning concrete created to remove significant amounts of environmental pollutants considered harmful to human health, ${ }^{2}$ should provide significant improvements in urban air quality, as it also can reduce micro-organisms such as bacteria and fungi and is capable of eliminating odours associated with pollutants. Other applications of these photocatalytic cements include architectural concrete panels, pavements, road surfaces, concrete masonry units, roof tiles and cement-based tiles. ${ }^{2}$ The best application has developed an artificial lighting system that generates enough UV light to activate the photocatalytic 
process. This product is a concrete with transparent property and the ability to transmit light; this light can pass through it and also show objects behind it. The lighting system and photocatalytic concrete cement have been used in the renovation of a heavily trafficked tunnel in Rome. ${ }^{2}$

According to the air quality standards in some parts of the world (Milan Italy), where occasionally automobile traffic has to be shut down for a full day, this transparent concrete can be helpful and also help with maintenance costs and a cleaner environment. ${ }^{2}$ It is estimated that if just $15 \%$ of the buildings and roads were resurfaced with photocatalytic cement products Milan could become 50\% cleaner. Nanoparticle photocatalytic cement containing titanium oxide as the photocatalytic agent is already being used for applications such as sound barriers, facade elements, pavement and road surfacing. ${ }^{2}$

Many research centres have been involved in examining the pollution-reducing capability of photocatalytic compounds, particularly those containing $\mathrm{TiO}_{2} \cdot \mathrm{TiO}_{2}$ photocatalyts in the presence of sun or artificial light react with air pollutants and oxidize the organic and inorganic air pollutants, converting them into small amounts of relatively benign molecules. Both laboratory and field experiments disclose that adding $\mathrm{TiO}_{2}$ to the surface of a pavement or building material can expressly reduce air pollution by up to $60 \%$ in some applications. ${ }^{5}$ It is obvious that reduction of the negative impact of air pollution with nano $\mathrm{TiO}_{2}$ is effective. Air pollution can be controlled by using photocatalytic $\mathrm{TiO}_{2}$ in concrete or as a surface covering. ${ }^{6}$ Figure 1.1. shows the photocatalysis reaction of precast and architectural Portland concrete panels in the presence of sunlight and how a photocatalytic city would work. The efficiency of the novel photocatalytic cement materials provides a real eco-sustainable value and according to the researchers this material can reduce pollution up to $75 \%$ under just 3 min. UV irradiation. ${ }^{7}$ This phenomenon is similar to photosynthesis in nature; therefore, the light irradiation causes the oxidation process and decomposition of the pollutants, converting them to benign compounds. Subsequently these contaminants can be removed and washed away by rain. 


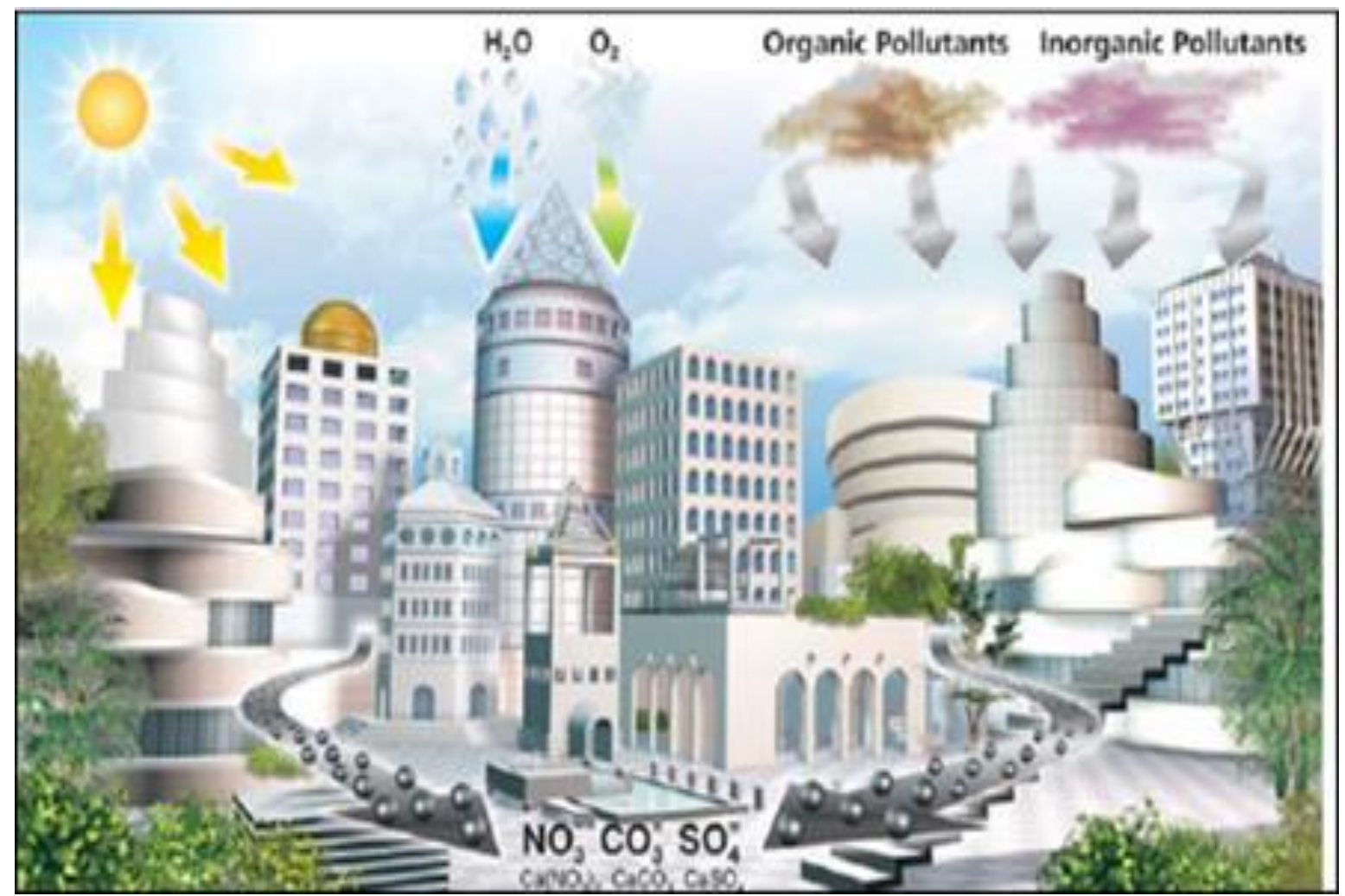

Figure 1.1. Inorganic pollutant: $\mathrm{CO}, \mathrm{VOC}$ (benzene, toluene, etc), methyl mercaptan (gas), organic chlorinated compounds, polycondensed aromatic compounds, acetaldehyde, formaldehyde. Organic pollutant: $\mathrm{NO}_{x}, \mathrm{SO}_{x}, \mathrm{NH}_{3}$ (gas). ${ }^{7}$

Water is the one of the sources of all life on Earth; nevertheless, 1.3 billion people do not have access to safe drinking water. Furthermore, polluted water is implicated in $80 \%$ of all cases of sickness and disease according to the World Health Organization. ${ }^{8}$ Water must be purified to remove harmful materials and make it suitable for human use. ${ }^{8} \mathrm{UV}$ light is an effective cleanser but is energy intensive, and its application in large-scale systems is sometimes considered to be of unreasonable cost. ${ }^{8}$ Nanotechnology is opening new doors to water decontamination, purification and providing improved detection of water-borne harmful substances. ${ }^{8}$ Photocatalytic nanomaterials enable UV light to destroy pesticides, industrial solvents and germs. $\mathrm{TiO}_{2}$ can be used to decontaminate bacteria-ridden water. When exposed to light, it breaks down bacterial cell membranes, killing the bacteria by the photochemical reactions which create hydroxyl radicals and superoxide anions under UV irradiation. $^{8}$

Researchers at the Queensland University of Technology have developed a novel form of titanium dioxide and a process for producing an environmentally-friendly product that purifies water (Figure 1.2). 


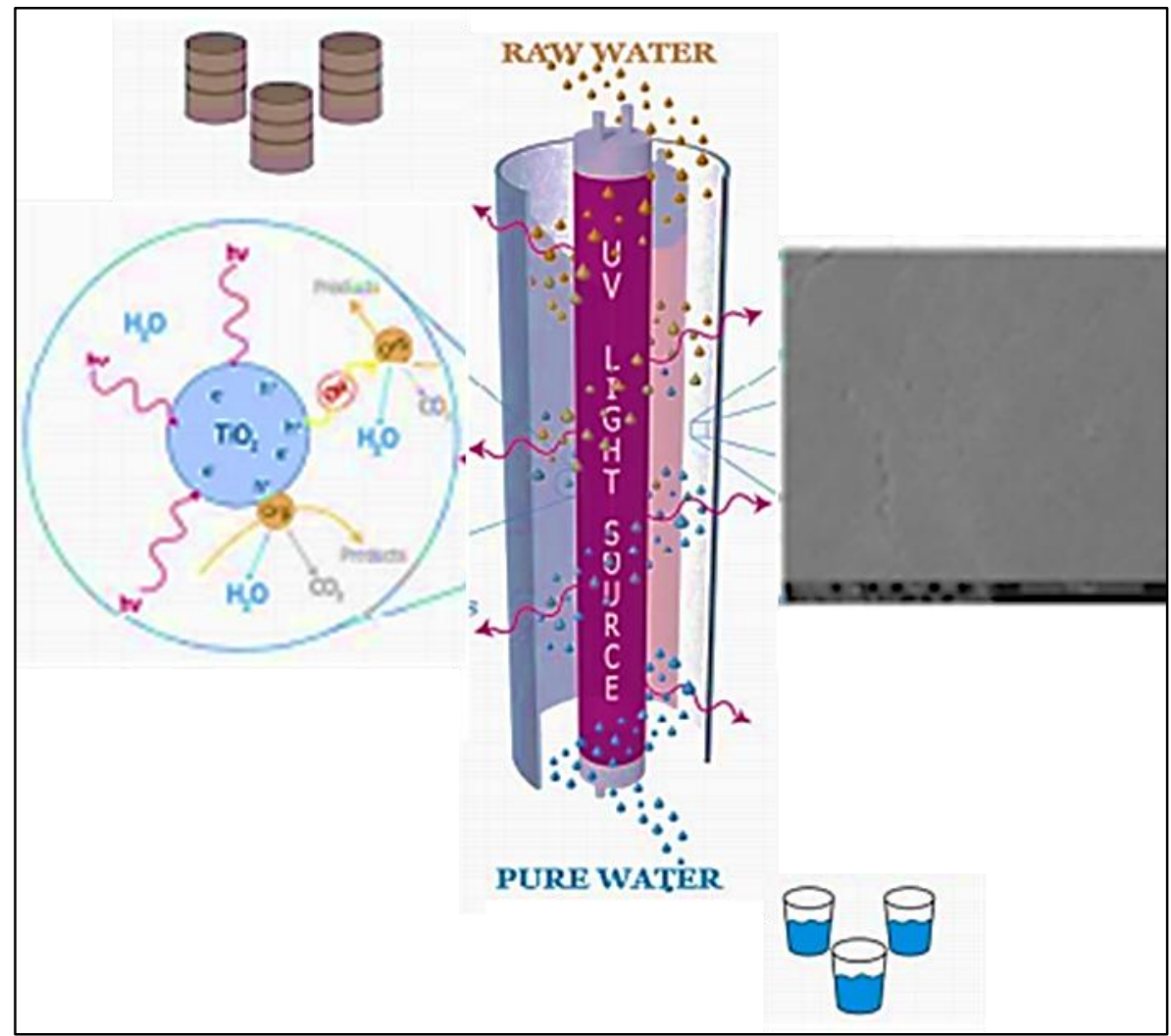

Figure 1.2. Titanium Dioxide nanoparticles used in an environmentally-friendly water purification system. ${ }^{8}$

\subsection{The goals of this research}

Although Copper (I) oxide $\left(\mathrm{Cu}_{2} \mathrm{O}\right)$ has not been as extensively considered as Titanium Dioxide $\left(\mathrm{TiO}_{2}\right)$ as a photocatalytic oxide, its bandgap suggests that it might be as efficient, if not more so, especially in conjunction with an environmentally-friendly matrix such as an inorganic polymer (geopolymer). In this study, several approaches for the preparation and characterization of different oxide nanoparticles (i.e., $\mathrm{Cu}_{2} \mathrm{O}, \mathrm{Cu}_{2} \mathrm{O} / \mathrm{TiO}_{2}$ and $\mathrm{TiO}_{2}$ ) were investigated, and the most promising of these products were inserted at various concentrations into unmodified and modified metakaolinite-based geopolymer prior to curing. A modified geopolymer matrix was also prepared by using a small amount of surfactant to expand the pore structure and control their size and shape. ${ }^{9}$ The aim of this project is therefore to develop and test new photocatalyst materials that combine an geopolymer matrix with photoactive oxide nanoparticles to promote adsorption of environmental pollutants and their photodegradation. By suspending oxide nanoparticles in these geopolymers, the filtering action should be improved, allowing the destruction of organic molecules, pesticides, dyes and other materials in wastewater. In other cases, 
photocatalysts have been used to increase the photodecomposition rate of pesticides or pollutants. ${ }^{10}$ To verify the catalytic effect of these newly developed materials, reliable methods to determine the photocatalytic activity were necessary.

Based on studies of other nano photocatalytic materials it was presumed that the $\mathrm{Cu}_{2} \mathrm{O}$ nanoparticles used in this study should have similar photocatalytic properties to $\mathrm{TiO}_{2}$. By comparison with $\mathrm{TiO}_{2}$, nanostructured $\mathrm{Cu}_{2} \mathrm{O}$ is even more attractive, being an inexpensive readily available p-type semiconductor with a direct band gap of $2.2 \mathrm{eV}$ and a high optical absorption coefficient. ${ }^{11,12} \mathrm{Cu}_{2} \mathrm{O}$ is also a powerful absorber of molecular $\mathrm{O}_{2}$, and can scavenge photoelectrons, thereby interfering with the combination of electrons and holes. ${ }^{13}$ This suggests that $\mathrm{Cu}_{2} \mathrm{O}$ should act as a stable photocatalyst for the photochemical decomposition of $\mathrm{H}_{2} \mathrm{O}$ with the generation of $\mathrm{O}_{2}$ and $\mathrm{H}_{2}$ under visible light irradiation, and should also be a good candidate for the photocatalytic degradation of organic pollutants under visible light irradiation. A further major attraction of $\mathrm{Cu}_{2} \mathrm{O}$ is its low toxicity, with a band gap that can be tuned by adjusting its particle size. ${ }^{14} \mathrm{Cu}_{2} \mathrm{O}$ nanoparticles can be prepared in a range of colours from yellow to dark brown, raising the possibility of its use in coloured geopolymer composites. Furthermore, geopolymers are porous, suggesting a possible use as water purifying filters when used as a matrix in conjunction with $\mathrm{Cu}_{2} \mathrm{O}$ nanoparticles.

Based on these previously reported observations, a series of new composites of $\mathrm{Cu}_{2} \mathrm{O} / \mathrm{TiO}_{2}$ nano-heterostructures incorporated into geopolymer matrix have also been prepared. The $\mathrm{Cu}_{2} \mathrm{O}$ was synthesized as cubic nanocrystals, and the $\mathrm{TiO}_{2}$ was commercial P25. The combination of nanosized $\mathrm{Cu}_{2} \mathrm{O}$ particles and photoreactive $\mathrm{P} 25$ titania in an aluminosilicate geopolymer matrix was found to be a more efficient photocatalyst under UV irradiation than geopolymer composites containing either of the individual oxides alone. These new geopolymer composites show promise as ecologically-friendly materials that can efficiently remove organic pollutants from water or the atmosphere.

The use of geopolymer matrices modified by the inclusion of a large quaternary ammonium ion, cetyltrimethylammonium bromide (CTAB) was also investigated in this work. These modified $\mathrm{Cu}_{2} \mathrm{O}$-geopolymer and $\mathrm{Cu}_{2} \mathrm{O} / \mathrm{TiO}_{2}$-geopolymer composites have much better photocatalyst properties than $\mathrm{Cu}_{2} \mathrm{O}$ and $\mathrm{Cu}_{2} \mathrm{O} / \mathrm{TiO}_{2}$ alone due to the improved dispersion of metal oxide nanoparticles at the external and interlayers of the geopolymer matrix.

The combination of ecologically-friendly geopolymers and nanocrystalline $\mathrm{Cu}_{2} \mathrm{O}$ and $\mathrm{Cu}_{2} \mathrm{O} / \mathrm{TiO}_{2}$ for absorption and photodegradation of harmful organic substances has not previously been investigated in detail, neither has the use of CTAB to expand the 
geopolymers matrix previously been considered. The present work showed that both these factor can be combined to produce extremely efficient materials for photodestruction of harmful organic compounds.

\subsection{Dissertation Objectives and Motivation}

Extensive work on geopolymer research has been conducted so far. Therefore, this Thesis focuses on a developing field that utilizes environmentally-friendly, cheap and plentiful aluminosilicate materials to make a geopolymer matrix containing efficient nanoparticle oxide photoactive components. The main objectives are:

$>$ To identify a suitable synthesis for nanoparticle $\mathrm{Cu}_{2} \mathrm{O}$.

$>$ To develop a process for inserting the nanoparticles into a geopolymer matrix.

$>$ To characterise the product (XRD, FTIR, SEM/EDX, TEM, MAS NMR, Cu NQR, BET)

$>$ To test the performance of these catalysts for photodegradation of methylene blue (MB).

To improve the photocatalyst action by combining $\mathrm{Cu}_{2} \mathrm{O}$ with $\mathrm{TiO}_{2}$.

$>$ To improve the performance of the geopolymer matrix by modifying with CTAB.

No known work so far has been reported to make photoactive geopolymer matrices containing $\mathrm{Cu}_{2} \mathrm{O}$ and $\mathrm{Cu}_{2} \mathrm{O} / \mathrm{TiO}_{2}$ nanoparticles, which indicates the innovative nature of this research. Although some publications have reported making photoactive geopolymers using metakaolin and $\mathrm{TiO}_{2}$ (e.g., Cerny et al. 2009, Tirado et al. 2013), this work presents the first effort to explore and validate a new potential application of metakaolin-based geopolymers, which are used as photocatalysts for decomposition of organic pollutants. Thus, the motivation of this dissertation can be summarized as follows:

Innovation

- Produce geopolymer matrices using oxide nanoparticles that have never been reported in the existing literature

- Present the first effort to validate the possibility of a new photoactive geopolymer composite.

Potential applications of the synthesized geopolymers 
- Construction materials

- Materials for photodecomposition of organic and some inorganic pollutants

\subsection{Thesis Layout}

This thesis consists of eight chapters, which papers have been published, or submitted to peer-reviewed journals or conferences.

Chapter 2 provides a literature review, which focuses on the raw materials used to make geopolymers and the oxide nanoparticles, the mechanism of geopolymer technology, the photocatalytic process, and the mechanism of photo-oxidation processes.

Chapter 3 demonstrates a methodology that describes experimental details, chemicals, materials and analysis techniques for characterization of the synthesised materials. This chapter explains several methods for synthesis of $\mathrm{Cu}_{2} \mathrm{O}$ nanoparticles and combination of the nano oxide particles with the geopolymer matrix.

Chapter 4 studies the effect of incorporation of $\mathrm{Cu}_{2} \mathrm{O}$ nanoparticles in a geopolymer matrix evaluated by XRD, SEM, TEM, BET, NMR and NQR. The photocatalytic properties of the composites were studied by the photodegradation of MB dye, which is commonly used for such degradation studies.

Chapter 5 examines a new geopolymer composite which consists of $\mathrm{Cu}_{2} \mathrm{O} / \mathrm{TiO}_{2}$ nanoparticles, characterized with XRD, SEM, TEM, BET, NMR and NQR. This product shows even better photocatalyst properties than geopolymers containing $\mathrm{Cu}_{2} \mathrm{O}$ and $\mathrm{TiO}_{2}$ alone.

Chapters 6 and 7 describe a new method for modifying the geopolymer matrix by using a large cation surfactant (CTAB). The modified geopolymer was combined with the oxide nanoparticles and the photocatalytic activities of the composites were investigated.

Chapter 8 presents a summary of all of the studies performed as part of this thesis and lists suggestions for future work. 


\section{Chapter 2}

\section{Literature Review}

\subsection{Fundamentals of the photocatalytic process}

Currently one focus of global concern is the presence of harmful organic compounds in water supplies and the discharge of wastewater from chemical industries, power plants, landfills, and agricultural sources. Traditional water treatment processes are filtration, thermal and catalytic oxidation, chemical treatment and biological treatment. ${ }^{15}$ Some of the materials used in this process are chlorine, potassium permanganate, ozone, hydrogen peroxide and highenergy UV light. However, there are some safety and economic restrictions on these water treatment processes. Phase transfer methods eliminate undesirable organic pollutants from wastewater, but they do not remove the pollutants entirely. Toxic organic compounds in water can be oxidized by powerful chemical treatment based on aqueous phase hydroxyl radical chemistry. This process uses either high-energy UV light or strong chemical oxidants whose hazardous nature is undesirable. ${ }^{16,17}$ Moreover, during this process several, even more hazardous intermediates are formed. An advanced oxidation technology process (AOT) has been developed as an efficient method for removing organic pollutants from water streams, based on a heterogeneous photocatalysis process using metal oxide semiconductor particles. ${ }^{17}$ Metal oxides, such as $\mathrm{ZrO}_{2}, \mathrm{Al}_{2} \mathrm{O}_{3}, \mathrm{Cu}_{2} \mathrm{O}, \mathrm{TiO}_{2}$ and $\mathrm{SiO}_{2}$ are widely used catalyst supports. These oxides are active towards many reactions, including oxidation of $\mathrm{CO}$, selective oxidation (alkenes, alcohols and even alkanes), water-gas shift, and removal of atmosphere pollutants $\left(\mathrm{NO}_{\mathrm{X}}, \mathrm{VOCs}\right){ }^{18}$

Varieties of air pollutants have been suspected to have harmful effects on human health and the environment. These pollutants are mainly the products of combustion from power generation, space heating or motor vehicle traffic. ${ }^{19}$ Secondary pollutants such as acid rain or ozone arise from the products created in the immediate area of the pollutant sources by chemical reactions in the atmosphere. The principal pollutants released by vehicles are carbon monoxide, oxides of nitrogen $\left(\mathrm{NO}_{\mathrm{X}}\right)$, volatile organic compounds (VOCs) and particulates. These pollutants are having an increasing influence on urban air quality. Photocatalytic materials can be added to the surface of pavements and building materials to oxidise the pollutants by the action of light irradiation and forming precipitates on the surface of the material, then these precipitates are eliminated from the surface by rain. ${ }^{19}$ 
Photocatalysis is a catalytic reaction including light absorption by a substrate containing a catalyst. Reactions involving the participation of catalysts are called catalytic. Photocatalysis is defined as a change in the rate of chemical reactions or their generation in the presence of substances that absorb light quanta that are then involved in the chemical transformations of the reaction participants. ${ }^{20}$ Photocatalytic degradation of environmental contaminants has been studied in the past two or three decades. In 1972, Fujishima and Honda reported the photocatalytic splitting of water on $\mathrm{TiO}_{2}$ electrodes, which was the first suitable photocatalyst for water splitting and the beginning of a new era of modern heterogeneous photocatalysis. ${ }^{21}$ The use of photocatalytic oxidation to remove trace-level organic contaminants in air, energy renewal and energy storage has recently received considerable attention since this technology has a broad range of potential applications, including air purification in office buildings, factories, homes, cars, and spacecraft. ${ }^{22}$

The importance of semiconductor-based photocatalysts is their charge separation ability (Figure 2.1). When a semiconductor is irradiated with light of energy greater than the bandgap, the excitation of an electron occurs from the VBto the CBand leaves a hole in the valence band. ${ }^{23}$ This separated hole has strong oxidizing power; this power comes from the electron of the absorbed species. The separated charge and hole can also recombine to release energy in the form of heat. The photocatalysis reaction is improved if the electron-hole pair recombination is inhibited. This can be achieved by trapping either the photogenerated electrons or the photogenerated holes at trapping sites in the structure.

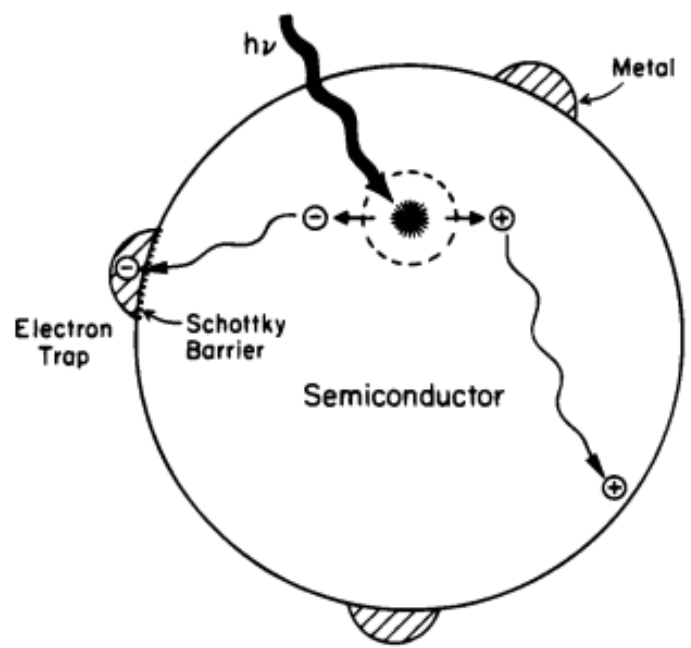

Figure 2.1. Metal-modified semiconductor photocatalyst particle. ${ }^{19}$ 


\subsection{Heterogeneous photocatalysis}

Photocatalytic reactions are divided into homogeneous and heterogeneous reactions. Heterogeneous photocatalysis has been far more intensively studied in recent years because it has potential applications in a variety of environmental and energy-related uses as well as in organic synthesis. Heterogeneous photocatalysis reaction systems involve the development of an interface between a solid photocatalyst (metal or semiconductor) and a fluid containing the reactants and products of the reaction. ${ }^{24}$

Heterogeneous photocatalysis can be carried out in different systems such as the gas phase, pure organic liquid phases or aqueous solutions. The overall process can be explained in several independent steps:

The reactants in the fluid phase are transferred to the surface of the photocatalyst, one or more of the reactants are absorbed to react with the absorbed phase; the released products are remove from the interface region. Thus, the photocatalytic reaction occurs in the adsorbed phase. $^{24}$

In homogeneous photocatalysis the photocatalyst is in the same phase as the reactant, and typically will exist as a gas or contained in a single liquid phase. Usually, homogeneous photocatalysts are dissolved in a solvent together with the substrates. Most of the processes using homogeneous photocatalysis occur in the liquid phase whereas in heterogeneous catalysis the photocatalyst is usually in the solid form, and the reaction occurs either in the liquid or gaseous phase.

In these systems a distinction must be made between adsorption and absorption. Adsorption is a surface phenomenon and involves unequal distribution of the molecular species in the bulk and at the surface; it is rapid to begin with but slows down as the system approaches equilibrium. By contrast, absorption involves uniform distribution of the molecular species throughout the body of material at a uniform rate.

Depending upon the nature of forces between the adsorbate molecules and the adsorbent, the adsorption can be classified into two types:

- Physical adsorption or physisorption

- Chemical adsorption or chemisorption

Where the forces between the adsorbate and adsorbent are van der Waals, the adsorption is called physisorption. Since the forces of this type are very weak, physisorption can be easily reversed by heating or decreasing the pressure. 
If the forces between the adsorbate particles and the adsorbent are of similar strength as chemical bonds, the adsorption is called chemisorption. Since these forces are very strong, this type of adsorption cannot be easily reversed. ${ }^{25}$

The major advantages/disadvantages of heterogeneous and homogeneous photocatalysis summarised in Table 2.1. ${ }^{26}$

Table 2.1. Comparison of main advantages/disadvantages of heterogeneous and homogenous photocatalysis. ${ }^{26}$

\begin{tabular}{lll}
\hline Property & Homogenous & Heterogeneous \\
Catalyst recovery & Difficult and expensive & Easy and cheap \\
Thermal Stability & Poor & good \\
Selectivity & Excellent/good-single active site & Good/Poor -multiple active site \\
\hline
\end{tabular}

\subsection{Fundamental Concepts}

\subsubsection{Insulators, conductors, and semiconductors}

Figure 2.2 shows the band structures of the three main classes of electrical materials, insulators, semiconductors and conductors. Due to the large band gaps in insulators, the valence band (VB) is full, and the conduction band (CB) is empty. There are two possibilities for conductors. One is that the valance band is not filled, so an electron in the VBcan be parted from its atom by simply being raised to a higher energy level within the same band. Another situation is that there is no energy gap between the VB and conduction band, and so electrons can easily make transitions from the valence to the CBe.g. metals. The energy gaps between the VB and CB are very small and different for different materials. Figure 2.2 (c) indicates in red the overlap of the VB and CB in some conductors. ${ }^{27}$

In semiconductors; (Figure 2.2d) the band gap is small enough to be navigated once an electron is sufficiently energized but the bandgap is still large enough to obstruct the conduction. This unique property makes semiconductors useful for many applications, such as circuit elements, computer chips, chemical catalysts, and photovoltaic devices. Changing the physical properties of semiconductors allows alteration of the width of the gap, as well as the position of the band, edges. ${ }^{28}$ 

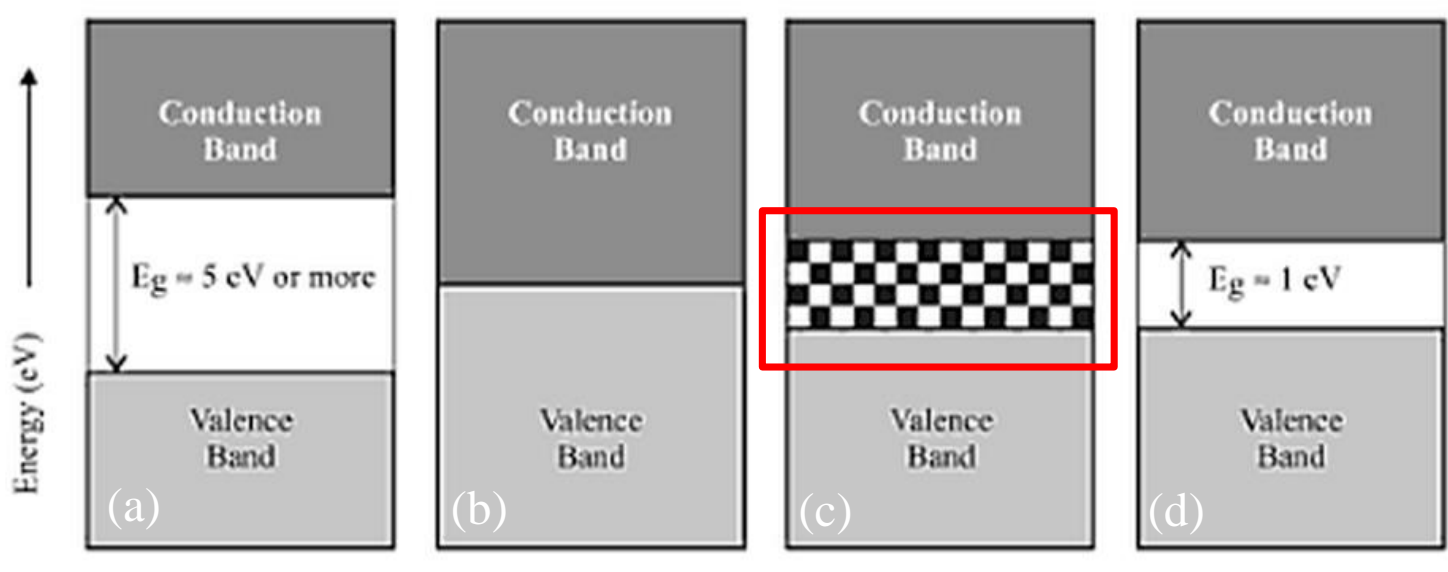

Figure 2.2. Energy band diagrams for (a) Insulators; (b) and (c) conductors, and (d) semiconductors. ${ }^{27}$

Semiconductors can be classified into two types, intrinsic and extrinsic. An intrinsic semiconductor is pure enough for impurities not to have an effect on its electrical behaviour. Elements (e.g. Si, Ge) and compounds (e.g. InSb, GaAs, $\mathrm{SiC}$ ) are intrinsic semiconductors that possess poor conductivity. At a temperature of absolute zero an intrinsic semiconductor does not have any charge carriers and consequently, the material behaves as an insulator. In energy band terms, the $\mathrm{CB}$ is empty of electrons and the VB is fully occupied by the valence electrons. At a temperature above absolute zero, a VB electron $\left(\mathrm{e}^{-}\right)$may be thermally excited into the CB, leaving an unoccupied state in the VBthat is called a hole $\left(\mathrm{h}^{+}\right)$. Electrons and holes flow in opposite directions in the presence of an electric field but contribute to a current in the same direction since they are oppositely charged. Holes and electrons created in this way known as intrinsic charge carriers. In intrinsic semiconductors, for each electron in $\mathrm{CB}$ the corresponding hole exists in the valance band. ${ }^{29}$ 


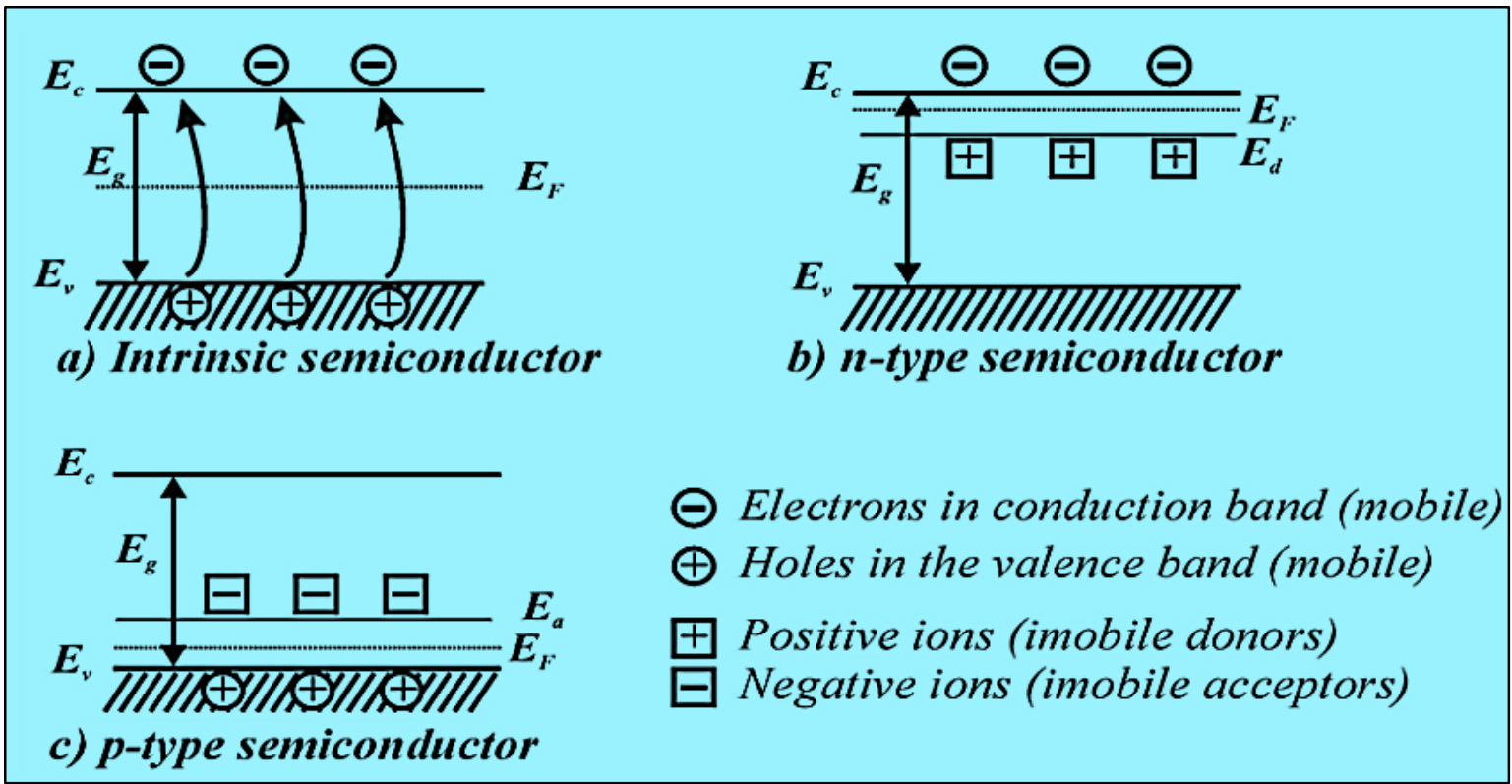

Figure 2.3. Three types of semiconductors: a) intrinsic semiconductors, b) n-type semiconductors, and c) p-type semiconductors. ${ }^{29}$

Extrinsic semiconductors can be formed by addition of impurity atoms into the intrinsic semiconductor, in a doping process. Alteration of the relative concentrations of electrons and holes in the material depends on the type and concentration of the dopant atom. The $N$-type semiconductors are doped with donors. The acceptors can remove an electron from the semiconductors and produce $p$-type semiconductors ( $\mathrm{p}$ stands for positive holes). The majority carriers in an $n$-type semiconductor are electrons and their concentration is equal to the donor impurity concentration. Holes are minority carriers in $n$-type semiconductors. Electrons are minority carriers in $p$-type semiconductors. ${ }^{29}$ (See Figure 2.3)

\subsection{Semiconductor Physics}

\subsubsection{Band gaps}

Electrons are locally bound to their corresponding atoms at the ground or lowest energy state and do not travel through the bulk of the solid. These low-energy electronic states determine the valance band, and if the electrons are energized sufficiently, they can leave the valance band and transfer through the solid. Figure 2.4 explains photon absorption. In this figure, a VBelectron $\left(\mathrm{e}_{\mathrm{vb}}\right)$ absorbs light with energy $\mathrm{h} v>\mathrm{E}_{\mathrm{g}}$ and then jumps to the conduction band. This situation creates a free roaming pair of charge carriers, namely a CBelectron $\left(\mathrm{e}_{\mathrm{cb}}{ }^{-}\right)$and a VBhole $\left(\mathrm{h}_{\mathrm{vb}}{ }^{+}\right)$. These charge carriers, $\mathrm{e}_{\mathrm{cb}}{ }^{-}$and $\mathrm{h}_{\mathrm{vb}}{ }^{+}$are of fundamental importance in semiconductor physics and photocatalysis. ${ }^{30}$ 


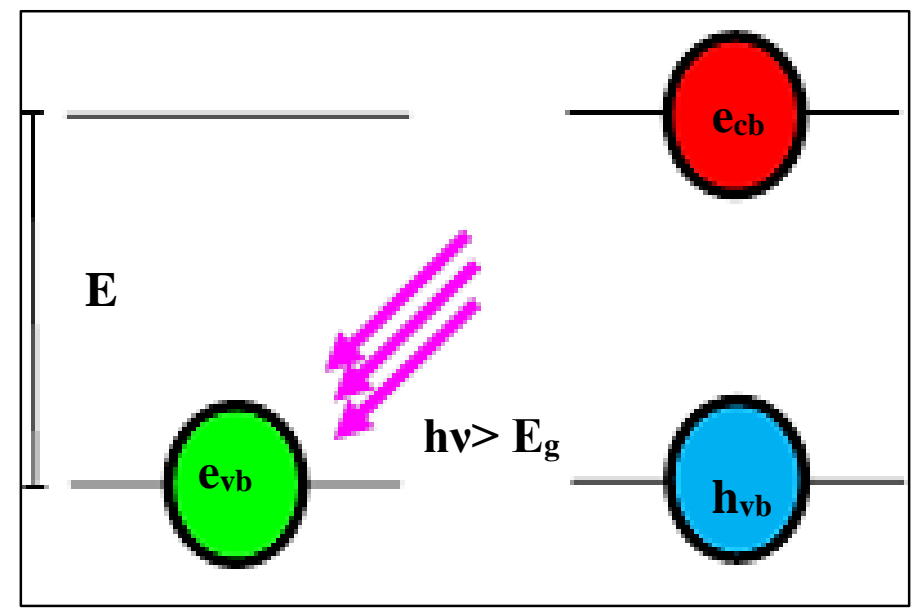

Figure 2.4. Photon absorption and charge carrier pair generation. ${ }^{31}$

\subsubsection{Band Theory}

Each band has a different energy, and the bands are filled with electrons from the lowest energy to the highest, in the same way as electrons occupy the orbitals in a single atom. The valance band (VB) is the filled band of highest energy, which is equivalent to the highest occupied molecular orbital (HOMO) in a molecule. The next highest energy band is called the $\mathrm{CB}$ which corresponds to the lowest unoccupied molecular orbital (LUMO) in a molecule. The energy gap called the bandgap $\left(E_{g}\right)$ separates the VB and the CB. Figure 2.5 shows band formation with increasing atom population. ${ }^{32}$ A greater number of atoms results in a larger number of possible electronic states collapsing the energy levels into a continuous band.

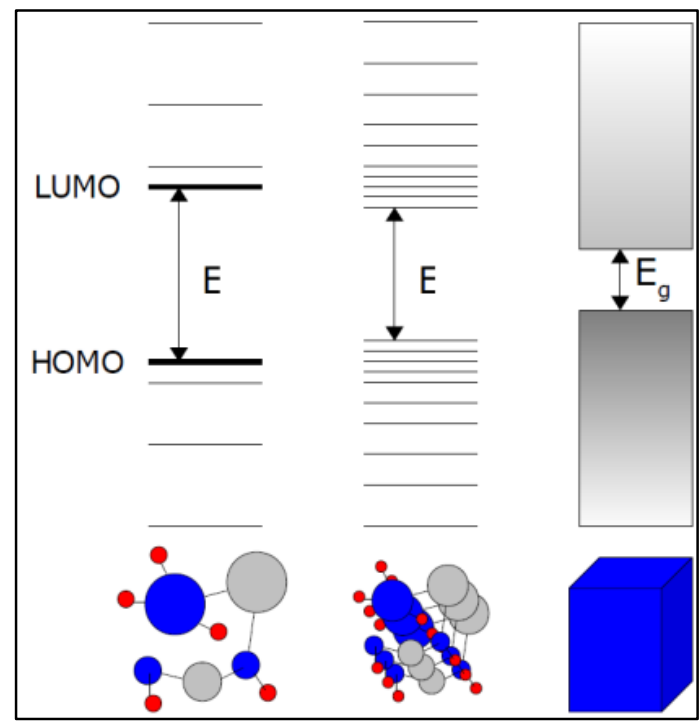

Figure 2.5. Formation of bands in a semiconductor. ${ }^{33}$ (blue $=$ metal, red $=$ oxygen, grey $=$ hydrogen) 


\subsection{Basic principles and mechanism for photocatalyzed dye degradation}

\subsubsection{Indirect dye degradation mechanism}

The mechanism of indirect heterogeneous photocatalytic oxidation using semiconducting materials can be summarized by four basic processes as follows:

\section{Photoexcitation}

The photocatalytic reaction is started by promotion of a photoelectron from the semiconductor (Figure 2.6) photocatalyst filled VB to the vacant $\mathrm{CB}$ as a result of irradiation. The energy (hv) of the absorbed photon is either equal to or greater than the band gap of the semiconductor photocatalyst. This excitation process leaves a hole in the VB $\left(\mathrm{h}_{\mathrm{VB}}{ }^{+}\right)$. Accordingly electron and hole pairs $\left(\mathrm{e}^{-} / \mathrm{h}^{+}\right)$are generated as specified by eq. (1) below ${ }^{31,33-36}$

Photocatalyst $+\mathrm{hv}(\mathrm{UV}) \rightarrow$ Photocatalyst $\left(\mathrm{e}^{-}(\mathrm{CB})+\left(\mathrm{h}^{+} \mathrm{VB}\right)\right)$

\section{Ionization of water}

$\mathrm{OH}^{\bullet}$ radicals are produced by reaction of the photogenerated holes in the VBwith water (eq. 2). (Figure 2.6)

$$
\mathrm{H}_{2} \mathrm{O}(\mathrm{ads})+\mathrm{h}^{+}(\mathrm{VB}) \rightarrow \mathrm{OH}^{\cdot}(\text { ads })+\mathrm{H}^{+}(\text {ads })
$$

The $\mathrm{HO}^{\bullet}$ radicals are extremely powerful oxidizing agents, and are produced on the surface of the irradiated semiconductor. They have the ability to attack adsorbed organic molecules, and also those located very close to the catalyst surface, non-selectively degrading these molecules to an extent depending on their structure and stability. These powerful radicals not only attack organic pollutants but can also attack and destroy microorganisms. ${ }^{37}$

\section{Oxygen ion sorption}

Anionic superoxide radicals $\left(\mathrm{O}_{2}^{-}\right)$are generated from oxygen via the electrons in the $\mathrm{CB}\left(\mathrm{e}_{\mathrm{CB}}\right)$; this occurs simultaneously with the creation of hydroxyl radicals by the reaction of photogenerated holes $\left(\mathrm{h}_{\mathrm{VB}}{ }^{+}\right.$) with surface bound water or $\mathrm{OH}^{-}$(eq. 3). (Figure 2.6)

$\mathrm{O}_{2}+\mathrm{e}^{-}(\mathrm{CB}) \rightarrow \mathrm{O}_{2}^{-}($ads $)$ 
Typically, this superoxide ion not only participates in the further oxidation process but also prevents electron-hole recombination, thereby maintaining electron neutrality within the photocatalyst molecule.

\section{Protonation of the superoxide}

The created superoxide $\left(\mathrm{O}^{2-}\right)$ becomes protonated and forms hydroperoxyl radicals, $\left(\mathrm{HO}_{2}^{-}\right)$, followed by the separation of $\mathrm{H}_{2} \mathrm{O}_{2}$ into highly reactive hydroxyl radicals $\left(\mathrm{OH}^{-}\right)$. Both oxidation and reduction processes commonly occur on the surface of the photoexcited semiconductor photocatalyst. The complete process is shown in Figure 2.7 and equations (4) to $(9)$ :

$$
\begin{aligned}
& \mathrm{O}_{2}^{-\cdot}(\text { ads })+\mathrm{H}^{+} \rightarrow \mathrm{HOO}^{\circ}(\text { ads }) \\
& 2 \mathrm{HOO}^{\circ}(\text { ads }) \rightarrow \mathrm{H}_{2} \mathrm{O}_{2}(\text { ads })+\mathrm{O}_{2} \\
& \mathrm{H}_{2} \mathrm{O}_{2}(\text { ads }) \rightarrow 2 \mathrm{OH}^{\cdot}(\text { ads }) \\
& \text { Dye }+\mathrm{OH}^{\cdot} \rightarrow \mathrm{CO}_{2}+\mathrm{H}_{2} \mathrm{O} \text { (intermediates) } \\
& \text { Dye }+\mathrm{h}^{+}(\mathrm{VB}) \rightarrow \text { oxidation products } \\
& \text { Dye }+\mathrm{e}^{-}(\mathrm{CB}) \rightarrow \text { reduction products }
\end{aligned}
$$

\subsubsection{Direct mechanism for dye degradation}

Another photocatalyst mechanism of photocatalytic dye degradation is the excitation of the dye under visible light $(\lambda>400 \mathrm{~nm})$ from the ground state (Dye) to the triplet excited state (Dye*). The excited state dye species are converted into semi-oxidized radical cations (Dye ${ }^{+}$) by electron injection into the CBof photocatalyst material. The superoxide radical anions $\left(\mathrm{O}_{2}{ }^{-}\right.$ ) are created by reaction between dissolved oxygen and trapped electrons and are then converted to hydroxyl radicals $\left(\mathrm{OH}^{*}\right)$. The $\mathrm{OH}^{*}$ is responsible for the oxidation of the organic compounds. Figure 2.7 represents this mechanism. ${ }^{38-43}$

$$
\begin{aligned}
& \text { Dye }+ \text { h } v \rightarrow \text { dye }^{*} \\
& \text { Dye }^{*}+\text { Photocatalyst } \rightarrow \text { dye }^{+}+\text {Photocatalyst }
\end{aligned}
$$




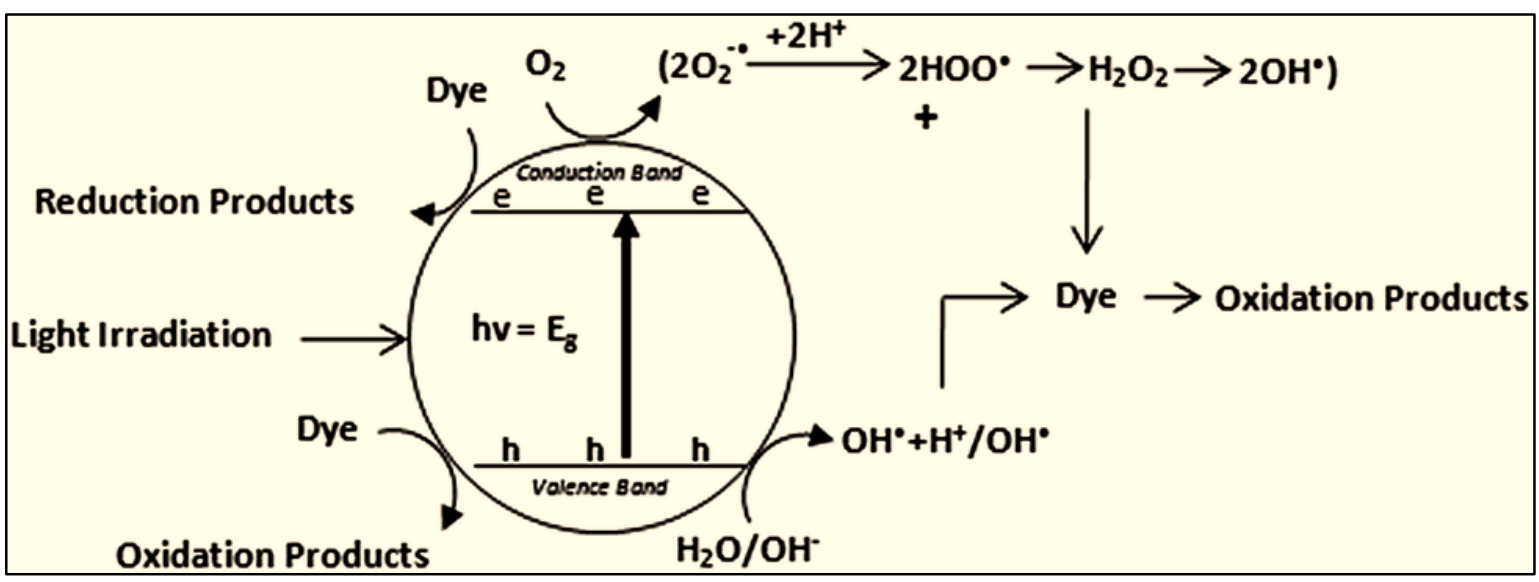

Figure 2.6. Pictorial representation of direct dye degradation process. ${ }^{44}$

The oxidative pathway leads in many cases, to complete conversion of an organic entity to $\mathrm{CO}_{2}, \mathrm{H}_{2} \mathrm{O}$, and in some instances, an inorganic acid. Table 2.2 gives the band energies and band gaps of these catalysts.

Table 2.2. Bandgap energy of various photocatalysts. ${ }^{41}$

\begin{tabular}{cccc}
\hline Photocatalyst & Band Gap Energy $(\mathbf{e V})$ & Photocatalyst & Band Gap Energy (eV) \\
\hline Diamond & 5.4 & $\mathrm{WO}_{3}$ & 2.76 \\
$\mathbf{C d S}$ & 2.42 & $\mathrm{Si}$ & 1.17 \\
$\mathbf{Z n S}$ & 3.6 & $\mathrm{Ge}$ & 0.744 \\
$\mathbf{Z n O}$ & 3.436 & $\mathrm{Fe}_{2} \mathrm{O}_{3}$ & 2.3 \\
$\mathbf{T i O}$ & 3.03 & $\mathrm{PbS}$ & 0.286 \\
$\mathbf{C d S}$ & 2.582 & $\mathrm{PbSe}_{2}$ & 0.165 \\
$\mathbf{S n O}$ & 3.54 & $\mathrm{ZrO}_{2}$ & 3.87 \\
$\mathbf{C d S e}$ & 1.7 & $\mathrm{Cu}_{2} \mathrm{O}$ & 2.172 \\
\hline
\end{tabular}




\section{$2.6 \mathrm{Cu}_{2} \mathrm{O}$ Photocatalyst}

A good photocatalyst should be photoreactive, capable of utilizing visible or near UV radiation, biologically and chemically inert, photostable (i.e. not disposed to photo corrosion), inexpensive and non-toxic. ${ }^{16}$ In the conversion of solar energy, it is essential to have a photocatalyst that works under visible light irradiation $(\lambda>400 \mathrm{~nm})$; however such a photocatalyst has not yet been created. Cuprous oxide has been investigated for decades for its unique semiconductor and optical properties. ${ }^{45} \mathrm{Cu}_{2} \mathrm{O}$, a well-known p-type semiconductor acts as a photocatalyst under visible light irradiation $(\leq 600 \mathrm{~nm})$ and has shown great potential for applications in electronics, communication, gas sensors, energy and environmental protection because of its useful electronic and optical properties. ${ }^{46}$ In addition, the conduction and $\mathrm{VBedges}$ of $\mathrm{Cu}_{2} \mathrm{O}$ are separated by a band gap energy of $2.0-2.2 \mathrm{eV}$ and the oxide has a considerable absorption coefficient (up to $\sim 10^{4} \mathrm{~cm}^{-1}$ ) in the visible-light region of the solar spectrum. ${ }^{45-49} \mathrm{Cu}_{2} \mathrm{O}$ is a brownish-red colour and crystallizes in a high-symmetry cubic structure. ${ }^{50}$ In cuprite-structured $\mathrm{Cu}_{2} \mathrm{O}$, each oxygen is surrounded by a tetrahedron of $\mathrm{Cu}$, and each $\mathrm{Cu}$ has two oxygen neighbours, as shown by its unit cell model (Figure 2.6a). ${ }^{51}$ Table 2.3. summarises the physical and chemical properties of $\mathrm{Cu}_{2} \mathrm{O} .{ }^{52}$

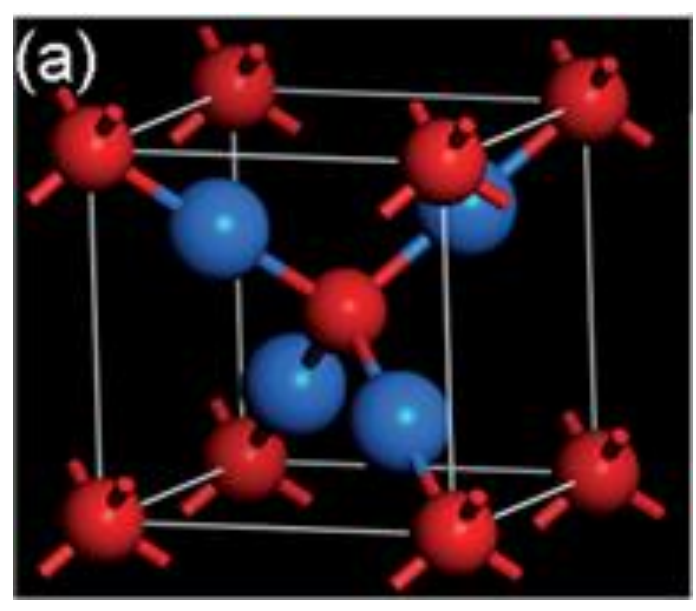

Figure 2.7. The unit cell of the cuprite $\mathrm{Cu}_{2} \mathrm{O}^{53}$ blue = copper, red = oxygen 
Table2.3. Physical and chemical properties of $\mathrm{Cu}_{2} \mathrm{O}^{52}$

\begin{tabular}{ll}
\hline IUPAC name & Copper $(\mathrm{I})$ oxide \\
\hline Synonyms Copper & Copper oxide; cuprous oxide; dicopper oxide \\
\hline CAS number & $1317-39-1$ \\
\hline Molecular Formula & $\mathrm{Cu}_{2} \mathrm{O}$ \\
\hline Molecular weight $(\mathbf{g} / \mathbf{m o l})$ & 143.09 \\
\hline Appearance & Yellow, red, or brown crystalline powder \\
\hline Odor & None \\
\hline Boiling point STPa $\left({ }^{\circ} \mathbf{C}\right)$ & 1800 \\
\hline Melting STPa $\left({ }^{\circ} \mathbf{C}\right)$ & 1235 \\
\hline Density $\left(\mathbf{g}_{\mathbf{c}} \mathbf{c m}^{\mathbf{3}}\right)$ & 6 \\
\hline Refractive index & 2.705 \\
\hline Vapour Pressure & Negligible \\
\hline Solubility & $\begin{array}{l}\text { Soluble in dilute mineral acid to form copper (I) salt or } \\
\text { copper (II) salt plus metallic copper; aqueous ammonia } \\
\text { and its salts }\end{array}$ \\
\hline Insoluble & Insoluble in water and organic solvents \\
\hline Stability & Stable in dry air; in moist air oxidizes to cupric oxide \\
\hline
\end{tabular}

The reactivity and selectivity of a nanocatalyst can be tailored by controlling the shape, which defines the number of atoms located at the edges or corners. Shape control can determine the properties of a nanocrystal with great flexibility. ${ }^{54}$ The common shapes of facecentred cubic (fcc) metals are surrounded by (111) and (100) facets and include a small percentage of corner and edge sites (Figure 2.8). Surface energies corresponding to different crystallographic facets usually increase in the order $\gamma_{(111)}<\gamma_{(100)} \leq \gamma_{(110)} \leq \gamma_{(\mathrm{hkl})}$, where (hkl) signifies high-index facets, with at least one $\mathrm{h}, \mathrm{k}$, and 1 value equal to two or greater. ${ }^{54}$ In the case of crystal growth, it is suggested that the primary driver for the development of the morphology is the reduction of surface energy. In principle, tuning the shape could be achieved by modifying the relative order of the surface energy of the different crystallographic facets. ${ }^{53}$ The rare occurrence of $\mathrm{O}-\mathrm{Cu}-\mathrm{O} 180^{\circ}$ in linear coordination in $\mathrm{Cu}_{2} \mathrm{O}$ gives its crystalline facets (111), (100), and (110) a unique chemical activity. ${ }^{55}$ 


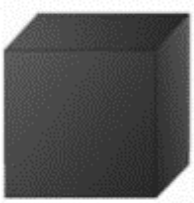

cube

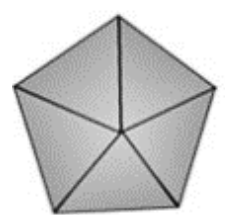

decahedron

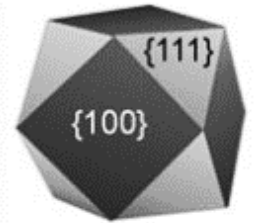

cuboctahedron

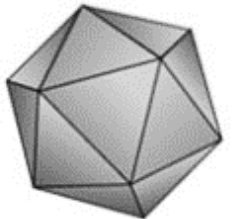

icosahedron

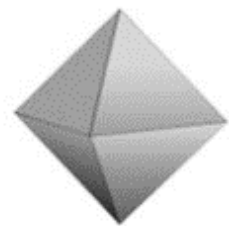

octahedron

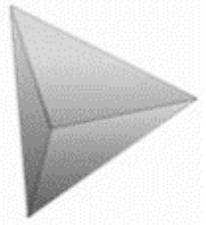

tetrahedron

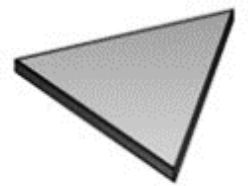

triangular plate

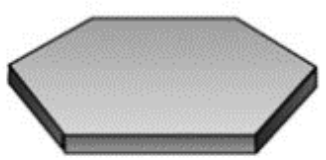

hexagonal plate

Figure 2.8. Conventional shapes of face-centered cubic (fcc) metals, surface is enclosed by (100) and (111) facets. Black and gray colors represent the (100) and (111) facets, correspondingly. ${ }^{54}$

Michael et al., (2009) have reported the synthesis of sub-micrometer-sized $\mathrm{Cu}_{2} \mathrm{O}$ crystals with morphological evolution from cubic to hexapod structures using $\mathrm{CuCl}_{2}$ as the precursor and sodium dodecyl sulphate (SDS) as a surfactant and hydroxylamine $\left(\mathrm{NH}_{2} \mathrm{OH} \bullet \mathrm{HCl}\right)$ reductant. ${ }^{56}$ (Figure 2.9)

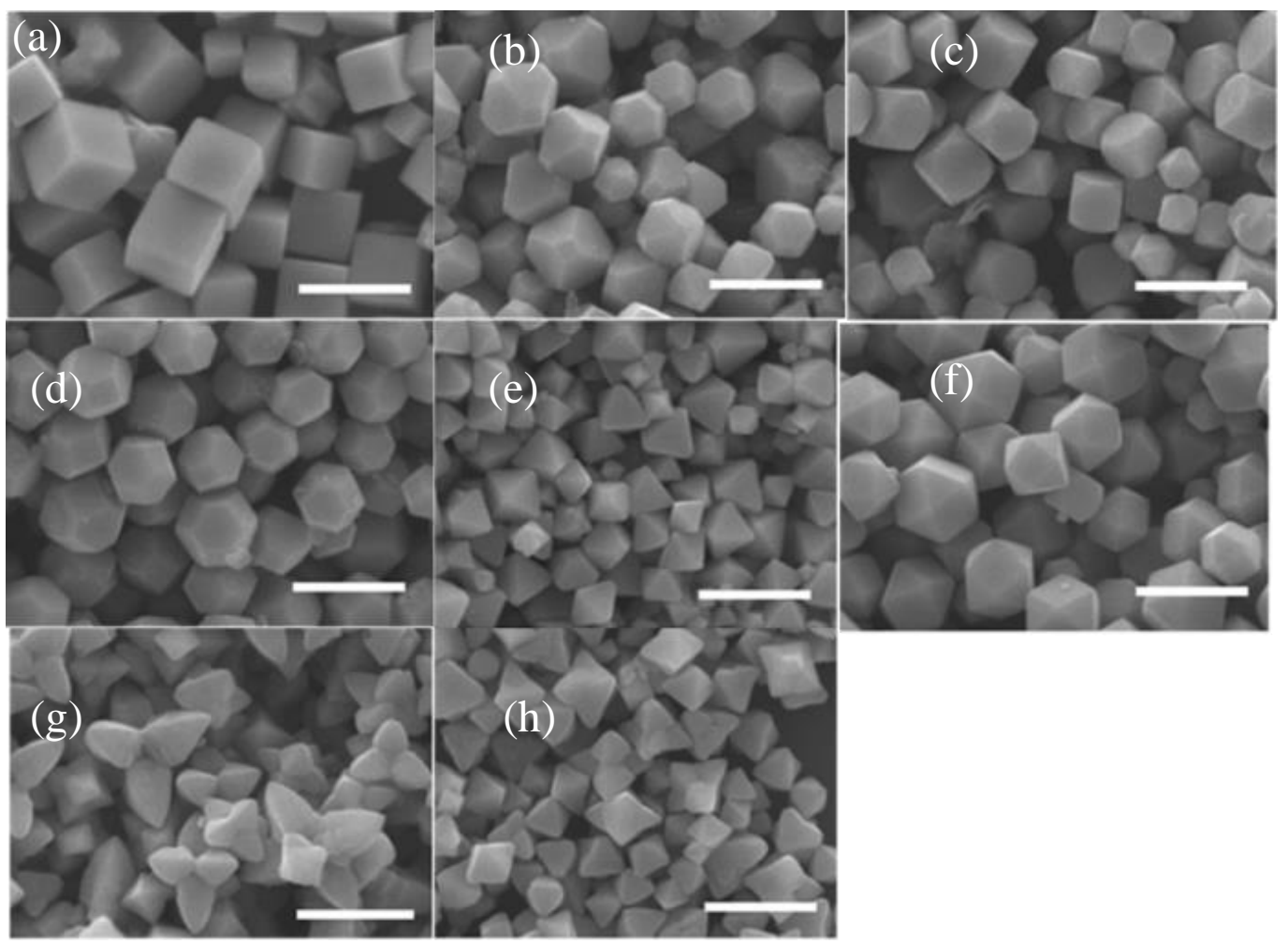

Figure 2.9. SEM images of the $\mathrm{Cu}_{2} \mathrm{O}$ crystals with various morphologies: (a) cubes, (b) type II truncated octahedra, (c) truncated cubes, (d) type I truncated octahedra, (e) octahedra, (f) cuboctahedra, $(\mathrm{g})$ extended hexapods, and $(\mathrm{h})$ short hexapods (scale bar) $1 \mu \mathrm{m} .{ }^{54}$ 
Figure 2.10 shows the XRD patterns of the different morphologies of $\mathrm{Cu}_{2} \mathrm{O}$ crystals reported by Michael et al., (2009). The diffraction patterns clearly display a change in the relative intensities of the (111) and the (200) peaks in relation to the morphology. As expected, cubes show an extremely strong (200) reflection peak and a weak (111) reflection peak. ${ }^{56}$

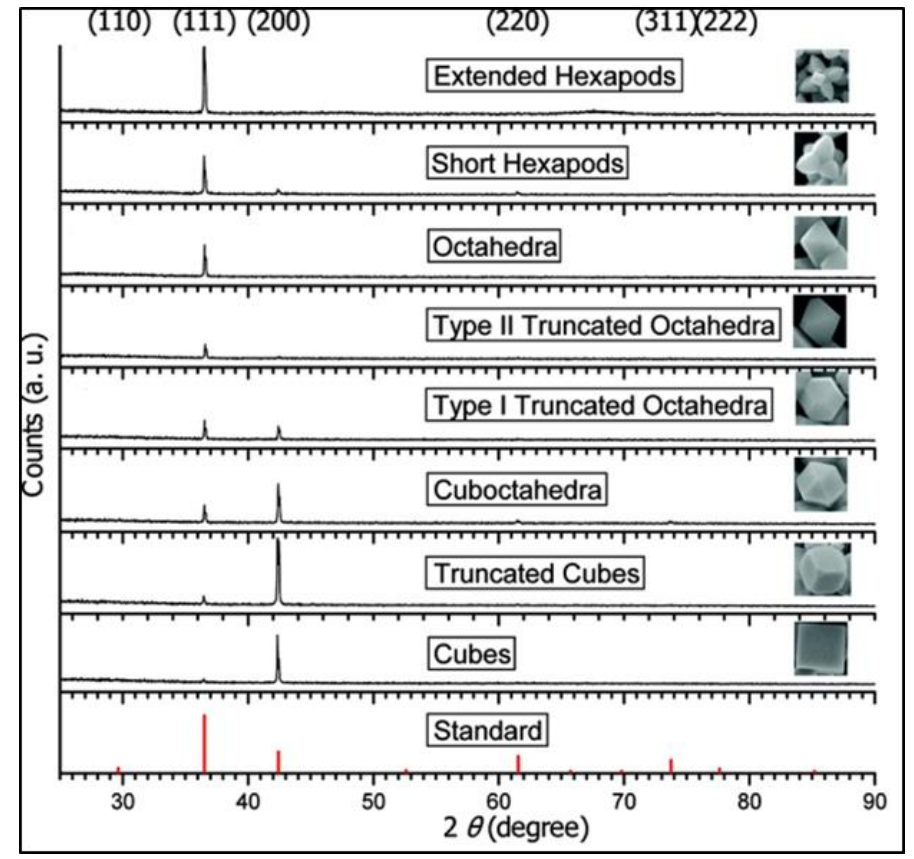

Figure 2.10. Powder XRD patterns of the different morphologies of $\mathrm{Cu}_{2} \mathrm{O}$ crystals. $\mathrm{A}$ standard diffraction pattern of $\mathrm{Cu}_{2} \mathrm{O}$ is also given. ${ }^{55}$

Recently, many researchers ${ }^{57,58,59,60}$ have studied $\mathrm{Cu}_{2} \mathrm{O}$ as a photocatalytic material because of its following advantages:

a) Low toxicity, environmentally acceptable, inexpensive, plentiful, readily available, and have antifouling properties when used in paints; these are the major attractions of $\mathrm{Cu}_{2} \mathrm{O} .{ }^{61}$

b) $\mathrm{Cu}_{2} \mathrm{O}$ can directly utilize visible light in the photocatalytic process, even though it is commonly used as a sensitized semiconductor material for a solar cell fabrication. ${ }^{39}$ These properties are related to the band gap tuning of the $\mathrm{Cu}_{2} \mathrm{O}$ by factors such as particle size. ${ }^{14,62-65}$

c) $\mathrm{Cu}_{2} \mathrm{O}$ effectively adsorbs oxygen molecules ${ }^{66}$ that scavenge the photogenerated electrons to restrict the recombination of electron-hole pairs, subsequently improving the efficiency of photocatalytic processes.

Furthermore, $\mathrm{Cu}_{2} \mathrm{O}$ can act as a stable photocatalyst for the photochemical decomposition of $\mathrm{H}_{2} \mathrm{O}$ and generation of $\mathrm{O}_{2}$ and $\mathrm{H}_{2}$ under visible light irradiation. ${ }^{13}$ Therefore, it is of great 
interest to investigate the stability of $\mathrm{Cu}_{2} \mathrm{O}$. In the field of photovoltaics, copper and copper oxide (a metallic semiconductor) were some of the first photovoltaic cells, invented by Pollack and Trivich in $1975 .{ }^{11}$ It has been reported that photocatalytic splitting water on $\mathrm{Cu}_{2} \mathrm{O}$ powder proceeded without any noticeable deactivation for more than $1900 \mathrm{~h} .{ }^{48}$ Huang et al. also reported that $\mathrm{Cu}_{2} \mathrm{O}$ particles with different sizes were used as photocatalysts to directly degrade methyl orange. The results showed that the stability of $\mathrm{Cu}_{2} \mathrm{O}$ was different under ambient atmosphere and photocatalytic conditions in solution. $\mathrm{Cu}_{2} \mathrm{O}$ nanoparticles can readily be deactivated during the photocatalytic reaction because their photocorrosion rate is very rapid. Therefore, it is great importance to investigate the stability of $\mathrm{Cu}_{2} \mathrm{O}^{50}$ and clarify the mechanism of deactivation of $\mathrm{Cu}_{2} \mathrm{O} .{ }^{48}$

$\mathrm{Cu}_{2} \mathrm{O}$ not only makes good use of visible light in the photolysis process but is also used as a sensitized semiconductor material for solar cell fabrication; this is related to its band gap tuning by factors such as its particle size and surface area. ${ }^{63,14,12}$ Large surface areas can provide more surface sites for the adsorption of reactant molecules and render the adsorption process more efficient. Thus, porous structures with large surface areas have prospective applications as photocatalysts. ${ }^{67}$ The band gap of a semiconductor determines its working wavelength. Semiconductors with bandgaps that are either too large or too small are not suitable for practical use. The reason is larger band gaps will not produce any photoreaction while narrow band gap materials will have problems with light corrosion. Figure 2.11 shows the band-edge positions of several semiconductors, along with the redox potentials of water. ${ }^{68}$

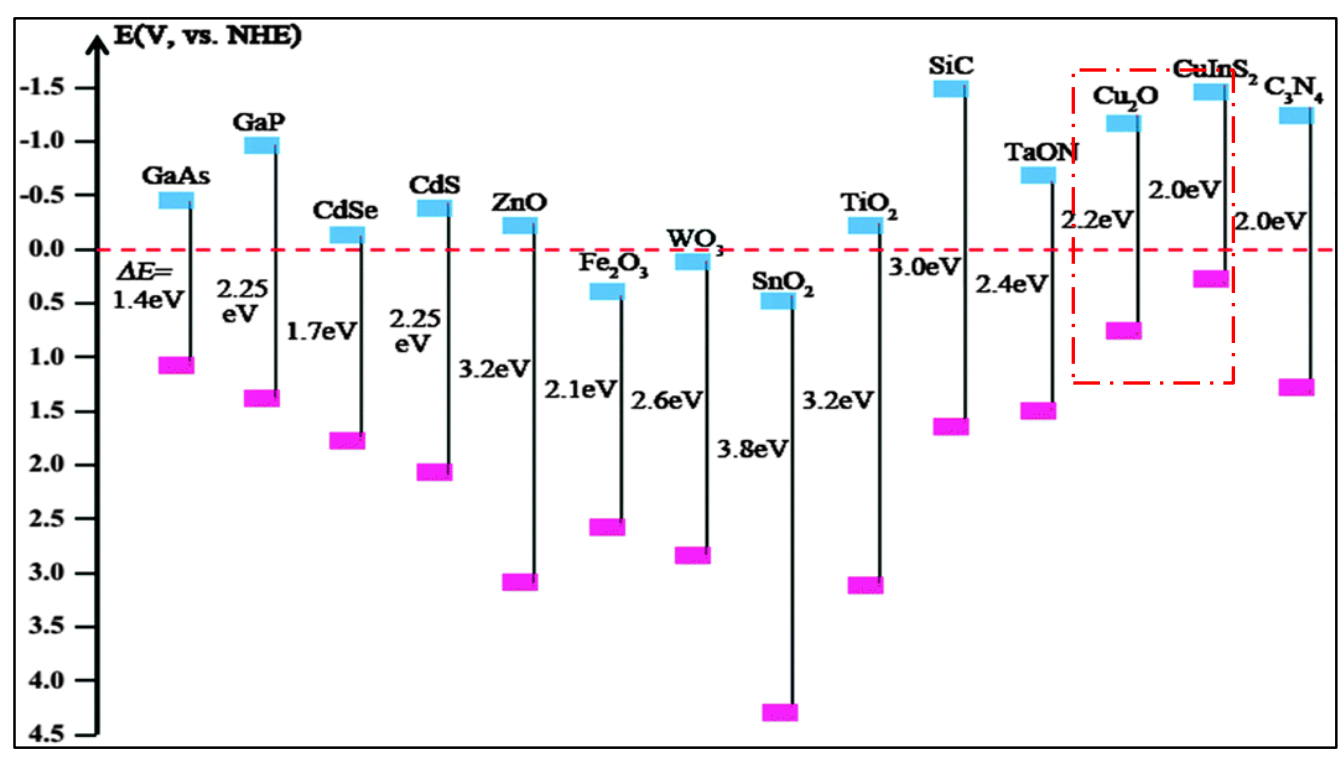

Figure 2.11. Eg values (in eV) and position of $C B$ (blue) and VB (pink) for various semiconductors. ${ }^{69}$ 
$\mathrm{TiO}_{2}(3.0-3.2 \mathrm{eV})$ has a suitable band edge but its solar light consumption is limited by its large band gap. ${ }^{70} \mathrm{WO}_{3}$ has a small band gap of $2.6 \mathrm{eV}$, and can utilize $\sim 12 \%$ solar light but for the reduction of water it needs a more negative $\mathrm{CB} .{ }^{71} \mathrm{Fe}_{2} \mathrm{O}_{3}$ has a smaller band gap of 2.1 $\mathrm{eV}$, which has the ability to absorb longer wavelengths, but one of its major drawbacks is that its $\mathrm{CB}$ edge position is not negative enough for solar water splitting, and it needs a large external bias to perform this function. ${ }^{72}$ Much work has been done during the past decades to overcome these limitations in semiconductor photocatalysts, and significant progress has been achieved.

One of the developments has been to increase the visible light photoactivity of metal oxides with elemental doping and sensitization with small band gap semiconductors. Hoang et al. created a $\mathrm{CdS} / \mathrm{TiO}_{2}$ electrode that exhibited good visible light photoactivity and excellent stability without showing any $\mathrm{CdS}$ photodegradation. ${ }^{73}$ Another improvement was the development of a nanostructured electrode, since the nanostructure can offer a better surface contact with the electrolyte and a smaller diffusion distance for photogenerated minority carriers. ${ }^{69} \mathrm{Cu}_{2} \mathrm{O}$ is one of the semiconductors that has a small enough band gap of $\sim 2.2 \mathrm{eV}$ and a $\mathrm{CB}$ that is negative enough for water splitting.

Additionally, $\mathrm{Cu}_{2} \mathrm{O}$ can effectively adsorb molecular oxygen, which can scavenge the photogenerated electrons to maintain the recombination of electron-hole pairs, and consequently facilitate the photocatalytic efficiency. ${ }^{66} \mathrm{Cu}_{2} \mathrm{O}$ can generate electrons and holes when irradiated by visible light.

The microstructure and morphology of $\mathrm{Cu}_{2} \mathrm{O}$ nanoparticles varies depending on the copper source and the additives used to produce them. Zheng et al., (2009) reported the use of $\mathrm{Cu}\left(\mathrm{CH}_{3} \mathrm{COO}\right)_{2} \cdot \mathrm{H}_{2} \mathrm{O}$ and $\mathrm{CH}_{3} \mathrm{COOH}$ as precursors to synthesise $\mathrm{Cu}_{2} \mathrm{O}$ particles. ${ }^{74}$ After one hour irradiation with visible light, the $\mathrm{Cu}_{2} \mathrm{O}$ (100) and (110) facets gradually transform into nanosheets and after 16 hour, the $\mathrm{Cu}_{2} \mathrm{O}$ microcrystals had completely changed into nanosheets (Figure 2.12). ${ }^{74}$ 


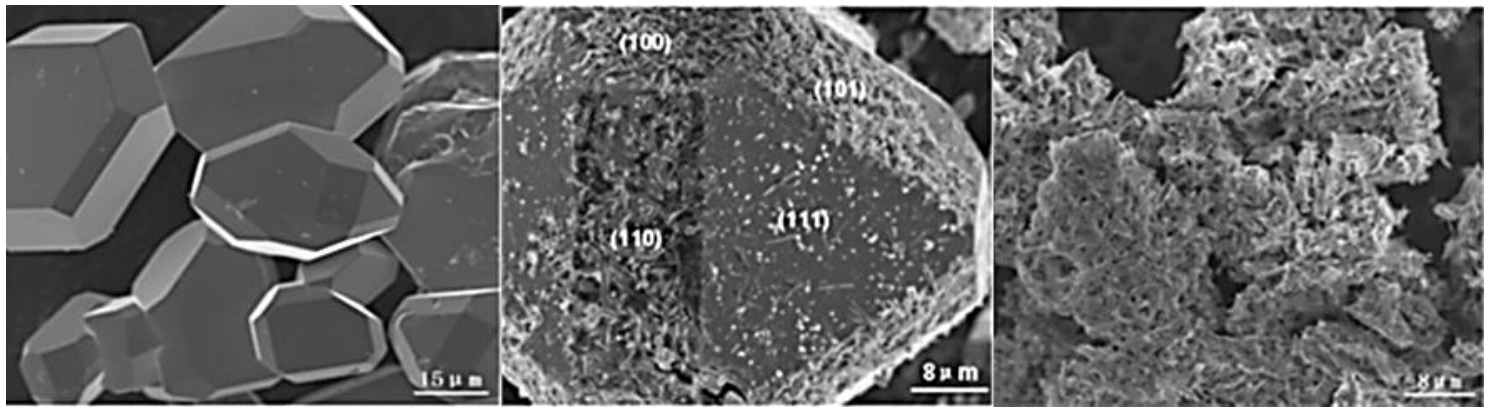

Figure 2.12. SEM images of $\mathrm{Cu}_{2} \mathrm{O}$ samples after irradiation for (a) 0 , (b) 1 , and (c) 16 hour. ${ }^{74}$

$\mathrm{XRD}$ analysis confirmed that $\mathrm{Cu}_{2} \mathrm{O}$ nanosheets are formed after 16 hour irradiation under visible light (Figure 2.13). ${ }^{74} \mathrm{Cu}_{2} \mathrm{O}$ (100) and (110) facets steadily convert into nanosheets during the photodegradation of methyl orange (MO) under visible light irradiation. The electrons and holes are generated when the intermediate $\mathrm{CuO}$ is irradiated by the visible light, and the MO may capture the photogenerated holes. As the holes are consumed, $\mathrm{CuO}$ formed on the (100) and (110) facets is reduced back to $\mathrm{Cu}_{2} \mathrm{O}$, ultimately forming $\mathrm{Cu}_{2} \mathrm{O}$ nanosheets. With increased irradiation time, $\mathrm{Cu}_{2} \mathrm{O}$ microcrystals are completely transformed into nanosheets. $^{74}$
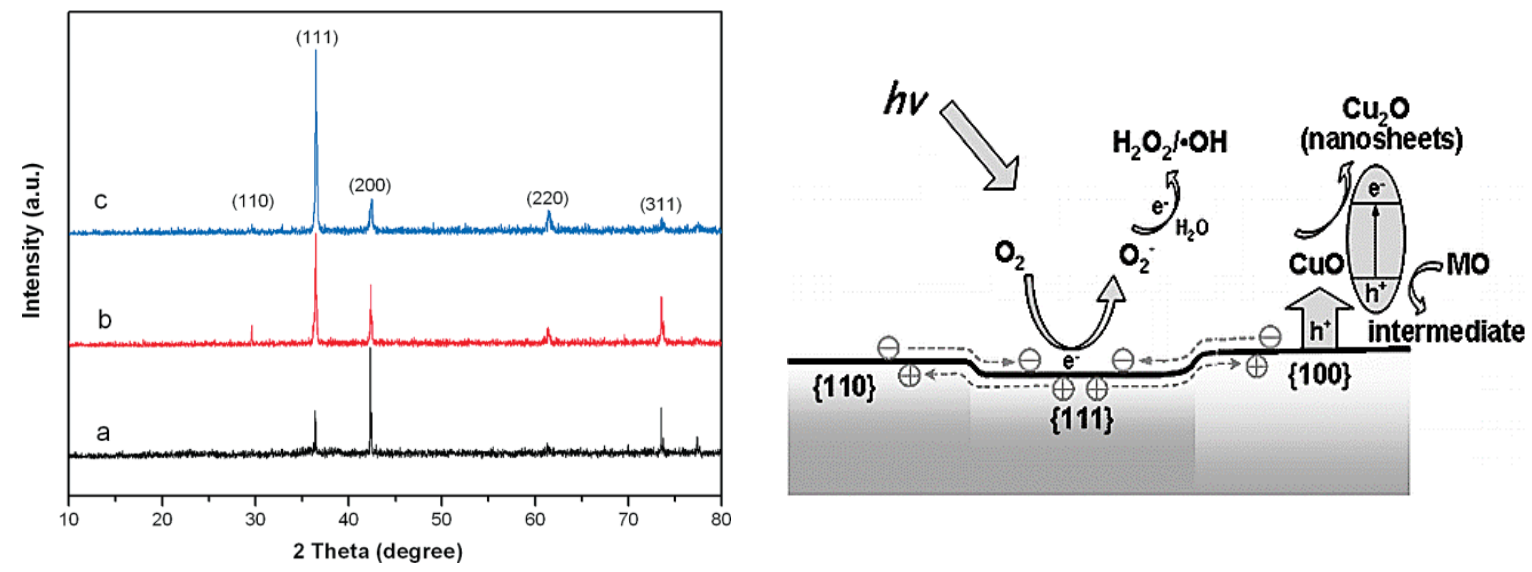

Figure 2.13. (Left), XRD patterns of $\mathrm{Cu}_{2} \mathrm{O}$ irradiated for (a) $0 \mathrm{~h}$, (b) $1 \mathrm{~h}$, (c) $16 \mathrm{~h}$ in $\mathrm{MO}$ solution. (Right) schematic diagram showing charge separation among the different crystal faces and regeneration of $\mathrm{Cu}_{2} \mathrm{O}$ nanosheets. ${ }^{74}$

By contrast with $\mathrm{Cu}_{2} \mathrm{O}$, a drawback to the use of $\mathrm{TiO}_{2}$ as a photocatalyst is its comparatively large band gap energy (3.0-3.2 eV), allowing it to be activated only by UV radiation $(\lambda<$ $387 \mathrm{~nm}$ ); this greatly limits its efficiency in coupling with solar radiation, of which less than $4 \%$ occurs in the UV region. On the other hand, cuprous oxide $\left(\mathrm{Cu}_{2} \mathrm{O}\right)$ is a p-type 
semiconductor ${ }^{75,76}$ with a direct band gap of $2.2 \mathrm{eV}$ and a high optical absorption coefficient compared with $\mathrm{TiO}_{2}$, allowing it to make direct use of visible light. ${ }^{77,78}$

Recently, $\mathrm{Cu}_{2} \mathrm{O}$ has shown promise as a visible light-driven photocatalyst for splitting water and degrading organic contaminants. ${ }^{59,79,80}$ Low toxicity, inexpensive and its environmentalfriendliness are some of the properties of $\mathrm{Cu}_{2} \mathrm{O}$ which make it a potential alternative to the other photocatalysts such as $\mathrm{TiO}_{2}$ in photocatalytic degradation of organic contaminants ${ }^{81}$. Different approaches are frequently used to overcome these disadvantages, including elemental doping of large and small band gap semiconductors to produce the most efficient photocatalysts. One possibility is to couple $\mathrm{Cu}_{2} \mathrm{O}$ with n-type semiconductors such as $\mathrm{TiO}_{2}$ since the two semiconductors possess matching band potentials. ${ }^{82}$ Han et al. reported $\mathrm{TiO}_{2} / \mathrm{Cu}_{2} \mathrm{O}$ composite films demonstrated better photocatalytic efficiencies than $\mathrm{TiO}_{2}$ and $\mathrm{Cu}_{2} \mathrm{O}$ alone under visible light irradiation. ${ }^{83}$ Bessekhouad and co-workers prepared $\mathrm{Cu}_{2} \mathrm{O} / \mathrm{TiO}_{2}$ heterojunctions via physical mixing that exhibited a higher activity for the degradation of $\mathrm{MB}$ as a dye than $\mathrm{Cu}_{2} \mathrm{O}$ alone. ${ }^{84}$ Huang et al. also described $\mathrm{Cu}_{2} \mathrm{O} / \mathrm{TiO}_{2}$ nanoheterostructures based on a chemical precipitation method and reported these to show better photocatalytic efficiencies than pure $\mathrm{TiO}_{2}(\mathrm{P} 25) .{ }^{85}$ Xue and co-workers produced core-shell $\mathrm{TiO}_{2} / \mathrm{Cu}_{2} \mathrm{O}$ heterostructures by an electrochemical method and reported that these had excellent photoelectrochemical performances under visible light. ${ }^{86}$

\subsubsection{The mechanism of photo-oxidation in $\mathrm{Cu}_{2} \mathrm{O}$}

Wang et al. discussed the mechanism of deactivation of $\mathrm{Cu}_{2} \mathrm{O}$ during the photocatalyst reactions. The thermodynamic possibility of both reduction and oxidation processes in the photocatalyst sample is essential, and this phenomenon for $\mathrm{Cu}_{2} \mathrm{O}$ has been verified. ${ }^{13}$ The photo-generated electrons can readily transfer to another semiconductor or be taken up by molecular oxygen $\mathrm{O}_{2}$ and $\mathrm{H}_{2} \mathrm{O}$. According to Figure 2.14 a type of overpotential occurs for this reduction reaction, as shown in Eqs. (13), (15) and (17). In reaction (13) the $\mathrm{Cu}_{2} \mathrm{O}$ is reduced to $\mathrm{Cu}$ by electrons and the reduction reaction (15) of water to hydrogen seems to be insignificant due to the competing reaction. On the other hand, the quantity of holes on the $\mathrm{Cu}_{2} \mathrm{O}$ increases when the electrons are transferred and scavenged. 


$$
\begin{aligned}
& \mathrm{Cu}_{2} \mathrm{O}+\mathrm{hv} \rightarrow \mathrm{e}^{-}\left(\mathrm{CBCu}_{2} \mathrm{O}\right)+\mathrm{h}^{+}\left(\mathrm{VBCu}_{2} \mathrm{O}\right) \\
& \mathrm{Cu}_{2} \mathrm{O}+\mathrm{H}_{2} \mathrm{O}+2 \mathrm{e}^{-} \rightarrow 2 \mathrm{Cu}+2 \mathrm{OH}^{-} \\
& \mathrm{Cu}_{2} \mathrm{O}+2 \mathrm{OH}^{-} \rightarrow 2 \mathrm{CuO}+\mathrm{H}_{2} \mathrm{O}+2 \mathrm{e}^{-} \\
& 2 \mathrm{H}_{2} \mathrm{O}+2 \mathrm{e}^{-} \rightarrow \mathrm{H}_{2}+2 \mathrm{OH}^{-} \\
& 2 \mathrm{H}_{2} \mathrm{O} \rightarrow \mathrm{O}_{2}+4 \mathrm{H}^{+}+4 \mathrm{e}^{-} \\
& \mathrm{O}_{2}+\mathrm{e}^{-} \rightarrow \mathrm{O}_{2}
\end{aligned}
$$

However, the holes are difficult to eliminate in the absence of other redox species, and therefore reaction (14) will take place preferentially. On the other hand, $\mathrm{Cu}_{2} \mathrm{O}$ can also be oxidized by the oxidizing potentials of $\mathrm{OH}^{\bullet}$ or $\mathrm{H}_{2} \mathrm{O}_{2}$ that are more positive than those of holes. Remarkably, in the photocatalysis of $\mathrm{TiO}_{2}, \mathrm{OH}^{\bullet}$ is produced while the holes oxidize $\mathrm{H}_{2} \mathrm{O}$. It is clear that the $\mathrm{TiO}_{2}$ VBedge level is higher than the oxidation potential of water, so both $\mathrm{TiO}_{2}$ holes and $\mathrm{OH}^{\bullet}$ are referred to "holes" without distinction. ${ }^{87}$

$$
\begin{aligned}
& \mathrm{O}_{2}+2 \mathrm{H}_{2} \mathrm{O}+2 \mathrm{e}^{-} \rightarrow \mathrm{H}_{2} \mathrm{O}_{2}+2 \mathrm{OH}^{-} \\
& \mathrm{O}_{2}+2 \mathrm{H}_{2} \mathrm{O}+4 \mathrm{e}^{-} \rightarrow 4 \mathrm{OH}^{-} \\
& \mathrm{H}_{2} \mathrm{O}_{2}+\mathrm{O}_{2}^{-} \rightarrow \mathrm{OH}^{-}+\mathrm{OH}^{-}+\mathrm{O}_{2} \\
& \mathrm{OH}^{-}+\mathrm{MO} \rightarrow \text { Degradation }
\end{aligned}
$$

Whereas in the photocatalysis of $\mathrm{Cu}_{2} \mathrm{O}$, the hole cannot be transferred to $\mathrm{OH}^{*}$ because it cannot oxidize $\mathrm{H}_{2} \mathrm{O}$ and the $\mathrm{Cu}_{2} \mathrm{O}$ VBedge level is lower than the oxidation potential of water, more and more holes accumulate on the surface of the $\mathrm{Cu}_{2} \mathrm{O}$ so that the concentration of holes is far greater than that of $\mathrm{OH}^{\circ}$. 


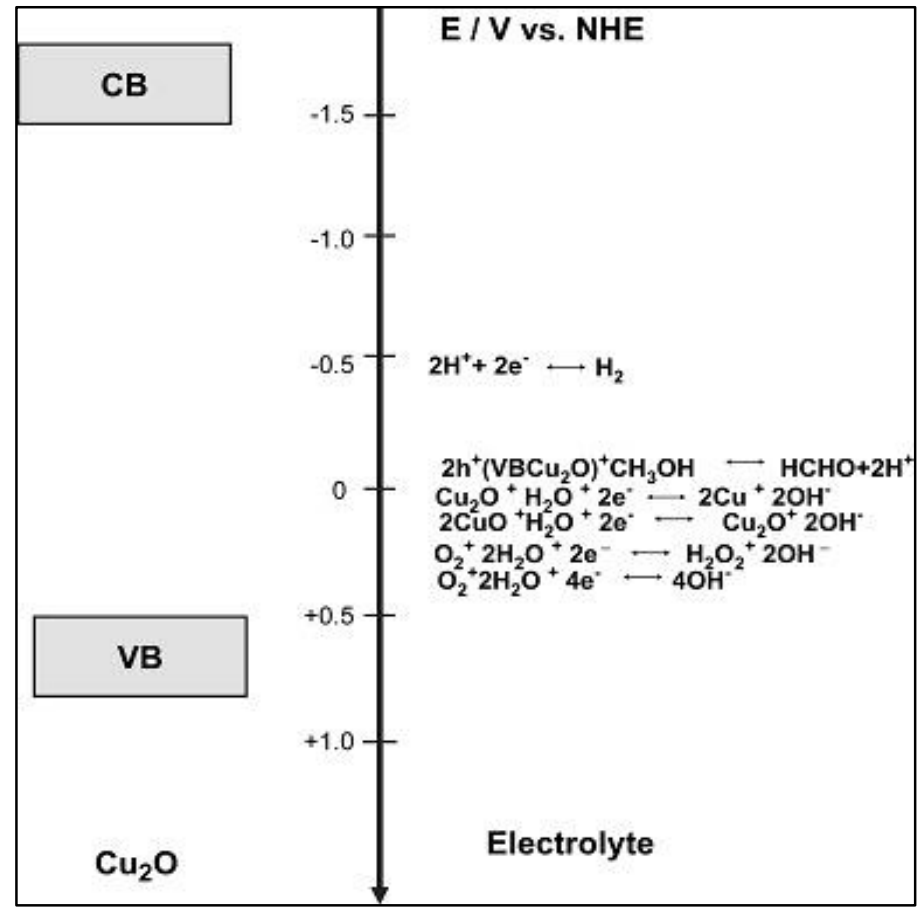

Figure 2.14. Overview of the redox potentials of the relevant reactions with respect to the estimated position of the $\mathrm{Cu}_{2} \mathrm{O}$ band edges. ${ }^{87}$

\subsection{The geopolymer matrix of the proposed new photocatalytic materials: Raw materials used to make geopolymers}

\subsubsection{Metakaolin (dehydroxylated kaolinite)}

Kaolinite is a 1:1 clay mineral which means each structural unit has one tetrahedral silica layer and one octahedral alumina layer with the chemical composition $\mathrm{Al}_{2} \mathrm{Si}_{2} \mathrm{O}_{5}(\mathrm{OH})_{4}$, (Figure 2.15). Individual particles of kaolinite form layers held together by hydrogen bonds and Van der Waals forces. The strength of these bonds prevents water from entering the interlayer spaces and cause swelling. ${ }^{88}$ The dehydroxylated form of the clay mineral kaolinite is metakaolin, formed by the reaction $\mathrm{Al}_{2} \mathrm{Si}_{2} \mathrm{O}_{5}(\mathrm{OH})_{4} \rightarrow \mathrm{Al}_{2} \mathrm{O}_{3} \cdot 2 \mathrm{SiO}_{2}+2 \mathrm{H}_{2} \mathrm{O}$. Halloysite $\left(\mathrm{Al}_{2} \mathrm{Si}_{2} \mathrm{O}_{5}(\mathrm{OH})_{4}\right)$, a hydrated form of kaolinite, loses most of its adsorbed water in the temperature range $100-200{ }^{\circ} \mathrm{C}$. Between $500-800{ }^{\circ} \mathrm{C}$, kaolinite-type minerals lose their hydroxyl water by dehydroxylation. A large amount of energy is required to remove the chemically bonded hydroxyl ions, breaking down the crystal structure and producing an Xray amorphous transition phase consisting of silica and amorphous alumina in a reactive form $;{ }^{89}$ this has a high surface area, so the dehydroxylation of kaolinite to form metakaolin is an endothermic process. Heating at a higher temperature will cause recrystallization into 
cristobalite $\left(\mathrm{SiO}_{2}\right)$ and mullite $\left(3 \mathrm{Al}_{2} \mathrm{O}_{3} \cdot 2 \mathrm{SiO}_{2}\right.$, the higher temperature form which is more thermodynamically stable than the lower-temperature form $2 \mathrm{Al}_{2} \mathrm{O}_{3} \cdot \mathrm{SiO}_{2}$ ).

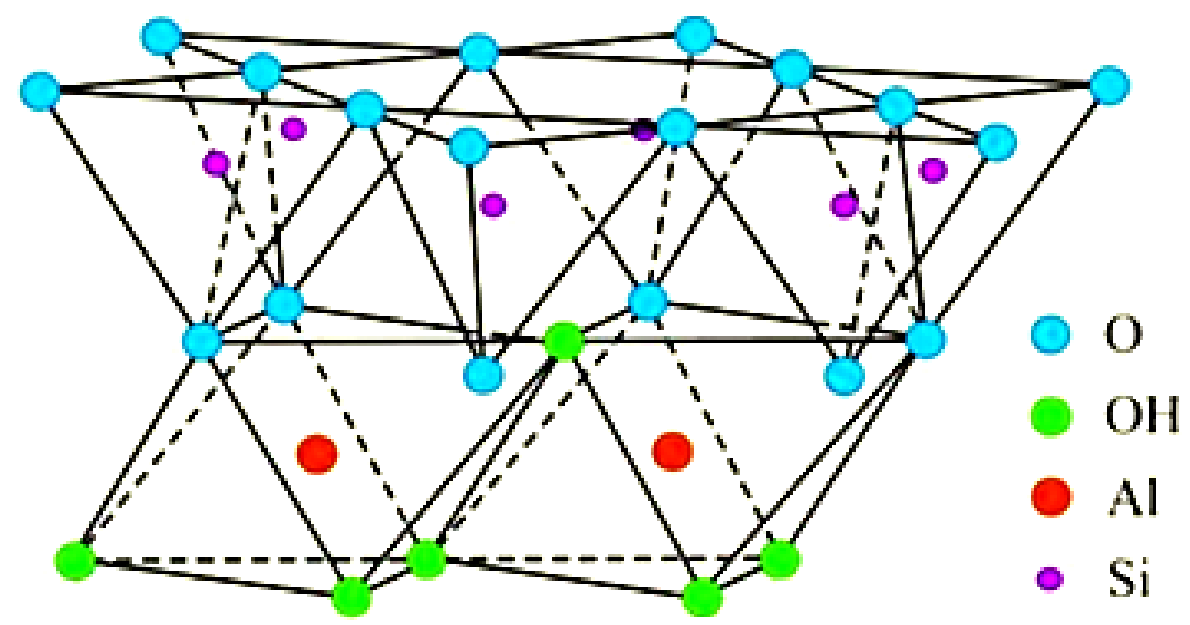

Fig 2.15. Structure of the kaolinite unit ${ }^{90}$

\subsection{Geopolymers}

Geopolymers are alumino-silicate materials formed by the reaction of alumina and silicate sources with an alkali metal activator. The solid source materials (typically aluminosilicates) should be rich in $\mathrm{Si}$ and $\mathrm{Al}$ and may be by-products or waste materials such as fly ash, silica fume, slag, rice husk ash, red mud, etc. ${ }^{91}$ Geopolymers are unique by comparison with other aluminosilicates (e.g. aluminosilicate gels, glasses, and zeolites), since the concentration of solids in the geopolymerization reaction is higher than in aluminosilicate gel or zeolite synthesis. ${ }^{92}$ Geopolymers are amorphous three-dimensional aluminosilicate binder materials, which were first discovered by Glukhovsky in the former Soviet Union in the $1950 \mathrm{~s} .{ }^{92}$ In 1979 Davidovits, a French scientist, created similar materials, giving them the name "geopolymers"; these are a type of geopolymer containing $\mathrm{SiO}_{4}$ and $\mathrm{AlO}_{4}$ tetrahedra as the structural units. In general, geopolymers are typically formed by reaction between an alkaline solution (e.g., sodium hydroxide and sodium silicate) and a solid aluminosilicate source (e.g., metakaolin, fly ash or slag). Currently, geopolymers are receiving increasing attention from researchers because of their useful properties such as their strength and low environmental impact. An important property is that geopolymer materials can be made at room temperature 
without firing; thus, an important reason for taking an interest in these materials is their lowtemperature formation and hence low energy requirement. ${ }^{93}$ Four essentials features have been proposed for distinguishing geopolymers from other aluminosilicate systems (i.e. zeolites, clays, etc. $):^{94}$

i. They are prepared by alkali activation of an aluminosilicate source.

ii. They formed at temperatures between ambient and $\sim 90{ }^{\circ} \mathrm{C}$.

iii. They consist of cross-linked tetrahedral $\mathrm{Si}$ and $\mathrm{Al}$ units with charge compensation provided by alkali ions.

iv. They are X-ray amorphous materials that display a lack of long range ordering.

In addition, due to their exceptionally high thermal and chemical stability, excellent mechanical strength, adhesive behaviour and long-term durability, they may be used as a viable economical alternative to organic polymers and inorganic cements in diverse applications such as military, ${ }^{95}$ aircraft, ${ }^{96,97,98}$ high-tech ceramics, thermal insulating foams, ${ }^{99}$ fire-proof building materials, ${ }^{94}$ protective coatings, ${ }^{98}$ refractory adhesives ${ }^{100}$ and hybrid inorganic-organic composites. ${ }^{101,102}$ Furthermore, early researchers have demonstrated that geopolymers are cheap to produce and can be made from a vast number of minerals and industrial by-products, including pozzolans, ${ }^{103,104}$ natural aluminosilicate minerals, metakaolin, ${ }^{105,106}$ fly ash and kaolinite mixtures. ${ }^{107,108}$ Geopolymers are resistant to fire and thermal shock and are used as a binder for the immobilisation of hazardous heavy metals and radioactive wastes. ${ }^{109}$ They also have very low corrosion properties compared to other materials. Geopolymers may be modified or functionalized for applications as catalysts, ${ }^{110}$ for purifying water ${ }^{109}$ or removing $\mathrm{CO}_{2}$, ammonia, or $\mathrm{NO}_{\mathrm{x}}$ gases from the atmosphere. ${ }^{111}$ They have attracted considerable attention as new, low $\mathrm{CO}_{2}$ emission replacements for Portland cement. ${ }^{109}$ Moreover, they are environmentally friendly materials from the point of view of reducing the greenhouse effects caused by $\mathrm{CO}_{2}$ emission from the manufacture of Portland cement.

The chemical compositions of geopolymers are similar to natural zeolitic materials, but the microstructure is amorphous rather than crystalline. ${ }^{112,32}$ According to Davidovits, ${ }^{113}$ geopolymers possess amorphous to semi-crystalline three-dimensional silico-aluminate structures consisting of $\mathrm{SiO}_{4}$ and $\mathrm{AlO}_{4}$ tetrahedra linked by sharing all the oxygen atoms, giving units that can be designated as poly-sialate (-Si-O-Al-O-) $(\mathrm{Si}: \mathrm{Al}=1)$, poly-sialatesiloxo (-Si-O-Al-O-Si-O-) ( $\mathrm{Si}: \mathrm{Al}=2$ ), poly-sialate-disiloxo (-Si-O-Al-O-Si-O-Si-O-) (Si:Al 
$=3$ ), and sialate units $(\mathrm{Si}: \mathrm{Al}>3)$. Sialate is an abbreviation for silicon-oxo-aluminate. The empirical formula for the geopolymer matrix is:

$\mathrm{M}_{\mathrm{n}}^{+}\left\{-\left(\mathrm{SiO}_{2}\right)_{\mathrm{z}}-\mathrm{AlO}_{2}-\right\}_{\mathrm{n}}$

where $\mathrm{M}^{+}=$an alkali cation $\left(\mathrm{K}^{+}, \mathrm{Na}^{+}\right)$to balance the negative charge of $\mathrm{Al}^{3+}$ in IV-fold coordination, $\mathrm{n}=$ the degree of polymerization and $\mathrm{z}=$ the $\mathrm{Si} / \mathrm{Al}$ ratio. By varying the $\mathrm{Si} / \mathrm{Al}$ ratios (i.e. $\mathrm{z}=1$ to 300 ), ${ }^{114}$ geopolymers exhibit different properties; low ratios (i.e., $\mathrm{Si} / \mathrm{Al} \leq$ 3) result in three-dimensional cross-linked rigid networks and stiff and brittle properties (as in cements and ceramics), while high ratios (i.e., $\mathrm{Si} / \mathrm{Al}>3$ ) result in 2-D networks and linearly linked polymeric structures with adhesive and rubbery properties, respectively.

Geopolymers appear to be good candidates as binders for ecologically friendly concrete, because of their durability. Furthermore, geopolymers can be used in concrete instead of Portland cement to give "green" concrete. Geopolymer cement concretes (GPCC) are geopolymer composites with the potential to form a substantial element of environmentally sustainable construction, by replacing or supplementing conventional concretes. GPCCs have high strength, with good resistance to chloride penetration, acid attack, etc. ${ }^{1}$ Geopolymer concrete has emerged as a new technology in construction materials. ${ }^{115}$

\subsubsection{Mechanism of Geopolymer Formation (Geopolymerization)}

Geopolymerization is an exothermic process that proceeds via oligomers (dimers, trimmers) which are the fundamental unit structures in the three-dimensional macromolecular structure. ${ }^{116}$ Davidovits suggested that geopolymerization could be regarded as the analogue of synthesis of zeolites. ${ }^{117}$ In other words, the geopolymer microstructure is amorphous or semi-crystalline rather than crystalline. ${ }^{117}$ The process of geopolymerization, represented schematically in Figure 2.16, ${ }^{51}$ is proposed to occur by a complex series of concurrent and coupled reactions, the mechanism of which is thought to involve several key processes. ${ }^{62,106 \text {, }}$ 117

I. The generation of reactive species by alkali activation; this is the dissolution of amorphous phases (e.g., aluminosilicates) by alkali to produce small units of reactive silica and alumina. 
II. Reorientation, which is the transportation or orientation or condensation of precursor ions into oligomers, and

III. The actual setting reaction, which is the polycondensation process leading to the formation of amorphous to semi-crystalline aluminosilicate polymers.

However, these three steps can overlap with each other and occur almost simultaneously, thus making it difficult to isolate and examine each of them separately. ${ }^{112}$ The following two reactions can illustrate the schematic formation of geopolymer materials.

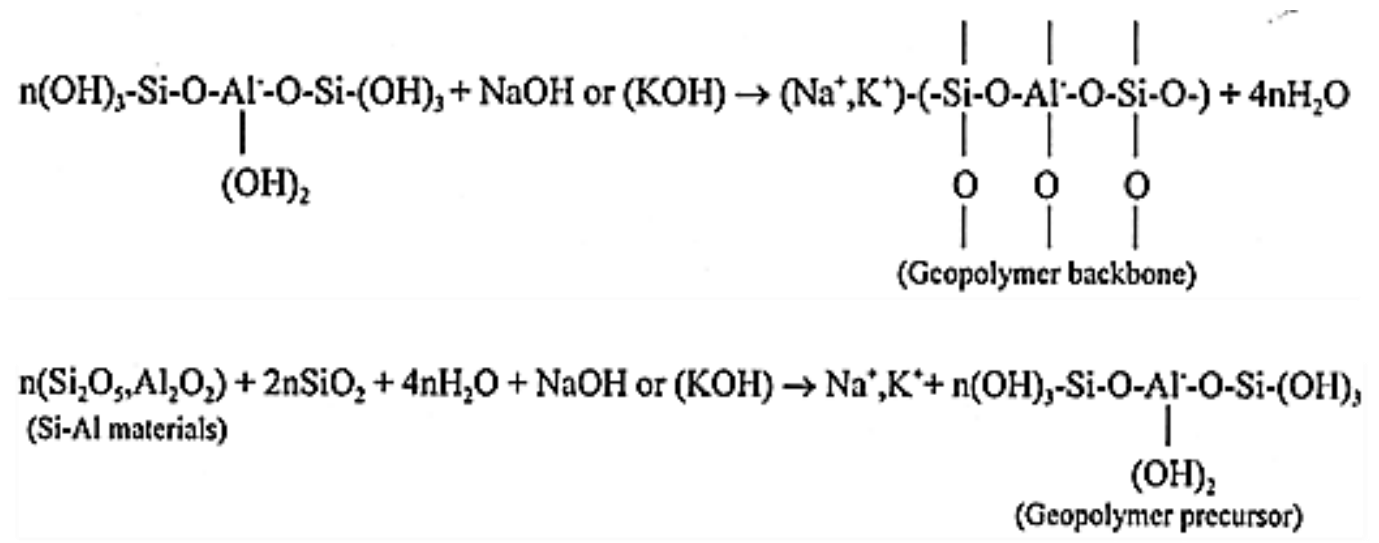

The two above reactions suggest that any material that contains mostly silica and alumina in an amorphous form is a possible source for the production of geopolymers. 


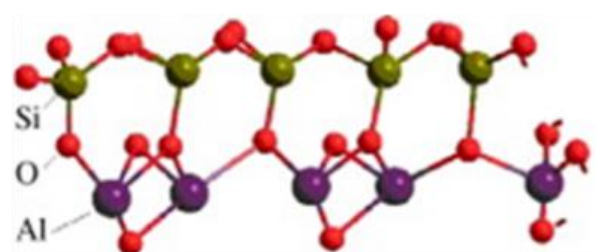

Raw Si-Al materials
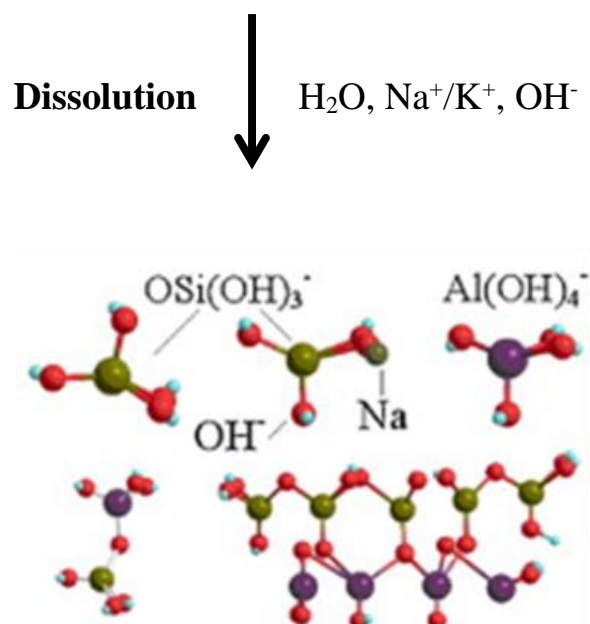

Raw Si-O-Al species polymerization

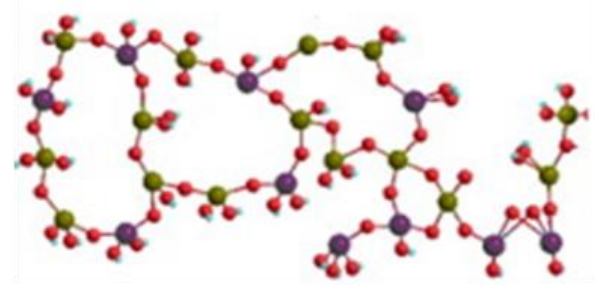

Geopolymer (Large network)

\section{Solidification}

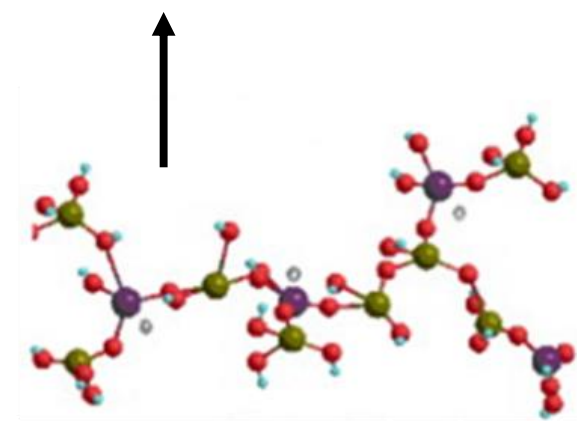

Gel network (geopolymer precursor)

Figure 2.16. Sketch of the typical reaction mechanism of geopolymerization. ${ }^{51}$

During the dissolution step, both $\mathrm{Si}$ and $\mathrm{Al}$ species are produced when $\mathrm{Si}-\mathrm{Al}$ raw materials come into contact with the alkaline solution. ${ }^{118}$ The concentration of the alkaline solution, the alkali metal cation (e.g., $\mathrm{Na}^{+}, \mathrm{K}^{+}$), the mixing rate and time, and the intrinsic structure and composition of the $\mathrm{Si}-\mathrm{Al}$ raw materials are the main factors controlling the generation of the $\mathrm{Si}$ and $\mathrm{Al}$ species. It has been suggested that the concentration of the alkaline solution and the intrinsic properties of the $\mathrm{Si}-\mathrm{Al}$ raw materials are the dominant factors in this reaction step. ${ }^{118}$ The reorientation step involves the dispersion of dissolved $\mathrm{Si}$ and $\mathrm{Al}$ species (e.g., $\mathrm{Al}^{3+}, \mathrm{Si}^{4+}$ ) into the oligomers, followed by the formation of a gel from the oligomers in the aqueous phase, producing relatively large networks by condensation. ${ }^{32,119}$ Once the dissolved $\mathrm{Al}^{3+}$ and $\mathrm{Si}^{4+}$ species on the surface of the source $\mathrm{Si}-\mathrm{Al}$ materials are removed, further leaching of reactive $\mathrm{Al}$ and $\mathrm{Si}$ species from the raw materials occurs.

Throughout the solidification step, the gelation process continues to rearrange and reorganize the product, increasing the connectivity of the gel network and resulting in the amorphous or semi-crystalline three-dimensional aluminosilicate network commonly attributed to the geopolymer. At this stage, the temperature and air circulation are two major factors determining the properties of the final geopolymeric products. ${ }^{118}$ These three major steps 
occur simultaneously; for instance, during the solidification step, both dissolution and reorientation are also occurring. ${ }^{112}$

The resulting monolithic solids consist of cross-linked polymeric sialate chains of tetrahedrally coordinated $\mathrm{Si}$ and $\mathrm{Al}$ units linked by $\mathrm{O}$. These tetrahedral $\mathrm{SiO}_{4}$ and $\mathrm{AlO}_{4}$ units have well-defined coordination geometries but form an extremely disordered network, shown in Figure 2.17. ${ }^{120}$

The alkali cations remain in the structure in irregular sites within the networks cavities. They take a range of hydrated states and provide the charge balance to the $\mathrm{AlO}_{4}{ }^{-}$or $\mathrm{Si}-\mathrm{O}-\mathrm{Si}$ bridges depending on the amount of free $\mathrm{OH}$ in the geopolymer structure. ${ }^{120}$ Although a significant quantity of the initial water content is lost during gelation and hardening due to evaporation, large quantities are also retained as free and exchangeable water within the porous microstructure of the monolith.

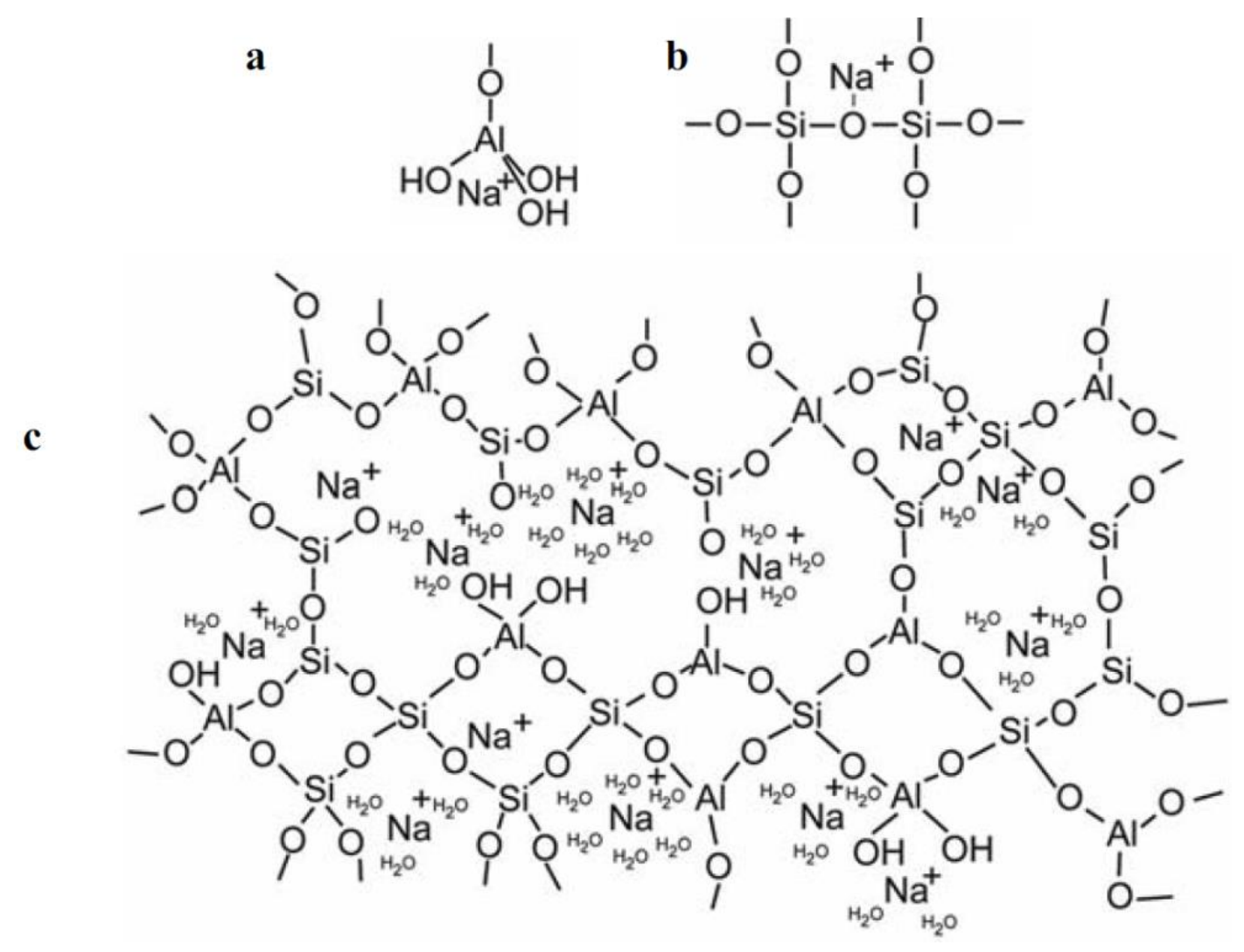

Figure 2.17. (a) Proposed model for the location of the charge balancing $\mathrm{Na}^{+}$cation that assumes the form of a semi attached $\mathrm{Na}$ aluminate species. (b) Proposed model for the site of the charge balancing $\mathrm{Na}^{+}$cation that assumes the form of a modified bridging network. (c) proposed a schematic structural model of AIP structure based on an original model by Barbosa et al. ${ }^{121}$ 


\subsubsection{Characteristics of geopolymers}

A principal characteristic of geopolymers cured at ambient temperatures is that they are x-ray amorphous. The XRD patterns of well-cured geopolymers do not normally show sharp peaks but present a large hump in the background at around $30^{\circ} 2 \theta$. A typical pattern is shown in Figure 2.18. The peak labelled "Q" is a quartz peak, from an impurity in the clay reactant.

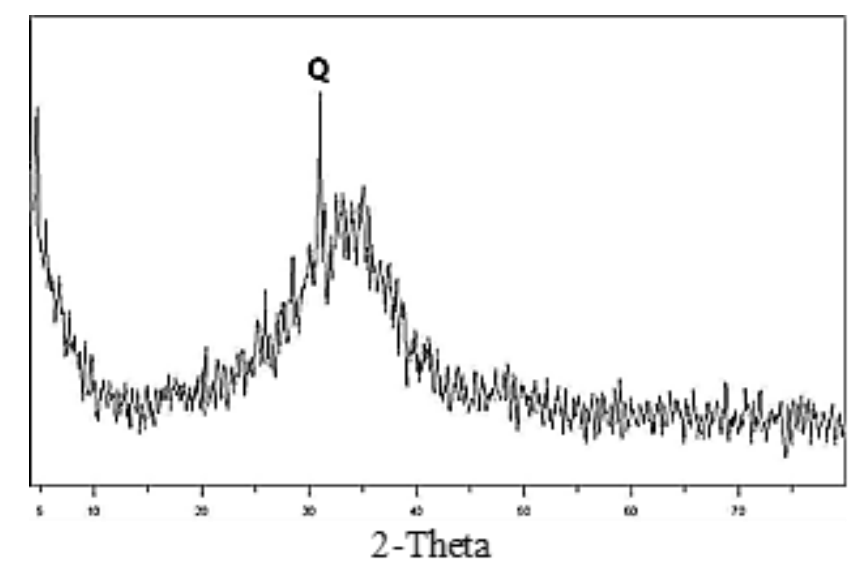

Figure 2.18. Typical XRD spectrum of a GP. ${ }^{122} \mathrm{Q}=$ quartz (PDF no.33-1161)

Geopolymers can be produced with various microstructures depending on the Al: Si ratio; two and three-dimensional cross-linked geopolymer structures are formed in compositions of high aluminium and silicon contents respectively. Because of the various microstructures, different mechanical and physical properties can be achieved. ${ }^{123}$ Since XRD cannot determine the coordination state of atoms in amorphous materials, ${ }^{27} \mathrm{Al}$ and ${ }^{29} \mathrm{Si}$ solid state nuclear magnetic resonance spectroscopy with magic angle spinning (MAS NMR) must be used to provide this information. ${ }^{124}$

\subsubsection{Application of geopolymers as photocatalytic materials}

Geopolymers derived from clay minerals can maintain elements of the layered structures and large surface areas of the precursor with the ability to absorb organic substances on both their external surfaces or within their internal spaces. ${ }^{125}$

In a potential application to decompose hazardous atmospheric pollutants, Tirado et al. ${ }^{126,127}$ have used an ion exchange procedure to incorporate photoactive $\mathrm{TiO}_{2}$ into an aluminosilicate 
geopolymer (geopolymer). $\mathrm{TiO}_{2}$ and $\mathrm{TiO}_{2}$-based nanomaterials are noted photocatalysts for effective treatment of wastewater polluted with toxic organic compounds. In another study, Cerney et al. ${ }^{128}$ have reported a simple method for the preparation of photocatalytically active layers of metakaolinite-based geopolymer composites containing $\mathrm{TiO}_{2}$ powders deposited on steel plate substrates. In both these studies the photoactive element was $\mathrm{TiO}_{2}$ and the geopolymer acted as the supporting matrix. In addition to geopolymers, other porous matrices that have been used for supporting $\mathrm{TiO}_{2}$ particles include silica ${ }^{129}$, 130, alumina ${ }^{131}$, ${ }^{132}$, activated carbon ${ }^{133,134}$, clays and zeolites ${ }^{135-137}$. The use of high surface area supports in conjunction with nanoparticle oxides provides more efficient adsorption sites by comparison with bare $\mathrm{TiO}_{2}{ }^{138}$

Tirado et al. prepared metakaolin-based geopolymers at different temperatures and ionexchanged them with solutions of $\left(\mathrm{NH}_{4}\right)_{2} \mathrm{TiO}\left(\mathrm{C}_{2} \mathrm{O}_{4}\right)_{2} \cdot \mathrm{H}_{2} \mathrm{O}$. This ion-exchange method incorporated the anatase form of $\mathrm{TiO}_{2}$ particles inside the geopolymers. ${ }^{110}$ The EDS of these materials (Figure 2.19) showed that the exchanged surfaces prepared at $90{ }^{\circ} \mathrm{C}$ from the $\mathrm{NH}_{4}$ geopolymer contained a greater percentage of titanium than samples prepared from the $\mathrm{Na}$ form of the geopolymer at same temperature.

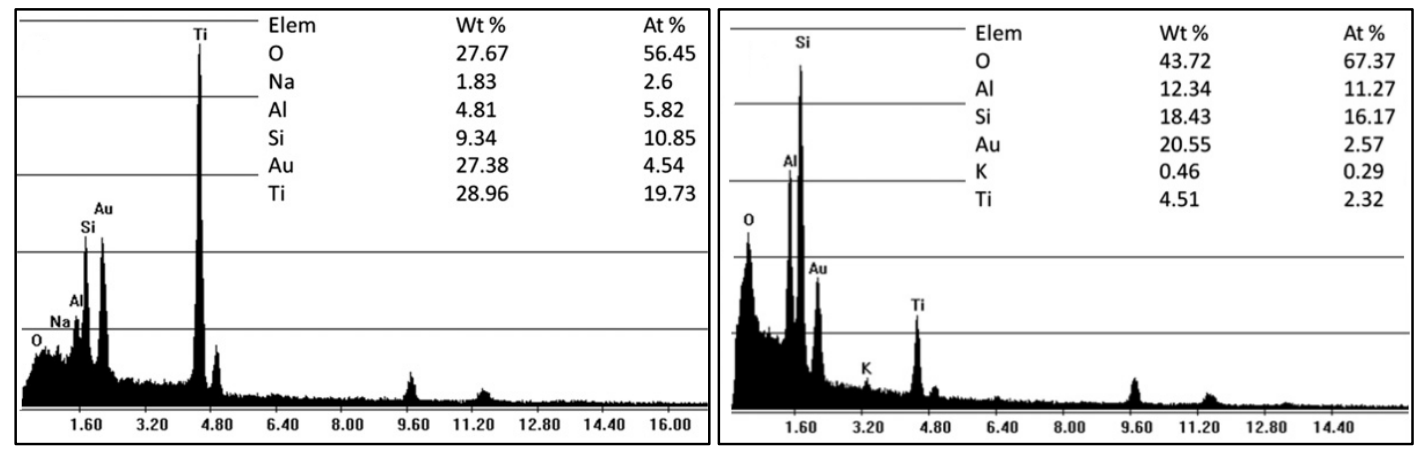

Figure 2.19. EDS element quantification of Ti ion-exchanged GPs: (right) $90 \stackrel{\circ}{\mathrm{C}} \mathrm{Na}$ GP, (left) $90 \stackrel{\circ}{\mathrm{C} \mathrm{NH}}{ }_{4 .}{ }^{110}$

Figure 2.20(a) shows that $\mathrm{TiO}_{2}$ is present as anatase in the composites, in different amounts as reflected in the XRD peak intensities. The UV-Vis reflectance spectra reported by Tirado et al. (Figure 2.20(b, c)) show differences between the reference and ion-exchanged geopolymers. The blue shifts in UV-visible spectra demonstrated the growth of $\mathrm{TiO}_{2}$ nanoparticles inside the micropores of the geopolymer which is related to quantum size effects of the $\mathrm{TiO}_{2}$ particles. The presence of micropores and mesopores of $<5 \mathrm{~nm}$ size in the 
geopolymers formed at $90^{\circ} \mathrm{C}$ restricts the $\mathrm{TiO}_{2}$ particles growing inside them to nanoscale dimensions.

The rate of degradation of MB by the sample with the highest amount of $\mathrm{TiO}_{2}$ compared with the blank geopolymer highlighted the photoactivity of the $\mathrm{TiO}_{2}$ particles inside the pores of the ion-exchanged geopolymer. ${ }^{110}$

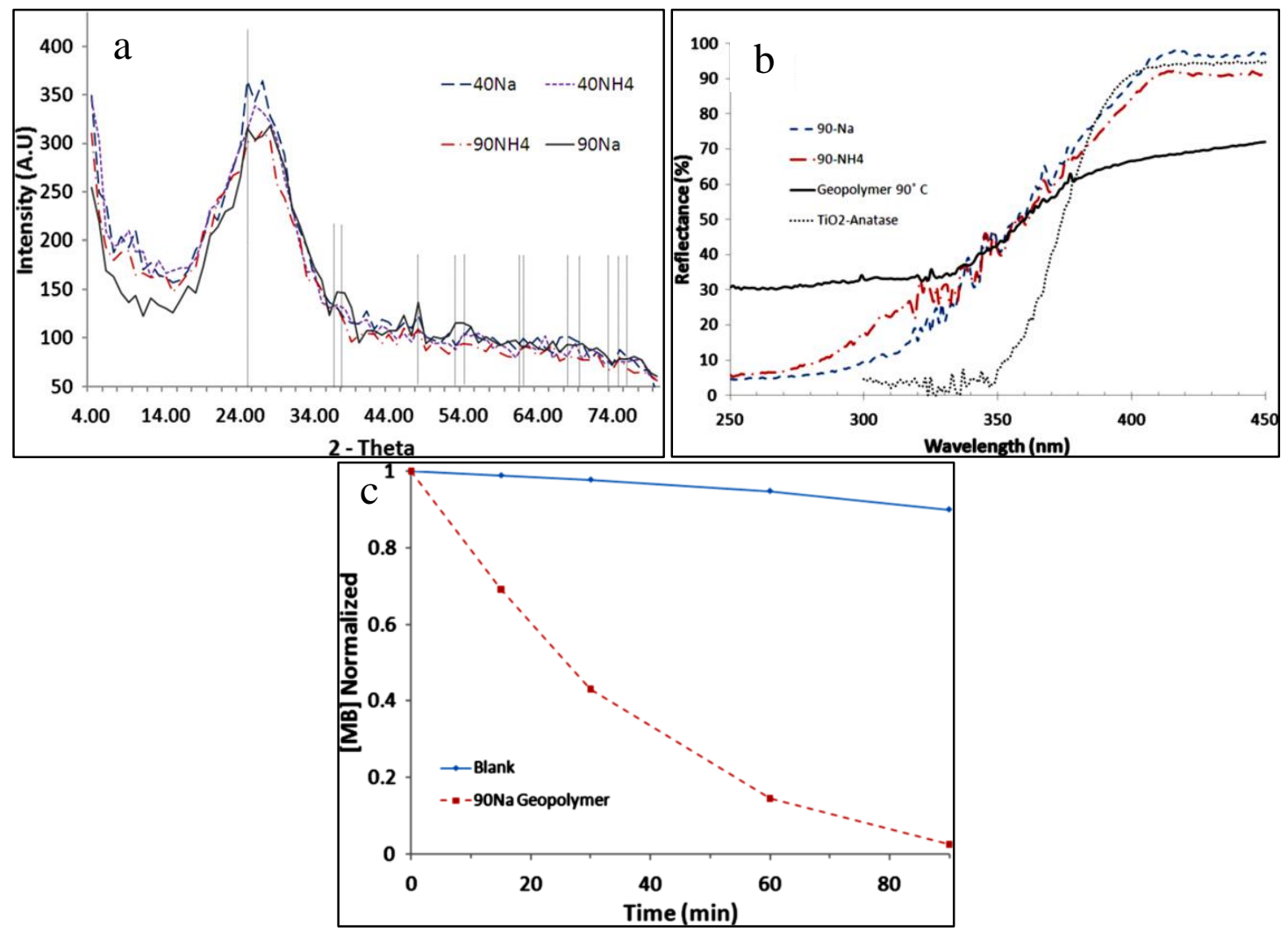

Figure 2.20. (a) XRD pattern of powdered ion-exchanged GPs, (b) UV-Vis reflectance spectra of $90 \stackrel{\circ}{\circ} \mathrm{Na}$-derived GP and $90 \stackrel{\circ}{\circ} \mathrm{NH}_{4}$-derived GP, (c) Photoactive bleaching of $\mathrm{MB}$ by $\mathrm{TiO}_{2}$ particles in Na-derived GP. ${ }^{110}$

On the basis of the effectiveness of these geopolymer- $\mathrm{TiO}_{2}$ composites, it is thought that by inserting $\mathrm{Cu}_{2} \mathrm{O}$ particles into a geopolymer matrix, the resulting composite photocatalyst with a direct band gap of $2.17 \mathrm{eV}$ should have the ability to show good photocatalytic activity in visible light and result in a material suitable for efficiently degrading toxic organic compounds.

\subsection{Modification of the geopolymer matrix}

Recently, clays such as kaolinite, montmorillonite, sepiolite, and mica have attracted much interest due to their high surface area and porosity, layered structure and high adsorption 
ability ${ }^{139}$. Kaolinite is a clay with strong interactions between the layers, with both cationic and anionic charge on the upper and the lower surfaces of the layers ${ }^{140}$. Moreover, dehydroxylated kaolinite reacts with alkali silicate solution under highly alkaline conditions to produce geopolymers (geopolymers) that are X-ray amorphous and consist of a random three-dimensional tetrahedral network of aluminate and silicate units ${ }^{141}$ as described in Section 2.8. Immobilization of nanoparticles on the inner and outer surfaces of these geopolymer matrices has the potential to produce improved heterogeneous photocatalysts. The role of these nanocomposite matrices is of great interest in the study of photocatalytic reactions for the removal of organic pollutants. ${ }^{142}$ Nano-composite matrices can adsorb organic substances either on their external surfaces or within their layer spaces via interactions or exchange reactions. ${ }^{76}$ One possible method for increasing the porosity and surface area of the composites by the use of a surfactant such as a large quaternary ammonium ion in the synthesis process. The modification of clays with quaternary ammonium ions has been reported by many research groups since the 1950's (de Paiva et $a l .,{ }^{143}$ Jordan et al., ${ }^{144}$ ). Organic compounds in aqueous solution are inserted in the interlayer of the clay mineral during cation exchange. The amount of exchange is specified by the hydrocarbon chain length and can be equal to or greater than the cation exchange capacity (CEC) of the clay. ${ }^{143}, 144$ In general, synthesis and characterization of photocatalytic $\mathrm{TiO}_{2}$ pillared clays, especially of montmorillonite type, by the use of small amounts of a quaternary ammonium ion has been reported extensively. The clay modification process not only expands the layers and controls the size of the clays but also can produce a hydrophobic photocatalyst composite. ${ }^{9,}$ 76, 145-150

In 1986, $\mathrm{TiO}_{2}$ pillars (anatase) were formed between the montmorillonite layers by Johan Sterte. ${ }^{151}$ The $\mathrm{TiO}_{2}$-cross-linked montmorillonite was prepared by dispersion of the montmorillonite powder into the distilled water, with a cross-linking agent of $\mathrm{TiCl}_{4}$ in $\mathrm{HCl}$. The mixture was then aged for $16 \mathrm{~h}$ and separated by centrifuging. The surface areas were in the range of $200-350 \mathrm{~m}^{2} / \mathrm{g}$ and pore volumes were about $0.2 \mathrm{~cm}^{3} / \mathrm{g}$, as determined by $\mathrm{N}_{2}$ desorption pore size analysis. The surface area increased, and the pore volume decreased with increasing $\mathrm{HCl}$-concentration in the Ti-solution. A further increase of $\mathrm{Ti}$ added resulted in a reduction in surface area, but the pore volume and the uptake of $\mathrm{TiO}_{2}$ remained almost constant. ${ }^{151}$

Later in 1999 Ooka et al. ${ }^{152}$ prepared a novel pillared montmorillonite with crystallized $\mathrm{TiO}_{2}$ that showed effective photocatalytic activity. The synthesis was hydrothermal and the 
porosity of the pillared clay was retained. The pillared montmorillonites exhibited higher catalytic activity by decreasing the $\mathrm{TiO}_{2}$ pillar size. ${ }^{152}$

In 2002, Zhu et al. ${ }^{153}$ reported the formation of bentonite pillared with a mixed solution of silicon and titanium hydroxides treated with quaternary ammonium surfactants. They found that titanium in these samples was highly dispersed in the silica matrix rather than existing in the form of small particles of pure titania. Excellent activity for catalytic oxidation reactions, increased porosity and improvement in thermal stability were reported to result from this surfactant treatment. ${ }^{153}$

Miao et al. successfully prepared titanium tetrabutyloxide by impregnating the interlayers of montmorillonite (MMT), followed by hydrolysis of the precursor in water and calcination at $500{ }^{\circ} \mathrm{C}$. XRD and electron microscopy showed that the layered structure of MMT was destroyed in the composites. High-resolution transmission electron microscopy revealed the loading of $\mathrm{TiO}_{2}$ particles in the exfoliated layers of the MMT. The samples also exhibited highly efficient removal of MB due to the adsorptive capacity of MMT and the catalytic degradation ability of $\mathrm{TiO}_{2}$ for $\mathrm{MB} .{ }^{139}$

Yan et al. reported the adsorption of benzoic acid from water on CTAB-exchanged montmorillonite. The largest adsorption was achieved at $\mathrm{pH} 9$, and the adsorption kinetic data were fitted by a pseudo-second-order equation. The results confirmed that CTABmontmorillonite is a potential adsorbent for benzoic acid. ${ }^{154}$

Kibanova et al. reported a new method for the synthesis of photocatalytically active smallsized $\mathrm{TiO}_{2}$ supported on hectorite and kaolinite. This method deposited the $\mathrm{TiO}_{2}$ on the clay mineral surface by a sol-gel process using titanium isopropoxide as a precursor. The synthesized clay- $\mathrm{TiO}_{2}$ composites were compared with pure commercial $\mathrm{TiO}_{2}$ (Degussa $\mathrm{P} 25)$. The results showed that the photocatalytic activity of the anatase phase $\mathrm{TiO}_{2}$ composite was similar to that of commercial $\mathrm{P} 25 \mathrm{TiO}_{2} .{ }^{155}$

Recently, Wang et al. developed a new method for immobilizing nano scaled $\mathrm{TiO}_{2}$ on the surface of montmorillonite clay. The $\mathrm{CTAB}$ cationic surfactant was inserted into the montmorillonite clay by ion exchange and physical adsorption processes, then the asprepared $\mathrm{TiO}_{2}$ solution was dispersed on the external and internal surface of the product after removal of the surfactant. These authors suggested that the cationic surfactant has a templating role, and can control the contents of the composite. The photocatalytic activities of these $\mathrm{TiO}_{2}$ composites were higher than that of P25. The method consists of the modification of the montmorillonite with the surfactant and then the formation of the $\mathrm{TiO}_{2}$ particles. According to their schematic model, as shown in Figure 2.21, montmorillonite has 
two siloxane tetrahedral sheets sandwiching an aluminum octahedral sheet with a negative surface charge on the clay. The cationic surfactants increase the surface area of the clay and the $\mathrm{TiO}_{2}$ particles hydrolyze and condense around or on the surface of the surfactant. ${ }^{156}$ Nano scaled $\mathrm{TiO}_{2}$ particles were created both on the surfaces and in between the montmorillonite layers, as shown by the high-resolution TEM image (Figure 2.22) of the intercalation of the titanium species between the layers of the clay. $\mathrm{TiO}_{2}$ is present both in the internal and external surfaces of the clay. ${ }^{76}$

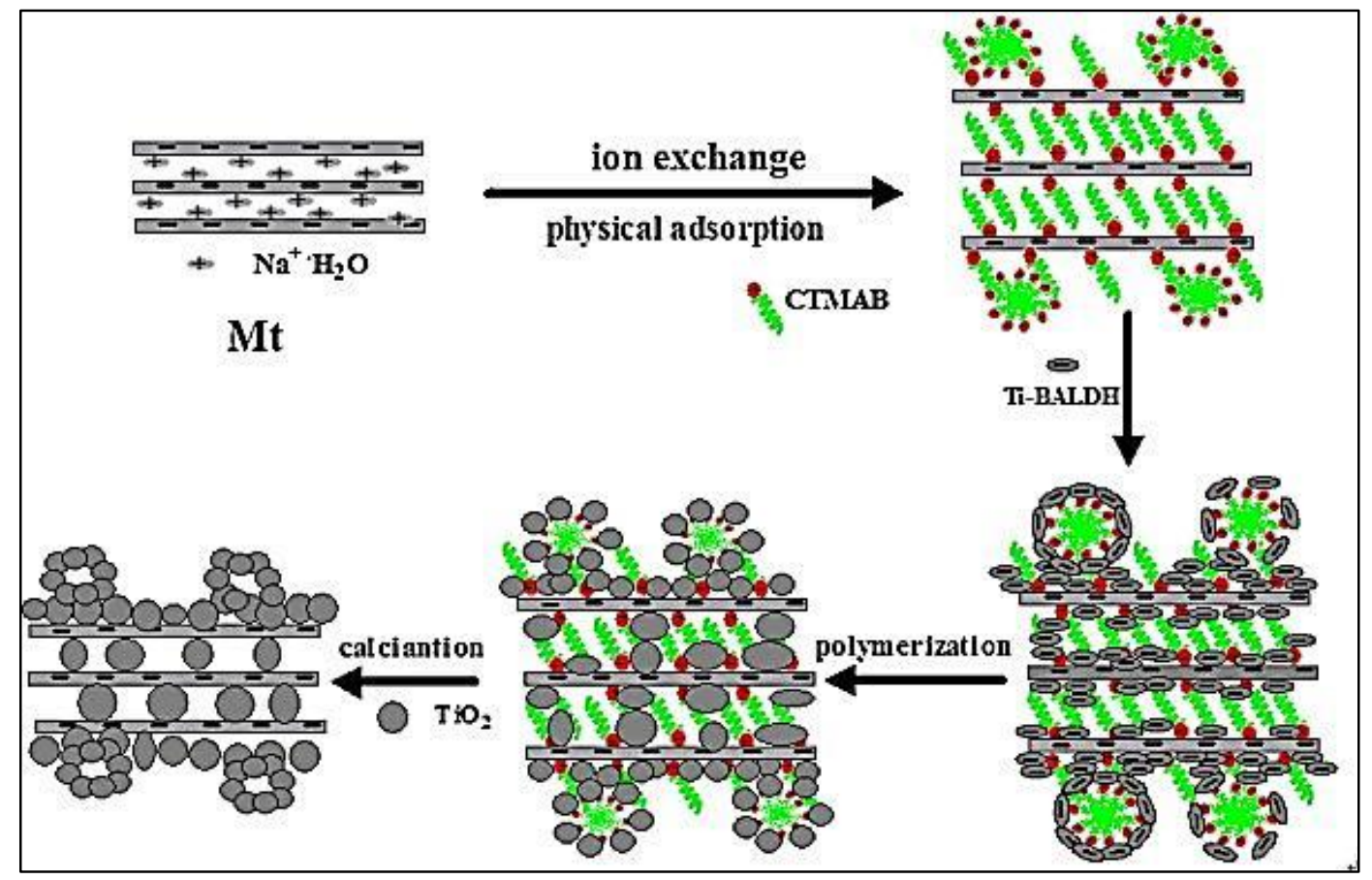

Figure 2.21. Schematic for the preparation of $\mathrm{Ti}(x) \mathrm{C}_{16}(y)-\mathrm{Mt}^{76}$

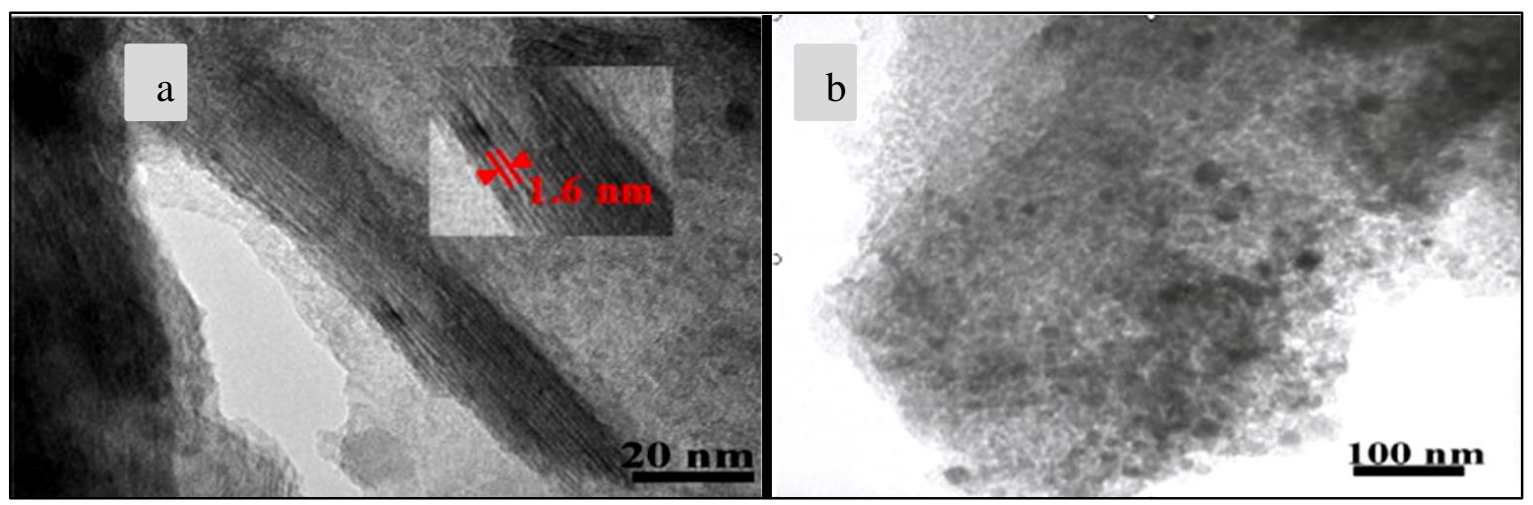

Figure 2.22. $(a, b)$ TEM images of $\mathrm{Ti}(25) \mathrm{C}_{16}(1.0)-\mathrm{MMT}$ sample calcined at $600{ }^{\circ} \mathrm{C}^{76}$

All these applications involve the formation or modification of a crystalline structure, but to our knowledge, CTAB has never previously been used to modify an X-ray amorphous 
material such as an aluminosilicate geopolymer. One part of this work was intended to exploit the ion-exchange properties of geopolymers by replacing the monovalent chargecompensating ion by the much larger $\mathrm{CTAB}$, thereby expanding the pore structure and facilitating the entry of the photoactive $\mathrm{Cu}_{2} \mathrm{O}$ and/or P25 titania deeper into the structure. It was also hoped that the presence of the CTAB might modify the mechanism by which the photoactive oxides are attached to the geopolymer matrix, and help to stabilize the $\mathrm{pH}$ of the solution, allowing the dye removal processes containing adsorption and photodegradation to be separately measured. 


\section{Chapter 3}

\section{Methodology}

This chapter describes the experimental details, chemicals, materials and characterization techniques used for this research.

\subsection{Preparation of Sodium-Geopolymer (Na-GP)}

The geopolymer matrix was prepared from New Zealand kaolinite-type halloysite clay (Imerys Premium Grade) dehydroxylated at $600{ }^{\circ} \mathrm{C}$ for 24 hour, sodium hydroxide (BDH reagent grade) and sodium silicate solution (FERNZ Chemical Co, NZ, Type " $\mathrm{D}$ ”, $\mathrm{Na}_{2} \mathrm{O} / \mathrm{SiO}_{2}$ $=0.48$, solids content $=41.1$ mass $\%$ ). These constituents, formulated to the molar oxide ratio $\mathrm{SiO}_{2} / \mathrm{Al}_{2} \mathrm{O}_{3}=2.91, \quad \mathrm{Na}_{2} \mathrm{O} / \mathrm{SiO}_{2}=0.34, \quad \mathrm{Na}_{2} \mathrm{O} / \mathrm{Al}_{2} \mathrm{O}_{3}=1.01$ and $\mathrm{H}_{2} \mathrm{O} / \mathrm{Na}_{2} \mathrm{O}=10.12$ were mechanically mixed for $15 \mathrm{~min}$. before transferring to cylindrical plastic molds and vibrating for $15 \mathrm{~min}$. to remove entrained air. The sealed composites were then cured for 12 hour at 40 ${ }^{\circ} \mathrm{C}$ and after unsealing, dried for another 12 hour. The prepared geopolymers matrix was finely ground and stored in sealed plastic bags for characterization. This molar composition has been reported ${ }^{121}$ by Clelio et al. to produce geopolymers with optimal mechanical properties.

\subsection{Synthesis of $\mathrm{Cu}_{2} \mathrm{O}$ nanoparticles}

Three published synthesis methods for $\mathrm{Cu}_{2} \mathrm{O}$ were investigated as outlined below: these were the precipitation method of Bai et.al ${ }^{157}$ which produces cubic crystallites, the method of Luo et.al ${ }^{64}$ which gives octahedral crystallites, and the method of Shah et.al. ${ }^{158}$ which gives spherical crystals. Although all three syntheses are reported to produce nanosized crystals, only the the method of Bai et al. was found to give nanoparticles with an average size of 80-150 nm; for this reason, this method was adopted because it was the only one that produced nanosized particles, and was a facile synthesis involving a lower synthesis temperature.

\subsubsection{Synthesis of cubic $\mathrm{Cu}_{2} \mathrm{O}$ particles}

An aqueous solution of copper acetate, $\mathrm{Cu}\left(\mathrm{CH}_{3} \mathrm{COO}\right)_{2} \cdot \mathrm{H}_{2} \mathrm{O}$ (May and Baker) and polyvinylpyrrolidone (PVP, K30, MW 10,000, Sigma-Aldrich) was stirred vigorously, producing a blue suspension after dropwise addition of $\mathrm{NaOH}$ solution. The colour of this 
suspension progressively changed from blue to green, and after stirring for $30 \mathrm{~min}$, to orange upon dropwise addition of a solution of ascorbic acid, $\mathrm{C}_{6} \mathrm{H}_{8} \mathrm{O}_{6}$ (Fisher, AR grade). The precipitate was then centrifuged, washed three times with deionized water and dried in air. The PVP surfactant is used to kinetically control the growth of the single crystal nanocubes, since surfactants play an important role in the development of the average size and morphology of nano crystals. When added to the solution, the active surfactant molecules are adsorbed on to specific crystal planes of the developing nano crystals. The shape of the crystal and the growth habit of the crystal planes are related to the type and amount of surfactant used. ${ }^{157}$

\subsubsection{Synthesis of octahedral $\mathrm{Cu}_{2} \mathrm{O}$ particles}

The synthesis was carried out by a simple solution-phase reduction system in which $\mathrm{CuCl}_{2} \cdot 2 \mathrm{H}_{2} \mathrm{O}$ (Alfa), is reduced by AR grade glucose and $\mathrm{NaHCO}_{3}$. The non-ionic surfactant octylphenyl ether Triton X-100, ( $\mathrm{x}=100$, Pure Science) was used as a capping agent to form the hybrid building blocks. Uniform octahedral polycrystals precipitated from the resulting blue-green mixture after heating at $60{ }^{\circ} \mathrm{C}$ for 4 hour under constant magnetic stirring. The solution was centrifuged at $4000 \mathrm{rpm}$ for $15 \mathrm{~min}$., and the orange precipitate was rinsed several times with distilled water and dried at room temperature for 12 hour.

\subsubsection{Synthesis of spherical $\mathrm{Cu}_{2} \mathrm{O}$ particles}

Polycrystalline spherical $\mathrm{Cu}_{2} \mathrm{O}$ particles were synthesized at $140{ }^{\circ} \mathrm{C}$ without any surfactant or additives. Copper metal powder was added to distilled water, sonicated for about $25 \mathrm{~min}$. and transferred to a stainless steel bomb that was sealed under ambient conditions. The bomb was then placed inside a preheated furnace at $140{ }^{\circ} \mathrm{C}$ for 15 hour. The resulting suspension was centrifuged, washed and dried at room temperature.

Since the spherical and octahedral $\mathrm{Cu}_{2} \mathrm{O}$ products were found by SEM analysis to be in the sub-micron size range, whereas the cubic oxide nanoparticles were of nanometer size, the latter were chosen for incorporation into the geopolymer matrix. Another advantage of the cubic $\mathrm{Cu}_{2} \mathrm{O}$ is its room- temperature synthesis, making it more ecologically friendly. 


\subsubsection{Another Method for Synthesising $\mathrm{Cu}_{2} \mathrm{O}$ Nanoparticles: The Gas Reduction Method}

\subsubsection{Preparation of brochantite $\left(\mathrm{Cu}_{4} \mathrm{SO}_{4}(\mathrm{OH})_{6}\right)$}

The first step in this synthesis was the preparation of brochantite $\left(\mathrm{Cu}_{4} \mathrm{SO}_{4}(\mathrm{OH})_{6}\right)$, as follows: 1.0 $\mathrm{M} \mathrm{NaOH}$ solution was very slowly ( 1 drop every $3 \mathrm{~s}$ ) added to a $1.0 \mathrm{M}$ aqueous of copper sulphate solution. The solution was stirred magnetically throughout the titration and the stirring continued for an additional $30 \mathrm{~min}$. The reactant was heated to $60{ }^{\circ} \mathrm{C}$ on a hotplate throughout the titration and stirring period. The product was filtered and air-dried.

\subsubsection{One-step synthesis of tenorite $(\mathrm{CuO})$ nanoparticles from $\mathrm{Cu}_{4}\left(\mathrm{SO}_{4}\right)(\mathrm{OH})_{6}$ by a direct thermal-decomposition method}

The product from the above step was calcined in air in a muffle furnace for 6 hour during which time the temperature was raised from $120-750{ }^{\circ} \mathrm{C}$ to form $\mathrm{CuO}$ nanoparticles. The reaction pathway of the thermal decomposition of brochantite to $\mathrm{CuO}$ includes thermal dehydration and desulfuration processes (Eqs. 22-24). ${ }^{159}$

$$
\begin{aligned}
& \mathrm{Cu}(\mathrm{SO})_{4}(\mathrm{OH})_{6} \cdot \mathrm{xH}_{2} \mathrm{O} \stackrel{80-170{ }^{\circ} \mathrm{C}}{\rightarrow} \mathrm{CuSO}_{4} \cdot 3 \mathrm{Cu}(\mathrm{OH})_{2}+\mathrm{xH}_{2} \mathrm{O} \\
& \mathrm{CuSO}_{4} \cdot 3 \mathrm{Cu}(\mathrm{OH})_{2} \stackrel{250-400{ }^{\circ} \mathrm{C}}{\rightarrow} \mathrm{CuSO}_{4} \cdot 2 \mathrm{Cu}(\mathrm{OH})_{2}+\mathrm{CuO}+\mathrm{H}_{2} \mathrm{O} \\
& \mathrm{CuSO}_{4} \cdot 2 \mathrm{Cu}(\mathrm{OH})_{2} \stackrel{610-700{ }^{\circ} \mathrm{C}}{\rightarrow} 3 \mathrm{CuO}+2 \mathrm{H}_{2} \mathrm{O}+\mathrm{SO}_{2}+1 / 2 \mathrm{O}_{2}
\end{aligned}
$$

\subsubsection{Formation of stable $\mathrm{Cu}_{2} \mathrm{O}$ by reduction of $\mathrm{CuO}$ nanoparticles}

The loose $\mathrm{CuO}$ powder was loaded into an open tube with an inner diameter of $2 \mathrm{~cm}$. One end of the tube was connected to an inlet with a gas mixture of $5 \% \mathrm{H}_{2}$ and $95 \% \mathrm{~N}_{2}(99.999 \%$ purity) while the other end was connected to a flow meter. The powder was heated in the tube furnace from room temperature to $250{ }^{\circ} \mathrm{C}$ for $135 \mathrm{~min}$. Every $45 \mathrm{~min}$. a small fraction of the produced precursor was collected for analysis. 
The $\mathrm{Cu}_{2} \mathrm{O}$ particles prepared by this method was not chosen for the continuing experiment because the preparation method was time-consuming and requires a temperature of about 750 ${ }^{\circ} \mathrm{C}$, militating against one of the main objectives of this research which was to prepare ecofriendly materials.

\subsection{Synthesis of spherical $\mathrm{Cu}_{2} \mathrm{O} / \mathrm{TiO}_{2}$ nano-heterostructures}

Representative $\mathrm{Cu}_{2} \mathrm{O} / \mathrm{TiO}_{2}$ nano-heterostructures were prepared by an alcohol-aqueous based chemical precipitation method reported by Huang et al. ${ }^{85}$

A calculated amount of copper acetate (May and Baker AR grade) was dissolved in $100 \mathrm{ml}$ absolute ethanol to form a deep green solution and stirred for around $30 \mathrm{~min}$. sufficient $\mathrm{TiO}_{2}$ (Degussa P25) was added to this solution such that the mass composition of the heterostructure was $50 / 50 \mathrm{Cu}_{2} \mathrm{O}: \mathrm{TiO}_{2}$ and the solution was sonicated to achieve a uniform suspension. $100 \mathrm{ml}$ aqueous glucose solution was then added drop wise to the suspension heated at $60^{\circ} \mathrm{C}$ in a water bath, followed by the drop wise addition of $\mathrm{NaOH}$ dissolved in $70 \mathrm{ml}$ absolute ethanol and $50 \mathrm{ml}$ distilled water. The resulting yellow precipitate was centrifuged from the solvent and washed several times with distilled water to remove residual acetate, glucose and $\mathrm{NaOH}$. The light orange product was then oven-dried at $50{ }^{\circ} \mathrm{C}$ overnight.

\subsection{Preparation of Na-Geopolymer Composites Containing $\mathrm{Cu}_{2} \mathrm{O}$}

The photocatalytic geopolymer/ $\mathrm{Cu}_{2} \mathrm{O}$ composites were prepared by blending the uncured geopolymer mixture, prepared as described in Section 3.1, with 10, 20 and $30 \mathrm{wt} \%$ of cubic nano crystalline $\mathrm{Cu}_{2} \mathrm{O}$ powder prepared as described in Section 3.2.1, stirring for 15 min. before transferring to cylindrical plastic moulds and vibrating for $15 \mathrm{~min}$. to remove entrained air. The composites were then cured for 12 hour at ambient temperature, finely ground and stored in sealed plastic bags. In an alternative approach, an attempt was made to synthesize the geopolymer/ $\mathrm{Cu}_{2} \mathrm{O}$ composites by mixing the matrix and $\mathrm{Cu}_{2} \mathrm{O}$-forming reagents in situ in a single step; this was abandoned however because of the high water content which militated against the formation of a well-reacted geopolymer as determined by ${ }^{27} \mathrm{Al}$ and ${ }^{29} \mathrm{Si}$ MAS NMR spectroscopy.

\subsection{Preparation of Na-Geopolymer Composites Containing $\mathrm{Cu}_{2} \mathrm{O} / \mathrm{TiO}_{2}$}

The photocatalytic geopolymer $/ \mathrm{Cu}_{2} \mathrm{O} / \mathrm{TiO}_{2}$ was prepared as described in section 3.4 except that the 10, 20 and $30 \mathrm{wt} \%$ nanoparticle oxide additions were of $\mathrm{Cu}_{2} \mathrm{O} / \mathrm{TiO}_{2}$ nano- 
heterostructures synthesised as described in Section 3.3. For comparison, a corresponding set of composites containing only P25 titania was synthesized and tested.

\subsection{Preparation of CTAB-Modified Na-Geopolymer Matrix}

The CTAB-modified geopolymer matrix was synthesised by mixing together New Zealand kaolinite-type halloysite clay (Imerys Premium Grade) dehydroxylated at $600{ }^{\circ} \mathrm{C}$ for 24 hour, sodium hydroxide (BDH reagent grade) and sodium silicate solution (FERNZ Chemical Co, $\mathrm{NZ}$, Type " $\mathrm{D}$ ", $\mathrm{Na}_{2} \mathrm{O} / \mathrm{SiO}_{2}=0.48$, solids content $=41.1$ mass \%), in proportions such that the molar oxide ratio was $\mathrm{SiO}_{2} / \mathrm{Al}_{2} \mathrm{O}_{3}=2.91, \mathrm{Na}_{2} \mathrm{O} / \mathrm{SiO}_{2}=0.34, \mathrm{Na}_{2} \mathrm{O} / \mathrm{Al}_{2} \mathrm{O}_{3}=1.01, \mathrm{H}_{2} \mathrm{O} / \mathrm{Na}_{2} \mathrm{O}=$ 10.18. A calculated amount of cetyltrimethylammonium bromide (CTAB) (Merck) based on the cation exchange capacity of the starting clay was added and the resulting paste mixed for $15 \mathrm{~min}$. before transferring to cylindrical plastic moulds and vibrating for $15 \mathrm{~min}$. to remove entrained air. The moulds were then sealed and their contents cured for 12 hour at $40{ }^{\circ} \mathrm{C}$, unsealed and dried for 12 hour.

The quantity of CTAB added to the geopolymer matrix was determined by:

$\mathrm{f}=\frac{\mathrm{M}_{\text {Cation }}}{\mathrm{CECM}_{\text {clay }} \mathrm{GMW}_{\text {Cation }} \mathrm{X}}$

where $\mathrm{f}$ is the fraction cation exchange capacity (dimensionless), $\mathrm{M}_{\text {cation }}$ the mass organic cation required to achieve desired fraction of CEC (mass), CEC the cation exchange capacity of clay (equivalents/mass), $\mathrm{M}_{\text {clay }}$ the mass clay (mass), $\mathrm{GMW}_{\text {cation }}$ the gram molecular weight of organic cation (mass/mol) and $\mathrm{X}$ is the moles of charge per equivalent $=1 \mathrm{~mol} / \mathrm{equiv}$. for the cations used in this study (mol/equiv.). ${ }^{160}$

\subsection{Preparation of CTAB-modified Na-Geopolymer Composites Containing $\mathrm{Cu}_{2} \mathrm{O}$}

The CTAB-modified geopolymer- $\mathrm{Cu}_{2} \mathrm{O}$ photocatalyst composite was prepared by powdering the matrix geopolymer and dispersing it as a $1 \%$ suspension in distilled water. To this suspension, after stirring for 2 hour at $\sim 50{ }^{\circ} \mathrm{C}$, was added 10,20 and $30 \mathrm{wt} \%$ of cubic nano crystalline $\mathrm{Cu}_{2} \mathrm{O}$ powder prepared as described in Section 3.2.1, stirring for $15 \mathrm{~min}$. before transferring to cylindrical plastic moulds and vibrating for $15 \mathrm{~min}$. to remove entrained air. The composites were then cured for 12 hour at ambient temperature, finely ground and stored in sealed plastic bags. 


\subsection{Preparation of CTAB-modified Na-Geopolymer Composites Containing $\mathrm{Cu}_{2} \mathrm{O} / \mathrm{TiO}_{2}$}

The procedure for preparing the photocatalyst composite of CTAB-modified geopolymer with $\mathrm{Cu}_{2} \mathrm{O} / \mathrm{TiO}_{2}$ followed the method described in the section 3.7 except that the 10,20 and $30 \mathrm{wt} \%$ nanoparticle oxide additions were of $\mathrm{Cu}_{2} \mathrm{O} / \mathrm{TiO}_{2}$ nano-heterostructures synthesised as described in Section 3.3. For comparison, a corresponding set of composites containing only P25 titania was synthesized and tested.

\subsection{Sample Characterization Techniques}

A number of techniques were used to characterise the crystalline phases, surface morphologies, and molecular structure and photocatalytic properties of composites. The instruments employed in this research are shown in Table 3.1.

Table 3.1. List of instruments used in this work.

\begin{tabular}{ll}
\hline Test & Model \\
\hline X-ray diffraction (XRD) & PANalytical X'Pert \\
\hline Scanning Electron Microscopy (SEM) & $\begin{array}{l}\text { JEOL 6500 F, JEOL JSM- } \\
6610 \text { LA }\end{array}$ \\
\hline Transition Electron Microscopy (TEM) & JEOL 2010, JEOL 2100 F \\
\hline Fourier Transform Infrared Spectroscopy (FTIR) & Perkin-Elmer model 2000 \\
\hline Nuclear Magnetic Resonance Spectroscopy (MAS NMR) & Bruker Avance 500 \\
\hline UV-Visible spectroscopy & Agilent 8453 \\
\hline Brunauer-Emmett-Teller (BET) & Micromeritics ASAP 2010 \\
\hline Nuclear quadrupole resonance (NQR) & Chemagnetics CMX \\
\hline
\end{tabular}

\subsection{Powder XRD Analysis (PXRD)}

$\mathrm{XRD}$ is an important method used for structural studies including crystal imperfections, preferred orientation in polycrystalline sheets and the network of atoms in solids. X-rays are 
electromagnetic waves, but have smaller wavelengths $\left(10^{-10} \mathrm{~m}\right)$ that are of the same magnitude as the interatomic spacing in crystals. Using XRD, crystallographic phases can be identified and quantitatively determined in materials such as metals, clays, ceramics or mineral mixtures. ${ }^{161}$

$\mathrm{XRD}$ is based on the diffraction of $\mathrm{x}$-rays from crystalline phases containing long-range order, hence characterization of amorphous phases with diffuse scattering patterns is not possible. Amorphous phases in such materials appear as broad humps and a raised background rather than well-defined peaks. However, the presence of a broad amorphous hump allows this technique to indicate the presence of the amorphous geopolymers. Any partially reacted crystalline phases still present in geopolymers will also be detected as sharp peaks, or as peaks related to the mineral phases present as impurities in the reactants.

\subsubsection{Basic Principles}

The x-ray beam interacts with a crystalline substance and the reflection of the beam results in a characteristic diffraction pattern of intensities at particular diffraction angles. Subsequently each crystalline material produces its unique diffraction pattern; each crystalline phase can be identified or determined within a substance containing multiple crystalline phases. X-ray patterns of pure substances are therefore like fingerprints. The resulting pattern is characteristic of the sample material and thus can be used for the identification by comparison with a pattern database. By measuring the spacing of the lines in the diffraction pattern, identification of the size and shape of the unit cell are achieved. The Bragg equation (eq. 26) is the central equation in analysing the results for a powder diffraction experiment. ${ }^{162}$ $\mathrm{X}$-rays are effective for analysis of crystal structures because their wave lengths of about $1 \AA$ are of the same order as the spacing of atomic planes in crystalline materials. One of the most commonly used interpretations of XRD is the Bragg Reflection Analogy, which describes the uniqueness of XRD in terms of the reflection of X-rays by planes of atoms in minerals. 


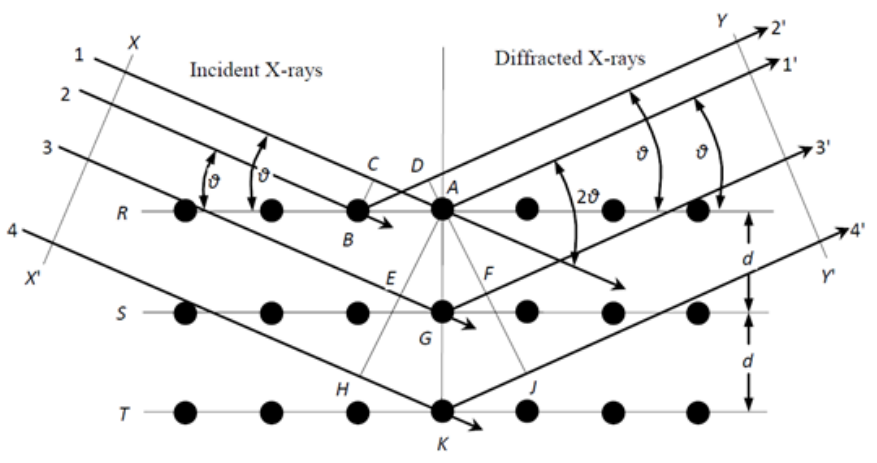

Figure 3.1. XRD by lattice planes. Schematic illustration of Bragg's Law. ${ }^{163}$

XRD analysis is based on the principles of XRD by a diffraction grating. Suitable "gratings" for x-ray beams are the planes of atoms in the crystal structures of crystalline phases. Without any diffraction effects, the incidence of a primary x-ray beam onto a sample volume would produce scattering in all directions. The directions in which the reflections can be observed depend on the intervals between the lattice planes scattering $x$-ray beams and interference of the scattering by scattering from neighbouring lattice planes. ${ }^{161}$

The most common expression of Bragg's Law is given by:

$$
\mathrm{n} \lambda=2 \mathrm{~d} \sin \theta
$$

Where $\lambda$ is the wave length of the X-rays, $\mathrm{d}$ is the distance between parallel atomic planes, $\theta$ is the angle between the incident rays and parallel atomic planes, and $\mathrm{n}$ is an integer. The values of $d$ and the number and types of atoms in each plane are unique for every mineral. Since each mineral has its specific spacing of interatomic planes in three dimensions, the angles at which diffraction occurs can be used for identification. ${ }^{161}$

\subsubsection{Preparation of the XRD Sample}

Phase analysis of powders using XRD requires sample preparation. To prevent contamination of the samples and give deceptive results, it is necessary to work in a clean environment. The solid pieces of starting material must be powdered using a mortar. Ideally the particles should not be larger than about $5 \mu \mathrm{m}$; a good indication of sufficient fineness is when the powder feels floury. The sample holder is filled with a slight excess of powder which is then compressed using a clean glass microscope slide. It is important that the powder is only pushed down; sliding or turning the glass slide across the powder bed should be avoided to 
prevent preferred orientation of crystals. To check if the powder is attached to the holder, it can be gently tipped.

Amorphous phases in geopolymer materials appear as broad humps in the background. However, the presence of such a broad amorphous hump allows this technique to indicate the presence of the amorphous geopolymers. Data were collected from powdered samples using a Panalytical Pro MPD diffractometer with $\mathrm{CuK} \alpha$-radiation and a PIXcel detector. Scans were determined in the region $10-80{ }^{\circ} 2 \theta$ with a $0.013{ }^{\circ}$ step operated at $45 \mathrm{kV}$ and $40 \mathrm{~mA}$. The details of the identified crystalline phases and reflection data for the principal components encountered in the present samples are summarized in Table 3.2.

Table 3.2. Assigned crystalline phases and measured reflections

\begin{tabular}{|c|c|c|c|c|}
\hline Crystalline Phase & JCPDS File No. & $\begin{array}{c}\text { Measured } 2 \theta \\
\text { degrees for } \mathrm{Cu} \\
\text { Kalpha }\end{array}$ & (hkl) & $\begin{array}{c}d \text {-Spacing } \\
\text { nm }\end{array}$ \\
\hline Cristobalite & $01-075-0923$ & 21.96 & (101) & 0.28 \\
\hline Quartz & 01-078-2076 & 26.75 & $(100)$ & 0.34 \\
\hline $\mathrm{Cu}_{2} \mathrm{O}$ (Cubic) & $01-073-6237$ & $\begin{array}{l}29.41 \\
36.28 \\
42.18 \\
52.39 \\
61.30 \\
73.49 \\
77.35\end{array}$ & $\begin{array}{l}(110) \\
(111) \\
(200) \\
(211) \\
(220) \\
(311) \\
(222)\end{array}$ & $\begin{array}{l}0.30 \\
0.24 \\
0.21 \\
0.17 \\
0.15 \\
0.13 \\
0.12\end{array}$ \\
\hline $\mathrm{TiO}_{2}$ (Rutile) & 04-006-1919 & $\begin{array}{l}27.51 \\
36.15 \\
41.31 \\
44.13 \\
54.01 \\
54.34 \\
56.68 \\
62.78 \\
64.09\end{array}$ & $\begin{array}{l}(110) \\
(101) \\
(111) \\
(211) \\
(210) \\
(211) \\
(220) \\
(002) \\
(310)\end{array}$ & $\begin{array}{l}0.33 \\
0.25 \\
0.22 \\
0.20 \\
0.16 \\
0.17 \\
0.16 \\
0.15 \\
0.15\end{array}$ \\
\hline $\mathrm{TiO}_{2}$ (Anatase) & $00-021-1272$ & $\begin{array}{l}25.37 \\
37.02 \\
37.89 \\
38.62 \\
48.13 \\
55.05 \\
55.15 \\
68.76 \\
70.31\end{array}$ & $\begin{array}{l}(101) \\
(103) \\
(004) \\
(112) \\
(200) \\
(211) \\
(211) \\
(116) \\
(220)\end{array}$ & $\begin{array}{l}0.35 \\
0.24 \\
0.24 \\
0.23 \\
0.19 \\
0.17 \\
0.17 \\
0.14 \\
0.13\end{array}$ \\
\hline
\end{tabular}




\subsection{Scanning Electron Microscopy (SEM)}

SEM is electron microscopy that images the sample surface by scanning it with a high-energy beam of electrons. The electrons interact with sample, producing various signals including secondary electrons, and back-scattered electrons, characteristic X-ray signals that contain information about the sample surface topography (e.g. microstructure or a composition).

From these signals we can image the sample and determine atomic composition. The SEM can produce images with a resolution up to $1 \mathrm{~nm} .{ }^{164}$ ENREF 120

\subsubsection{Energy-dispersive X-ray Spectroscopy (EDXS)}

Highly energetic electrons re-emitted from the sample surface after being scattered within the specimen. In backscattered imaging mode regions with higher average atomic number appears brighter than regions with lower average atomic number.

EDXS is a type of X-ray detector used for quantitative elemental microanalysis. ${ }^{164}$ Areas of interest of a sample are exposed to the atoms in the sample have unexcited electrons (or electrons in ground state) in their electron shells. The highly energetic beam excites these electrons and forces them into a higher energy level (higher shell) which causes an electron gap. This gap is filled by another electron from a higher energy level (higher shell). The energy difference between these two shells is expressed by the emission of specific $\mathrm{x}$-ray radiation characteristic of the energy difference. Every element has a specific x-ray radiation energy if its electrons are excited in this way which can therefore be used as a "fingerprint" or unique identifier.

SEM images of the geopolymer composites and oxide nanoparticles were acquired under high vacuum using high and low resolution analytical SEM. The probe current was $15 \mathrm{kV}$, and the working distance was $10 \mathrm{~mm}$. The sample powders were placed on carbon tape attached to an aluminium stub and coated with 7-9 $\mathrm{nm}$ carbon using high-vacuum carbon coater. Elemental analysis was achieved by the EDXS unit operating in the backscattered mode.

\subsection{Transition Electron Microscopy (TEM)}

TEM images were obtained using a JEOL 2010 or JEOL $2100 \mathrm{~F}$ electron microscope with an integrated EDXS detector and operated at $200 \mathrm{keV}$. For sample preparation the powdered sample was suspended in $5 \mathrm{ml}$ absolute ethanol, and the suspension was dropped onto 400 
mesh ProSciTech copper grids and 200 mesh ProSciTech gold grids with a holey carbon film. Lattice fringes and selected area electron diffraction (SAED) measurements were performed and analysed using Digital Micrograph software.

\subsection{Fourier Transform Infrared Spectroscopy (FTIR)}

Infra-red spectroscopy exploits the interaction of infrared radiation with matter, whereupon absorption takes place, which then causes the chemical bonds in the material to vibrate. The functional groups present in the constituent molecules absorb infrared radiation at diagnostic frequencies. Thus, the structure of an unknown molecule can be determined by its infra-red spectrum. ${ }^{166}$ Infra-red spectroscopy provides molecular structural information by determining the frequency of the vibrational modes of a compound.

\subsubsection{FTIR Principle}

When IR radiation interacts with a compound at the proper frequency, it results in the transfer of energy to the molecule. ${ }^{166}$ When the frequency of the IR radiation matches the vibrational frequency of a functional group in a compound, absorption occurs. Absorbing of this energy causes the molecule to transition between two vibrational energy levels.

IR spectroscopy has three typical spectral regions based on wavelength. The infrared region is subdivided into the near infra- red, infrared and far- infrared spectrum. ${ }^{167}$

The IR spectrum records absorbed light which tells how energy was absorbed at each wavelength when the IR radiation passes through the sample. The fingerprint region is 1450 to $600 \mathrm{~cm}^{-1}$ and is unique to a given molecule. Absorption bands in the region 4000 to 1450 $\mathrm{cm}^{-1}$ are known as the group frequency region. ${ }^{168}$ ENREF 123

\subsubsection{FTIR instrumentation}

An FTIR spectrophotometer has four main components, namely, a radiation source, analyser, detector and electronics for signal processing which can change according to the instrument type and application. ${ }^{169}$ 


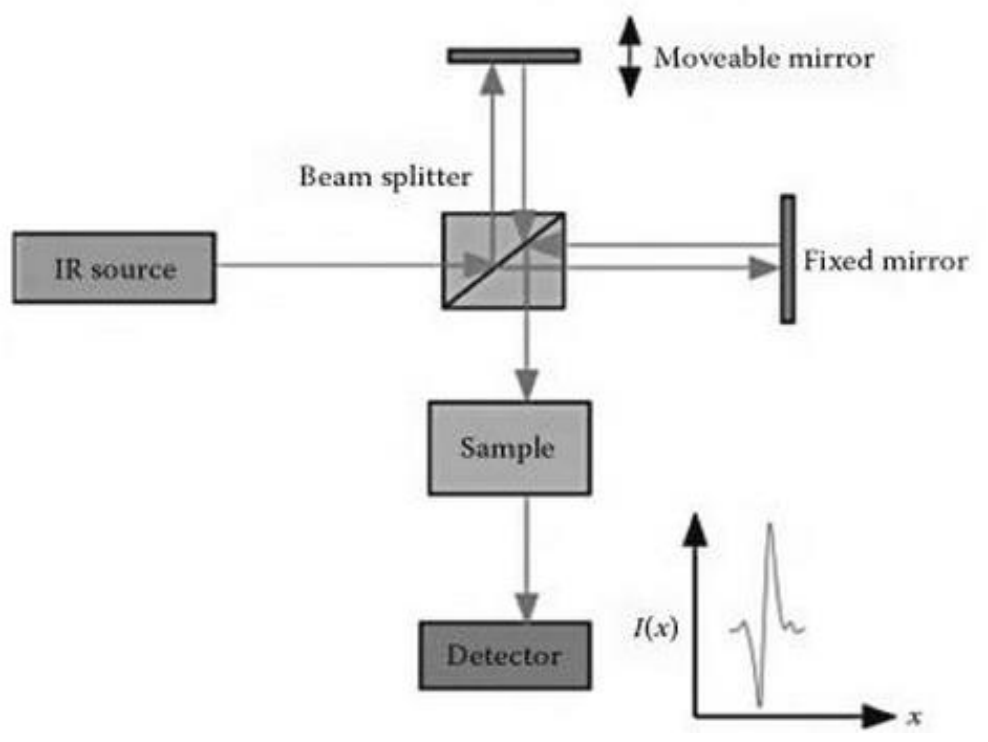

Figure 3.2. Diagram of an FTIR spectrophotometer. ${ }^{168}$

The IR radiation source consists of a Nernst glower or a Glowbar unit (silicon carbide rod). The interferometer combines the separate waves together. The monochromatic light, after being split into two beams, is then recombined to form a visible pattern of areas of constructive and destructive interference of bright and dark fingers. The signal is fed to a computer where the data are Fourier transformed and a spectrum having a transmission versus wavenumber is obtained. The IR spectrum records transmitted light which shows how energy was absorbed at each wavelength when the IR radiation passes through the sample. The fingerprint region is 1450 to $600 \mathrm{~cm}^{-1}$ and is unique to any given molecule. Absorption bands in the region 4000 to $1450 \mathrm{~cm}^{-1}$ are known as the group frequency region. ${ }^{168}$

Powdered samples are suspended in $1.000 \pm 0.003 \mathrm{~g}$ of potassium bromide in approximately $0.1-0.3 \mathrm{wt} \%$ concentration. The sample is prepared by grinding with the $\mathrm{KBr}$ powder using a mortar and a pestle. The mixture is then placed between a punch and die and compacted into a translucent film using a mechanical die press. Spectra were collected in the range 4000 - $400 \mathrm{~cm}^{-1}$ in the absorbance mode. The main IR characteristic peaks corresponding to metakaolin and geopolymeric matrices are summarised in Table 3.3. 
Table 3.3. IR characteristic bands and corresponding species of metakaolin and geopolymeric matrices

\begin{tabular}{lcl}
\hline Assignment & Wavenumber $\left(\mathbf{c m}^{-\mathbf{1}}\right)$ & Characteristic band \\
\hline$-\mathrm{OH}$ & $3700-3600$ & Stretching vibration $(-\mathrm{OH})$ \\
$-\mathrm{OH}, \mathrm{HOH}$ & $3600-2200$ & Stretching vibration $(-\mathrm{OH}, \mathrm{HOH})$ \\
$\mathrm{HOH}$ & $1700-1600$ & Bending vibration $(\mathrm{HOH})$ \\
$\mathrm{Si}-\mathrm{O}-\mathrm{Si} \&$ & $1200-950$ & Asymmetric stretching $(\mathrm{Si}-\mathrm{O}-\mathrm{Si}$ and \\
$\mathrm{Al}-\mathrm{O}-\mathrm{Si}$ & & Al-O-Si) \\
$\mathrm{Si}-\mathrm{O}$ & 1086 & (symmetrical vibration) \\
$\mathrm{Si}(\mathrm{Al})-\mathrm{O}$ & 1008 & (asymmetrical vibration) \\
$\mathrm{Al}-\mathrm{OH}$ & 914 & (six-coordinated Al-OH stretching \\
& & vibration) \\
$\mathrm{Si}-\mathrm{OH}$ & 840 & (bending vibration) \\
$\mathrm{Al}-\mathrm{O}$ & 798 & (six-coordinated Al-O stretching \\
& & vibration) \\
$\mathrm{Si}-\mathrm{O}$ & 694 & (symmetrically stretching vibration) \\
$\mathrm{Si}-\mathrm{O}-\mathrm{Al}$ & 540 & (bending vibration) \\
$\mathrm{Si}-\mathrm{O}$ & 469 & (in-plane bending vibration) \\
\hline
\end{tabular}

Note: The assignments of the IR characteristic bands are based on references. ${ }^{123,170,171}$

\subsection{Nuclear Magnetic Resonance Spectroscopy (MAS NMR)}

Solid state nuclear magnetic resonance spectroscopy (NMR) is a relatively new method for exploring solid materials. As comparison between XRD and NMR analysis, NMR provides structural information that is not available from $\mathrm{x}$-ray diffractometry especially for amorphous materials, for specific NMR-active elements. ${ }^{172}$

NMR is a radio frequency spectroscopy and exploits the nuclear spin of specific nuclei to determine factors such as their bonding to surrounding atoms and coordination state. When nuclei with a nuclear spin are located in a strong magnetic field, the energy levels of the different spin states separate. In the strong magnetic field, the nuclear spin has an associated magnetic moment and therefore the nucleus spins around an axis of the magnetic field at a specific frequency (the Larmor frequency). The sample is then irradiated with a pulse of plane polarised rf radiation at the Larmor frequency, causing a tipping of the spin system with respect to the magnetic field axis. At the end of the pulse, the spin system returns to its original axis with a characteristic time constant and the emission of a decaying pulse. Since the nucleus of an atom is shielded from the applied magnetic field by its surrounding electrons, this changes the emitted frequency slightly by an amount called the chemical shift. 


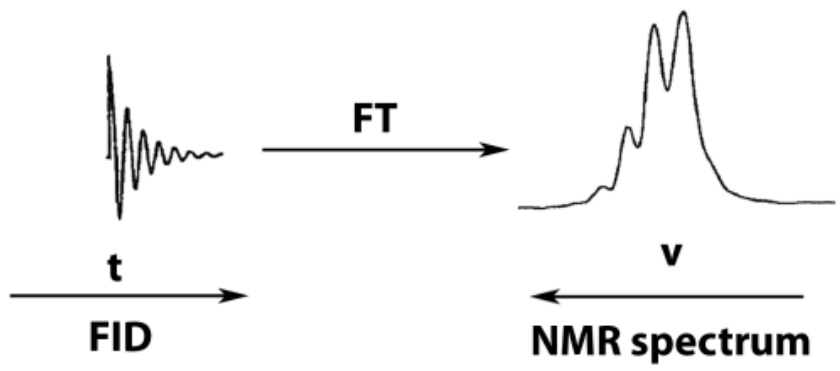

Figure 3.3. Fourier transformation of free induction decay (FID) in the time domain to an NMR spectrum in the frequency domain. ${ }^{173}$

This emitted frequency is detected by a coil surrounding the sample as a decaying voltage and is called free induction decay (FID) which is transformed from the time domain to the frequency domain using Fourier transformation. ${ }^{173}$

Solid state NMR spectra are broadened due to a number of interactions including dipole moments and, in quadrupolar nuclides, quadrupole moments. ${ }^{124}$ Some of these broadening effects can be cancelled out by spinning the sample at high speeds (up to 20000 revolutions $\mathrm{s}^{-1}$ ) The sample is spun at the specific angle of $54.7^{\circ}$ to the magnetic field axis (called the "magic angle") to reduce the broadening of the NMR peaks and give a sharp spectrum. This technique is known as magic angle spinning (MAS) and produces sharp peaks in the spectra of solids. However, not all elements possess nuclei suitable for NMR spectroscopy. The NMR- active nuclei in the present system are ${ }^{27} \mathrm{Al}$ and ${ }^{29} \mathrm{Si}$ in various environments ${ }^{124}$.

\subsubsection{Solid-state NMR sample preparation}

NMR spectra are acquired using similar powder samples as are used for $\mathrm{x}$-ray diffraction. It is most important that the powders are finely ground and oven dried. High spinning speeds and residual water cause the sample to solidify in the rotor. The powder is gently tamped into the rotor in layers and the rotor cap fitted.

Solid-state ${ }^{27} \mathrm{Al}$ and ${ }^{29} \mathrm{Si}$ MAS NMR spectroscopy were used to study the chemical environment of these elements in the system before and after their use as photocatalysts. The NMR spectra were acquired using similar powdered samples as are used for XRD. The spectra were acquired at a magnetic field of $11.7 \mathrm{~T}$ using a Bruker Avance III 500 spectrometer operating at a ${ }^{27} \mathrm{Al}$ frequency of $130.24 \mathrm{MHz}$ and a ${ }^{29} \mathrm{Si}$ frequency of 99.29 MHz. The ${ }^{27} \mathrm{Al}$ solid-state spectra were acquired using a $4 \mathrm{~mm}$ Doty MAS probe with a 
silicon nitride rotor spun at $10-12 \mathrm{kHz}$, a $1 \mu$ s pulse and a $1 \mathrm{~s}$ recycle time, the spectra referenced with respect to $\mathrm{Al}\left(\mathrm{H}_{2} \mathrm{O}\right)_{6}{ }^{3+}$. The ${ }^{29} \mathrm{Si}$ spectra were acquired with a $5 \mathrm{~mm}$ Doty MAS probe and a zirconia rotor spun at $\sim 6 \mathrm{kHz}$. The excitation pulse for ${ }^{29} \mathrm{Si}$ was $7 \mu$ s with a recycle time of $30 \mathrm{~s}$ and the spectra were referenced with respect to tetramethyl silane (TMS).

\subsection{Nuclear quadrupole resonance (NQR)}

\subsubsection{Principle of NQR}

Unlike NMR, in which the nuclei have spins of $\geq 1$ with energy levels split by an external magnetic field, NQR is used to study nuclei with spins $\leq 1$ such as ${ }^{63} \mathrm{Cu}$, which have an electric quadrupole moment so that their energies are split by the electric field gradient associated with the immediate environment of the nucleus. As in the case of NMR, the nuclear spin states are perturbed by the application of a radio frequency pulse of appropriate energy to excite the particular nucleus under investigation, but unlike NMR, the NQR experiment is conducted in the absence of an external magnetic field.

The state of the copper $(\mathrm{Cu})$ in the present samples before and after their use as photocatalysts was studied by ${ }^{63} \mathrm{Cu}$ NQR spectroscopy. ${ }^{63} \mathrm{Cu}$ (and ${ }^{65} \mathrm{Cu}$ ) quadrupole frequencies $\left(v_{\mathrm{Q}}\right)$ were obtained at ambient temperature through the use of a Chemagnetics CMX console pulsing into a probe arrangement that was well-removed from the magnet $(>5$ m) and shielded from extraneous magnetic and radio frequency interference by a mumetal container. The quadrupole frequency range scanned was determined from previous ${ }^{63,65} \mathrm{Cu}$ NQR and NMR studies of two, three and four coordinate $\mathrm{Cu}$ (I) systems. ${ }^{174-177}$ The location of both ${ }^{63} \mathrm{Cu}$ and ${ }^{65} \mathrm{Cu}$ isotope resonances (related by the ratio $\left.v_{\mathrm{Q}(63 \mathrm{Cu})} / v_{\mathrm{Q}(65 \mathrm{Cu})}\right)=1.081$ ) verified that true copper NQR frequencies were being observed. A scan of $\sim \pm 500 \mathrm{kHz}$ around the central $\mathrm{Cu}_{2} \mathrm{O}$ frequency was undertaken for each sample by stepping the spectrometer frequency in $100 \mathrm{kHz}$ increments through this range and retuning the probe at each frequency. A Hahn echo ( $\theta-\tau-2 \theta$ - $\tau$-acquire) sequence with extended phase cycling was employed to obtain undistorted echoes, ${ }^{178}$ where the recycle delay was $0.5 \mathrm{~s}$ and hard $\theta / 2 \theta$ pulses of $2 / 4 \mu$ s duration, respectively, were implemented.

\subsection{UV-Visible spectroscopy}

Ultraviolet-visible (UV-vis) spectroscopy was used to acquire the absorbance spectra of compounds in solution. UV-visible adsorption of the solutions were acquired using an Agilent 8453 spectrophotometer operated in single beam mode using $1 \mathrm{~cm}$ quartz cuvettes 
(frosted opposite faces) of $1 \mathrm{~cm}$ thickness (path length) and the spectra were recorded between 200 and $800 \mathrm{~nm}$. This technique measures the absorbance of light energy or electromagnetic radiation, which excites electrons from the ground state to the first singlet excited state of the compound. The UV-vis region of energy for the electromagnetic spectrum covers the range $1.5-6.2 \mathrm{eV}$, which relates to a wavelength range of $200-800 \mathrm{~nm}$.

The Beer-Lambert equation is the principle behind absorbance spectroscopy:

$$
\mathrm{A}=\varepsilon b c
$$

For a single wavelength, $\mathrm{A}$ is the absorbance, $\varepsilon$ is the molar absorptivity of the compound or molecule in solution $\left(\mathrm{M}^{-1} \mathrm{~cm}^{-1}\right), \mathrm{b}$ is the path length of the cuvette or sample holder (usually 1 $\mathrm{cm}$ ), and $\mathrm{c}$ is the concentration of the solution $(\mathrm{M}) .{ }^{179}$

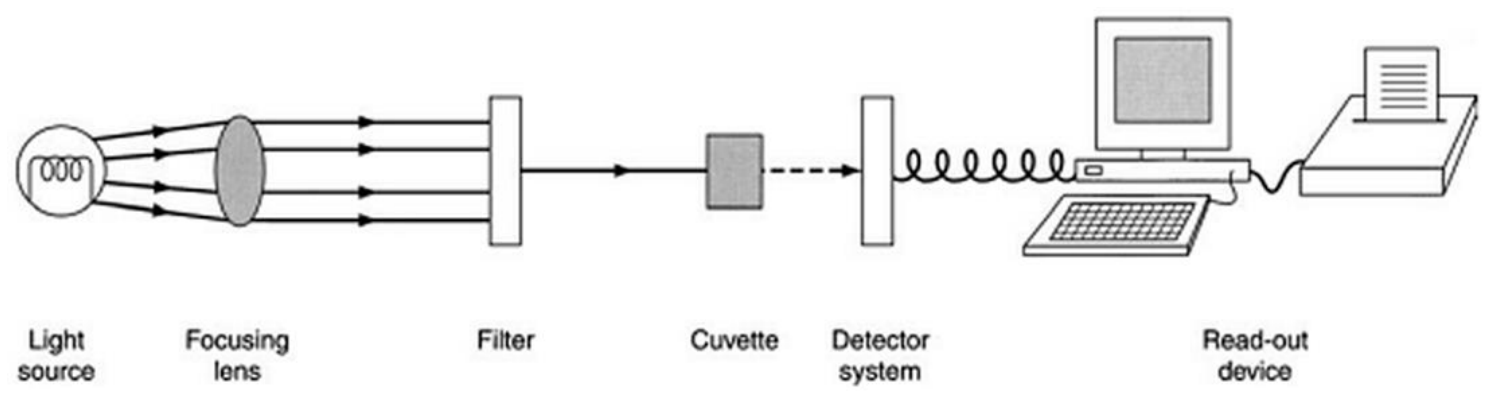

Figure 3.4. Illustration of a single beam UV-visible instrument. ${ }^{180}$

\subsubsection{Photodegradation measurements}

The photoactivity of the composites was evaluated by measuring the bleaching of a model organic compound (MB dye) under dark and UV illumination by UV-visible spectroscopy. MB (MB) was preferred for these experiments since its colour is stable at the high $\mathrm{pH}$ of the geopolymer matrix.

The interaction of the composites with the MB was carried out by the batch method in which $100 \mathrm{mg}$ of the powdered sample was mixed with $100 \mathrm{ml}$ of $0.1 \mathrm{mM}$ aqueous MB solution in a round bottom flask and magnetically stirred throughout the experiment. The experiments were carried out both in the dark and under UV illumination using a $150 \mathrm{~W}$ xenon lamp as the light source. 
Photodegradation experiments are normally carried out by allowing the photocatalyst sample in contact with the solution to be degraded (in this case MB dye) under dark conditions, then exposing the system to UV irradiation and monitoring the removal of the dye colour by spectrophotometry. This approach proved not to be possible with the present samples based on an unmodified geopolymer matrix, since equilibrium under dark conditions was never reached because the $\mathrm{pH}$ of the system never stabilized, but the geopolymer continued to remove the dye by adsorption. For this reason, two sets of experiments were carried out in attempt to separate the two processes occurring with these samples, namely adsorption of the dye and its photodecomposition. In one set of experiments the adsorption of the dye by photocomposites of the unmodified geopolymer with the oxide nanoparticles was measured in the dark and the adsorption characteristic (kinetics and adsorption isotherms) were determined from these data. In a second set of experiments, new samples were exposed to fresh MB dye and immediately irradiated with UV radiation; the decolouration of the dye in this case was due to a combination of adsorption by the geopolymer composite and the photodegradation process. The situation was found to be different in the composites based on the modified geopolymer matrices, in which a stable $\mathrm{pH}$ was achieved under dark conditions, allowing the system to come to equilibrium, and photodegradation measurements to be made in the usual manner. In these experiments, the photocatalys/MB system was equilibrated overnight in the dark, and then exposed to UV irradiation.

After varying reaction periods, $5 \mathrm{~mL}$ aliquots of the sample were taken, the suspension centrifuged off and the concentration of the dye remaining in the solution determined by measuring the height of the absorbance maximum at $664 \mathrm{~nm}$ in the UV-visible spectrum using a spectrometer between 200 and $800 \mathrm{~nm}$. The amount of dye uptake (q) and the removal efficiency $(\eta)$ of the dye were then calculated by eq. 28 and 29:

$$
\begin{aligned}
& \mathrm{q}=\frac{\mathrm{C}_{0}-\mathrm{C}_{\mathrm{t}}}{\mathrm{m}} \times \mathrm{V} \\
& \eta=\frac{\left(C_{0}-C_{t}\right)}{C_{0}} \times 100
\end{aligned}
$$

$\mathrm{V}$ is the volume of dye solution $(\mathrm{mL})$, and $\mathrm{m}$ is the mass $(\mathrm{g})$ of the adsorbent, $\mathrm{C}_{0}$ and $\mathrm{C}_{\mathrm{t}}$ are the concentration of the dye solution at the initial time and after time $\mathrm{t}$ of absorption respectively. 


\subsubsection{Dye adsorption kinetics under dark conditions}

The kinetics of dye adsorption on the geopolymer composites measured under dark conditions were analysed using two kinetic models previously proposed, namely, pseudofirst-order (eq. 30) and pseudo-second-order models (eq. 31) ${ }^{181}$

$$
\begin{aligned}
& \mathrm{q}=\mathrm{q}_{\mathrm{e}}\left(1-\exp \left(-\mathrm{k}_{1} \mathrm{t}\right)\right) \\
& \mathrm{q}=\frac{\left(\mathrm{k}_{2} \mathrm{q}_{\mathrm{e}}{ }^{2} \mathrm{t}\right)}{\left(1+\mathrm{k}_{2} \mathrm{q}_{\mathrm{e}} \mathrm{t}\right)}
\end{aligned}
$$

Where $\mathrm{q}$ is the amount of dye adsorbed $(\mathrm{mg} / \mathrm{g})$ at time $\mathrm{t}(\mathrm{min}), \mathrm{q}_{\mathrm{e}}$ is the amount of dye adsorbed at equilibrium ( $\left.\mathrm{mg} \mathrm{g}^{-1}\right)$, $\mathrm{k}_{1}$ is the equilibrium rate constant for pseudo-first-order kinetics $\left(\mathrm{min}^{-1}\right)$ and $\mathrm{k}_{2}$ is the equilibrium rate constant for pseudo-second-order kinetics ( $\mathrm{g}$. $\left.\mathrm{mg}^{-1} \mathrm{~min}^{-1}\right)$. The adsorption data were fitted to these two equations by a nonlinear method with successive interactions calculated by the Levenberg-Marquardt algorithm ${ }^{182}$ using OriginPro 2015 software.

\subsubsection{Dye adsorption isotherms under dark conditions}

The relationship between the amount of solute adsorbed and the concentration of the solution in the liquid phase at a given constant temperature can be described by an adsorption isotherm. The present experimental data for dye adsorption on the geopolymer composites were fitted to three equations commonly used to describe adsorption isotherms, namely, the Langmuir isotherm, which assumes that the adsorption process occurs at specific homogeneous sites within the adsorbent, ${ }^{178}$ the Freundlich isotherm which is an empirical equation used to describe heterogeneous systems, and the Langmuir-Freundlich isotherm which provides a more flexible analytical modelling framework by use of a three-parameter equation that can give a better fit to the data.

The Langmuir isotherm takes the form:

$$
q=\frac{\left(Q_{s} k C\right)}{1+k C}
$$


where $\mathrm{q}$ is the adsorbed amount of the dye $(\mathrm{mg} / \mathrm{g}), \mathrm{C}$ is the equilibrium concentration of the dye in solution $(\mathrm{mg} / \mathrm{L}), \mathrm{Q}_{\mathrm{s}}$ is the adsorption capacity $(\mathrm{mg} / \mathrm{g})$ and $\mathrm{k}$ is a constant related to the free energy of adsorption (L/mg).

The Freundlich isotherm can be written:

$\mathrm{q}=\mathrm{kC}^{\mathrm{n}}$

where $\mathrm{k}$ and $\mathrm{n}$ are constants specifying the extent of the adsorption and the degree of nonlinearity between the solution concentration and $\mathrm{q}$ the adsorption.

The Langmuir-Freundlich equation takes the form:

$\mathrm{q}=\frac{\left(\mathrm{Q}_{\mathrm{s}} \mathrm{kC} \mathrm{C}^{\mathrm{n}}\right)}{\left(1+\mathrm{k} \mathrm{C}^{\mathrm{n}}\right)}$

\subsection{Brunauer-Emmett-Teller (BET) Surface Area Analysis}

Nitrogen adsorption/desorption isotherms were recorded for powdered samples using a Micrometrics model ASAP2010 analyzer at $77 \mathrm{~K}$. The samples were degassed at $\sim 100{ }^{\circ} \mathrm{C}$ overnight prior to the measurement. The surface area was obtained by the Brunauer-EmmettTeller (BET) method, and pore size distribution was calculated from the adsorption branch of the isotherm by the Barret-Joyner-Halenda (BJH) model. 


\section{Chapter 4}

\section{Synthesis and characterization of new photoactive inorganic polymer composites with $\mathrm{Cu}_{2} \mathrm{O}$ nanoparticles}

\section{Introduction}

This chapter describes the synthesis of geopolymer composites produced by incorporating $\mathrm{Cu}_{2} \mathrm{O}$ nanoparticles and the characterization of these novel composites. It should be noted the use of ecologically-friendly geopolymers in conjunction with nanocrystalline $\mathrm{Cu}_{2} \mathrm{O}$ for photodegradation of harmful organic substances has not previously been reported. The synthesis method was outlined in chapter 3, section 3.4 and the morphology of the product composites was assessed using SEM and TEM. The crystallinity and structure of the samples was evaluated using XRD and FTIR. MAS NMR and NQR spectroscopy confirm the formation of well-reacted geopolymer composites containing $\mathrm{Cu}_{2} \mathrm{O}$ nanoparticles. The specific surface areas were determined by the adsorption and desorption of nitrogen gas on the composites, and their important photocatalytic properties and degradation processes of $\mathrm{MB}$ dye were determined using UV- visible absorption spectra.

\subsection{Results and Discussion}

\subsubsection{XRD Analysis}

XRD was used to confirm the crystallinity of the $\mathrm{Cu}_{2} \mathrm{O}$ and the structure of the geopolymer matrix and $\mathrm{Cu}_{2} \mathrm{O}$ /geopolymer composites. A selection of typical powder XRD patterns of the geopolymer matrix and composites with different $\mathrm{Cu}_{2} \mathrm{O}$ loadings are shown in Figure 4.1. Geopolymers are usually described as X-ray amorphous, with an XRD pattern consisting of a largely featureless hump at about 20-35 $2 \theta$ (Figure 4.1, (black line). Impurities in the clay starting material are responsible for the sharp peaks at $26.75^{\circ} 2 \theta$ (quartz) and $21.96^{\circ} 2 \theta$ (cristobalite). The as-synthesized cubic $\mathrm{Cu}_{2} \mathrm{O}$ (Figure 4.1, yellow line) and the geopolymer$\mathrm{Cu}_{2} \mathrm{O}$ composites 10-30 wt\% (Figure 4.1. red, blue, and green line) contain all the expected peaks from cubic bcc $\mathrm{Cu}_{2} \mathrm{O}$ (PDF no. 01-073-6237), (Table 3.1) confirming the successful synthesis of $\mathrm{Cu}_{2} \mathrm{O}$, with no peaks from $\mathrm{CuO}, \mathrm{Cu}$ or other impurities.

The intensities of the $\mathrm{Cu}_{2} \mathrm{O}$ reflections increase with the addition of $30 \mathrm{wt} \%$ and with the 10 wt $\%$ addition of $\mathrm{Cu}_{2} \mathrm{O}$ showing the lowest $\mathrm{Cu}_{2} \mathrm{O}$ intensity. As expected, the intensities of the 
geopolymer quartz reflections decrease with increasing oxide content of the composite (Figure 4.1).

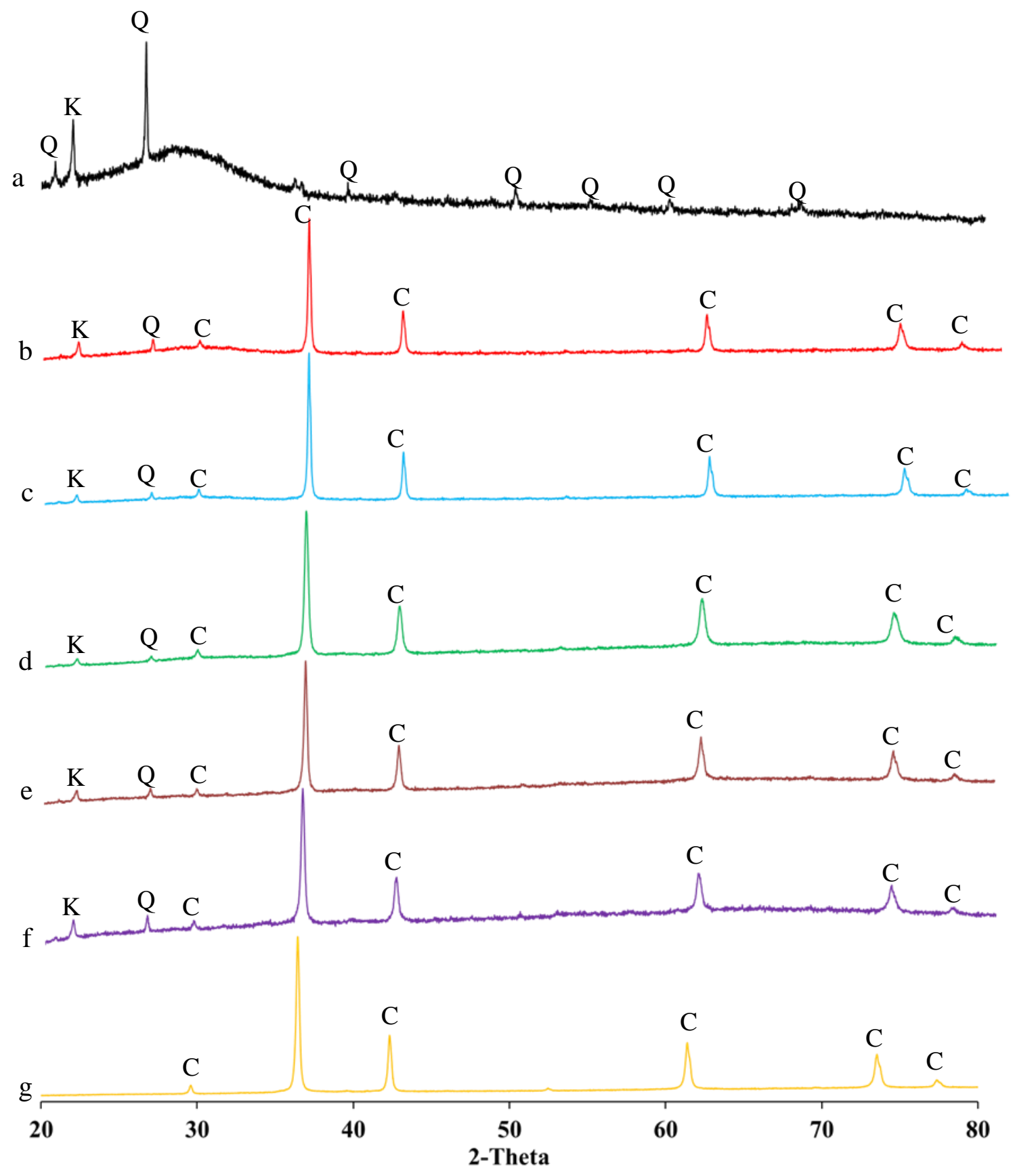

Figure 4.1. Normalized XRD patterns of $\mathrm{GP}$ and $\mathrm{Cu}_{2} \mathrm{O}$ and $\mathrm{Cu}_{2} \mathrm{O}$ supported by $\mathrm{GP}$ with different loading contents; (a) GP, (b) GP-10 wt $\% \mathrm{Cu}_{2} \mathrm{O}$, ( (c) GP-20 wt $\% \mathrm{Cu}_{2} \mathrm{O}$, (d) GP-30 wt $\% \mathrm{Cu}_{2} \mathrm{O}$, (e) GP-30 wt $\% \mathrm{Cu}_{2} \mathrm{O}$-under UV with MB, (f) GP-20 wt $\% \mathrm{Cu}_{2} \mathrm{O}$-under UV with $\mathrm{MB}$, (g) $\mathrm{Cu}_{2} \mathrm{O} . \mathrm{Q}=$ quartz, $\mathrm{K}=$ cristobalite, $\mathrm{C}=$ cuprous oxide. 


\subsection{Scanning electron microscopy}

SEM micrographs (Figure 4.2) confirm the success of the $\mathrm{Cu}_{2} \mathrm{O}$ synthesis methods of Luo et $a l .{ }^{64}$ and Shah et al. ${ }^{158} . \mathrm{Cu}_{2} \mathrm{O}$ crystals with uniform octahedral shape are shown in Figure 4.2. a,b, the average particle size of $200-500 \mathrm{~nm}$. The uniform spherical $\mathrm{Cu}_{2} \mathrm{O}$ crystals are shown by SEM in Figure $4.2 \mathrm{c}$ and d with an average size of $\sim 600 \mathrm{~nm}$. $\mathrm{Cu}_{2} \mathrm{O}$ crystals synthesized by the method of Bai et al. ${ }^{157}$ are shown by SEM (Figure 4.3) to be nanocrystals of uniform cubic morphology with an edge length of $80-150 \mathrm{~nm}$. This unique morphology is a result of ripening and surface reconstruction processes in the $\mathrm{Cu}^{2+}$ solution capped with PVP. The addition of $\mathrm{OH}^{-}$forms a blue insoluble $\mathrm{Cu}(\mathrm{OH})_{2}$ precipitate which changes through light yellow to orange with increasing particle size. ${ }^{183}$ The nanometer size of the cubic crystals confirms the decision to use these in the subsequent experiments.

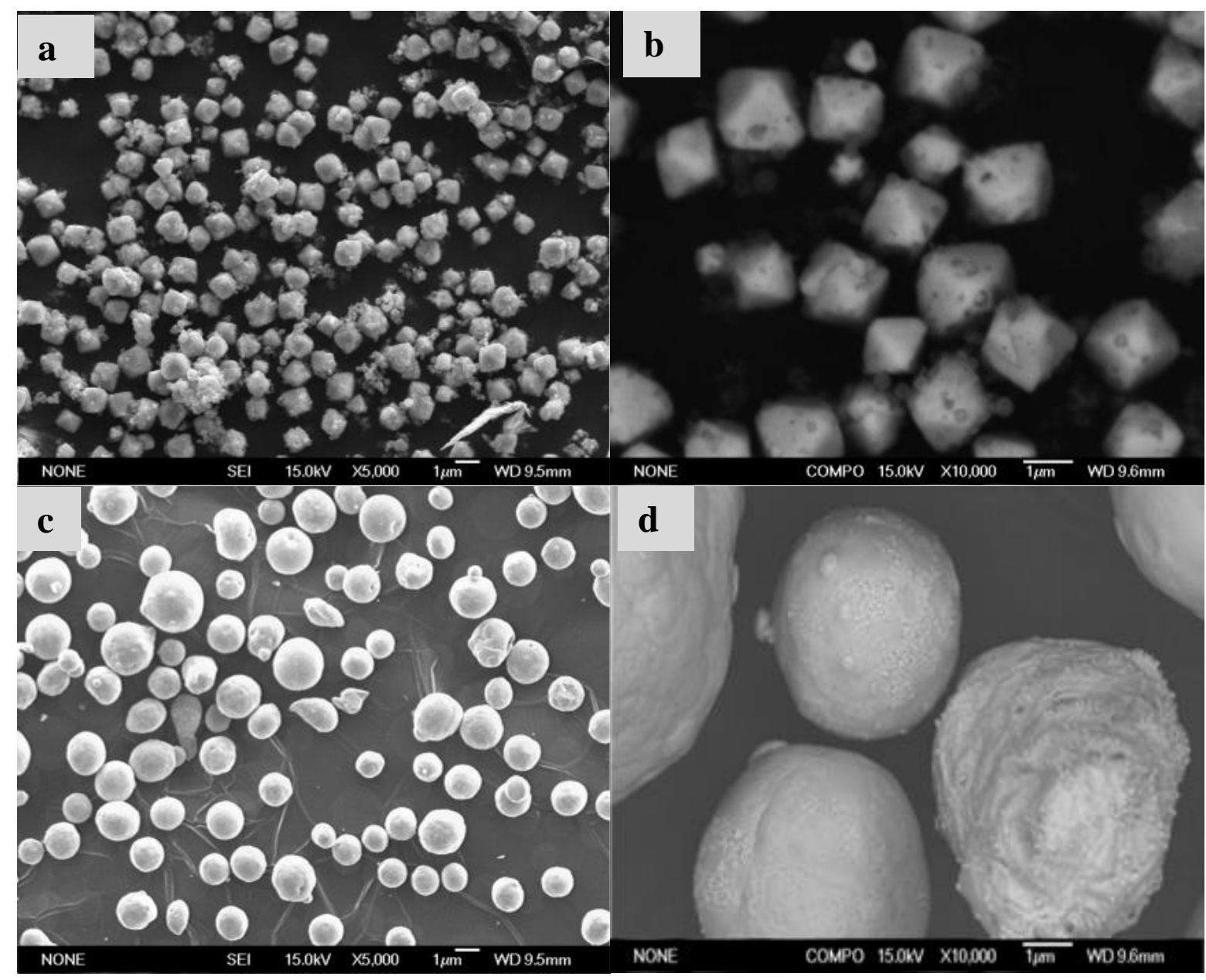

Figure 4.2. SEM micrographs of $\mathrm{Cu}_{2} \mathrm{O}$ octahedral $(\mathrm{a}, \mathrm{b})$ and spherical $(\mathrm{c}, \mathrm{d})$ synthesized via a typical procedure described in the experimental section 3.2.2 and 3.2.3. 


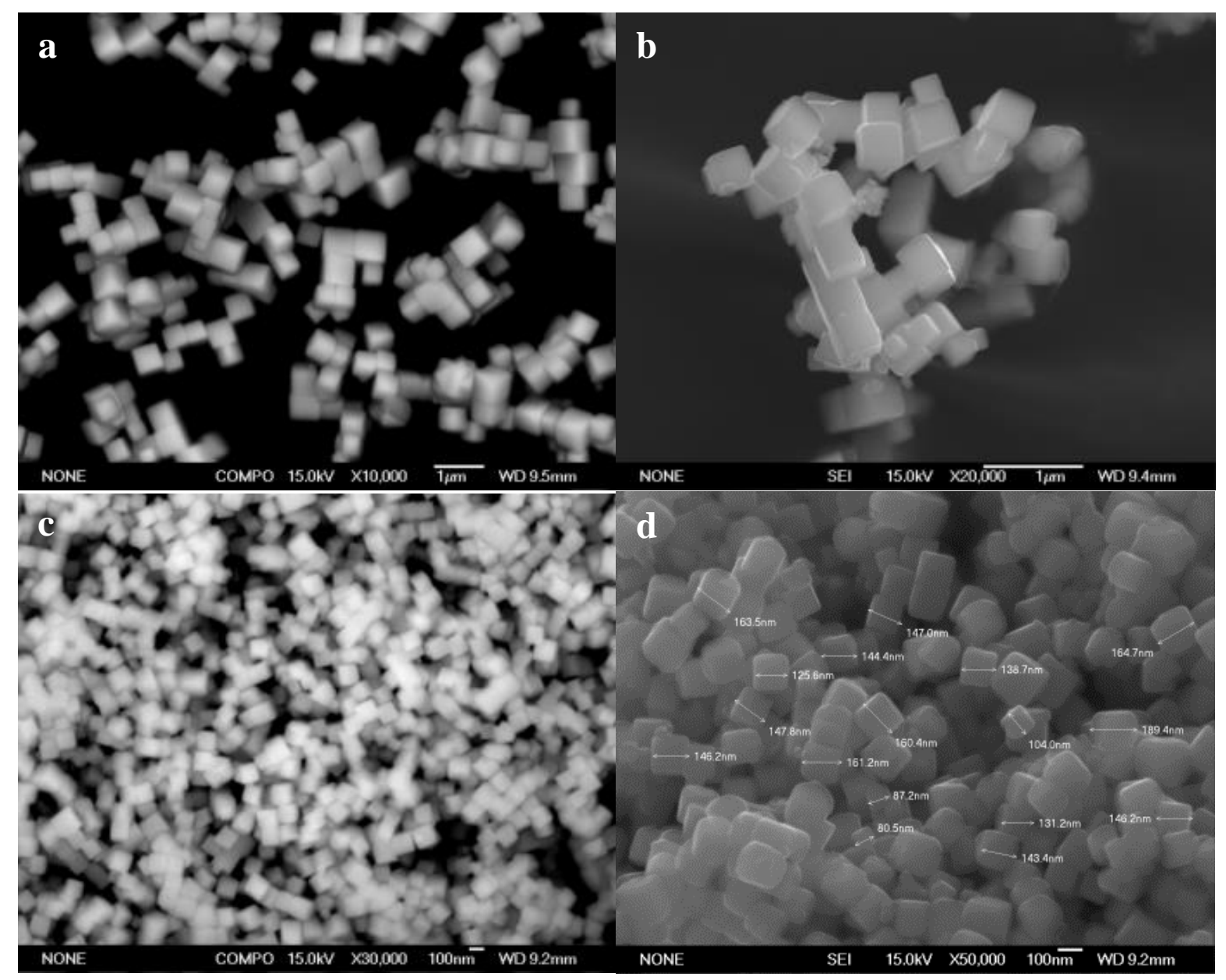

Figure 4.3. (a-d) SEM micrographs of $\mathrm{Cu}_{2} \mathrm{O}$ nanocubes at different magnifications synthesized via a typical procedure described in the experimental section 3.2.1.

Figure 4.4 (a-c) shows high resolution TEM micrographs of the $\mathrm{Cu}_{2} \mathrm{O}$ nanocubes synthesized by the method of Bai et al. ${ }^{159}$ The HRTEM image of $\mathrm{Cu}_{2} \mathrm{O}$ area (Figure 4.4e) confirmed its crystalline structure (region I) in which lattice planes could be detected with a d-spacing of $0.21 \mathrm{~nm}$ corresponding to the (200) plane of the cubic $\mathrm{Cu}_{2} \mathrm{O}$ phase. Figure 4.4(g,i) shows the corresponding Fast Fourier Transformation (FFT) patterns of regions I,II in Figure 4.4e. These FFT patterns verified that region I consisted of crystalline $\mathrm{Cu}_{2} \mathrm{O}$. Selected Area Diffraction patterns (SAED) (Figure 4.4d) show principally three rings which are attributed to the (111), (200) and (110) of the cubic $\mathrm{Cu}_{2} \mathrm{O}$. These lattice spacing are in agreement with the (cubic) structure of $\mathrm{Cu}_{2} \mathrm{O}$ (JCPDS file 01-073-6237). This HRTEM analysis provides a reliable confirmation of the XRD analysis.(Figure 4.5) 


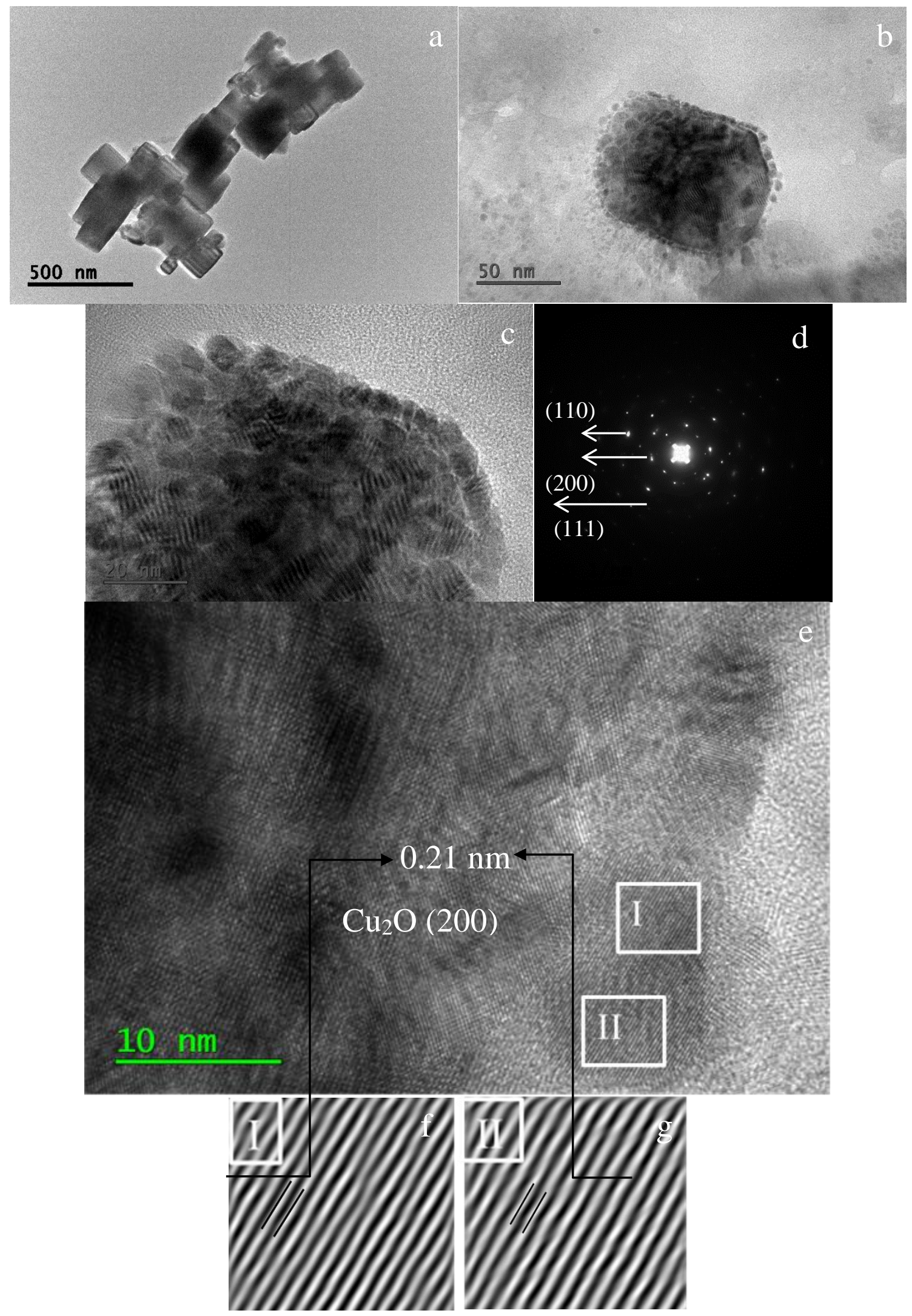

Figure 4.4. (a-c) TEM micrographs of the $\mathrm{Cu}_{2} \mathrm{O}$ nanocubes, (d) SAED pattern, (e) HRTEM image of $\mathrm{Cu}_{2} \mathrm{O},(\mathrm{f}, \mathrm{g})$ corresponding Fast Fourier Transformation (FFT) patterns of region I and II in panel e. 


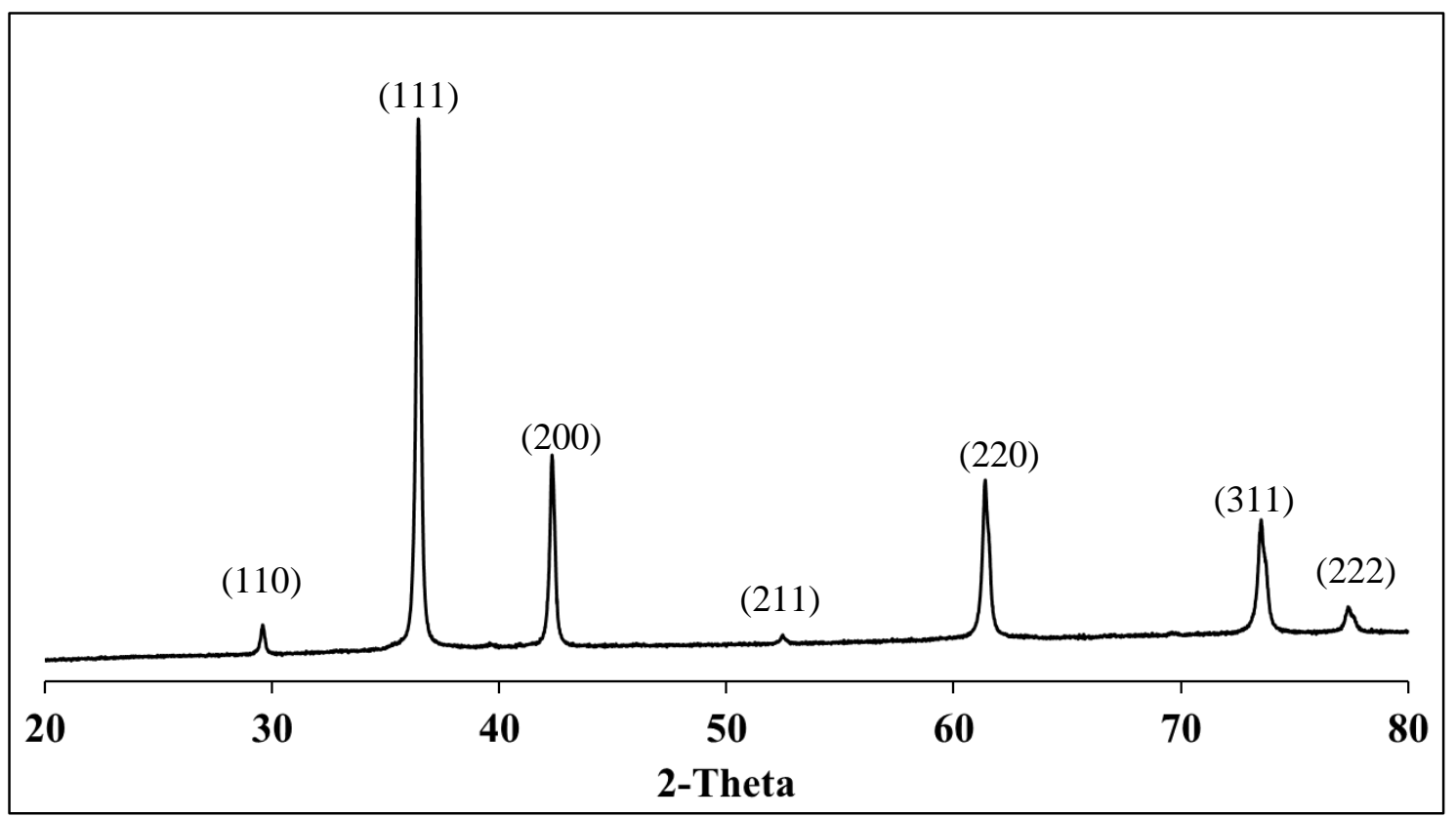

Figure 4.5. XRD pattern of as-prepared $\mathrm{Cu}_{2} \mathrm{O}$ nanocubes synthesised by the method of Bai et al. ${ }^{159}$

The morphology of the as-synthesized Na-geopolymer without $\mathrm{Cu}_{2} \mathrm{O}$ (Figure 4.6a) shows a homogenous microstructure of particles with a few voids, which suggests a high degree of gel reorganization during the geopolymerization processes.

The SEM images of the Na-geopolymer composites with a $\mathrm{Cu}_{2} \mathrm{O}$ loading of 10, 20 and 30 wt\% (Figure 4.6 (b-d) respectively) reveal well-dispersed $\mathrm{Cu}_{2} \mathrm{O}$ nanocubes throughout the geopolymer matrix. SEM micrographs of the $10 \mathrm{wt} \%$ of $\mathrm{Cu}_{2} \mathrm{O} /$ geopolymer composite (Figure 4.6) confirm the entry of $\sim 100 \mathrm{~nm} \mathrm{Cu}_{2} \mathrm{O}$ nanocubes into the pore structure of the geopolymer matrix even at $10 \mathrm{wt} \% \mathrm{Cu}_{2} \mathrm{O}$ concentration. 


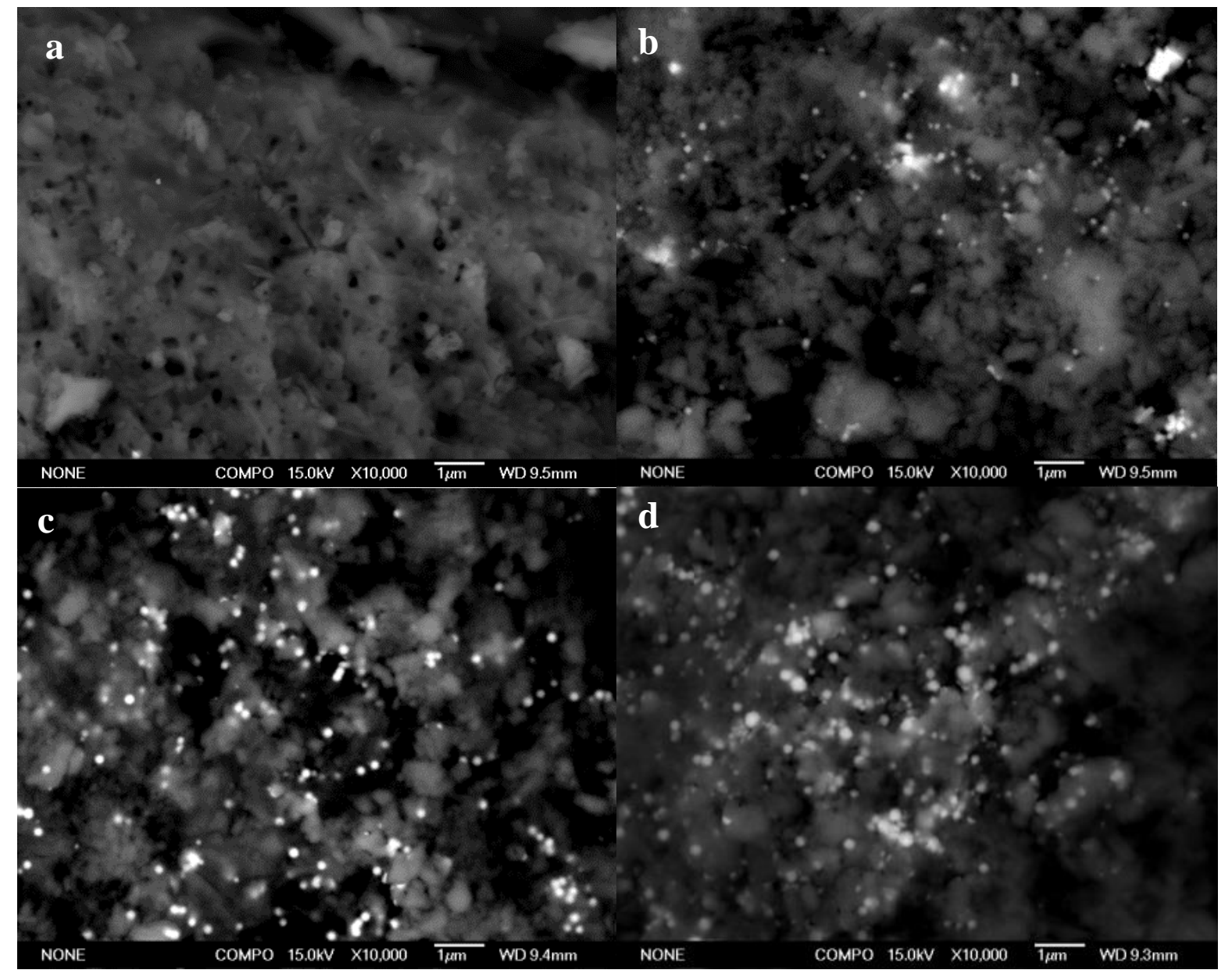

Figure 4.6. SEM micrographs of (a) GP matrix, (b) GP-10 wt\% $\mathrm{Cu}_{2} \mathrm{O}$, (c) $\mathrm{GP}-20$ wt $\% \mathrm{Cu}_{2} \mathrm{O}$, (d) $\mathrm{GP}-30 \mathrm{wt} \% \mathrm{Cu}_{2} \mathrm{O}$.

EDS analysis of the surface of the geopolymer- $\mathrm{Cu}_{2} \mathrm{O}$ composites reveals the presence of $\mathrm{Si}$, $\mathrm{Al}, \mathrm{Na}$, and $\mathrm{Cu}$ atoms (Figure 4.8), with no change in the surface morphology after incorporation of $\mathrm{Cu}_{2} \mathrm{O}$ but an increase in the height of the $\mathrm{Cu}$ peak with increased loadings. The $\mathrm{Cu}_{2} \mathrm{O}$ particles of $90-150 \mathrm{~nm}$ average size appear to cover most of the geopolymer surfaces, especially at the highest loading of $30 \mathrm{wt} \%$. This homogenous distribution of $\mathrm{Cu}_{2} \mathrm{O}$ particles on the composite surface should facilitate the photocatalytic activity. The average atomic number of $\mathrm{Cu}_{2} \mathrm{O}$ and the geopolymer composite is approximately 22 and 8 respectively. As shows in the BSE map, the $\mathrm{Cu}_{2} \mathrm{O}$ will appear as bright spots on the darker geopolymer matrix. 

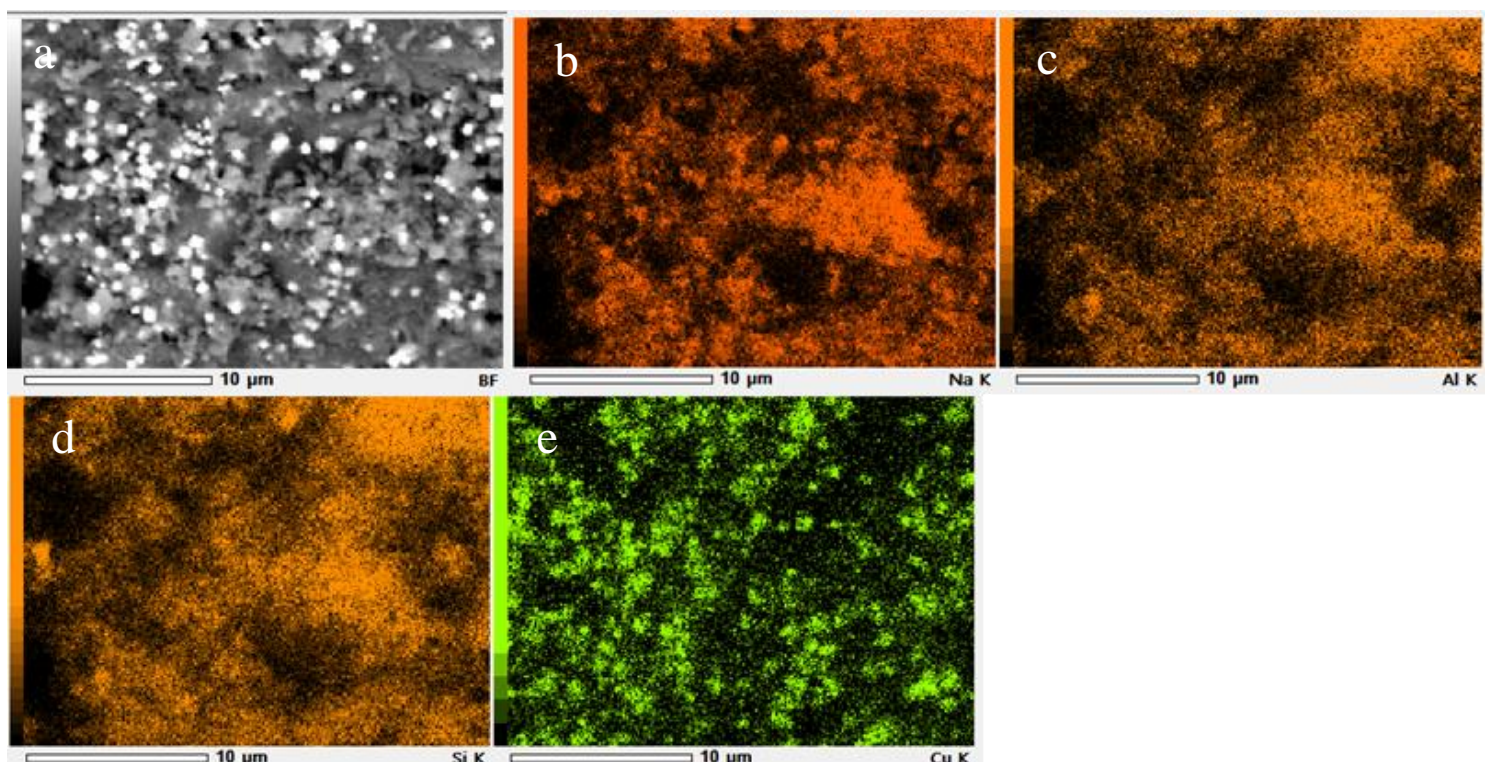

Figure 4.7. (a) Backscattered SEM image of ground GP- 30 wt $\% \mathrm{Cu}_{2} \mathrm{O}$ with corresponding, (b) $\mathrm{Na}$, (c) $\mathrm{Al}$, (d) $\mathrm{Si}$, (e) Cu elemental map.

Figure 4.8 shows the EDS spectra and the percentage of $\mathrm{Cu}$ particles spread over the geopolymer matrix. It is clear that increasing the percentage of $\mathrm{Cu}_{2} \mathrm{O}$ loading into the matrix, the height of the $\mathrm{Cu}$ peak increases as expected.

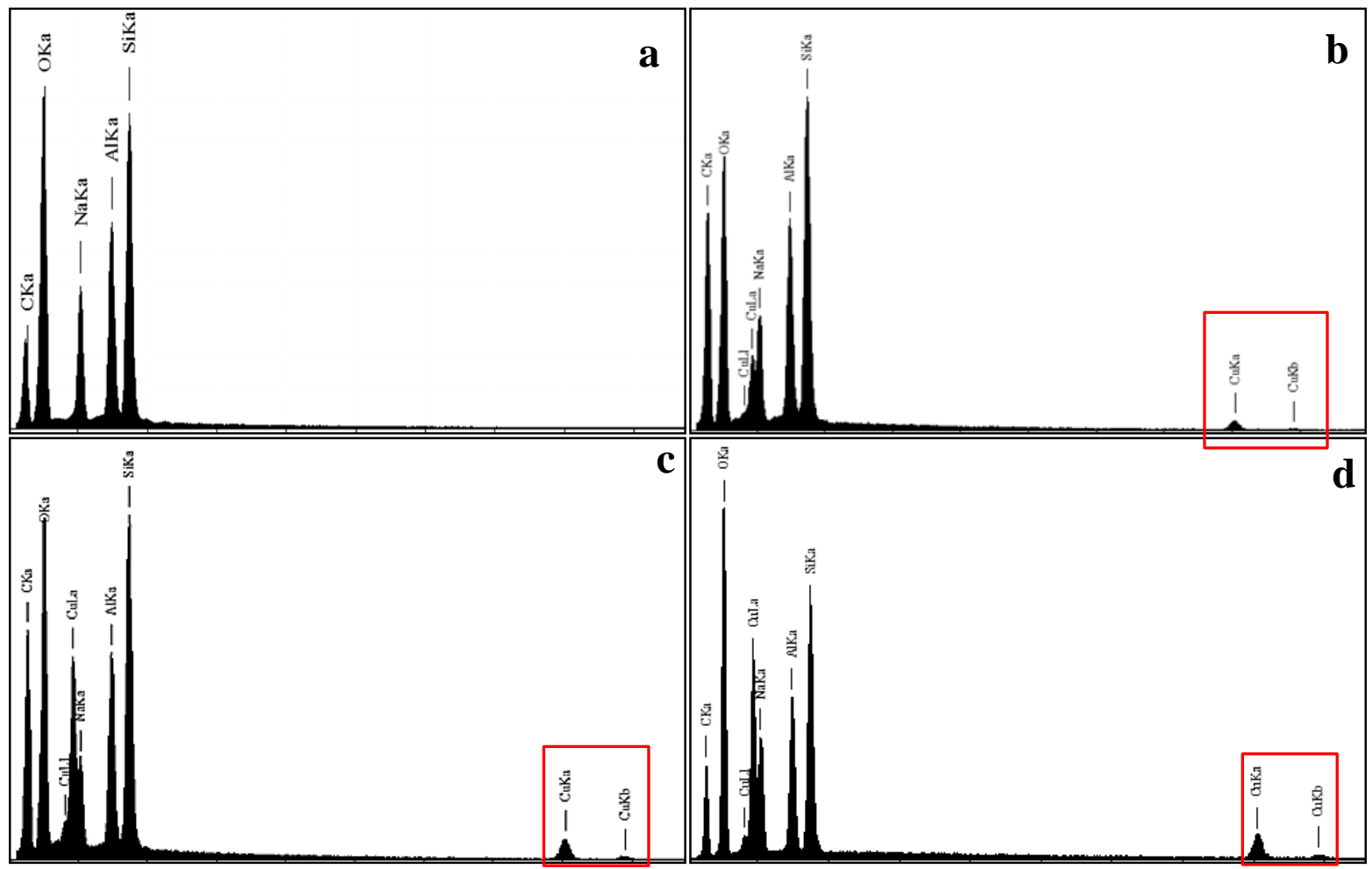

Figure 4.8. EDS data of (a) GP, (b) GP- 10 wt $\% \mathrm{Cu}_{2} \mathrm{O}$ (c) GP- 20 wt $\% \mathrm{Cu}_{2} \mathrm{O}$ (d) GP- 30 wt\% $\mathrm{Cu}_{2} \mathrm{O}$. 


\subsection{FTIR spectra of these samples}

In order to investigate the structure of the as-prepared materials the FTIR spectra were acquired in the range $400-4000 \mathrm{~cm}^{-1}$. Representative FTIR spectra of these samples are shown in Figure 4.9. The positions of the main IR bands and corresponding species are listed in Chapter 3, Table 3.3.

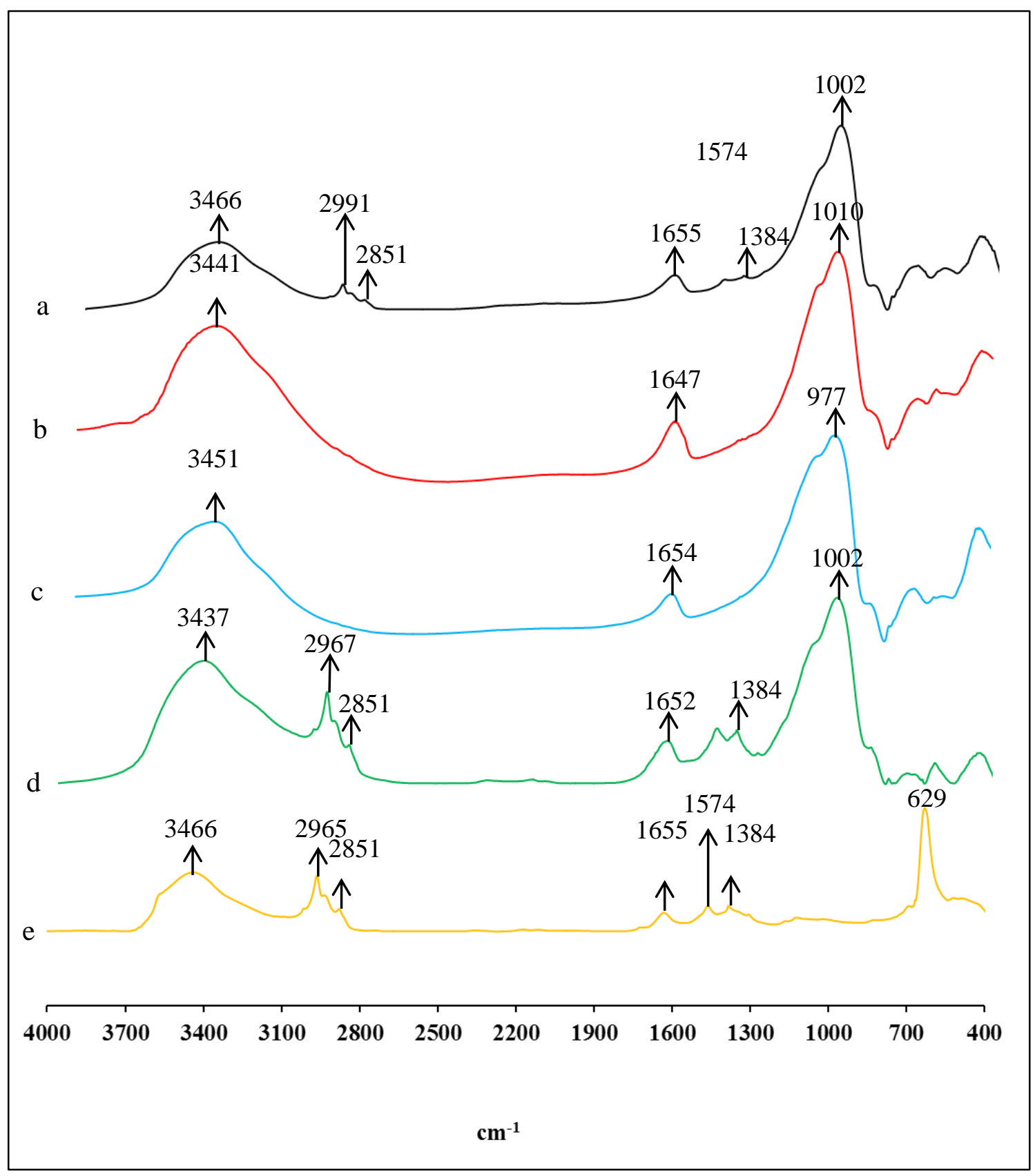

Figure 4.9. FTIR spectra of (a) GP, (b) GP- 10 wt $\% \mathrm{Cu}_{2} \mathrm{O}$, (c) GP- 20 wt $\% \mathrm{Cu}_{2} \mathrm{O}$, (d) GP- 30 wt\% $\mathrm{Cu}_{2} \mathrm{O}$, (e) $\mathrm{Cu}_{2} \mathrm{O}$. 
The peaks at about $1000 \mathrm{~cm}^{-1}$ are typical of the geopolymer matrix, with the presence of both Al-O and Si-O asymmetric stretch ${ }^{184}$ (Figure 4.9). This peak appeared at $1002 \mathrm{~cm}^{-1}$ in the reference geopolymer and with $10 \mathrm{wt} \%$ addition of $\mathrm{Cu}_{2} \mathrm{O}$ it was shifted to 1010 and $977 \mathrm{~cm}^{-1}$ for 20 and $30 \mathrm{wt} \%$ addition of $\mathrm{Cu}_{2} \mathrm{O}$ respectively, indicating that the presence of the oxide particles does affect the structure. Three fundamental vibration modes indicate the presence of water molecules; the spectral regions are the $\mathrm{OH}$ stretching region, $\mathrm{H}-\mathrm{O}-\mathrm{H}$ bending region of $\mathrm{H}_{2} \mathrm{O}$, and the structural $\mathrm{OH}$-bending region of the structural $\mathrm{OH}$ groups. ${ }^{185}$ The absorption bands related to the $\mathrm{H}-\mathrm{O}-\mathrm{H}$ bending vibration of water appears at $1645 \mathrm{~cm}^{-1}$, and are all very similar, resulting from the slight differences in water content in these geopolymer preparations.

The FTIR spectra also display a band at $3440 \mathrm{~cm}^{-1}$ in the geopolymer matrix due to the symmetric O-H stretching vibration of H-bonded water. ${ }^{185}$ This wave number shifted to 3441 , 3451 , and $3437 \mathrm{~cm}^{-1}$ for different percentages $\mathrm{Cu}_{2} \mathrm{O}$ addition from 10 to $3 \mathrm{wt} \%$ which corresponds to the hydroxyl group involved in water-water hydrogen band. ${ }^{186}$ The absorption band at $629 \mathrm{~cm}^{-1}$ appearing in pure $\mathrm{Cu}_{2} \mathrm{O}$ is assigned to the phase bending vibration of surface $\mathrm{OH}$ group. The $\mathrm{OH}_{2}$ stretching band at $2967 \mathrm{~cm}^{-1}$ is assigned to asymmetric stretching of $\mathrm{OH}_{2}$ groups and this peak disappears in the samples with 10 and $20 \mathrm{wt} \%$ additions of $\mathrm{Cu}_{2} \mathrm{O}$ and was shifted to $2965 \mathrm{~cm}^{-1}$ in the $30 \mathrm{wt} \% \mathrm{Cu}_{2} \mathrm{O}$ sample.

\section{$4.4{ }^{63} \mathrm{Cu}$ NQR Spectroscopy}

${ }^{63} \mathrm{Cu} \mathrm{NQR}$ spectra of the $\mathrm{Cu}_{2} \mathrm{O}$ and $\mathrm{Cu}_{2} \mathrm{O}$ /geopolymer composites (Figure 4.10) show the expected single line in the reported position for the pure oxide ${ }^{187}$ (Figure 4.10a) which is unchanged by its incorporation in the geopolymer matrix (Figure 4.10c), indicating that the $\mathrm{Cu}_{2} \mathrm{O}$ has not been incorporated into the geopolymer matrix. 
(a)

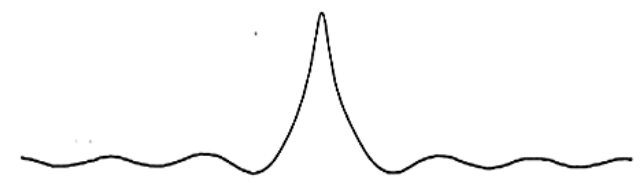

(b)

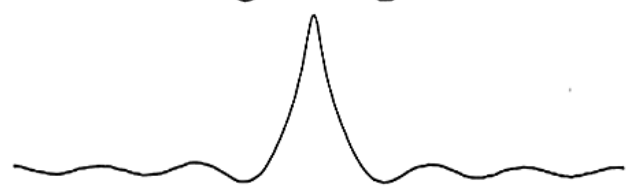

(c)

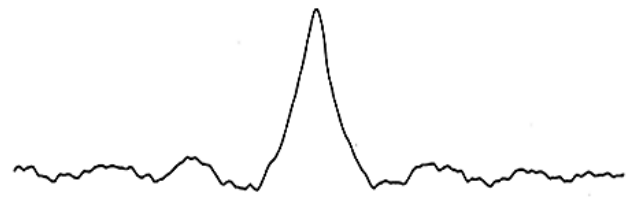

(d)

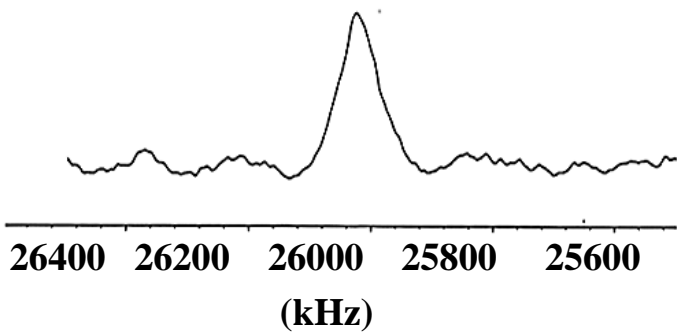

Figure 4.10. ${ }^{63} \mathrm{Cu} N Q R$ spectra of nanoparticle $\mathrm{Cu}_{2} \mathrm{O}$ and $\mathrm{Cu}_{2} \mathrm{O} / \mathrm{GP}$ composites. (a) assynthesized $\mathrm{Cu}_{2} \mathrm{O}$, (b) $\mathrm{Cu}_{2} \mathrm{O}$ after UV irradiation, (c) $\mathrm{Cu}_{2} \mathrm{O} / \mathrm{GP}$ composite before UV irradiation, (d) $\mathrm{Cu}_{2} \mathrm{O} / \mathrm{GP}$ composite after UV irradiation.

\section{$4.5{ }^{29} \mathrm{Si}$ and ${ }^{27} \mathrm{Al}$ solid state MAS NMR}

Representative ${ }^{27} \mathrm{Si}$ MAS NMR spectra of the geopolymer and geopolymer composites (Figure 4.11.) show that these are all well-formed geopolymers with a broad principal resonance at about -85 to $-87 \mathrm{ppm}$, corresponding to a framework structure significantly saturated in $\mathrm{Al}$, but broadened by the presence of several slightly different Si-O-Al environments. ${ }^{121}$ 


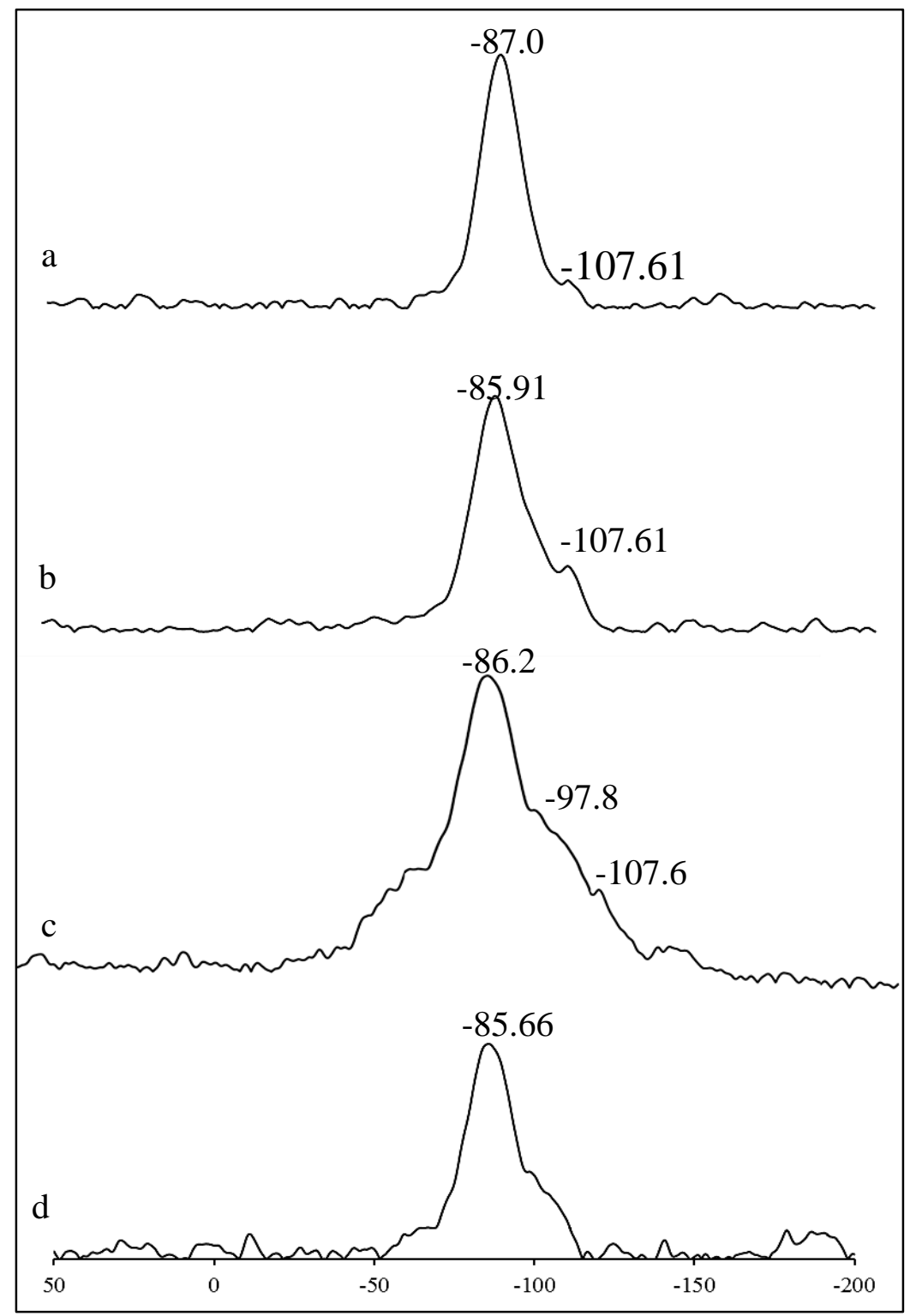

Figure 4.11.11.7 $\mathrm{T}^{29} \mathrm{Si}$ MAS NMR spectra. (a) GP, (b) GP-10 wt $\% \mathrm{Cu}_{2} \mathrm{O}$, (c) GP-20 wt $\%$ $\mathrm{Cu}_{2} \mathrm{O}$, (d) $\mathrm{GP}-30 \mathrm{wt} \% \mathrm{Cu}_{2} \mathrm{O}$

A feature at about -100 to -107 ppm which broadens into a shoulder in the composites with higher $\mathrm{Cu}_{2} \mathrm{O}$ content (Figure 4.11) denotes the presence of a greater number of sites in which the silicon atoms are bonded through oxygen to other silicon. ${ }^{188}$

The corresponding ${ }^{27} \mathrm{Al}$ MAS NMR spectra (Figure 4.12) all contain a predominant sharp resonance at about $59 \mathrm{ppm}$ corresponding to the tetrahedral Al-O units of a well-developed geopolymer structure. ${ }^{121}$ The small broad feature in some of the samples arises from Al-O in octahedral coordination, ${ }^{188}$ as a residual trace of unreacted metakaolin. ${ }^{121}$ 


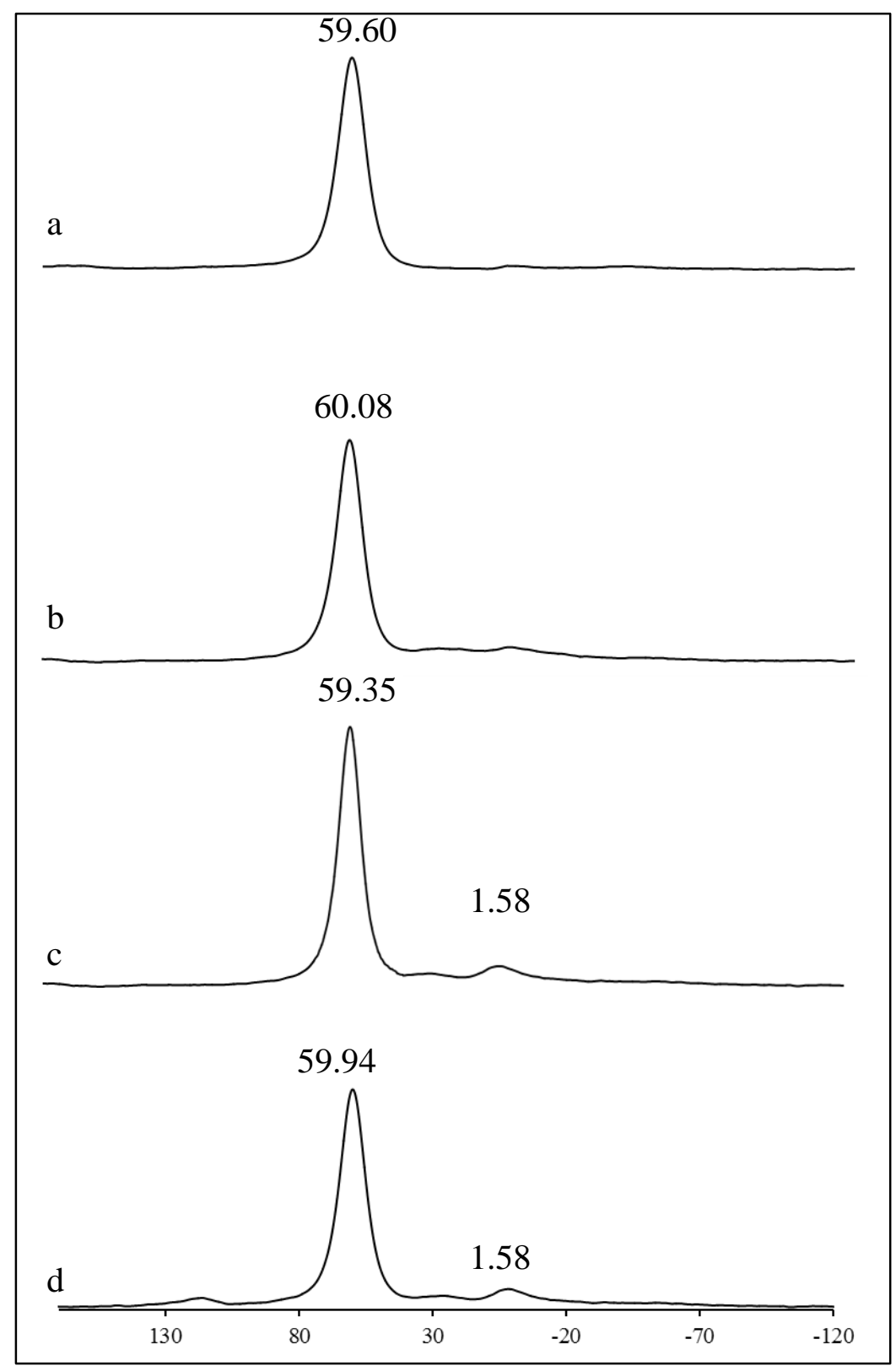

Figure 4.12.11.7 T ${ }^{27} \mathrm{Al}$ MAS NMR spectra. (a) GP, (b) GP-10 wt $\% \mathrm{Cu}_{2} \mathrm{O}$, (c) GP-20 wt\% $\mathrm{Cu}_{2} \mathrm{O}$, (d) $\mathrm{GP}-30$ wt $\% \mathrm{Cu}_{2} \mathrm{O}$

To summarize, these results confirm the successful formation of aluminosilicate geopolymer composites containing homogeneously distributed nanosized cubic $\mathrm{Cu}_{2} \mathrm{O}$ particles.

\subsection{Dye Adsorption experiments}

Reference geopolymers which do not contain $\mathrm{Cu}_{2} \mathrm{O}$ can remove $\mathrm{MB}$ from aqueous solution by adsorption. This suggests a dual mechanism for the present geopolymer composites, 
whereby the geopolymer matrix removes the dye by adsorption under dark conditions, whereas under UV illumination, photodegradation also occurs concomitantly with the adsorption process. ${ }^{139}$ Thus, in the present experiments an initial attempt was made to distinguish the two processes by carrying out separate experiments under dark conditions and UV illumination. As noted in Chapter 3, section 3.16.1, it did not prove possible to bring the samples to equilibrium under dark conditions in order to measure the photodegradation step, so the experiments under UV illumination were carried out on fresh samples and dye solutions without equilibration in the dark, and therefore represent a combination of the two dye removal processes.

Adsorption of $\mathrm{MB}$ by the composites and geopolymers alone was investigated under dark conditions by the batch method. The results for the $\mathrm{MB}$ complex of geopolymer and $\mathrm{Cu}_{2} \mathrm{O}-$ GEOPOLYMER at an initial MB concentration of $0.1 \mathrm{mM}$ solution are plotted as a function of adsorption time in Figure 4.13. The absorption spectra show a maximum absorption band at approximately $664 \mathrm{~nm}$. A shoulder at $620 \mathrm{~nm}$ which indicates a blue shift after 4 hour stirring in the dark is more obvious in the geopolymer containing $20 \mathrm{wt} \% \mathrm{Cu}_{2} \mathrm{O}$. At this stage dye penetrates into the pores of the geopolymer composite and causes this spectral shift. Since the solution $\mathrm{pH}$ remains in the range of 9-11 during the sorption experiments, it appears that the positively charged surface hydroxyl groups on the edges of the geopolymer may repel the similarly charged MB cations, which can then enter the pores of the composite where there are no outer exchange sites. ${ }^{189}$ The adsorption mechanism of a cationic dye such as MB is related to its point of zero charge (PZC) with respect to that of the adsorbent. No PZC values for geopolymers are available in the literature, but those of zeolites, with which geopolymers are closely related, are known to vary widely with the Al/Si ratio. At higher $\mathrm{pH}$ values corresponding to the alkaline geopolymers, electrostatic adsorption of cationic species is likely to occur on the silanol groups present, and these are probably the adsorption sites in the present composites.

The absorption spectrum shape remains unchanged for the first 2 hour but its intensity decreases as adsorption occurs. The percentage removal of dye is fast at the beginning but steadily diminishes with time. Rapid adsorption of the dye at the initial contact time may be due to the initial availability of the active surface of the adsorbents. In the later stages, the slower rate of adsorption is a result of less accessibility of the active sites of the adsorbent, accompanied by the slow diffusion of the dye molecules into the porous structure of the adsorbent. After 120 min. 83, 86, 77 and $96 \%$ of the dye is removed in the dark by the 
geopolymer matrix, geopolymer- $\mathrm{Cu}_{2} \mathrm{O} 10 \mathrm{wt} \%$, geopolymer- $\mathrm{Cu}_{2} \mathrm{O} 20 \mathrm{wt} \%$ and geopolymer$\mathrm{Cu}_{2} \mathrm{O} 30 \mathrm{wt} \%$.
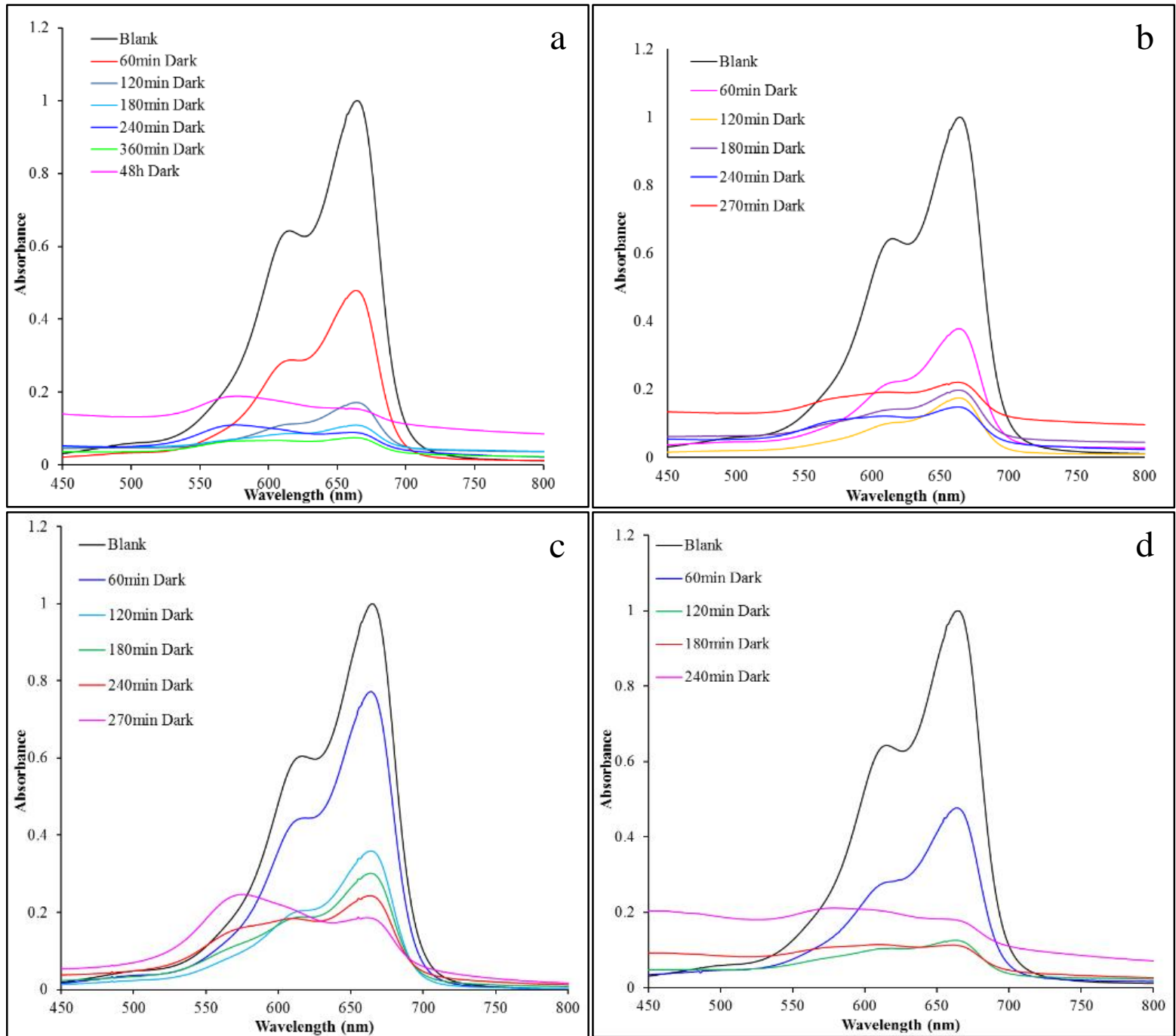

Figure 4.13. UV-vis absorption spectra of the $\mathrm{MB}$ solution during adsorption in the dark by (a) GP, (b) GP-10 wt $\% \mathrm{Cu}_{2} \mathrm{O}$, (c) GP-20 wt $\% \mathrm{Cu}_{2} \mathrm{O}$, (d) GP-30 wt $\% \mathrm{Cu}_{2} \mathrm{O}$.

All adsorbents have a limited number of active sites which become saturated at a certain concentration of adsorbate. Dark adsorption experiments involving all the catalysts indicate that the effective surface area and adsorption capacity of the supported $\mathrm{Cu}_{2} \mathrm{O}$ were much higher than that of the bare $\mathrm{Cu}_{2} \mathrm{O}$. Figure 4.14. shows the variation in the relative concentration $\left(\mathrm{C} / \mathrm{C}_{0}\right)$ of $\mathrm{MB}$ dye solution with time for the geopolymer matrix, geopolymer$\mathrm{Cu}_{2} \mathrm{O} 10 \mathrm{wt} \%$, geopolymer- $\mathrm{Cu}_{2} \mathrm{O} 20 \mathrm{wt} \%$ and geopolymer- $\mathrm{Cu}_{2} \mathrm{O} 30 \mathrm{wt} \%$. This indicates that the composite containing $20 \mathrm{wt} \% \mathrm{Cu}_{2} \mathrm{O}$ shows the most rapid adsorption of $\mathrm{MB}$; the decreased adsorption rate resulting from the inclusion of further $\mathrm{Cu}_{2} \mathrm{O}$ may be due to blocking of the active adsorption sites by the additional oxide. 


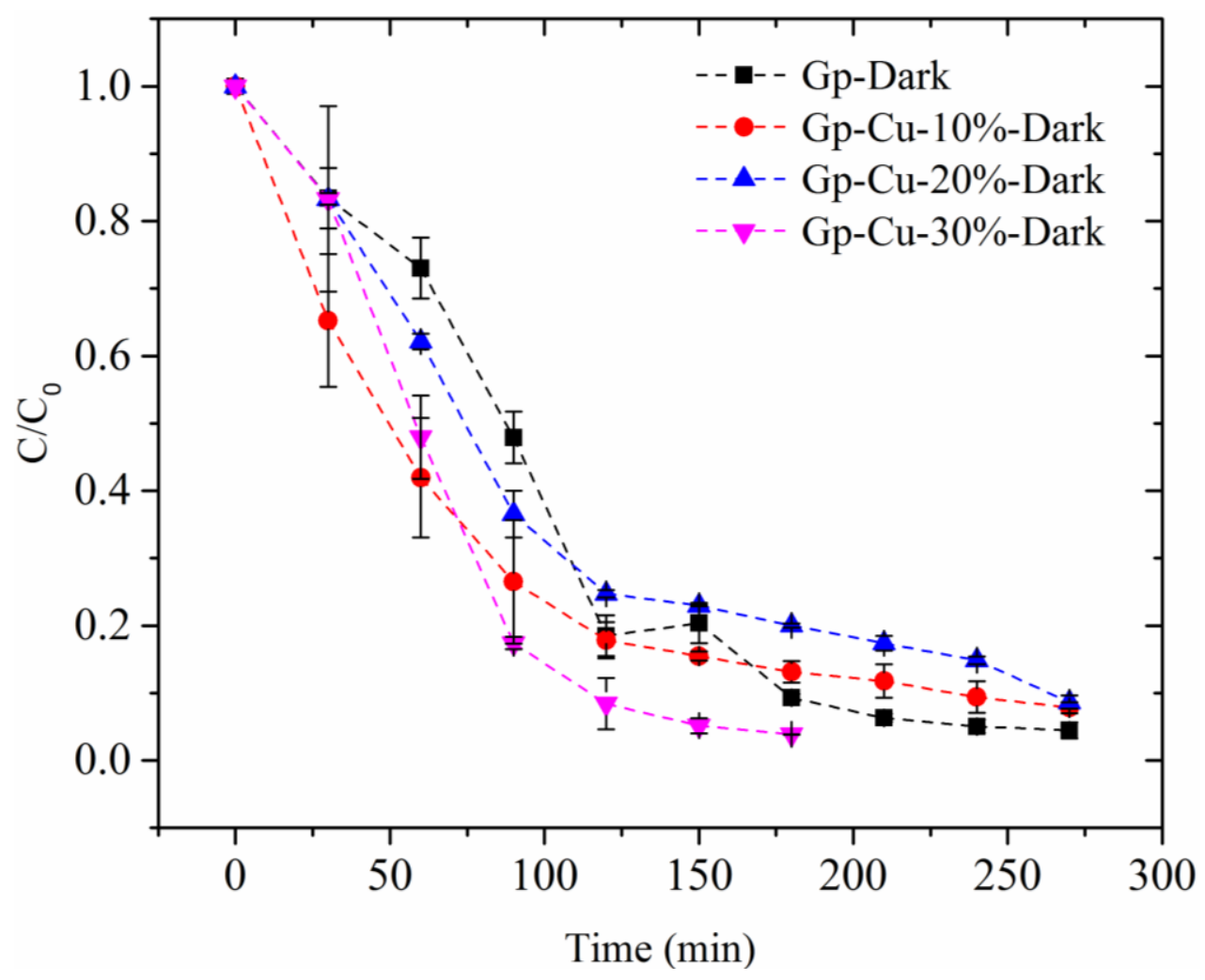

Figure 4.14. Plots of the residual concentration $\left(\mathrm{C} / \mathrm{C}_{0}\right)$ vs. time $(\mathrm{t})$ onto the GP matrix, GP$\mathrm{Cu}_{2} \mathrm{O} 10,20$, and $30 \mathrm{wt} \%$. (monitored at $664 \mathrm{~nm}$ in the dark)

\subsubsection{Dye adsorption kinetics under dark conditions}

The adsorption data (Figure 4.15) were fitted to pseudo-first-order (eq. 27) and pseudosecond-order (eq. 28) kinetic equations by a nonlinear method with successive interactions calculated by the Levenberg-Marquardt algorithm ${ }^{182}$ using OriginPro 2015 software. The resulting plots of the data fitted to these two equations are shown in Figure 4.15, with the resulting pseudo-first and pseudo-second order rate constants, the $\mathrm{q}_{\mathrm{e}}$ values, and the correlation coefficients $\mathrm{R}^{2}$ shown in Table 4.1. Comparison of the $\mathrm{q}_{\mathrm{e}}$ values calculated from these equations with the experimental values $\mathrm{q}_{\exp }$ (Table 4.1) shows that in all samples the pseudo-first order model provides a better fit to the experimental data; this is also supported by the superior fit of the experimental and calculated curve shapes (Figure 4.15a). The firstorder rate constants (Table 4.1) increase slightly with increasing $\mathrm{Cu}_{2} \mathrm{O}$ content of the geopolymer $/ \mathrm{Cu}_{2} \mathrm{O}$ composites, reflecting the improved adsorption by the composites. 


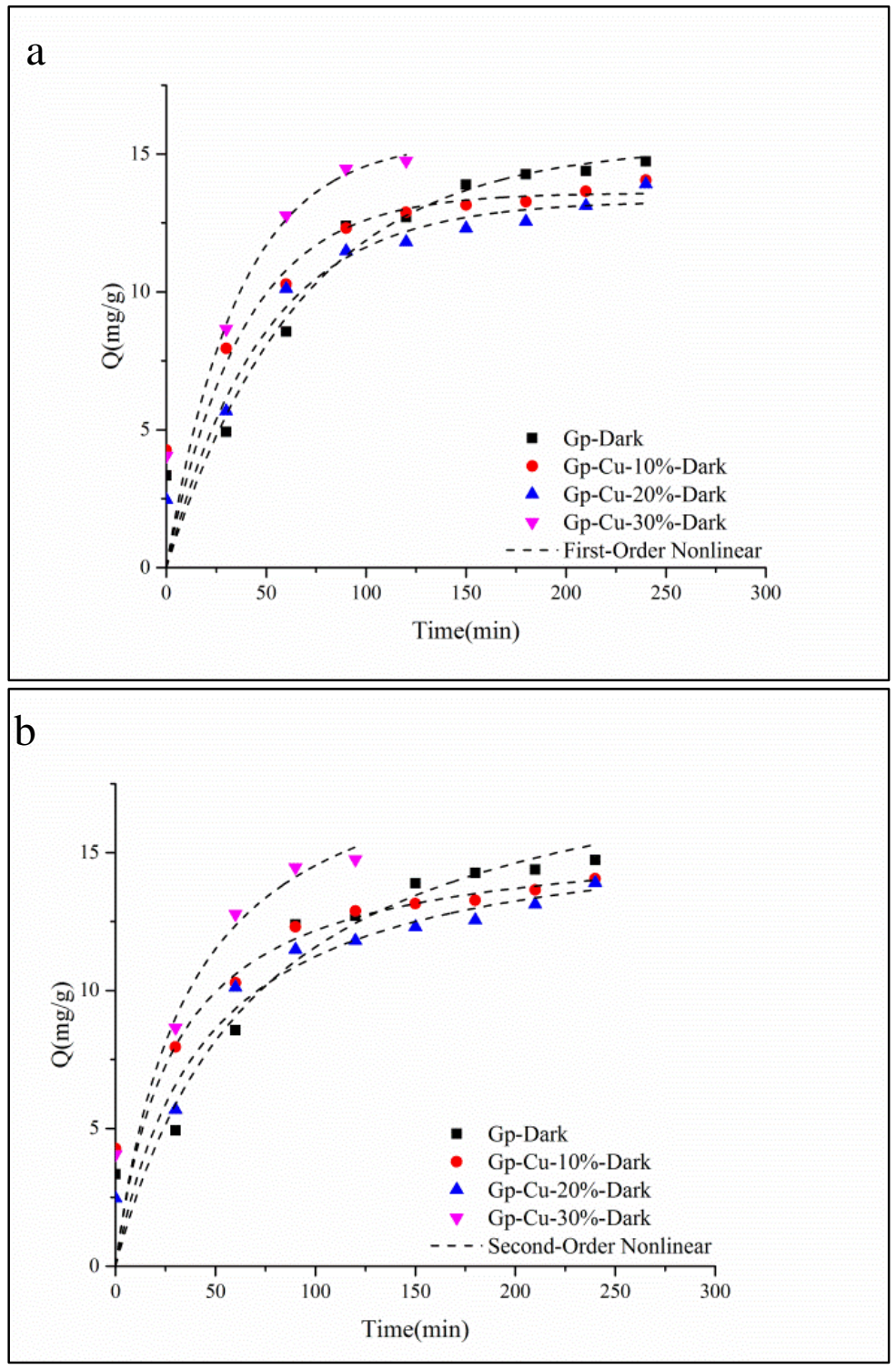

Figure 4.15. (a) Pseudo first-order kinetics, (b) Pseudo second-order kinetics by the nonlinear method and experimental kinetics for the adsorption of MB onto the GP matrix and GP composites. 
Table 4.1. Parameters for kinetic models of MB adsorption on samples

\begin{tabular}{|c|c|c|c|c|}
\hline Sample & Kinetic model & $\mathrm{q}_{\exp (\mathrm{mg} / \mathrm{g})}$ & $\mathrm{q}_{\mathrm{e}(\mathrm{mg} / \mathrm{g})}$ & $\mathrm{k}$ \\
\hline GP & $1^{\text {st }}$-order & 14.74 & 15.33 & 0.015 \\
\hline$" 1$ & $2^{\text {nd }}$-order & " & 19.85 & $7.05 \mathrm{e}^{-04}$ \\
\hline $\mathrm{GP} / 10 \% \mathrm{Cu}_{2} \mathrm{O}$ & $1^{\text {st }}$-order & 14.05 & 13.59 & 0.026 \\
\hline " " & $2^{\text {nd }}$-order & " & 15.69 & 0.002 \\
\hline $\mathrm{GP} / 20 \% \mathrm{Cu}_{2} \mathrm{O}$ & $1^{\text {st }}$-order & 13.91 & 13.10 & 0.021 \\
\hline " " & $2^{\text {nd }}$-order & $"$ & 16.14 & 0.001 \\
\hline $\mathrm{GP} / 30 \% \mathrm{Cu}_{2} \mathrm{O}$ & $1^{\text {st }}$-order & 14.76 & 15.51 & 0.028 \\
\hline " " & $2^{\text {nd }}$-order & $"$ & 17.73 & 0.001 \\
\hline
\end{tabular}

\subsubsection{Dye adsorption isotherms under dark conditions}

The relationship between the amount of solute adsorbed and the concentration of the solution in the liquid phase at a given constant temperature can be described by an adsorption isotherm. As described in Section 3.16.3, three isotherm equations commonly used to describe adsorption isotherms are the Langmuir isotherm (eq. 31), which assumes that the adsorption process occurs at specific homogeneous sites within the adsorbent, ${ }^{178}$ the Freundlich isotherm (eq. 32) which is an empirical equation used to describe heterogeneous systems, and the Langmuir-Freundlich isotherm (eq. 33) which provides a more flexible analytical modelling framework by use of a three-parameter equation that can give a better fit to the data.

Figure 4.16 (a-c) shows the experimental MB adsorption data for the geopolymer matrix, and all the geopolymer/ $\mathrm{Cu}_{2} \mathrm{O}$ composites fitted to the Langmuir and Langmuir-Freundlich equations. When the present dye adsorption data were fitted to these three isotherm equations, the goodness of fit, evidenced by the $\mathrm{R}^{2}$ values, varies with the amount of $\mathrm{Cu}_{2} \mathrm{O}$ in the composite (Table 4.2), those composites containing 20 and 30 wt $\% \mathrm{Cu}_{2} \mathrm{O}$ being well described by all three isotherms. The fit of these composite compositions to the Langmuir isotherm suggests that at these high $\mathrm{Cu}_{2} \mathrm{O}$ contents, adsorption of the dye is occurring on 
specific sites which are associated with the oxide itself. At lower concentrations of $\mathrm{Cu}_{2} \mathrm{O}$, the Freundlich isotherm does not fit the data as well as the empirical Langmuir and LangmuirFreundlich isotherms, suggesting that adsorption in these composites is not occurring by a single identifiable mechanism. The plots of the data (Figure 4.16) indicate that the more empirical Langmuir-type isotherms are in general the most appropriate to describe the absorption of the dye on the geopolymer and geopolymer composites.

Table 4.2. Calculated isotherm parameters for MB adsorption on samples

\begin{tabular}{|c|c|c|c|}
\hline \multicolumn{4}{|c|}{ Freundlich equation $\left(q=k C^{n}\right)$} \\
\hline & & $\mathrm{n}$ & $\mathrm{R}^{2}$ \\
\hline \multicolumn{2}{|l|}{ GP-Dark } & 2.9 & 0.85 \\
\hline \multicolumn{2}{|l|}{ GP-Cu-10\%-Dark } & 1.22 & 0.80 \\
\hline \multicolumn{2}{|l|}{ GP-Cu-20\%-Dark } & 2.40 & 0.95 \\
\hline \multicolumn{2}{|l|}{ GP-Cu-30\%-Dark } & 2.52 & 0.97 \\
\hline \multicolumn{4}{|c|}{ Langmuir-Freundlich Equation $\left(q=\left(Q_{s k C} /\left(1+k C^{n}\right)\right)\right.$} \\
\hline & $\mathrm{Qs}(\mathrm{mg} / \mathrm{g})$ & $\mathrm{n}$ & $\mathrm{R}^{2}$ \\
\hline GP-Dark & 0.94 & 3.68 & 0.97 \\
\hline GP-Cu-10\%-Dark & 0.97 & 2.29 & 0.98 \\
\hline GP-Cu-20\%-Dark & 1.08 & 2.94 & 0.96 \\
\hline GP-Cu-30\%-Dark & 1.02 & 1.42 & 0.99 \\
\hline \multicolumn{4}{|c|}{ Langmuir Equation $\left(q=\left(Q_{s k C} /(1+k C)\right)\right.$} \\
\hline & \multicolumn{2}{|c|}{ Qs $(\mathrm{mg} / \mathrm{g})$} & $\mathrm{R}^{2}$ \\
\hline GP-Dark & \multicolumn{2}{|c|}{1.18} & 0.90 \\
\hline GP-Cu-10\%-Dark & \multicolumn{2}{|c|}{1.27} & 0.79 \\
\hline GP-Cu-20\%-Dark & \multicolumn{2}{|c|}{1.77} & 0.91 \\
\hline GP-Cu-30\%-Dark & \multicolumn{2}{|c|}{1.06} & 0.99 \\
\hline
\end{tabular}




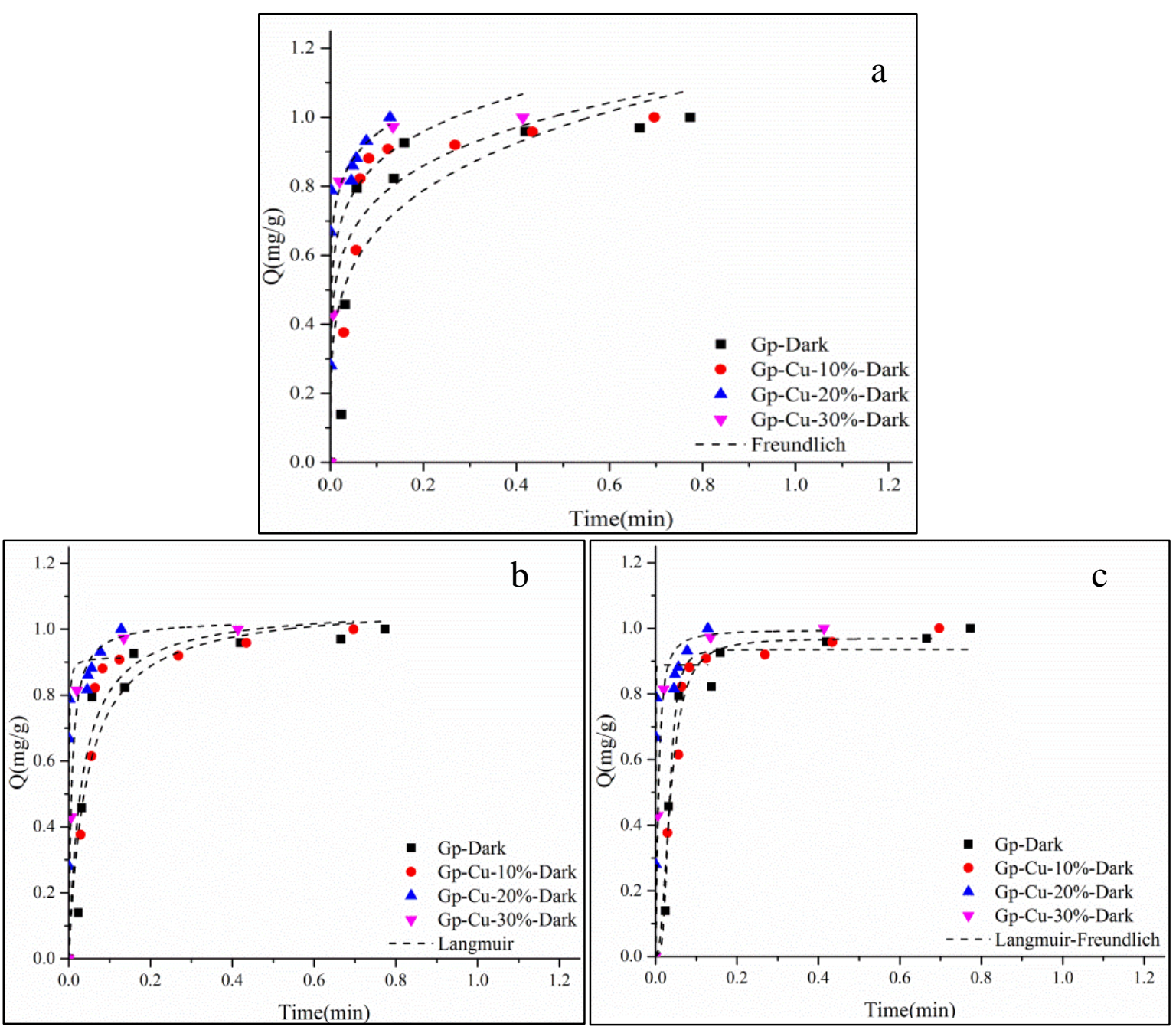

Figure 4.16. (a) adsorption isotherms for MB adsorption and the corresponding Langmuir, (b-c) adsorption isotherms for MB adsorption and the corresponding Freundlich and Langmuir-Freundlich models fits (dashed lines)

\subsubsection{Reactions under UV irradiation}

Figure 4.17 shows MB removal under UV irradiation by the geopolymer containing different amounts of added $\mathrm{Cu}_{2} \mathrm{O}$. Changes in the UV-vis spectra of the dye solutions at different reaction times are presented in Figure 4.17(a-d). 


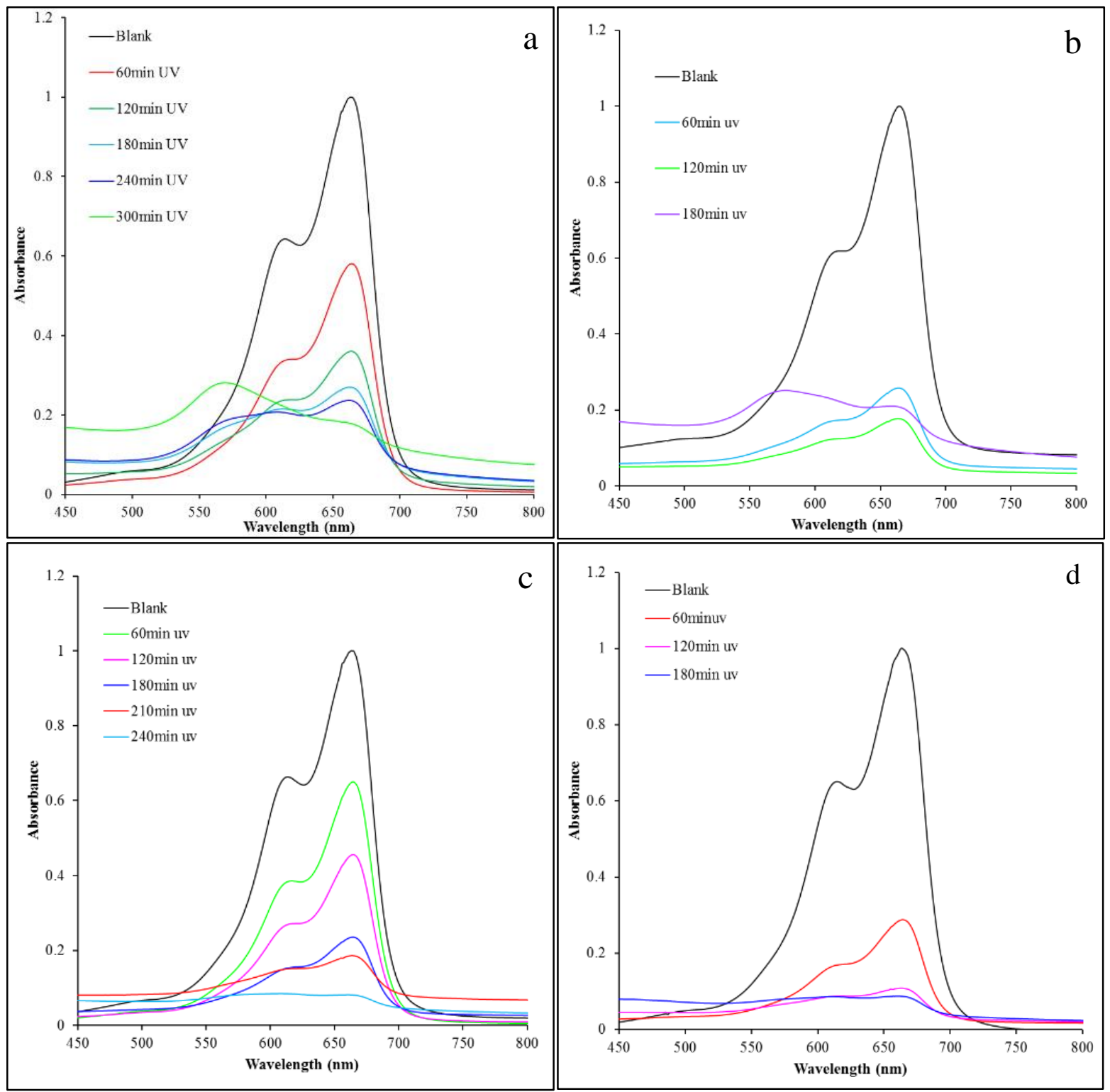

Figure 4.17.The UV-vis absorption spectra of the $\mathrm{MB}$ solution during the photocatalytic degradation in the presence of (a) GP, (b) GP-10 wt $\% \mathrm{Cu}_{2} \mathrm{O}$, (c) GP-20 wt\% $\mathrm{Cu}_{2} \mathrm{O}$, (d) GP$30 \mathrm{wt} \% \mathrm{Cu}_{2} \mathrm{O}$ under UV light irradiation.

As shown in Figure 4.17, when the dye solution in the presence of the photocatalyst materials was exposed to UV irradiation, it was degraded within $120 \mathrm{~min}$. with a maximum degradation rate of $100 \%$ in the presence of the geopolymer containing $10 \% \mathrm{Cu}_{2} \mathrm{O}$. The color of the $\mathrm{MB}$ dye changed from dark blue to colorless, confirming its photodestruction. The degree of degradation was $77 \%, 79 \%$ and $98 \%$ for the geopolymer matrix, and the geopolymer containing $20 \%$ and $30 \% \mathrm{Cu}_{2} \mathrm{O}$ respectively. In the reference geopolymer the UV peak was not completely removed but with increasing the reaction time it shifted to a lower wavelength. 
The two processes operating in the decoloration of the MB dye under UV irradiation can be seen in Figure4.18. which illustrates the difference between the behavior of the geopolymer matrix and the composite containing $30 \mathrm{wt} \% \mathrm{Cu}_{2} \mathrm{O}$ in the dark and under $\mathrm{UV}$ illumination. The geopolymer matrix behaves essentially similarly in dark and UV conditions, showing the adsorption of the dye but no evidence of photoactive properties, as would be expected. By contrast, the $\mathrm{Cu}_{2} \mathrm{O}$-containing composite is more efficient in removing the dye, due to a combination of the adsorption and photodegradation processes.

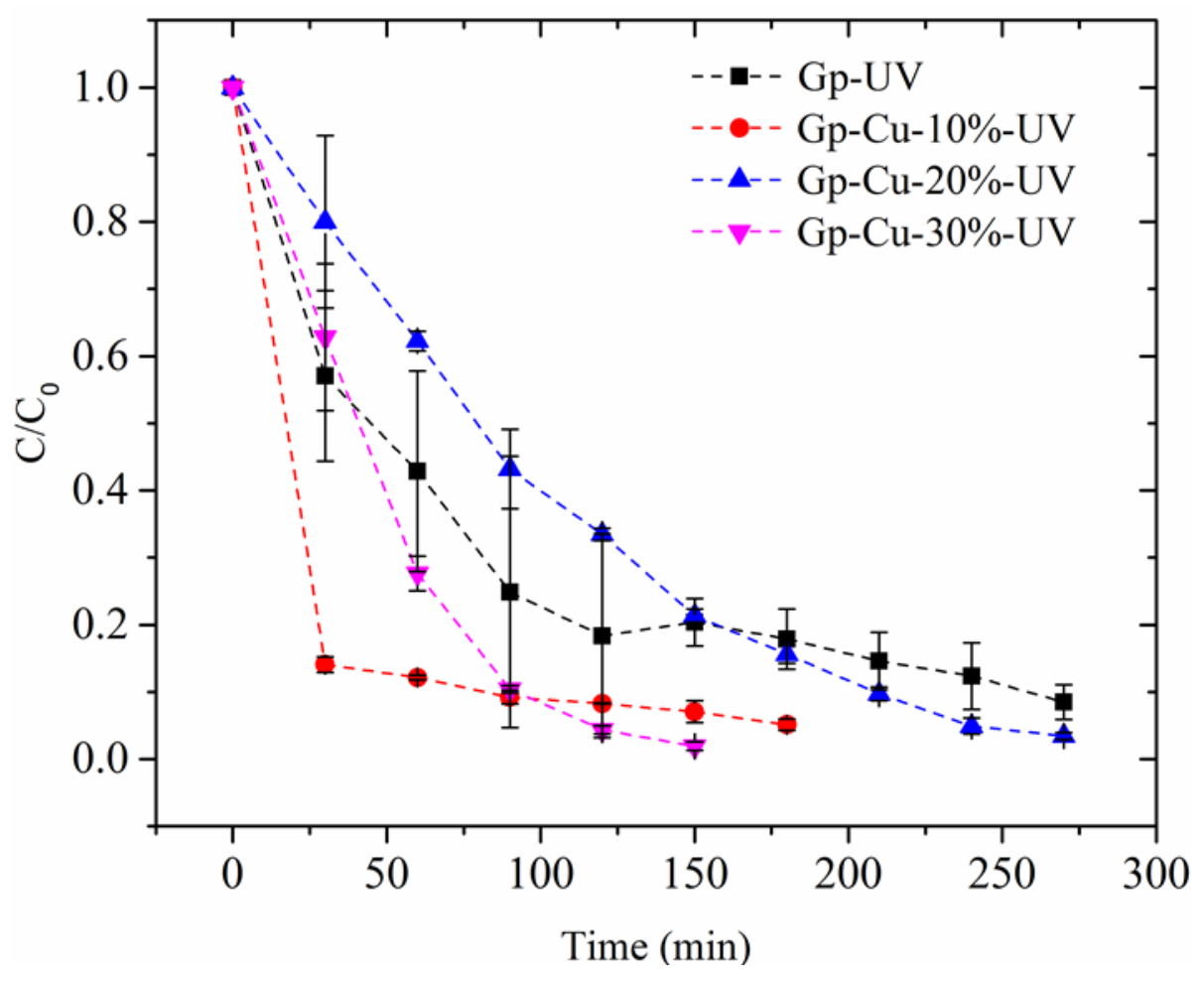

Figure 4.18. Plots of the residual concentration $\left(\mathrm{C} / \mathrm{C}_{0}\right)$ vs. time $(\mathrm{t})$ onto the $\mathrm{GP}, \mathrm{Cu}_{2} \mathrm{O}-\mathrm{GP}$ $10,20,30 \mathrm{wt} \%$. (monitored at $664 \mathrm{~nm}$ under UV)

After adsorption or photodegradation of the $\mathrm{MB}$, the structures of the geopolymer matrix and the $\mathrm{Cu}_{2} \mathrm{O}$ /geopolymer composites are essentially unchanged, according to their XRD patterns (Figure 4.1, purple line). The photoactive $\mathrm{Cu}_{2} \mathrm{O}$ itself is unaffected by exposure to the $\mathrm{MB}$, either in the dark or under UV irradiation, as evidenced by ${ }^{63} \mathrm{Cu} \mathrm{NQR}$ spectroscopy (Figure $4.10 \mathrm{~b}, \mathrm{~d})$. Thus, these composites should continue to remove organic substances from their immediate environment by a combination of adsorption and photodegradation without deterioration of their structure or of the photoactive component. Figure 4.19 shows the 
combined adsorption and photodegradation processes of the MB dye under UV irradiation in the composite containing $30 \mathrm{wt} \% \mathrm{Cu}_{2} \mathrm{O}$. The geopolymer matrix should behave essentially similarly in dark and UV conditions, adsorbing the dye but should show no evidence of photoactive degradation. By contrast, the $\mathrm{Cu}_{2} \mathrm{O}$-containing composite is more efficient in removing the dye due to the combination of adsorption and photodegradation processes.

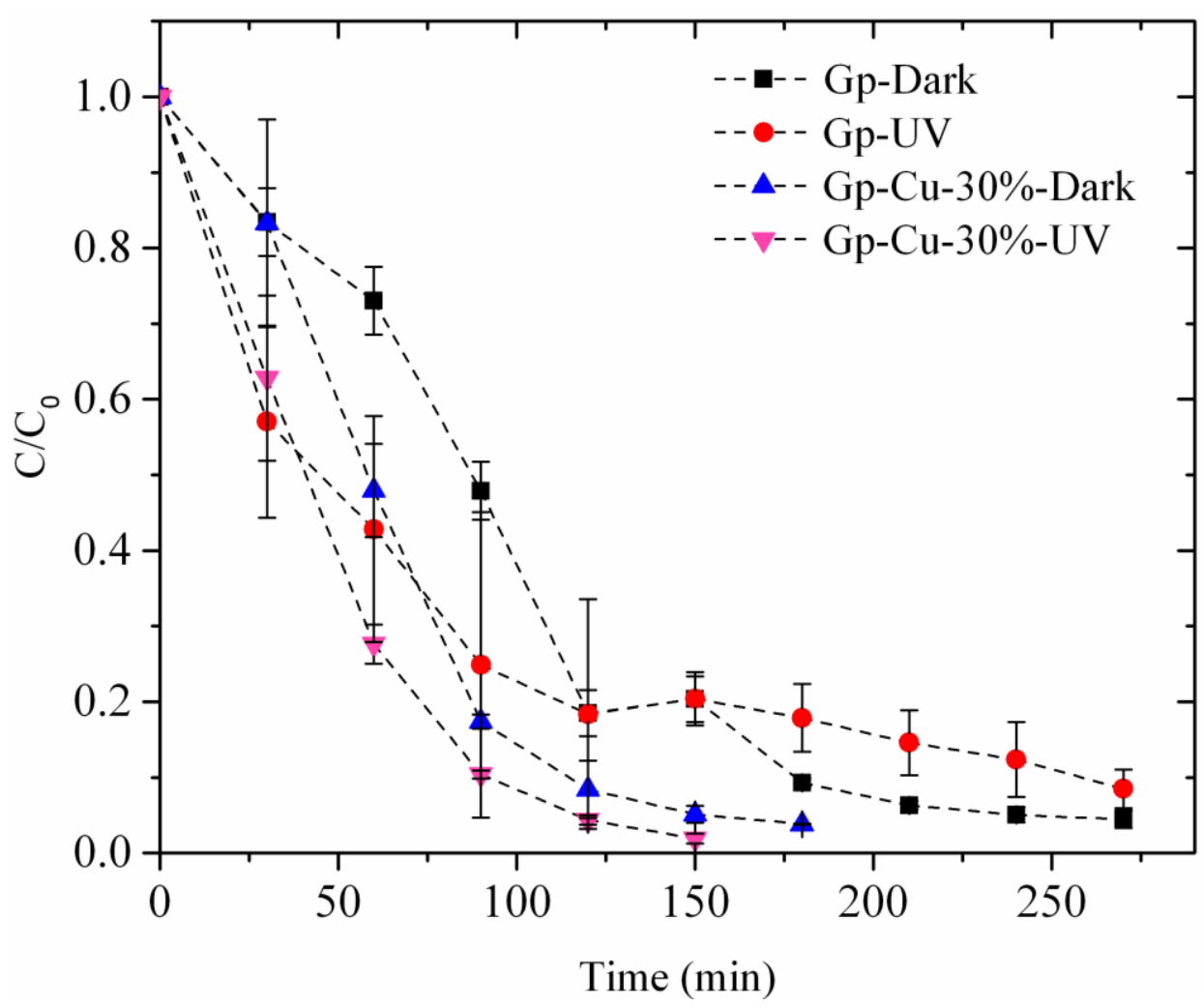

Figure 4.19. Residual concentration $\left(\mathrm{C} / \mathrm{C}_{0}\right)$ of $M B$ upon exposure to the $\mathrm{GP}$ matrix $(\mathrm{GP})$ and the $30 \mathrm{wt} \% \mathrm{Cu}_{2} \mathrm{O}$ GP composite versus time in the dark and under UV illumination.

Figure 4.20 compares the removal of $\mathrm{MB}$ by the composites after $60 \mathrm{~min}$. The geopolymer matrix and $\mathrm{Cu}_{2} \mathrm{O}$ itself in the dark and under UV irradiation, showing the ability of the samples to eliminate MB from the aqueous solution under UV irradiation by a combination of adsorption and photodegradation. ${ }^{150}$ It was found that only about $10 \% \mathrm{MB}$ is removed in the dark by $\mathrm{Cu}_{2} \mathrm{O}$ alone, indicating that $\mathrm{Cu}_{2} \mathrm{O}$ by itself only weakly adsorbs $\mathrm{MB}$, by comparison with the geopolymer matrix alone, which removes about $40 \% \mathrm{MB}$ within $30 \mathrm{~min}$. More than $54 \%$ of the $\mathrm{MB}$ was removed within $60 \mathrm{~min}$. with the addition of $10 \% \mathrm{Cu}_{2} \mathrm{O}$ to the geopolymer, this number changing to $66 \%$ and $83 \%$ for composites containing $20 \%$ and 30 wt $\% \mathrm{Cu}_{2} \mathrm{O}$ respectively. This confirms the result that the $\mathrm{MB}$ is strongly adsorbed from its 
aqueous solution by the geopolymer matrix, and is then degraded by the $\mathrm{Cu}_{2} \mathrm{O}$ photoactive component in the composites.

Under both dark conditions and UV irradiation, the colour of the geopolymer matrix becomes progressively bluer due to adsorption of the MB. However, a similar observation was not recorded for the geopolymer composites, since their yellowish-brown color obscured any other changes in colour due to the presence of MB.

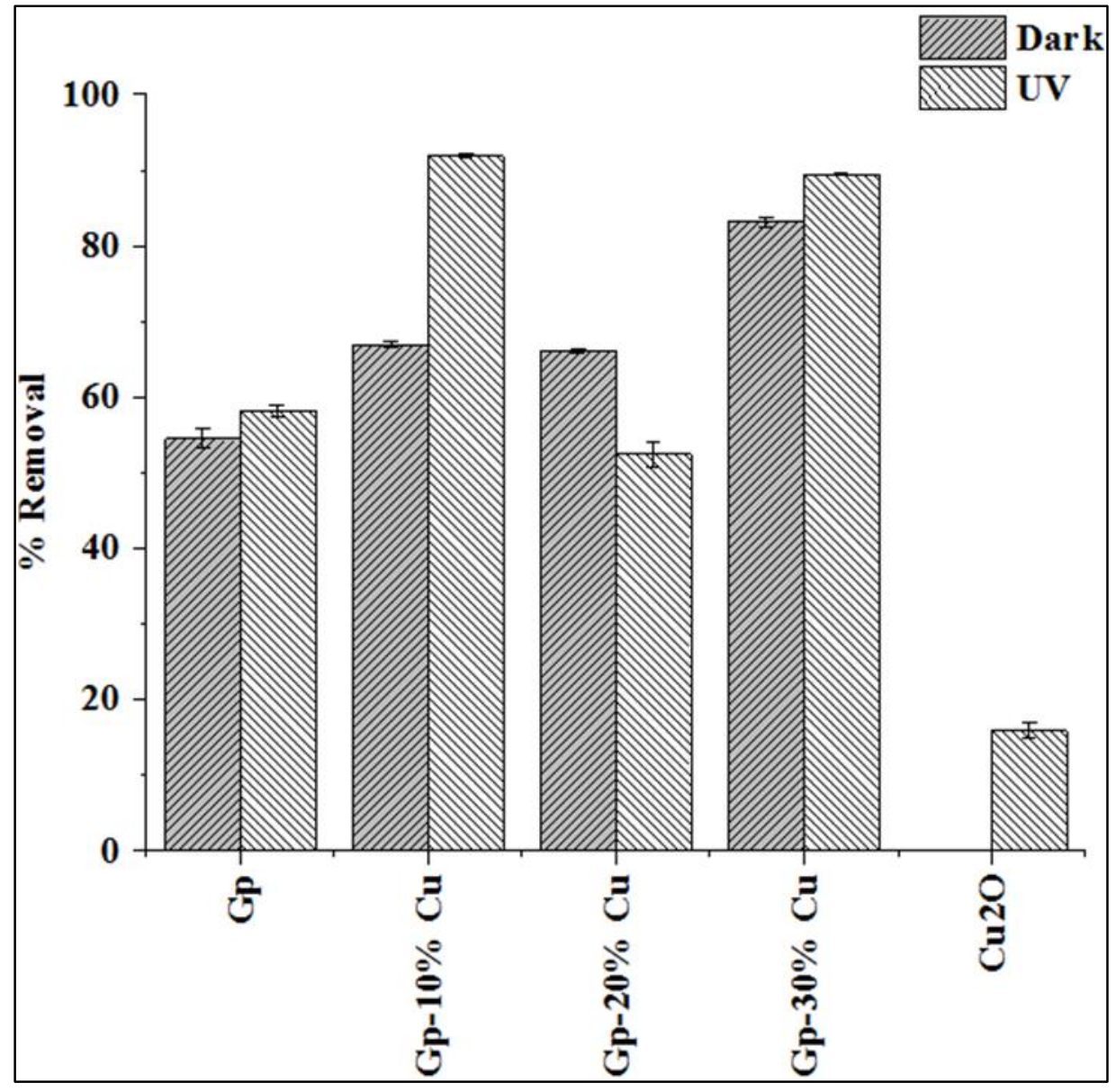

Figure 4.20. Comparison of $\mathrm{MB}$ removal in the dark and under UV irradiation by the GP matrix, GP-(10-30 wt\%) $\mathrm{Cu}_{2} \mathrm{O}$ composites and $\mathrm{Cu}_{2} \mathrm{O}$ after 60 min. reaction.

\section{Conclusions}

This chapter describes the successful synthesis of cubic $\mathrm{Cu}_{2} \mathrm{O}$ nanoparticles and their incorporation into aluminosilicate geopolymer matrices. The homogeneity of the oxide nanoparticle dispersion within the geopolymer matrix was demonstrated by SEM/EDS and TEM. Other experimental techniques (XRD, FTIR, ${ }^{27} \mathrm{Al}$ and ${ }^{29} \mathrm{Si}$ MAS NMR and ${ }^{63} \mathrm{Cu}$ NQR spectroscopy) confirmed the formation of a well-reacted geopolymer matrix with a structure that was unaffected by the insertion of the $\mathrm{Cu}_{2} \mathrm{O}$ nanoparticles, or by the adsorption or 
photodegradation of a model organic compound (MB, chosen for its color stability at high $\mathrm{pH})$.

Experiments to determine the photodegradation of MB dye by these composites showed that the solid/dye interaction occurs by two processes, namely, adsorption by the matrix (in the dark) and photodegradation (under UV irradiation). Since the adsorption process in the dark did not come to equilibrium, conventional photodegradation experiments were not possible, but the dye adsorption step, monitored by experiments in the dark, were found to follow pseudo first-order kinetics. The adsorption data were fitted to adsorption isotherms which depended on the concentration of $\mathrm{Cu}_{2} \mathrm{O}$ present; at higher concentrations (20-30 wt\%) the data were described by Langmuir-type isotherms, whereas at lower concentrations, the empirical Langmuir-Freundlich isotherms were more appropriate. Although the nano- $\mathrm{Cu}_{2} \mathrm{O}$ particles themselves do not adsorb the MB dye, their incorporation of up to $20 \mathrm{wt} \%$ into the geopolymer composites increases their adsorption ability, probably by increasing the porosity of the matrix. At concentrations $>20 \mathrm{wt} \%$, the oxide decreases the adsorption by blocking the active adsorption sites of the geopolymer. Under UV radiation, the composites remove the MB by a combination of adsorption and photodegradation, evidenced by a more rapid dye removal by comparison with the adsorption process alone. The combined adsorption/photodegradation process occurs without deterioration of the geopolymer structure or the photoactive $\mathrm{Cu}_{2} \mathrm{O}$ component, confirming the original premise that these geopolymer composites should function as efficient new materials for the removal of organic pollutants from water or the atmosphere. 


\section{Chapter 5}

\section{Synthesis, characterization and photoactive properties of geopolymercomposites with $\mathrm{Cu}_{2} \mathrm{O} / \mathrm{TiO}_{2}$ nano-heterostructures and P25 titania}

\section{Introduction}

In the previous chapter, the feasibility of producing viable composites of geopolymers with $\mathrm{Cu}_{2} \mathrm{O}$ was established and the structures and photoactivity of these products was determined. In this chapter, attention is turned towards improving the photocatalytic performance of the photoactive component by combining the $\mathrm{Cu}_{2} \mathrm{O}$ with another well-known photoactive compound, $\mathrm{TiO}_{2}$. The form of $\mathrm{TiO}_{2}$ that has been found to perform most efficiently as a photocatalyst is a mixture of the anatase and rutile poymorphs, synthesized by an Aerosil process and known commercially as $\mathrm{P} 25$. This material consists of a mixture of $80 \%$ anatase and $20 \%$ rutile, present as a thin layer covering the anatase particles. ${ }^{190}$ The enhanced photocatalytic effect has been suggested to arise from the enhanced space-charge potential resulting from the contact between the two phases; the resulting electron transfer from the anatase to lower-energy electron trapping sites in the rutile reduces the recombination rate in the anatase, improving the efficiency of the electron-hole separation and thus the catalytic activity. ${ }^{190}$ A more recent study using electron paramagnetic resonance spectroscopy suggests that the presence of nanoclusters of rutile crystallites act as transition points for the rapid exchange of electrons to the anatase, ${ }^{191}$ but a study in which the anatase and rutile components of P25 were separated and their individual photocatalytic behavior determined has cast doubt on the role of anatase-rutile interactions. ${ }^{192}$ In the present work we prepared a series of composites of $\mathrm{Cu}_{2} \mathrm{O} / \mathrm{TiO}_{2}$ nano-heterostructures incorporated into an aluminosilicate geopolymer host. The $\mathrm{Cu}_{2} \mathrm{O} / \mathrm{TiO}_{2}$ heterostructures were synthesized as spherical nanocrystals combined with commercial P25 titania as described in chapter 3, Section 3.3. The $\mathrm{Cu}_{2} \mathrm{O}$ particles in this part of the study result from the synthesis method used to prepare the $\mathrm{TiO}_{2} / \mathrm{Cu}_{2} \mathrm{O}$ nano-heterostructures, as described in Chapter 3. The structures of the resulting nanocomposites were characterized by XRD, FTIR, SEM/EDS and HRTEM and the photocatalytic properties of the composites for the destruction of MB were determined as in the previous chapter both in the dark and under UV radiation. For comparison, a corresponding series of samples containing P25 titania only were prepared and studied. 


\section{Results and Discussion}

\subsection{XRD Analysis}

Figure 5.1 shows representative XRD patterns of the starting $\mathrm{Cu}_{2} \mathrm{O} / \mathrm{TiO}_{2}$ and geopolymer composites with different $\mathrm{Cu}_{2} \mathrm{O} / \mathrm{TiO}_{2}$ contents. The geopolymer matrix is typically $\mathrm{x}$-ray amorphous, with superimposed sharp peaks at $26.75^{\circ} 2 \theta$ (quartz) and $21.96^{\circ} 2 \theta$ (cristobalite) arise from as-prepared impurities in the clay starting materials. Figure 5.1 (Purple line) shows that the as-synthesised $\mathrm{Cu}_{2} \mathrm{O}$ contains no other peaks related to $\mathrm{Cu}$ or $\mathrm{CuO}$. The diffraction peaks for $\mathrm{P} 25 \mathrm{TiO}_{2}$ correspond to anatase and rutile. The $\mathrm{Cu}_{2} \mathrm{O} / \mathrm{TiO}_{2}$ heterostructure (Figure 5.1, yellow line) shows the presence of both $\mathrm{Cu}_{2} \mathrm{O}$ and $\mathrm{TiO}_{2}$ with no other impurities. Geopolymer- $\mathrm{Cu}_{2} \mathrm{O} / \mathrm{TiO}_{2}$ composites 10-30 wt\% (Figure 5.1. (Red, blue, and green line) contain all the expected peaks from cubic bcc $\mathrm{Cu}_{2} \mathrm{O}$ (PDF no. 01-073-6237) and the anatase and rutile phases of $\mathrm{P} 25 \mathrm{TiO}_{2}$ confirming the synthesis of $\mathrm{Cu}_{2} \mathrm{O} / \mathrm{TiO}_{2}$. The intensities of the geopolymer quartz reflections decrease with increasing oxide content of the composite but the $\mathrm{Cu}_{2} \mathrm{O}$ and $\mathrm{TiO}_{2}$ intensities remain constant. 


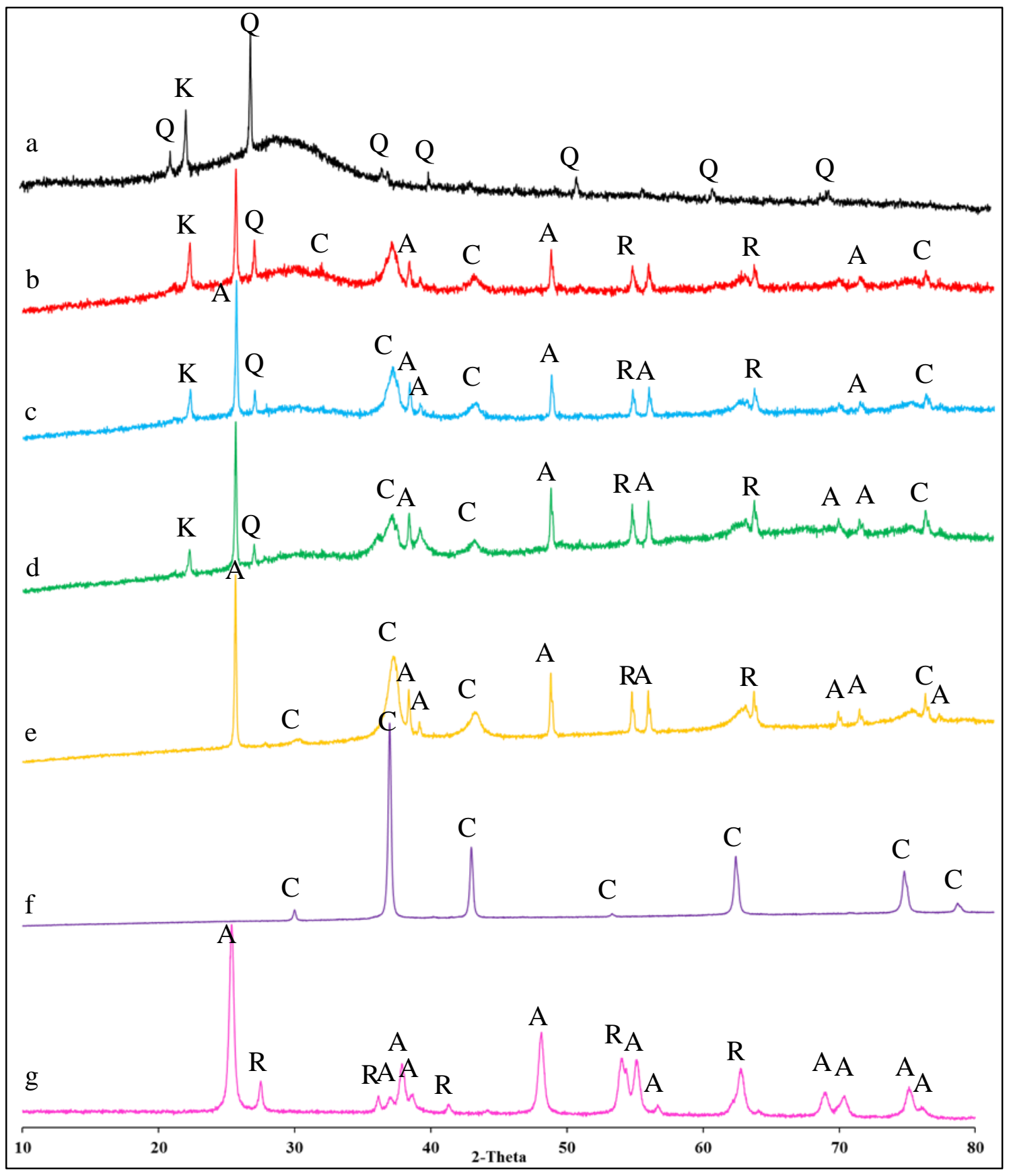

Figure 5.1. XRD patterns of GP and GP composites with different loading contents; (a) GP, (b) $\mathrm{Cu}_{2} \mathrm{O} / \mathrm{TiO}_{2}-\mathrm{GP}$ (10 wt \%), (c) $\mathrm{Cu}_{2} \mathrm{O} / \mathrm{TiO}_{2}-\mathrm{GP}$ (20 wt \%), (d) $\mathrm{Cu}_{2} \mathrm{O} / \mathrm{TiO}_{2}-\mathrm{GP}$ (30 wt \%), (e) $\mathrm{Cu}_{2} \mathrm{O} / \mathrm{TiO}_{2}$, (f) $\mathrm{Cu}_{2} \mathrm{O},(\mathrm{g}) \mathrm{TiO}_{2}(\mathrm{P} 25)$.

Key: $\mathrm{Q}=$ quartz, $\mathrm{K}=$ cristobalite and $\mathrm{A}=\left(\mathrm{TiO}_{2}\right.$-anatase $)$ and $\mathrm{R}=\left(\mathrm{TiO}_{2}\right.$-rutile $)$.

\subsection{Scanning electron microscopy}

The morphology of the $\mathrm{Cu}_{2} \mathrm{O} / \mathrm{TiO}_{2}$ heterostructure (Figure 5.2) shows small interconnected sub-micron spherical $\mathrm{Cu}_{2} \mathrm{O}$ and $\mathrm{TiO}_{2}$ particles (bright spots), the $\mathrm{Cu}_{2} \mathrm{O}$ particles of 200-300 $\mathrm{nm}$ size and the $\mathrm{TiO}_{2}$ particles $25-50 \mathrm{~nm}$ in size (Figure 5.2 (a-c). No obvious aggregation of $\mathrm{TiO}_{2}$ or $\mathrm{Cu}_{2} \mathrm{O}$ is seen in the $\mathrm{Cu}_{2} \mathrm{O} / \mathrm{TiO}_{2}$ sample, suggesting that the $\mathrm{TiO}_{2}$ and $\mathrm{Cu}_{2} \mathrm{O}$ are 
homogenously deposited through the heterostructure. This is confirmed by $\mathrm{Cu}$ and Ti EDXS maps, indicating that both elements are present in the sample with a homogenous distribution. The XRD pattern of the sub-micron $\mathrm{Cu}_{2} \mathrm{O} / \mathrm{TiO}_{2}$ heterostructure (Figure 5.4e) confirms the coexistence of $\mathrm{Cu}_{2} \mathrm{O}$ and the two polymorphs of $\mathrm{TiO}_{2}$ present in $\mathrm{P} 25$.

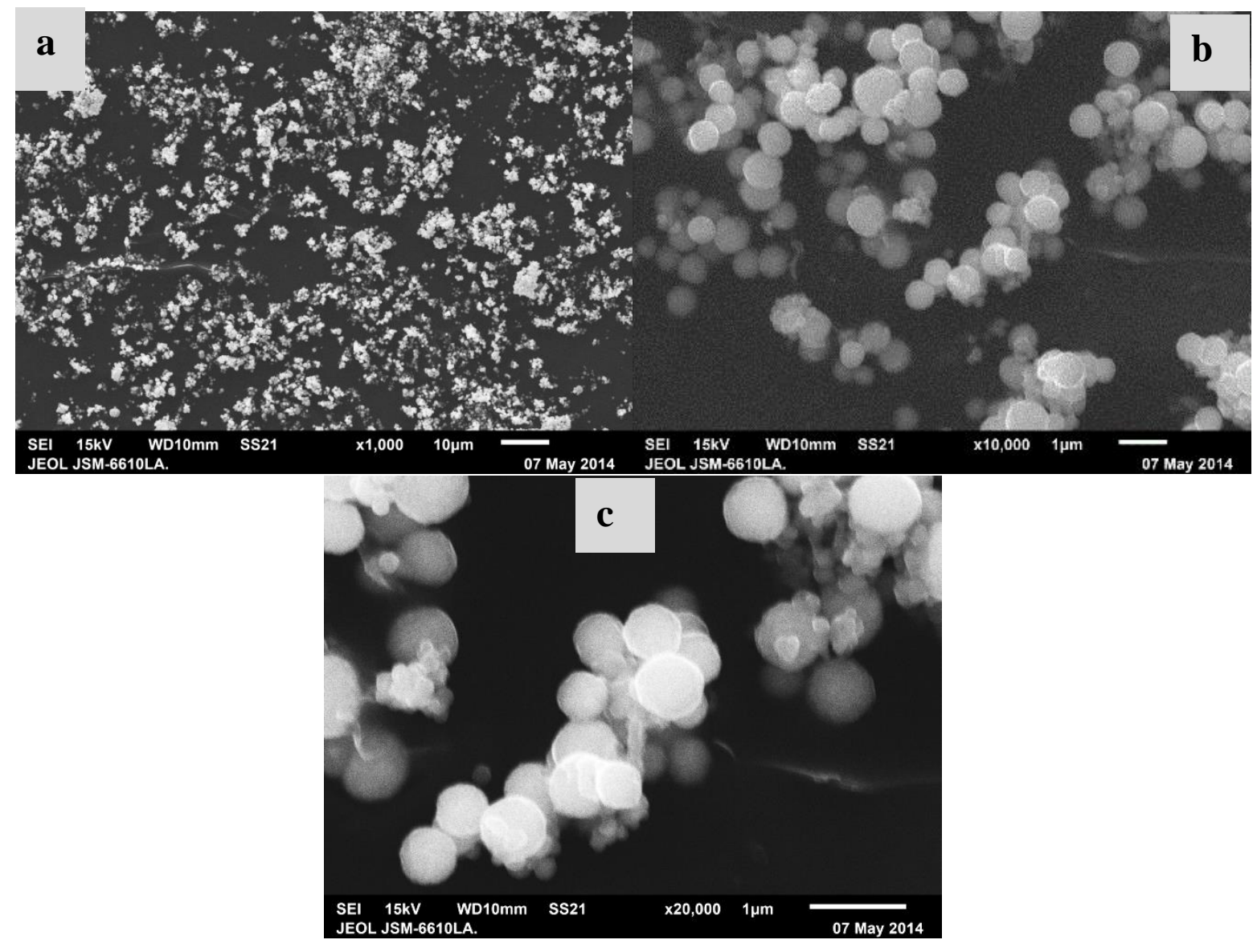

Figure 5.2. (a-c) SEM micrographs of spherical $\mathrm{Cu}_{2} \mathrm{O} / \mathrm{TiO}_{2}$ at different magnifications, synthesized via the procedure described in Chapter 3.

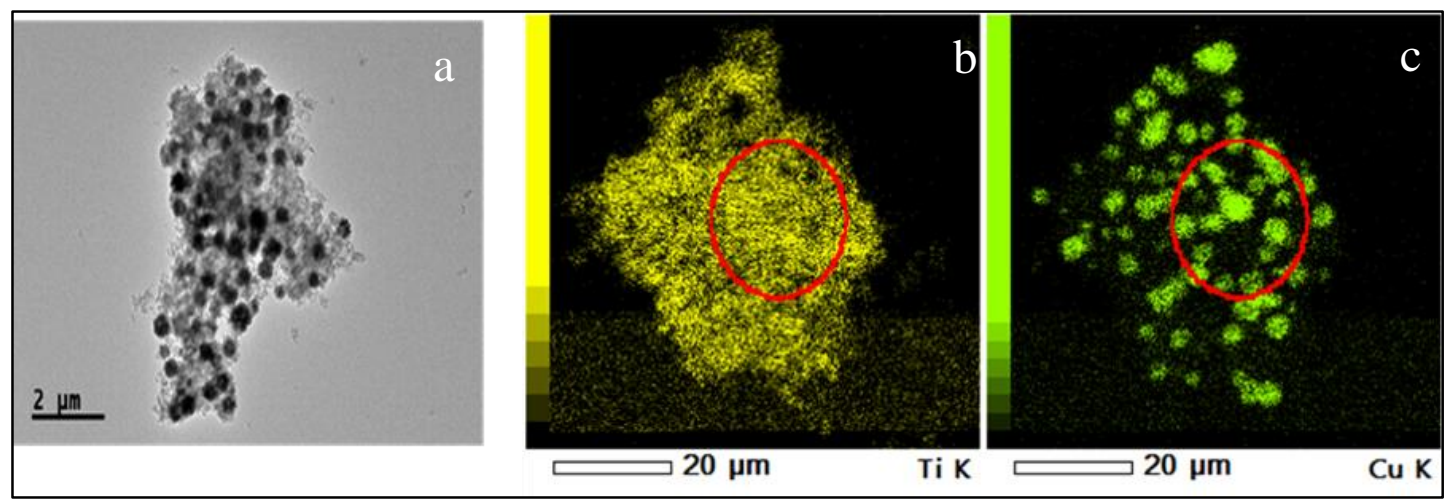

Figure 5.3. (a) STEM image of $\mathrm{Cu}_{2} \mathrm{O} / \mathrm{TiO}_{2}$, with (b, c) corresponding $\mathrm{Cu}$, Ti elemental maps. 


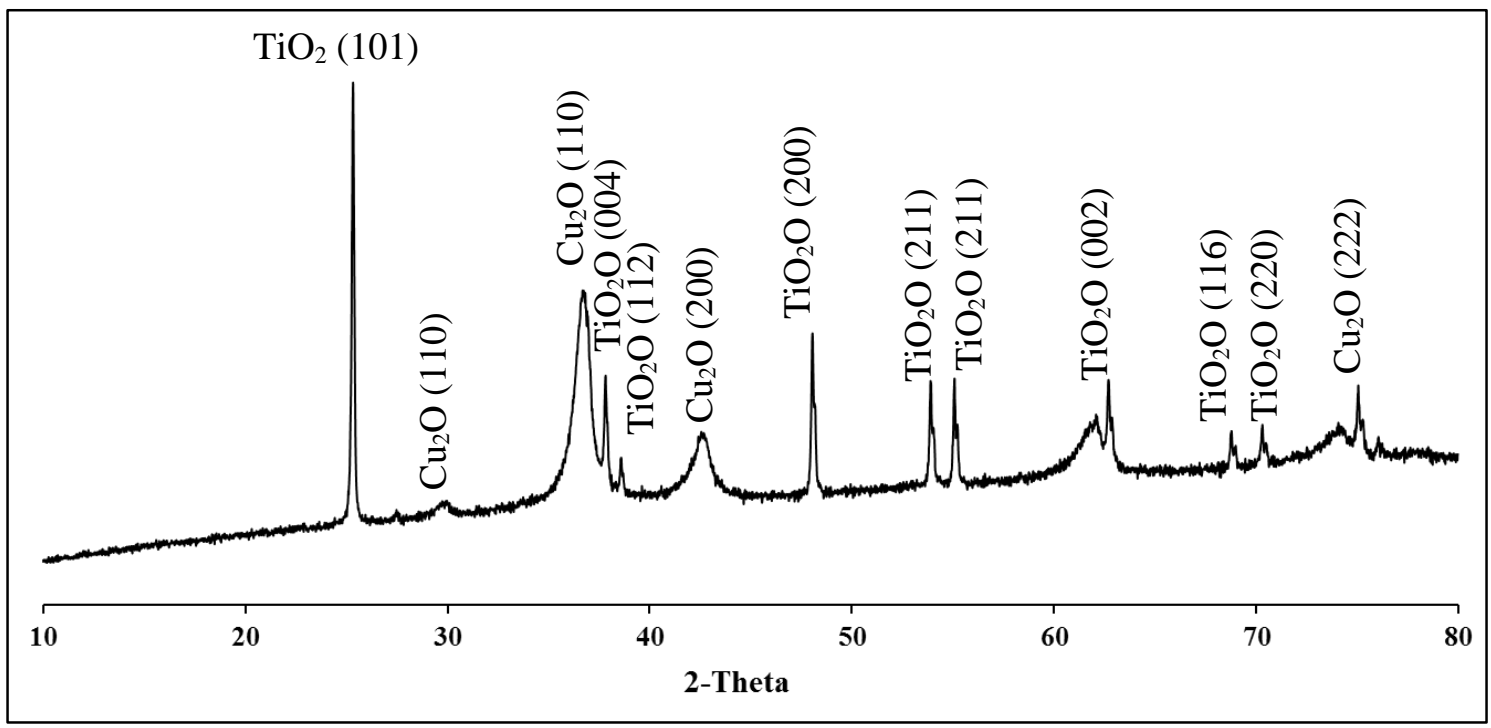

Figure 5.4. XRD pattern of $\mathrm{Cu}_{2} \mathrm{O} / \mathrm{TiO}_{2}$.

The SEM images of the GP composites with a $\mathrm{Cu}_{2} \mathrm{O} / \mathrm{TiO}_{2}$ loading of 10,20 and 30 wt\% (Figure 5.5 (a-c) respectively) show $\mathrm{Cu}_{2} \mathrm{O} / \mathrm{TiO}_{2}$ nanoparticles deposited mainly on the geopolymer surface of the geopolymer matrix.

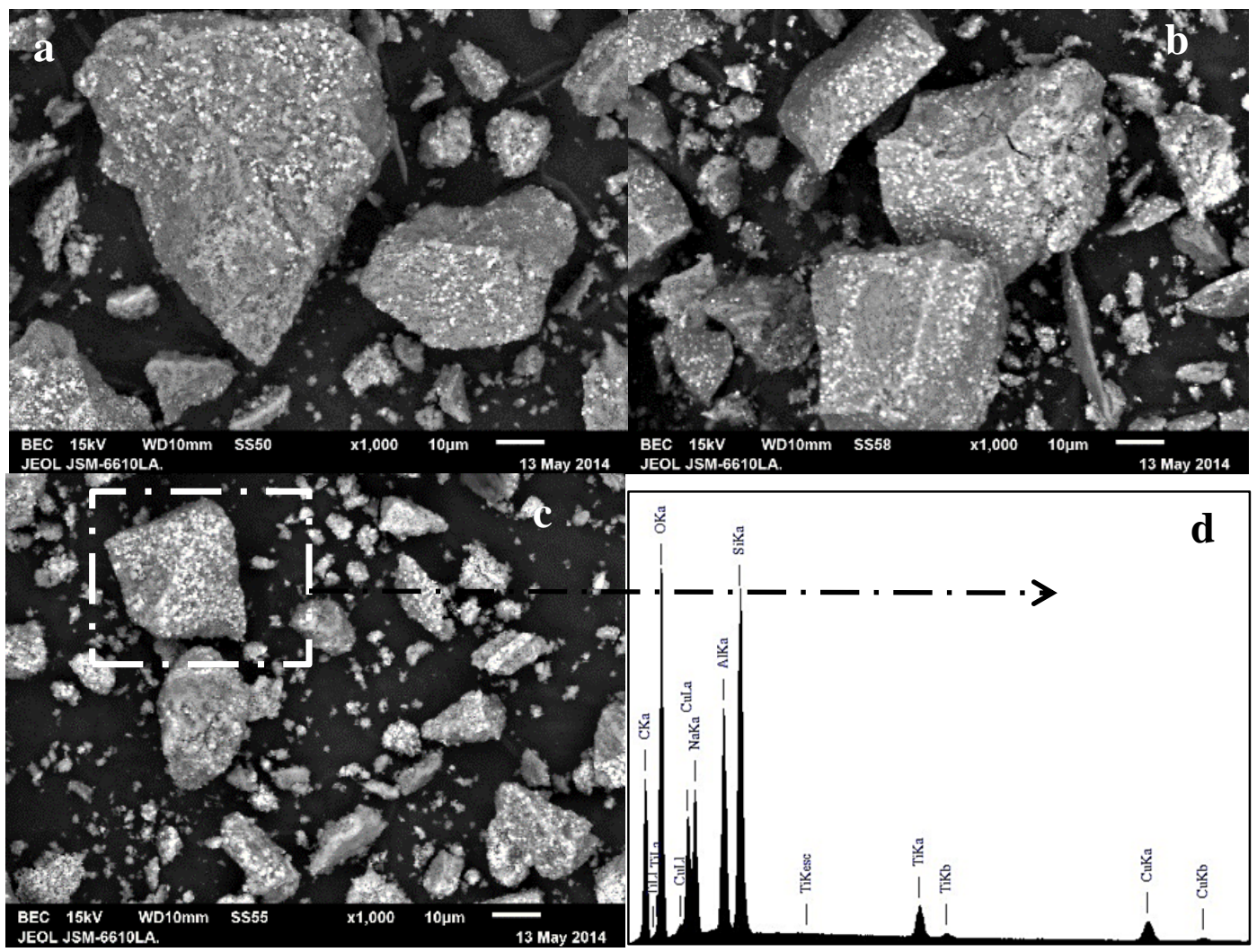

Figure 5.5. Backscattered SEM micrographs of (a) GP-10 wt $\% \mathrm{Cu}_{2} \mathrm{O} / \mathrm{TiO}_{2}$ composite, (b) GP-20 wt $\% \mathrm{Cu}_{2} \mathrm{O} / \mathrm{TiO}_{2}$ composite, (c) GP-30 wt $\% \mathrm{Cu}_{2} \mathrm{O} / \mathrm{TiO}_{2}$ composite, (d) EDS element spectra of the indicated area of image. 
EDS elemental map of the GP- $30 \mathrm{wt} \% \mathrm{Cu}_{2} \mathrm{O} / \mathrm{TiO}_{2}$ composite (Figure 5.6) shows the expected presence of $\mathrm{Si}, \mathrm{Al}, \mathrm{Na}, \mathrm{Ti}$ and $\mathrm{Cu}$. The lighter spherical regions signify the presence of $\mathrm{Cu}_{2} \mathrm{O} / \mathrm{TiO}_{2}$ throughout the geopolymer matrix and which is evidenced by the $\mathrm{Cu}$ and $\mathrm{Ti}$ elemental maps.

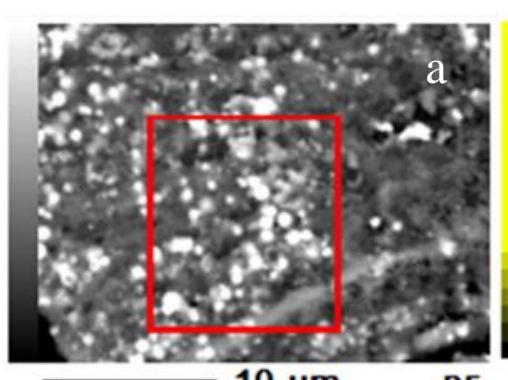

$10 \mu \mathrm{m}$

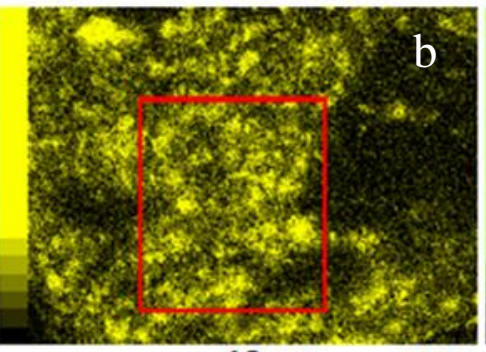

$10 \mu \mathrm{m}$

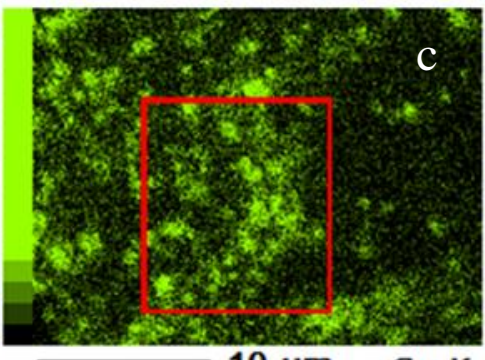

$10 \mu \mathrm{m} \quad \mathrm{Cu} \mathrm{K}$

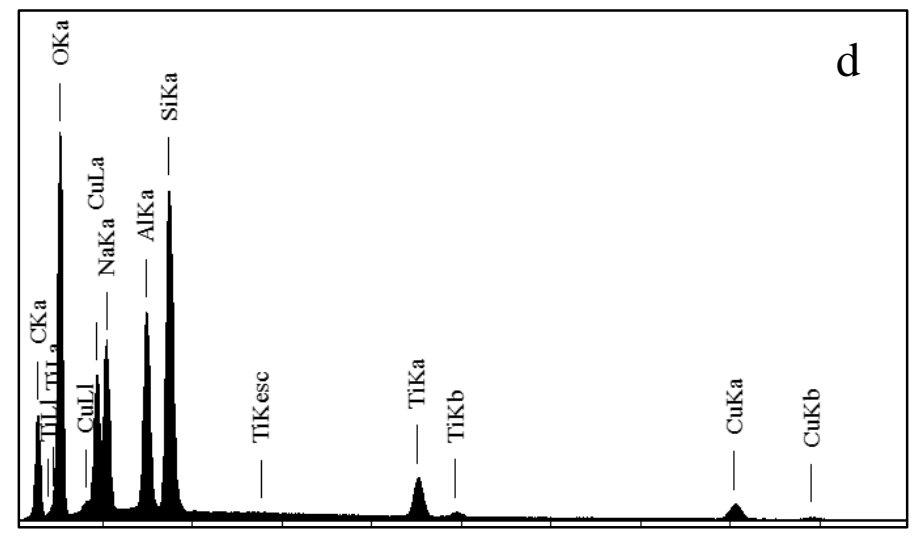

Figure 5.6. (a) Backscattered SEM image of ground GP-30 wt $\% \mathrm{Cu}_{2} \mathrm{O} / \mathrm{TiO}_{2}$ and (b) $\mathrm{Ti}$, (c) $\mathrm{Cu}$, EDS maps, (d) EDS element spectra of the indicated area of image.

\subsection{High-Resolution Transmission Electron Microscopy}

Figure 5.7 is a series of lower magnification and higher magnification TEM micrographs of the $\mathrm{GP}-10 \% \mathrm{Cu}_{2} \mathrm{O} / \mathrm{TiO}_{2}$ sample. In the low magnification image (Figure 5.7a) small dark spots are observed evenly dispersed though a lighter matrix. It is assumed that the lighter matrix is the GP and the small grains are either the $\mathrm{TiO}_{2}$ or the $\mathrm{Cu}_{2} \mathrm{O}$. From initial grain size analysis (Figure 5.2) there appears to be a bimodal grain size distribution, the $\mathrm{TiO}_{2}$ being considerably smaller than the $\mathrm{Cu}_{2} \mathrm{O}$ grains $(200-300 \mathrm{~nm})$.

To confirm that both $\mathrm{TiO}_{2}$ and $\mathrm{Cu}_{2} \mathrm{O}$ are present, HRTEM images were acquired (Figure 5.7 b). Image analysis from this HRTEM confirms a d-spacing of 0.22 and $0.45 \mathrm{~nm}$ in two different regions which corresponds to the $\mathrm{Cu}_{2} \mathrm{O}$ (200) and $\mathrm{TiO}_{2}$ (110) respectively. Both these grains are smaller than $20 \mathrm{~nm}$ in size. As these grains are small, and as the GP is reacted 
after the nanoparticles have been added, it is proposed that the nanoparticles are not only present on the sample surface (as observed in SEM), but also dispersed throughout the GP bulk.
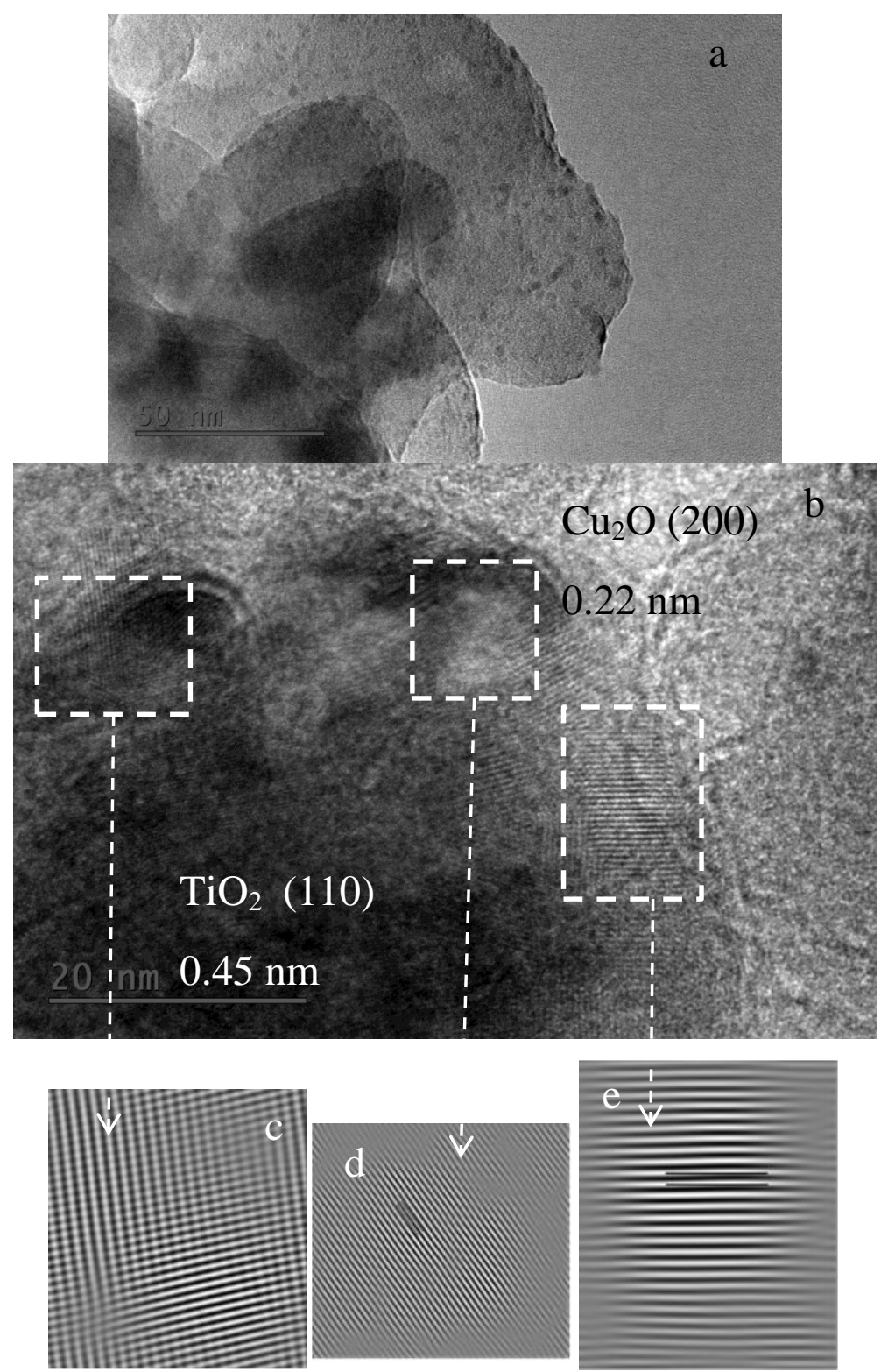

Figure 5.7. (a,b) TEM images of GP-10\%-Cu $2 \mathrm{O} / \mathrm{TiO}_{2}$ composite, (c-e) HRTEM image of a selected area in (b). 


\subsection{FTIR spectroscopy}

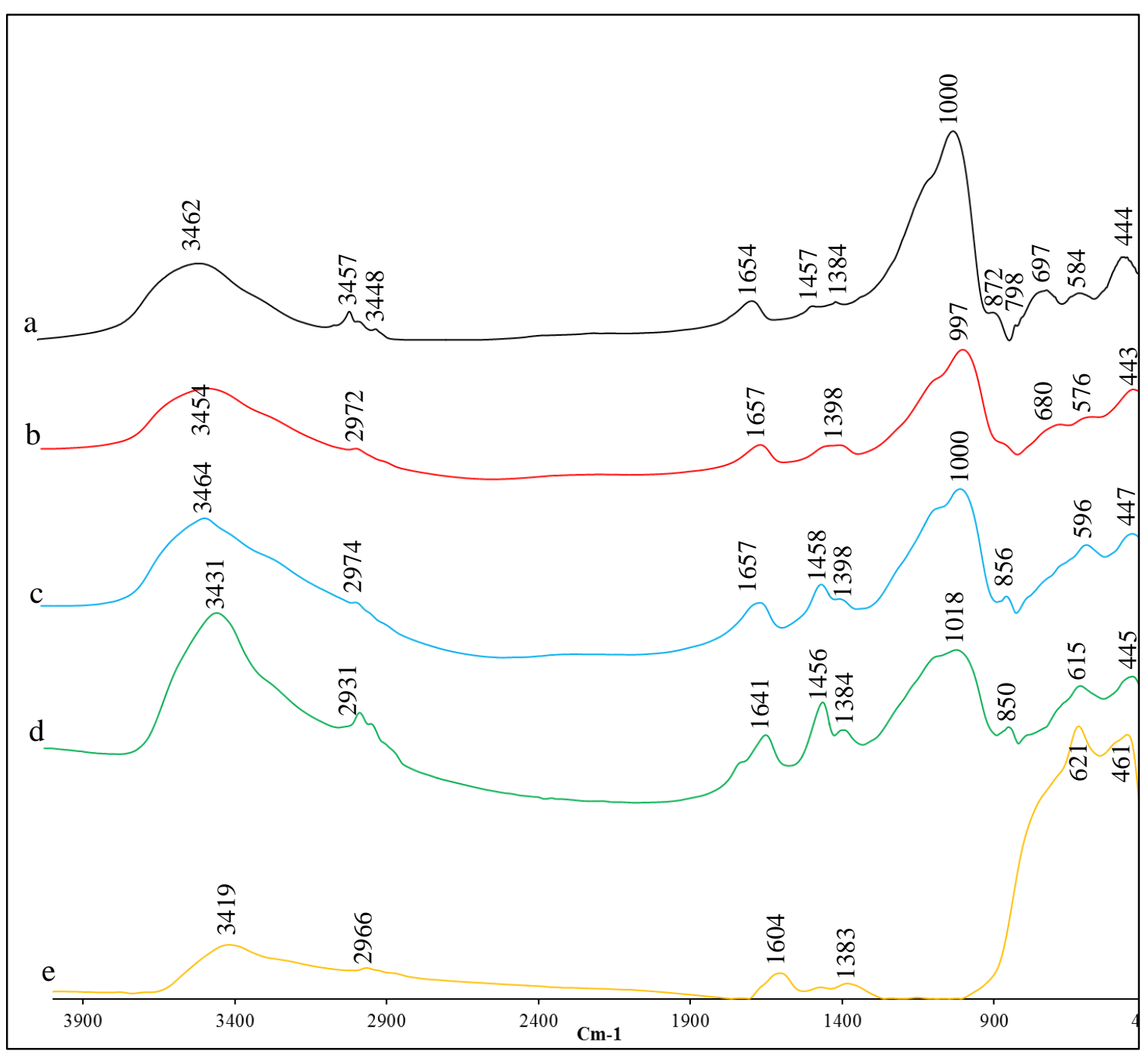

Figure 5.8. FTIR spectra of (a) GP matrix, (b) GP-10 wt \% $\mathrm{Cu}_{2} \mathrm{O} / \mathrm{TiO}_{2}$, (c) GP-20 wt \% $\mathrm{Cu}_{2} \mathrm{O} / \mathrm{TiO}_{2}$, (d) $\mathrm{GP}-30$ wt $\% \mathrm{Cu}_{2} \mathrm{O} / \mathrm{TiO}_{2}$, (e) $\mathrm{Cu}_{2} \mathrm{O} / \mathrm{TiO}_{2}$

The FTIR spectra of these samples (Figure 5.8) show a principal band in the region 997-1018 $\mathrm{cm}^{-1}$ arising from the $\mathrm{Si}-\mathrm{O}-\mathrm{Si}$ and $\mathrm{Si}-\mathrm{O}-\mathrm{Al}$ asymmetric stretching vibrations. ${ }^{123}$ The $(\mathrm{H}-\mathrm{O}-\mathrm{H})$ bending and $(\mathrm{OH})$ stretching bands at 1641-1657 and 3431-3462 $\mathrm{cm}^{-1}$ respectively indicate that the geopolymer retains absorbed water following polycondensation of the $(\mathrm{OH})$ groups. ${ }^{185}$ Addition of 10 and $20 \mathrm{wt} \% \mathrm{Cu}_{2} \mathrm{O} / \mathrm{TiO}_{2}$ to the geopolymer causes a small shift in the position of the asymmetric $\mathrm{Si}-\mathrm{O}-\mathrm{Si}$ stretching vibration at $1000 \mathrm{~cm}^{-1}$ and a reduction in the intensity of this band. At lower wave numbers, the Si-O-Si bands of the geopolymer matrix are observed at $444 \mathrm{~cm}^{-1}$ and $798 \mathrm{~cm}^{-1}$ (Si-O-Si symmetric stretching mode), while other significant asymmetric bands appear at $576-615 \mathrm{~cm}^{-1}$ in the $\mathrm{Cu}_{2} \mathrm{O} / \mathrm{TiO}_{2}$ composites; these probably arise from the superposition of $\mathrm{Cu} / \mathrm{Ti}-\mathrm{O}-\mathrm{Cu} / \mathrm{Ti}$, since they progressively shift 
from 576 to $615 \mathrm{~cm}^{-1}$ with the addition of $10 \mathrm{wt} \%$ to $30 \mathrm{wt} \%$ of $\mathrm{Cu} / \mathrm{Ti}$ to the nanocomposites. These spectra are consistent with a conventional geopolymer matrix in which the $\mathrm{Cu}_{2} \mathrm{O} / \mathrm{TiO}_{2}$ heterostructure has not significantly distorted the matrix structure.

\subsection{Adsorption of MB}

\subsubsection{Reactions under dark conditions (adsorption on the matrix)}

As described in the previous chapter, an identical series of experiments on the removal of $\mathrm{MB}$ dye was carried out using these $\mathrm{Cu}_{2} \mathrm{O} / \mathrm{TiO}_{2}$ composites. As concluded from the results of the previous chapter, the geopolymer matrix should be an efficient absorbers of organic dyes in its own right since its surface hydroxyl groups can attract and hold cationic organic species. ${ }^{178}$ As in the experiments of chapter 4, the adsorption of MB on the composites was monitored by measuring the decolorization of the MB dye under dark conditions (Figure 5.9). Incorporation of $10 \mathrm{wt} \% \mathrm{Cu}_{2} \mathrm{O} / \mathrm{TiO}_{2}$ nanoparticles into the geopolymer matrix results in a significant slowing of the rate of dye adsorption (Figure 5.9), probably because of blocking of the adsorption sites by the non-adsorbing oxide particles as was the case with $\mathrm{Cu}_{2} \mathrm{O}$ alone. However, this effect is reversed by the addition of larger concentrations of $\mathrm{Cu}_{2} \mathrm{O} / \mathrm{TiO}_{2}$ (Figure5.9), suggesting that the $\mathrm{Cu}_{2} \mathrm{O} / \mathrm{TiO}_{2}$ heterostructures are now acting to open up the geopolymer matrix structure, facilitating access of the dye to the internal adsorption sites. 


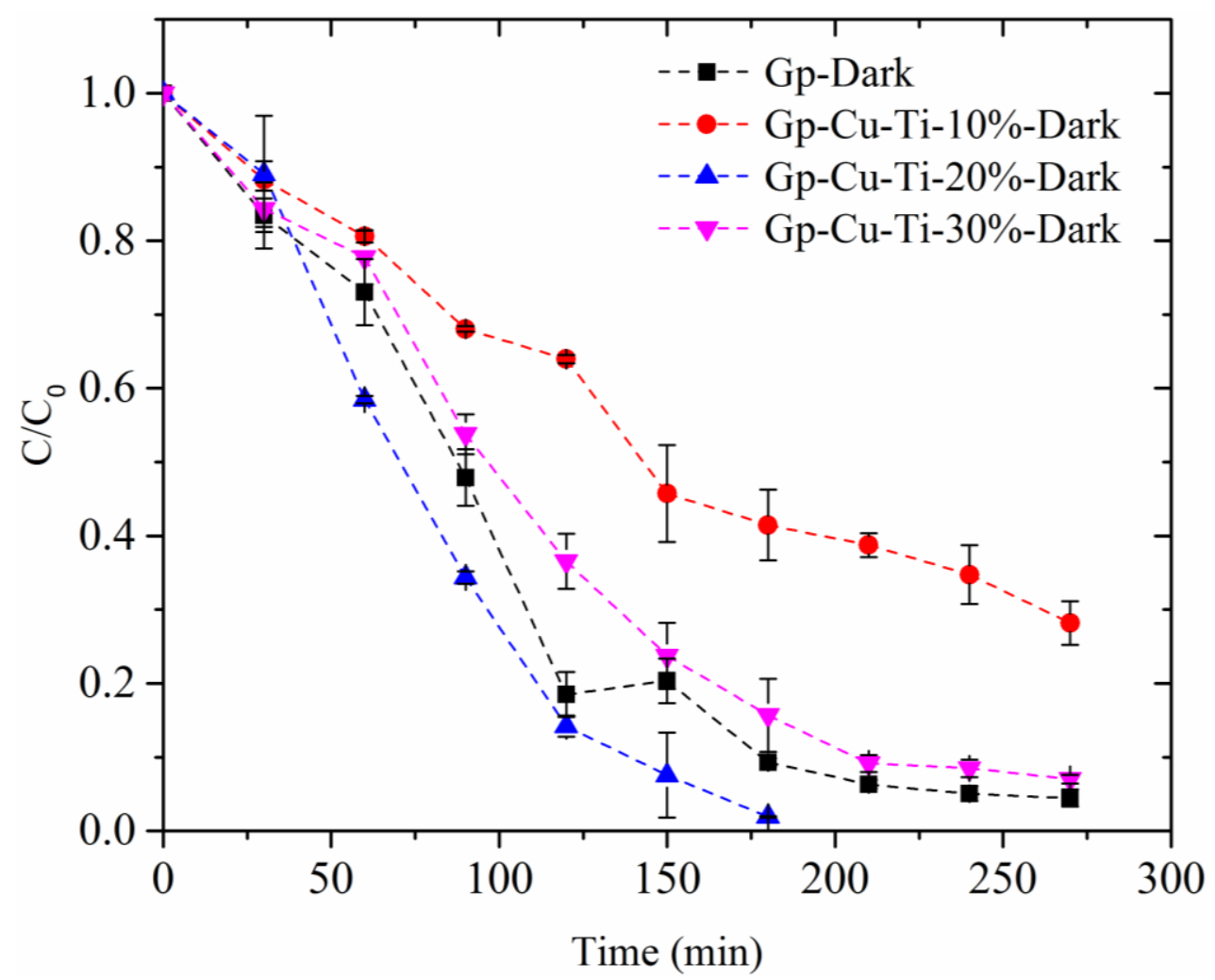

Figure 5.9. Plot of the residual concentration $\left(\mathrm{C} / \mathrm{C}_{0}\right)$ vs. time $(\mathrm{t})$ on the $\mathrm{GP}, \mathrm{Cu}_{2} \mathrm{O} / \mathrm{TiO}_{2}-\mathrm{GP}$ 10,20 , and $30 \mathrm{wt} \%$ (monitored at $664 \mathrm{~nm}$ ) under dark conditions.

Following the procedure outlined in the previous chapter, the MB adsorption data were fitted to pseudo-first order and pseudo-second-order models (equations 29 and 30 respectively in chapter 3). ${ }^{181,182}$ The resulting plots of $q$ versus time ( $t$ ) for the adsorption of MB on these adsorbents are presented in Figure $5.10(\mathrm{a}, \mathrm{b})$. Comparison of the $\mathrm{q}_{\mathrm{e}}$ values calculated from these equations with the experimental values of $\mathrm{q}_{\exp }$ (Table 5.1) shows that for all the samples the pseudo-first order model provides a better fit to the experimental data. Apart from the 10 $\% \mathrm{Cu}_{2} \mathrm{O} / \mathrm{TiO}_{2}$ geopolymer composite, which has already been noted as being less absorptive for MB dye, the first-order rate constants (Table 5.1) are very similar, as are the correlation coefficients $\mathrm{R}^{2}$ for both the pseudo-first order and pseudo-second order models. 

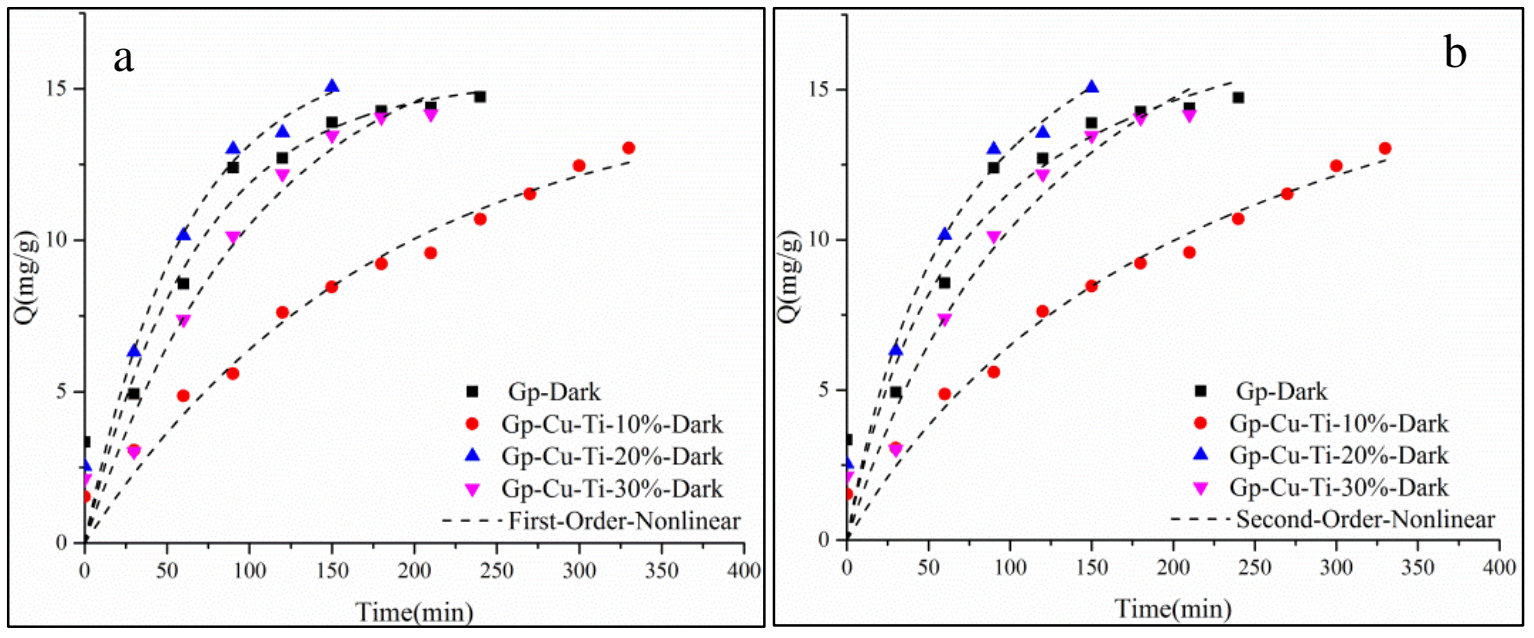

Figure 5.10. (a) Pseudo first-order kinetics and (b) Pseudo second-order kinetics by the nonlinear method and experimental kinetics for the adsorption of $\mathrm{MB}$ on the geopolymer matrix and geopolymer composites containing $\mathrm{Cu}_{2} \mathrm{O} / \mathrm{TiO}_{2}$ heterostructures.

Table 5.1. Kinetic parameters for adsorption of $\mathrm{MB}$ under dark conditions by geopolymer composites with $\mathrm{Cu}_{2} \mathrm{O} / \mathrm{TiO}_{2}$

\begin{tabular}{|c|c|c|c|c|c|}
\hline Sample & Kinetic model & $\mathrm{q}_{\exp (\mathrm{mg} / \mathrm{g})}$ & $\mathrm{q}_{\mathrm{e}(\mathrm{mg} / \mathrm{g})}$ & $\mathrm{k}$ & $\mathrm{R}^{2}$ \\
\hline GP & $1^{\text {st }}$-order & 14.74 & 15.33 & 0.015 & 0.90 \\
\hline " & $2^{\text {nd }}$-order & " & 19.85 & $7.05 \mathrm{e}^{-04}$ & 0.89 \\
\hline $\mathrm{GP} / 10 \% \mathrm{Cu}_{2} \mathrm{O} / \mathrm{TiO}_{2}$ & $1^{\text {st }}$-order & 14.76 & 14.92 & 0.006 & 0.97 \\
\hline " & $2^{\text {nd }}$-order & " & 21.56 & $2.00 \mathrm{e}^{-04}$ & 0.97 \\
\hline $\mathrm{GP} / 20 \% \mathrm{Cu}_{2} \mathrm{O} / \mathrm{TiO}_{2}$ & $1^{\text {st }}$-order & 14.76 & 16.23 & 0.016 & 0.93 \\
\hline " & $2^{\text {nd }}$-order & " & 22.31 & $6.24 \mathrm{e}^{-04}$ & 0.93 \\
\hline $\mathrm{GP} / 30 \% \mathrm{Cu}_{2} \mathrm{O} / \mathrm{TiO}_{2}$ & $1^{\text {st }}$-order & 14.76 & 17.13 & 0.010 & 0.95 \\
\hline$" 1$ & $2^{\text {nd }}$-order & " & 25.43 & $2.71 \mathrm{e}^{-04}$ & 0.94 \\
\hline
\end{tabular}

\subsubsection{MB dye adsorption isotherms under dark conditions}

As in the previous chapter, the experimental MB adsorption data determined under dark conditions were fitted to the Freundlich, Langmuir and Langmuir-Freundlich isotherms (equations 31-33 in chapter 3). ${ }^{17,} 178$ The resulting plots of the data are shown in Figure 5.11 $\mathrm{a}, \mathrm{b}$ and $\mathrm{c}$ respectively. The correlation coefficient $\left(\mathrm{R}^{2}\right)$ of all these fits for the geopolymer- 
$10 \% \mathrm{Cu}_{2} \mathrm{O} / \mathrm{TiO}_{2}$ composite is $>0.98$, indicating that the adsorption of $\mathrm{MB}$ by this composite can be described equally well by all three isotherms; however, the $\mathrm{R}^{2}$ values for all the composites fitted by all three isotherms are satisfactorily high (0.90-0.99), suggesting that the most appropriate isotherm cannot be identified from a consideration of the $\mathrm{R}^{2}$ values alone. The slightly better adsorption characteristics of the geopolymer- $10 \% \mathrm{Cu}_{2} \mathrm{O} / \mathrm{TiO}_{2}$ composite are consistent with the differences already noted between the adsorption behaviour of the geopolymer- $10 \% \quad \mathrm{Cu}_{2} \mathrm{O} / \mathrm{TiO}_{2}$ composite and those containing higher $\mathrm{Cu}_{2} \mathrm{O} / \mathrm{TiO}_{2}$ concentrations.

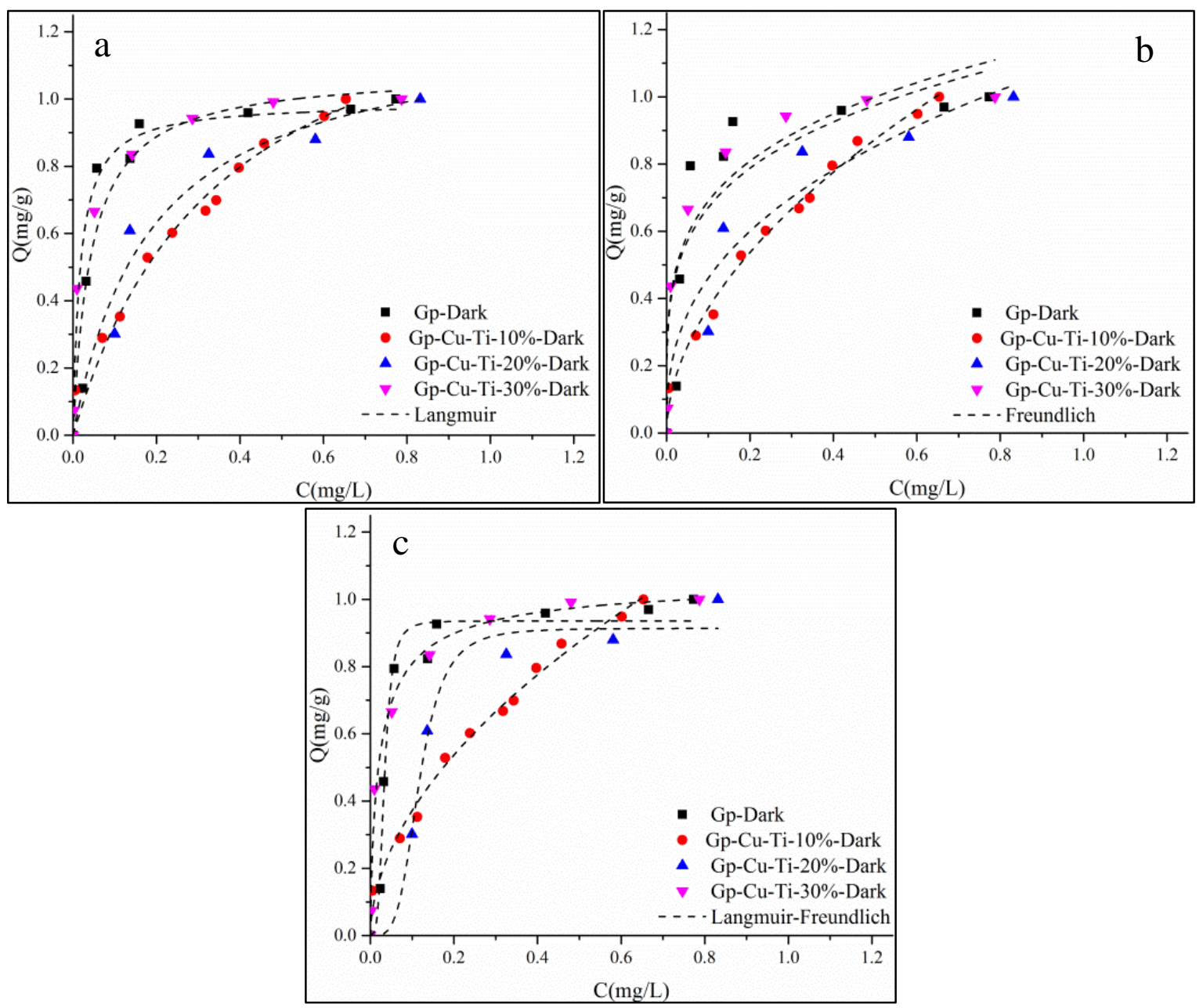

Figure 5.11. (a-c). Adsorption isotherms for MB adsorption and the corresponding Langmuir, Freundlich and Langmuir-Freundlich models fit (dashed lines). 


\subsubsection{Reactions under UV radiation}

As discussed in Chapter 4, the decolouration of MB dye under UV radiation shown in Figure 5.12 was determined in a separate series of experiments in which fresh MB solutions were mixed with fresh composite samples and immediately exposed to UV irradiation. As with the composites containing only $\mathrm{Cu}_{2} \mathrm{O}$ (Chapter 4), removal of the dye is due to a combination of adsorption and photodegradation processes and should therefore be more rapid than in the dark. Comparison of Figure 5.12 with the process in the dark (Figure 5.9) shows this to be the case, particularly in the geopolymer- $20 \% \mathrm{Cu}_{2} \mathrm{O} / \mathrm{TiO}_{2}$ composite, in which the destruction of the MB is markedly faster than in the dark.

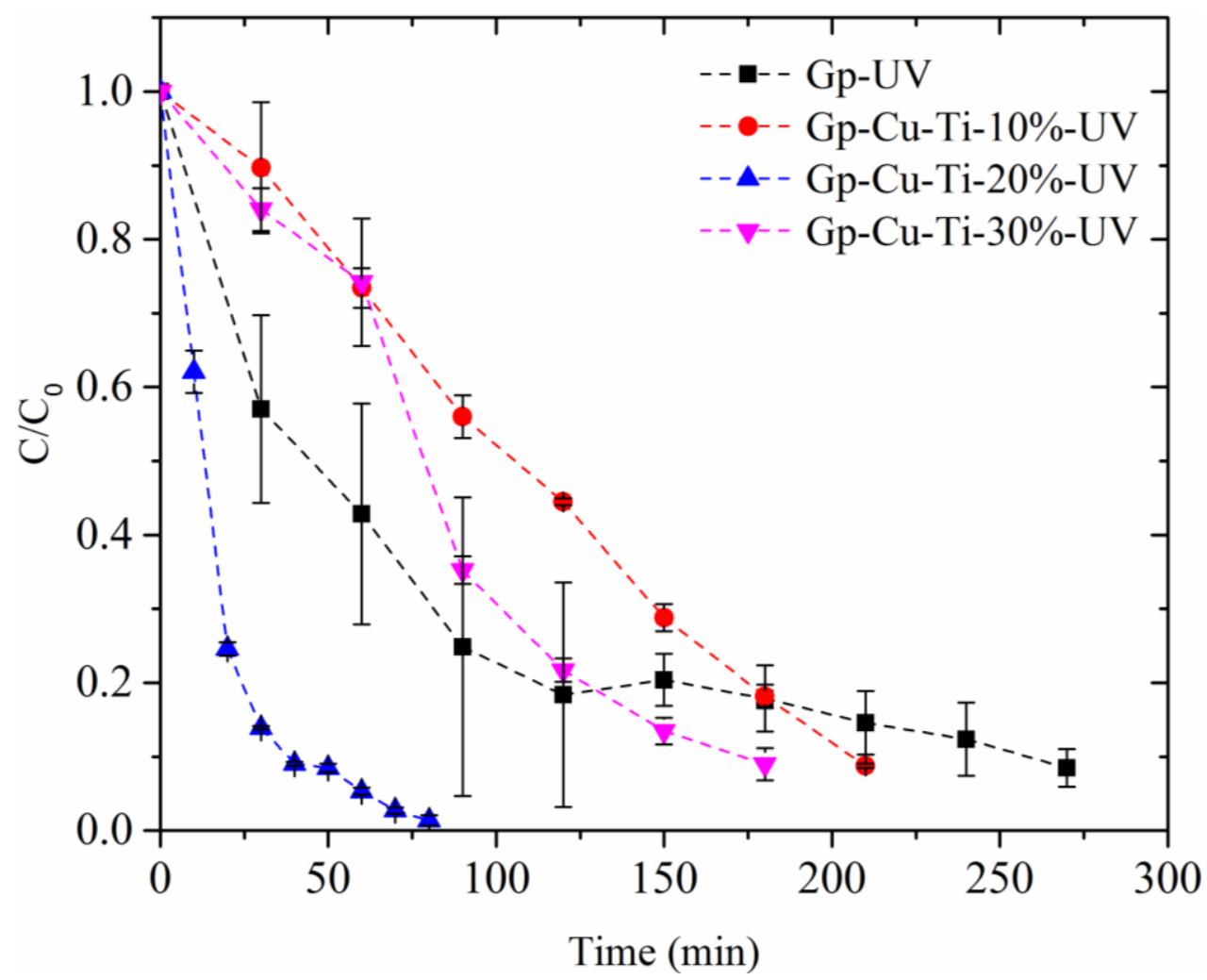

Figure 5.12. Plots of the residual concentration $\left(\mathrm{C} / \mathrm{C}_{0}\right)$ vs. time $(\mathrm{t})$ on the $\mathrm{GP}$ matrix and $\mathrm{Cu}_{2} \mathrm{O} / \mathrm{TiO}_{2}-\mathrm{GP} 10,20$, and $30 \mathrm{wt} \%$ composites (monitored at $664 \mathrm{~nm}$ ) under UV irradiation.

Figure 5.13, which compares the behavior of the all the materials towards MB in the dark and under UV radiation after 60 min., clearly shows the expected increase in photodegradation with increasing $\mathrm{Cu}_{2} \mathrm{O} / \mathrm{TiO}_{2}$ content of the composites, with $98 \%$ dye removal achieved by the geopolymer- $20 \% \mathrm{Cu}_{2} \mathrm{O} / \mathrm{TiO}_{2}$ composite in this time interval. The photodegradation properties of the $\mathrm{Cu}_{2} \mathrm{O} / \mathrm{TiO}_{2}$ component alone are not as marked as those of the composites, since these results represent a combination of adsorption and photodegradation, and this component of the composites does not adsorb the dye (Figure 5.13). The response of the geopolymer 
matrix to the MB is similar under both dark conditions and UV radiation, suggesting that irradiation has little effect on the dye adsorption characteristics of the geopolymer.

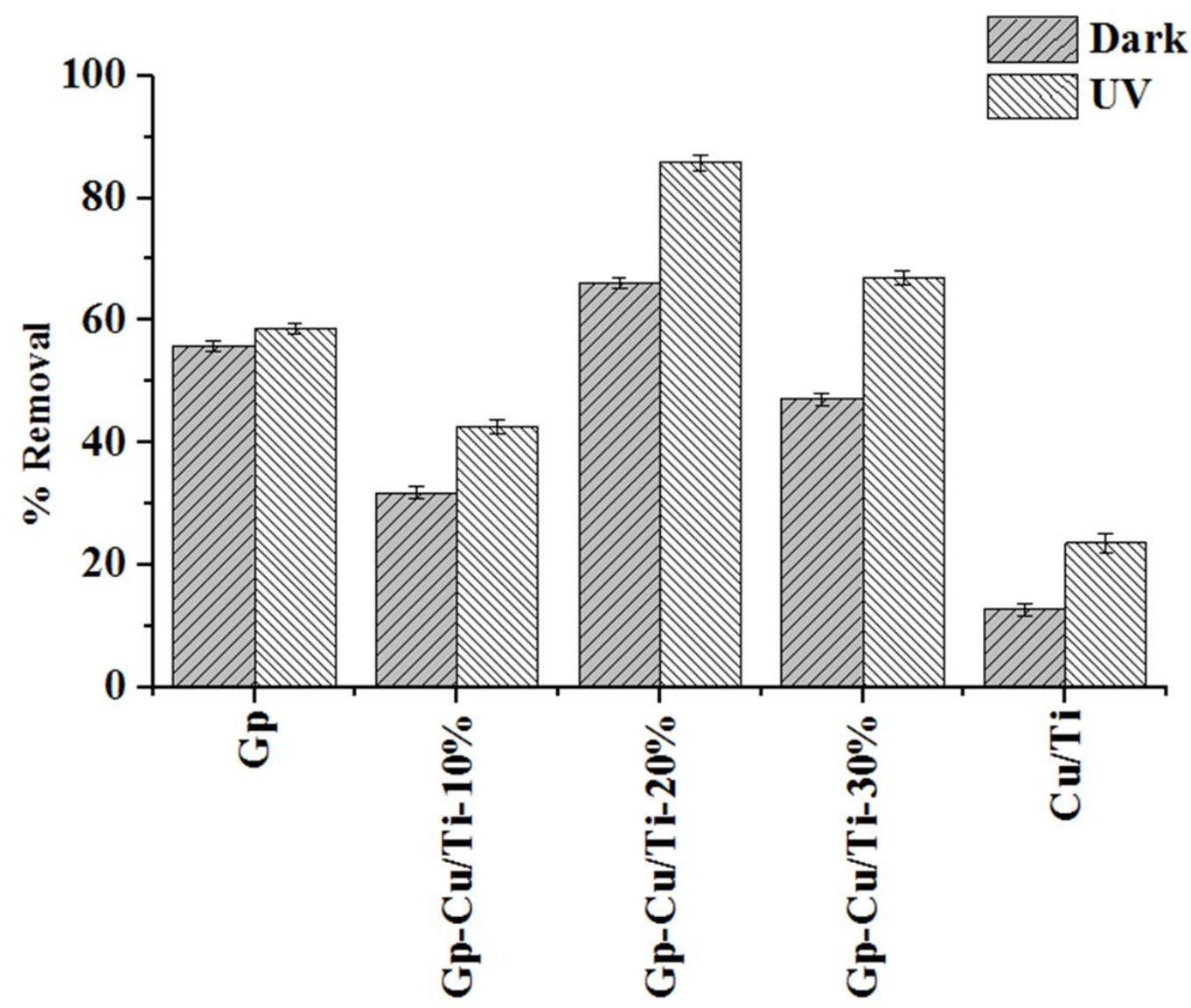

Figure 5.13. $\mathrm{MB}$ removal after 60 min. by the GP matrix, (10-30 wt\%) $\mathrm{GP}-\mathrm{Cu}_{2} \mathrm{O} / \mathrm{TiO}_{2}$ composites and the $\mathrm{Cu}_{2} \mathrm{O} / \mathrm{TiO}_{2}$ nano-heterostructure.

\subsubsection{Adsorption and degradation of $\mathrm{MB}$ dye by $\mathrm{P} 25$ titania, $\mathrm{Cu}_{2} \mathrm{O}$ and their geopolymer composites}

For comparison with the $\mathrm{Cu}_{2} \mathrm{O} / \mathrm{TiO}_{2}$ nanocomposites, the behaviour of $\mathrm{P} 25$ titania alone and in conjunction with the geopolymers matrix was measured under dark conditions and UV radiation and compared with and the $\mathrm{Cu}_{2} \mathrm{O}$ results of the previous chapter (Figure 5.14). Under dark conditions, neither $\mathrm{TiO}_{2}$ nor $\mathrm{Cu}_{2} \mathrm{O}$ alone nor their mixture removes $\mathrm{MB}$ from solution, indicating that the nanostructure and surface properties of these oxides is not effective in absorbing the dye. However, in combination with the geopolymer matrix, adsorption occurs on the geopolymer (Figure 5.13a). When fitted to pseudo- first and pseudosecond order kinetic equations, the data of Figure 5.13a behave similarly to the geopolymer $\mathrm{Cu}_{2} \mathrm{O} / \mathrm{TiO}_{2}$ composites, being best described by the pseudo first-order equation (Table 5.1). 
Likewise, these data are well fitted by Freundlich-type isotherms, confirming that the behaviour of these geopolymer composites under dark conditions represent adsorption of the dye on the matrix.

Under UV irradiation (Figure 5.14b) both the $\mathrm{TiO}_{2}$ and $\mathrm{Cu}_{2} \mathrm{O}$ alone, and their nanoheterostructure exhibit the expected photodegradation of the $\mathrm{MB}$ dye, the $\mathrm{Cu}_{2} \mathrm{O}$ being markedly less efficient that the P25 titania. However, combination of $\mathrm{Cu}_{2} \mathrm{O}$ with P25 titania greatly improves its performance (Figure 5.14b), but the incorporation of this nano oxide combination into the geopolymer matrix produces an even greater effect than with the $\mathrm{Cu}_{2} \mathrm{O} / \mathrm{TiO}_{2}$ combination by itself, particularly in composites containing $20 \mathrm{wt} \% \mathrm{Cu}_{2} \mathrm{O} / \mathrm{TiO}_{2}$. Since it was shown in Figure 5.14 that the photoactive oxides $\mathrm{Cu}_{2} \mathrm{O}$ and $\mathrm{TiO}_{2}$ separately and in combination do not have any significant absorption characteristics compared with the geopolymer matrix, their removal of $\mathrm{MB}$ under UV irradiation is solely due to photodegradation.

The excellent performance of the geopolymer- $\mathrm{Cu}_{2} \mathrm{O} / \mathrm{TiO}_{2}$ composites in destroying the model organic compound result is probably due to the ability of the matrix to trap and hold the dye during the photocatalysis process. The facilitating effect of the matrix, in terms of its pore size and structure will be addressed in the following chapters. The present results suggest however that composites of nanosized $\mathrm{Cu}_{2} \mathrm{O}$ particles and photoreactive P25 titania in an aluminosilicate geopolymer matrix have been successfully synthesised, and have an improved potential as materials for environmental protection applications to efficiently remove organic pollutants from water or the atmosphere. 

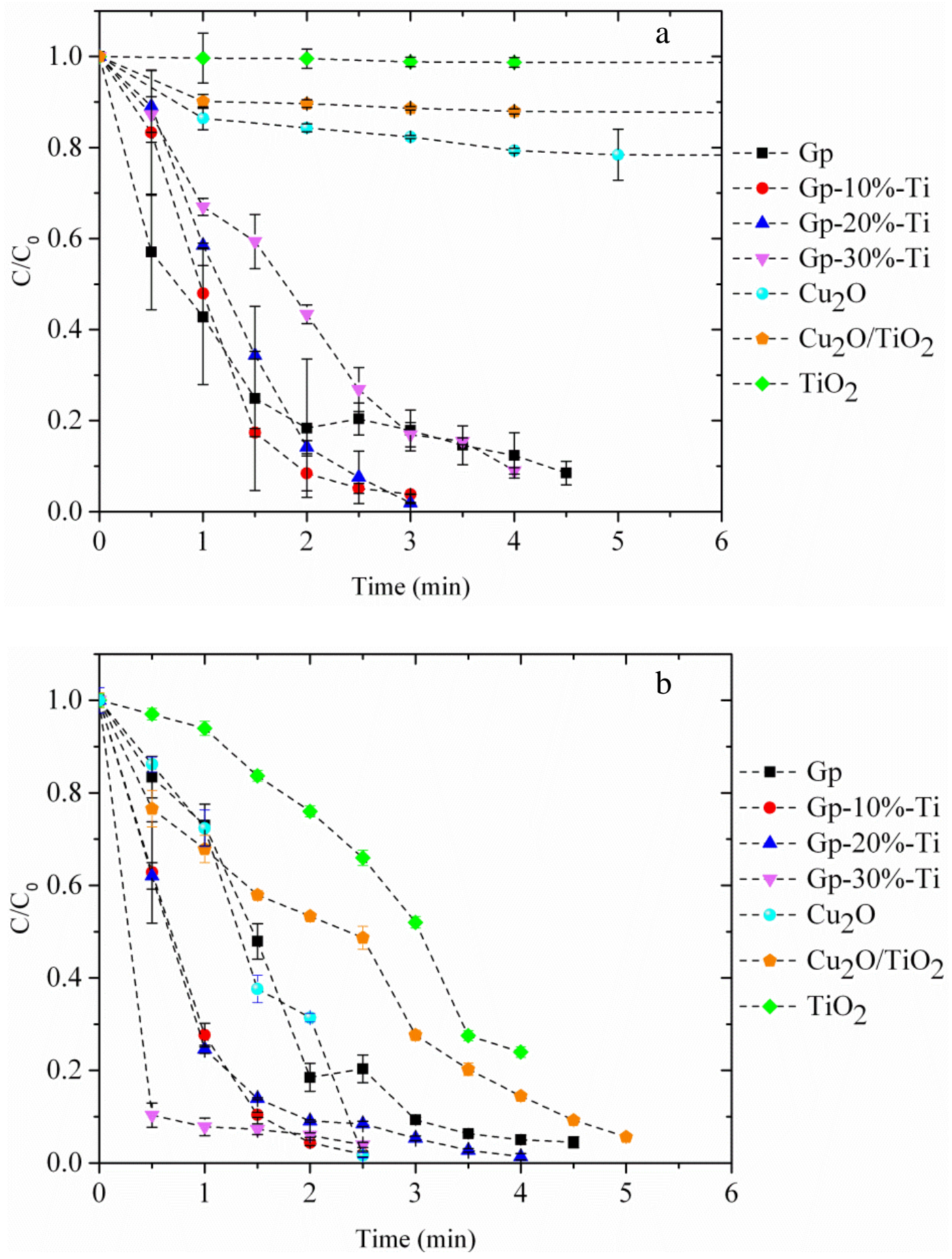

Figure 5.14. Residual concentration $\left(\mathrm{C} / \mathrm{C}_{0}\right)$ vs. time $(\mathrm{t})$ of $\mathrm{MB}$ dye adsorbed and photodegraded on the $\mathrm{TiO}_{2}, \mathrm{Cu}_{2} \mathrm{O}$ and $\mathrm{Cu}_{2} \mathrm{O} / \mathrm{TiO}_{2}$, compared with the $\mathrm{GP}-\mathrm{Cu}_{2} \mathrm{O} / \mathrm{TiO}_{2}$ composites under (a) dark conditions, (b) UV radiation. 


\subsection{Geopolymer composites of P25 titania alone}

\subsubsection{XRD Analysis}

The XRD traces of geopolymer composites containing only P25 titania (Figure 5.15) are as expected, containing only the broad X-ray amorphous feature overlaid by the sharp peaks of the anatase and rutile forms of titania.

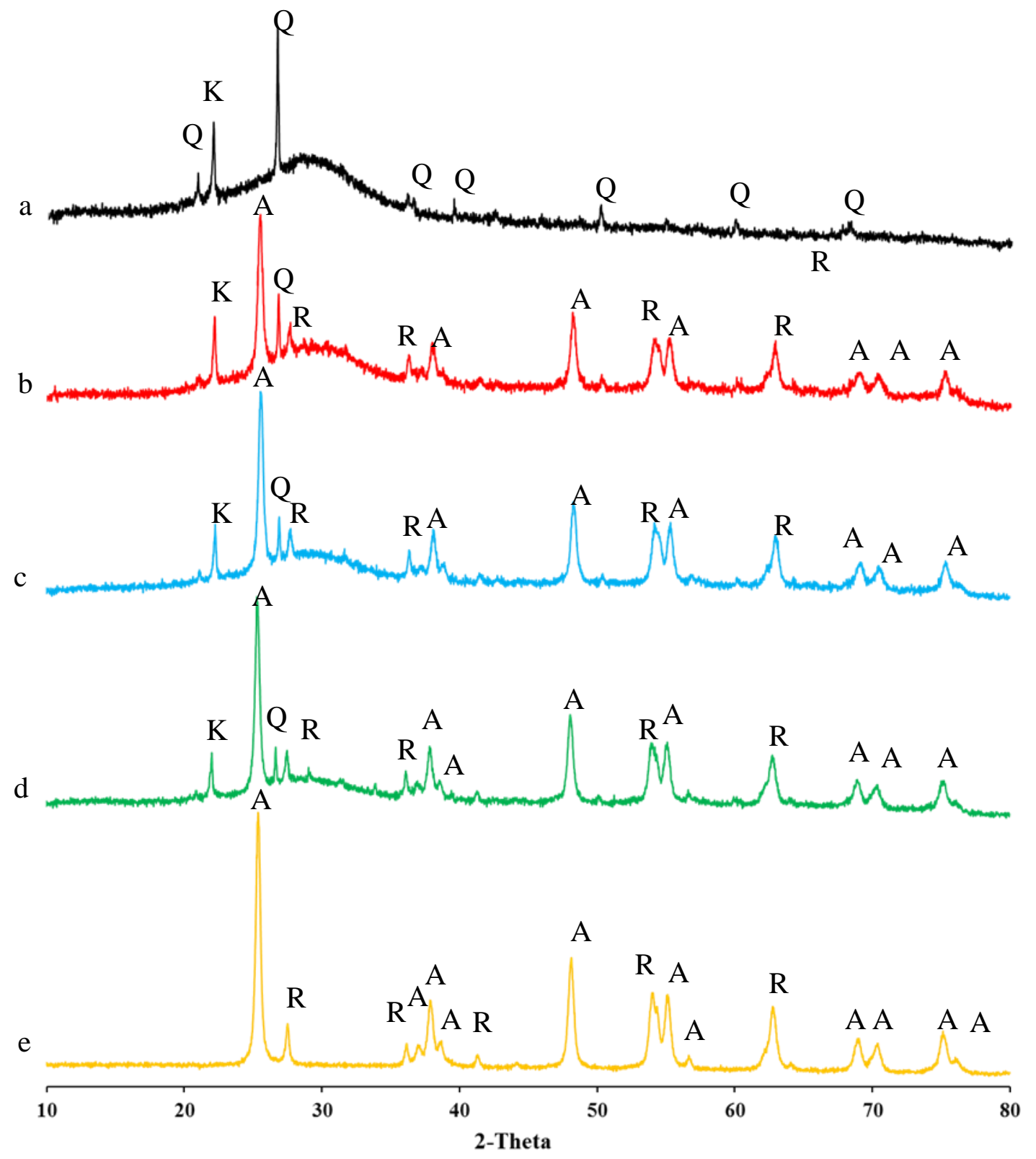

Figure 5.15. XRD patterns of $\mathrm{GP}$ and $\mathrm{TiO}_{2}$ and $\mathrm{TiO}_{2}$ supported by GP with different loading contents; (a) GP, (b) GP-10 wt \% $\mathrm{TiO}_{2}$, (c) GP-20 wt \% $\mathrm{TiO}_{2}$, (d) $\mathrm{GP}-30$ wt \% $\mathrm{TiO}_{2}$, (e) $\mathrm{TiO}_{2}$. $\mathrm{Q}=$ quartz, $\mathrm{K}=$ cristobalite, $\mathrm{A}=\mathrm{TiO}_{2}$ anatase, $\mathrm{R}=\mathrm{TiO}_{2}$ Rutile 


\subsubsection{Scanning electron microscopy}

SEM micrographs (Figure 5.16) confirm the homogeneous dispersion of the P25 $\mathrm{TiO}_{2}$ particles on the surface of the geopolymer composites with no obvious particle aggregation (Figure 5.16). As expected, increasing the oxide concentration part is evidenced by a greater concentration of $\mathrm{TiO}_{2}$ particles, especially on the surface of the composite matrix, as shown by the backscattered images (Figure 5.16 b,d,f).

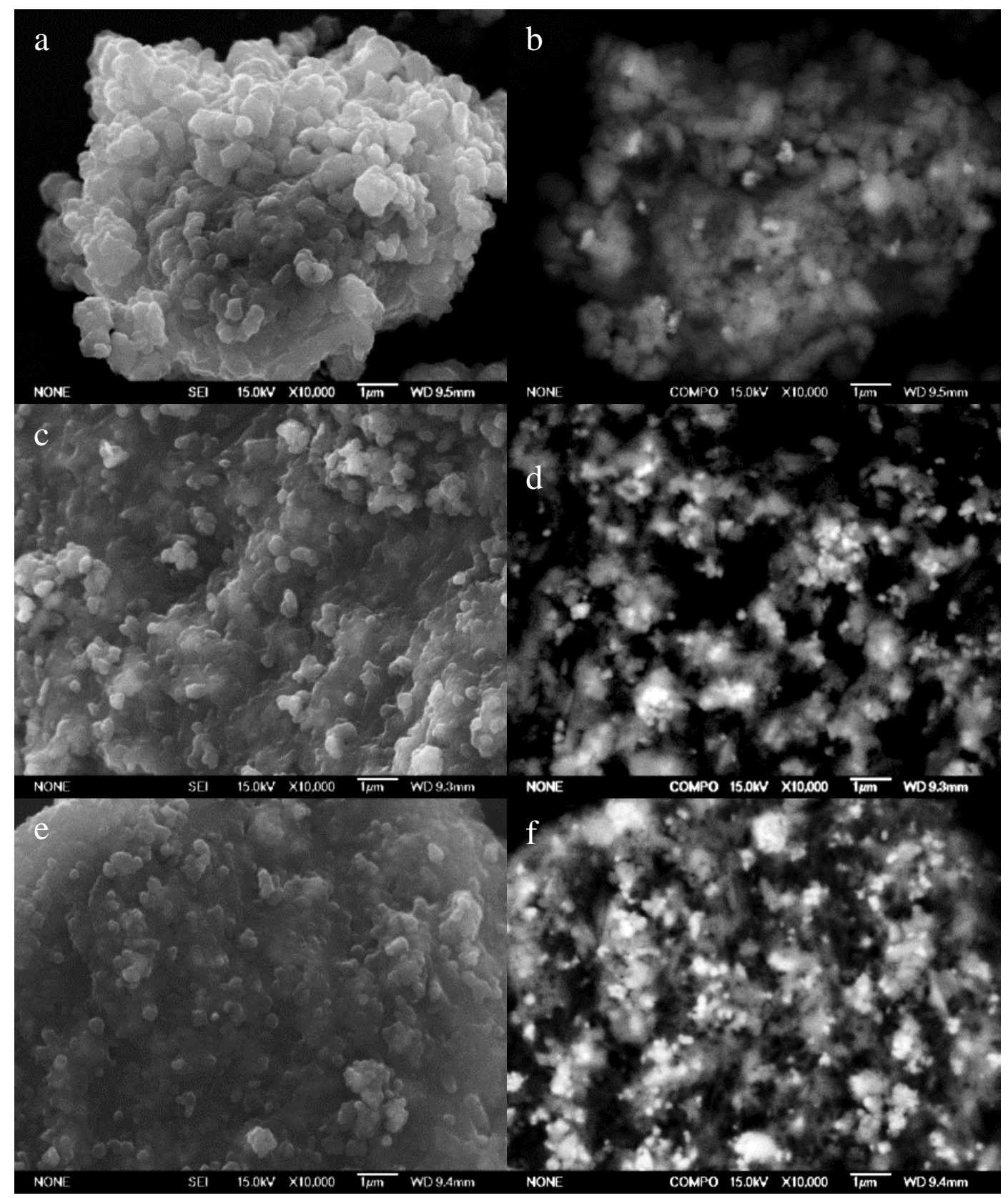

Figure 5.16. SEM micrograph of (a) GP-10 wt $\% \mathrm{TiO}_{2}$, (b) BSE of GP-10 wt $\% \mathrm{TiO}_{2}$, (c) SEM micrograph of GP-20 wt \% $\mathrm{TiO}_{2}$, (d) BSE of GP-20 wt \% $\mathrm{TiO}_{2}$, (e) SEM micrograph of GP-30 wt $\% \mathrm{TiO}_{2}$, (f) $\mathrm{BSE}$ of $\mathrm{GP}-30$ wt $\% \mathrm{TiO}_{2}$, showing $\mathrm{TiO}_{2}$ nanoparticles deposited mainly on the GP surface. 
Figure $5.17 \mathrm{a}$ is a BSE micrograph of the GP-30\% $\mathrm{TiO}_{2}$ sample. The bright regions in the BSE image correspond to the $\mathrm{TiO}_{2}$ rich regions, which have a higher average atomic number than the GP matrix. Figure $5.17 \mathrm{~b}$ - e are the corresponding EDS elemental maps from $\mathrm{Na}, \mathrm{Al}, \mathrm{Si}$ and $\mathrm{Ti}$. There are some higher concentration regions in the Na, Al, Si EDS maps, which may be attributed to the sample morphology or to phase segregation yielding the observed quartz and cristobalite XRD peaks. The $\mathrm{TiO}_{2}$ grains look evenly distributed on the sample surface, but it is interesting to note that the Ti EDS maps do not always directly correspond with the bright regions in the BSE image. As the BSE interaction volume region is larger than the EDS interaction volume, it is proposed that the $\mathrm{TiO}_{2}$ grains are embedded to some extent in the GP matrix.

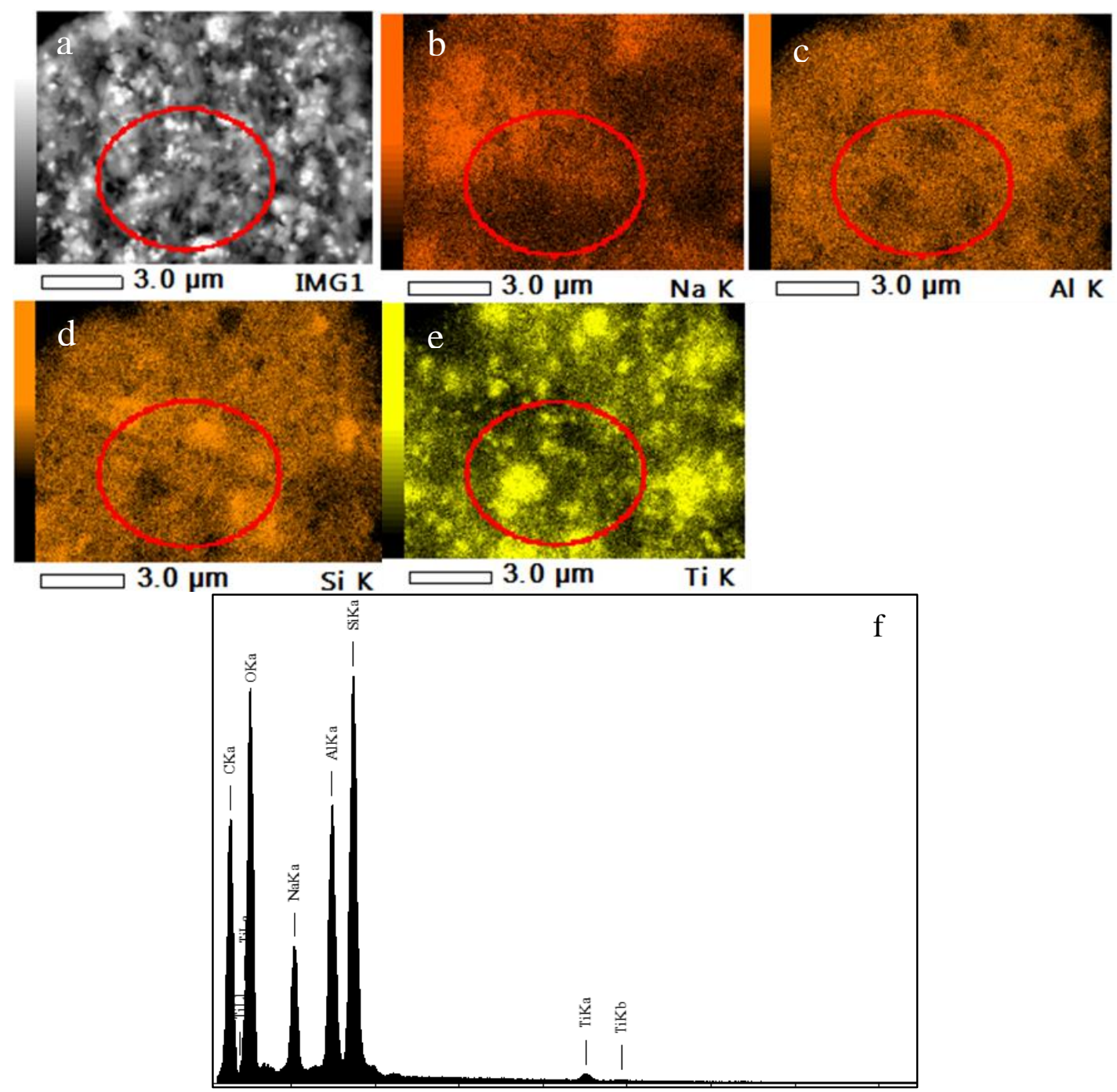

Figure 5.17. (a) Backscattered electron image of GP composite containing $30 \mathrm{wt} \% \mathrm{TiO}_{2}$ and (b) sodium, (c) aluminium, (d) silicon, (e) titanium EDS maps, (f) EDS element spectra of the indicated area of image. 


\subsubsection{High-Resolution Transmission Electron Microscopy}

Figure 5.18 shows a series of low magnification and high magnification TEM micrographs. Figure 5.18 shows dark ca. 10 - $20 \mathrm{~nm}$ sized grains embedded within a lighter matrix. It is proposed that the lighter matrix is the GP, whereas the dark particles are the $\mathrm{TiO}_{2}$ grains. This is confirmed in Figure $5.18 \mathrm{~b}$ which shows lattice fringes with a $d$-spacing of $0.42-0.45$ corresponding to the $\mathrm{TiO}_{2}\{110\}$ plane. The GP pore size has experimentally been determined to range from $24-55 \mathrm{~nm}$. As such, it is possible that the $10-20 \mathrm{~nm}$ sized $\mathrm{TiO}_{2}$ could be incorporated into the GP matrix.

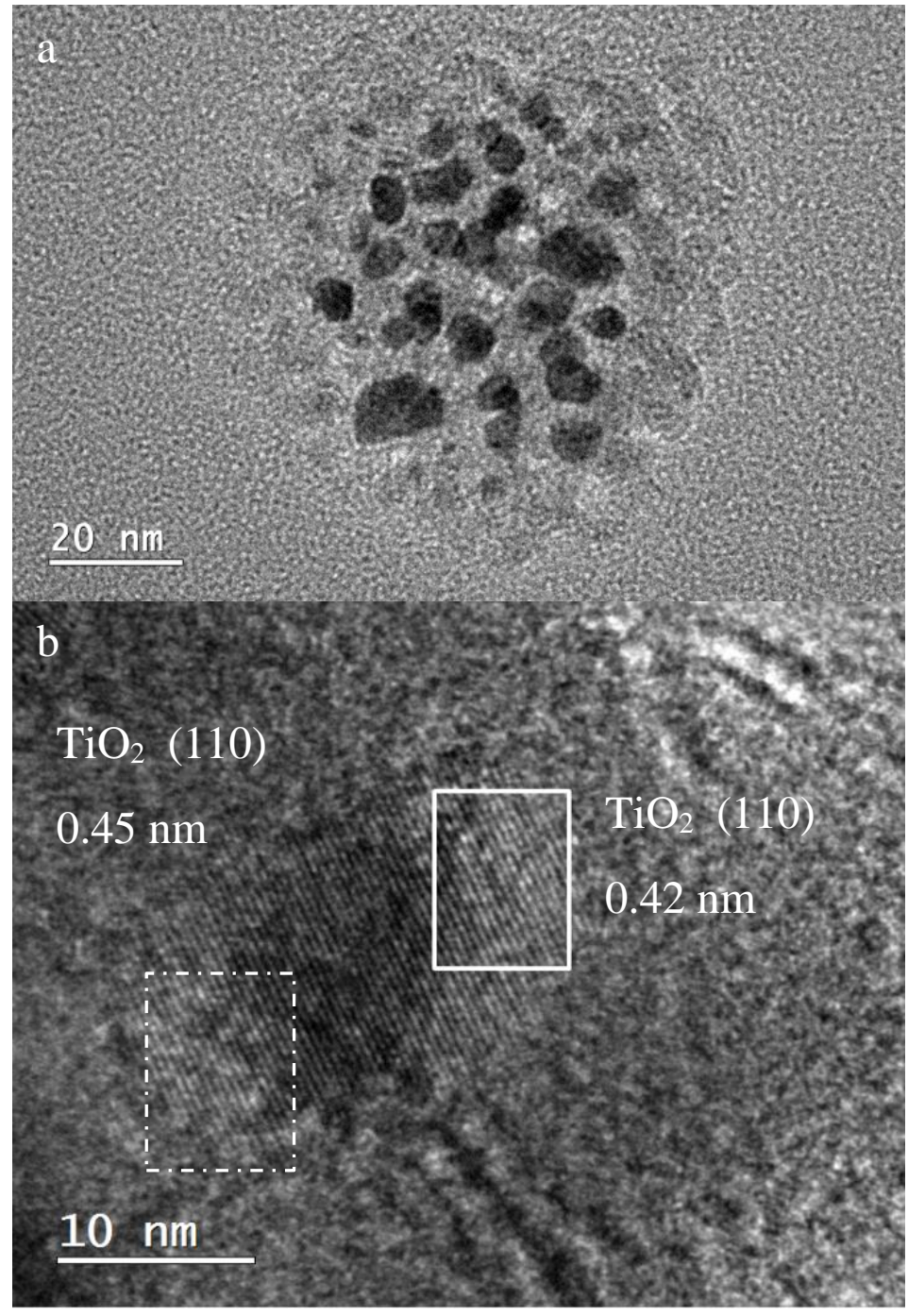

Figure 5.18. $(a, b)$ TEM images of GP-10\%- $-\mathrm{TiO}_{2}$ composite 


\subsubsection{Nitrogen Adsorption/Desorption Isotherms}

Information about the pore structures of the composites was obtained by measuring the $\mathrm{N}_{2}$ adsorption-desorption isotherms of the composites containing $10 \mathrm{wt} \% \mathrm{Cu}_{2} \mathrm{O}$ and $10 \mathrm{wt} \%$ $\mathrm{TiO}_{2}$ (Figure 5.19). The specific surface areas were obtained by several different methods: single point BET, multiple-point BET, Langmuir, BJH adsorption and BJH desorption measurements (Table 5.3). All these techniques show similar trends, with a significant increase in area from the geopolymer matrix alone to the composite containing $10 \mathrm{wt} \% \mathrm{TiO}_{2}$ and a significant decrease in the area of the composite containing $10 \mathrm{wt} \% \mathrm{Cu}_{2} \mathrm{O}$, the latter possibly due to blocking the pores by the $\mathrm{Cu}_{2} \mathrm{O}$ particles as previously suggested. This observation is also consistent with the much smaller pore volumes recorded for the $\mathrm{Cu}_{2} \mathrm{O}$ composites, and the decreased adsorption of MB dye under dark conditions in this composite (Figure 4.14). The increased surface area of the titania-geopolymer composite (Table 5.3) suggests that in this composite the titania nanoparticles are more readily able to enter into and expand the internal structures of the geopolymer matrix, or that the surface area of the titania itself is contributing to this result. The present experiments do not allow these possibilities to be distinguished.

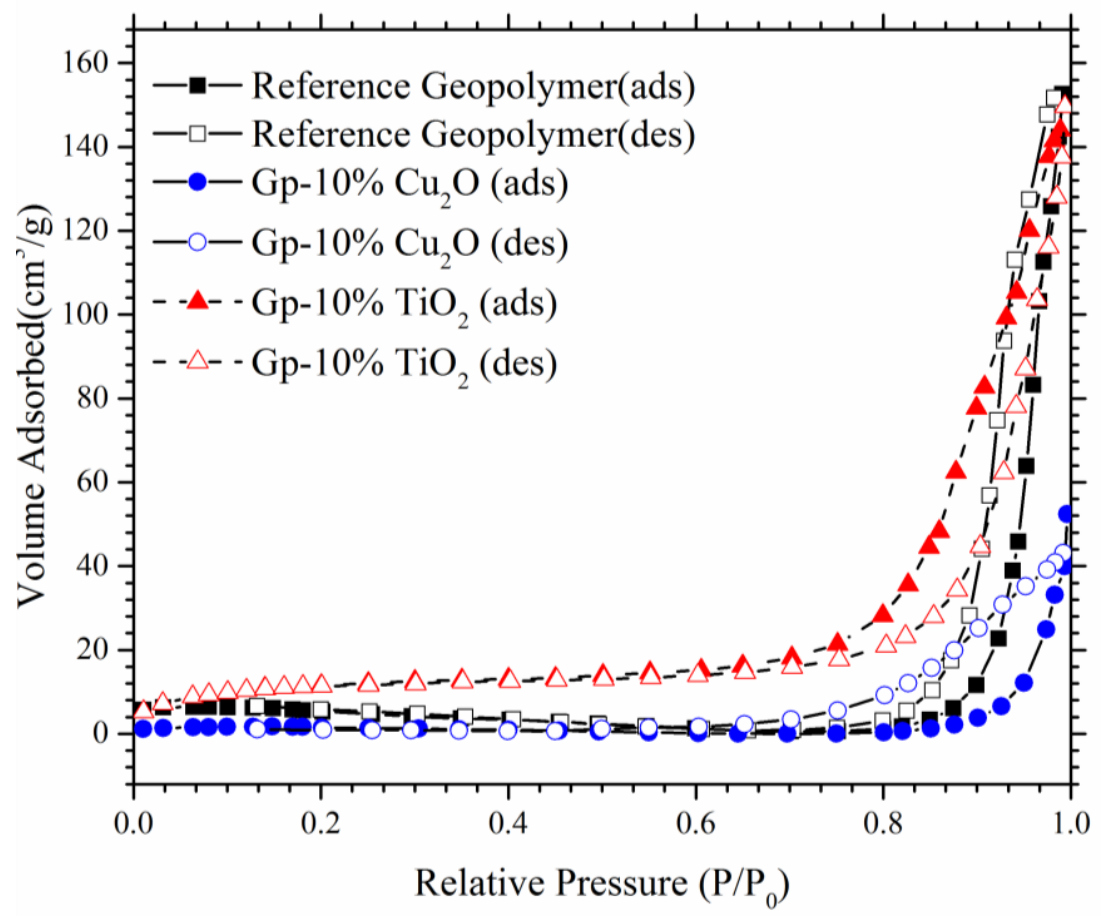

Figure 5.19. Nitrogen sorption isotherms of the GP matrix ( $\square$, adsorption $\square$, desorption), GP-10 wt \% $\mathrm{Cu}_{2} \mathrm{O}-\left(\bullet\right.$, adsorption $\bigcirc$, desorption ) and GP-10 wt $\% \mathrm{TiO}_{2^{-}}(\boldsymbol{\Delta}$, adsorption $\triangle$, desorption) 
Table 5.2. Specific surface areas and pore parameters of geopolymer and geopolymer composites

\begin{tabular}{|l|l|l|l|}
\hline & GP-Reference & GP-10\%-TiO2 & GP-10\%-Cu2O \\
\hline Single Point Surface Area & $18.44 \mathrm{~m}^{2} / \mathrm{g}$ & $39.60 \mathrm{~m}^{2} / \mathrm{g}$ & $5.14 \mathrm{~m}^{2} / \mathrm{g}$ \\
\hline $\mathrm{S}_{\text {BET }}$ & $17.23 \mathrm{~m}^{2} / \mathrm{g}$ & $41.75 \mathrm{~m}^{2} / \mathrm{g}$ & $5.21 \mathrm{~m}^{2} / \mathrm{g}$ \\
\hline $\mathrm{S}_{\text {Langmuir }}$ & $21.92 \mathrm{~m}^{2} / \mathrm{g}$ & $57.98 \mathrm{~m}^{2} / \mathrm{g}$ & $6.82 \mathrm{~m}^{2} / \mathrm{g}$ \\
\hline $\mathrm{S}_{\text {BJH Adsorption Cumulative }}$ & $23.06 \mathrm{~m}^{2} / \mathrm{g}$ & $30.87 \mathrm{~m}^{2} / \mathrm{g}$ & $5.79 \mathrm{~m}^{2} / \mathrm{g}$ \\
\hline $\mathrm{S}_{\text {BJH Desorption Cumulative }}$ & $38.94 \mathrm{~m}^{2} / \mathrm{g}$ & $46.55 \mathrm{~m}^{2} / \mathrm{g}$ & $17.76 \mathrm{~m}^{2} / \mathrm{g}$ \\
\hline Volume & \multicolumn{5}{|l}{} \\
\hline Single Point Adsorption & $0.24 \mathrm{~cm}^{3} / \mathrm{g}$ & $0.23 \mathrm{~cm}^{3} / \mathrm{g}$ & $0.081 \mathrm{~cm}^{3} / \mathrm{g}$ \\
\hline V pore BJH Adsorption Cumulative & $0.236 \mathrm{~cm}^{3} / \mathrm{g}$ & $0.23 \mathrm{~cm}^{3} / \mathrm{g}$ & $0.061 \mathrm{~cm}^{3} / \mathrm{g}$ \\
\hline V pore BJH Desorption Cumulative & $0.236 \mathrm{~cm}^{3} / \mathrm{g}$ & $0.23 \mathrm{~cm}^{3} / \mathrm{g}$ & $0.081 \mathrm{~cm}^{3} / \mathrm{g}$ \\
\hline Pore Size & $55 \mathrm{~nm}$ & $22 \mathrm{~nm}$ & $62 \mathrm{~nm}$ \\
\hline D Adsorption & $41 \mathrm{~nm}$ & $30 \mathrm{~nm}$ & $42 \mathrm{~nm}$ \\
\hline D BJH Adsorption & $24 \mathrm{~nm}$ & $20 \mathrm{~nm}$ & $18 \mathrm{~nm}$ \\
\hline D BJH Desorption & & & \\
\hline
\end{tabular}

\section{Conclusions}

This chapter demonstrates that composites of spherical nanoparticle $\mathrm{Cu}_{2} \mathrm{O}$ with $\mathrm{P} 25$ titania homogeneously distributed within a well-formed aluminosilicate geopolymer matrix can successfully be prepared, as shown by SEM/EDS and HRTEM. XRD and FTIR confirmed the formation of a well-reacted geopolymer matrix that was unaffected by the insertion of the $\mathrm{Cu}_{2} \mathrm{O} / \mathrm{TiO}_{2}$ heterostructures or by the adsorption or photodegradation of $\mathrm{MB}$ dye. The entry of the $\mathrm{Cu}_{2} \mathrm{O} / \mathrm{TiO}_{2}$ heterostructures into the geopolymer matrix is shown to facilitate the removal of $\mathrm{MB}$ dye from solution under dark conditions, but $\mathrm{P} 25$ titania or $\mathrm{Cu}_{2} \mathrm{O}$ alone do not show this facility for dye adsorption. Under dark conditions, the geopolymer matrix, and, in particular, the $\mathrm{Cu}_{2} \mathrm{O} / \mathrm{TiO}_{2}$ geopolymer composites, remove the dye by an adsorption process which can best be described by pseudo first-order kinetics and Freundlich-type isotherms, as 
was shown in the previous chapter to be the case for $\mathrm{Cu}_{2} \mathrm{O} /$ geopolymer composites. Nitrogen adsorption/desorption isotherms of the composites containing $10 \mathrm{wt} \% \mathrm{TiO}_{2}$ show a significantly larger specific surface area than the geopolymer matrix alone, possibly due to expansion of the pore structure by the titania, whereas the specific surface area of the composite containing $10 \mathrm{wt} \% \mathrm{Cu}_{2} \mathrm{O}$ is significantly decreased, possibly due to blocking of the pores by the $\mathrm{Cu}_{2} \mathrm{O}$ nanoparticles. These observations provide a qualitative explanation for the differences in dye absorption behaviour of the different composites.

Under UV irradiation, the composites remove the MB dye by a combination of adsorption and photodegradation, as was found for $\mathrm{Cu}_{2} \mathrm{O}$ /geopolymer composites (chapter 4). The combination of a nano-heterostructure composed of $\mathrm{Cu}_{2} \mathrm{O}$ particles and photoreactive $\mathrm{P} 25$ titania in an aluminosilicate geopolymer matrix was found to be a more efficient photocatalyst under UV irradiation than geopolymer composites of the individual oxides alone, and represents an improvement in the performance of these composite photocatalysts over those containing $\mathrm{Cu}_{2} \mathrm{O}$ alone. 


\section{Chapter 6}

\section{Composites containing $\mathrm{Cu}_{2} \mathrm{O}$ nanoparticles supported on an expanded geopolymer matrix}

\section{Introduction}

In previous chapters it was shown that composites of geopolymers with nanoparticles of $\mathrm{Cu}_{2} \mathrm{O}$ can efficiently remove $\mathrm{MB}$ dye from solution by a combination of adsorption (in the dark) and photodegradation (under UV irradiation), and the efficiency of this process is considerably improved by combining the $\mathrm{Cu}_{2} \mathrm{O}$ with a photoreactive form of titania (P25). In this chapter, attention is turned to the role of the geopolymer matrix, to determine whether by modifying its pore structure, the efficiency of the photoactive component might be improved further.

Although geopolymers, are X-ray amorphous, the negative charges on the aluminate units which are compensated by the presence of cations leads to similarities with zeolite structures, particularly with respect to cation exchange behaviour, which in turn suggests a possible procedure for expanding the pore structure of the geopolymer by the use of a large quaternary ammonium cation such as the cetyltrimethylammonium ion (CTAB), normally used as the bromide salt. CTAB is extensively used to expand the basal spacings of layer-lattice clay minerals such as montmorillonite, ${ }^{125,} 140$ rectorite $^{76}$ and kaolinite. ${ }^{9}$ Okada et al. synthesised $\mathrm{TiO}_{2} /$ mesoporous silica composites using the surfactant properties of CTAB as a structure directing agent under alkaline hydrothermal conditions, ${ }^{150}$ and it is commonly used in a similar role in the hydrothermal synthesis of zeolites. ${ }^{185}$ All these applications involve the formation or modification of a crystalline structure, but to our knowledge, CTAB has never previously been used to modify an X-tray amorphous material such as an aluminosilicate geopolymer which does not possess a layer structure, but contains pores which might be modified by yje inclusion of a large quaternary ammonium cation. The work presented in this chapter exploits the ion-exchange properties of geopolymers by replacing the monovalent charge-compensating ion by the much larger $\mathrm{CTAB}$, thereby expanding the pore structure and facilitating the entry of the photoactive $\mathrm{Cu}_{2} \mathrm{O}$ deeper into the structure. It was also hoped that the presence of the $\mathrm{CTAB}$ might modify the pore surfaces of the geopolymer and thus the mechanism by which the photoactive oxide is attached to the geopolymer matrix, resulting in 
a geopolymer matrix of stable $\mathrm{pH}$ which would act as a $\mathrm{pH}$ buffer, allowing the two dye removal processes to be separately measured.

Immobilization of oxide nanoparticles on the inner and outer surfaces of these inorganic materials has been shown in previous chapters to produce efficient photocatalysts. Nano composite matrices adsorb organic substances either on their external surfaces or within their internal spaces via interactions or exchange. ${ }^{193}$ Reports in the literature show that small amounts of surfactant such as CTAB can expand the layers of a clay mineral and control their separation, producing hydrophobic photocatalyst composites. ${ }^{184,}{ }^{194}$ Such a modified nano $\mathrm{Cu}_{2} \mathrm{O}$-geopolymer-composite is expected to show better photocatalyst properties than the unmodified $\mathrm{Cu}_{2} \mathrm{O}$-geopolymer composites developed in chapters 4 and 5 , due to the improved dispersion of the metal oxide nanoparticles at external and interlayers of the geopolymer matrix.

The CTAB-expanded geopolymer matrices were synthesised as described in Chapter 3, and the structure and properties of the resulting composites of $\mathrm{Cu}_{2} \mathrm{O}$ with the modified matrix were determined as described in chapters 4 and 5.

\section{Result and Discussion}

\subsection{Elemental Analysis}

The major element analyses by XRF (Table 6.1) show similar matrix compositions of the CTAB-modified geopolymer and, for comparison, a unmodified Na-geopolymer, apart from the $\mathrm{Br}$ content of the modified geopolymer; this decreases to almost zero upon formation of the oxide composite, indicating the effectiveness of the washing procedure followed in this part of the synthesis. Composite formation is also accompanied by a reduction in the $\mathrm{Na}$ content, again a result of the washing step. The $\mathrm{Cu}$ and $\mathrm{Ti}$ contents show the expected increase with increasing $\mathrm{Cu}_{2} \mathrm{O} / \mathrm{TiO}_{2}$ contents of the composites. 
Table 6.1. XRF analysis (wt\%) of major elements of geopolymer samples with different compositions

\begin{tabular}{lcccc}
\hline & GP & M-GP & M-GP-10 wt\% $\mathbf{C u}_{2} \mathrm{O}$ & M-GP-15 wt\% $\mathrm{Cu}_{2} \mathrm{O}$ \\
\hline $\mathrm{Na}_{2} \mathrm{O}$ & 15.2 & 16.8 & 12.0 & 10.8 \\
$\mathrm{Al}_{2} \mathrm{O}_{3}$ & 23.7 & 23.0 & 20.5 & 18.8 \\
$\mathrm{SiO}_{2}$ & 46.2 & 44.8 & 40.8 & 37.8 \\
$\mathrm{TiO}_{2}$ & 0.043 & 0.048 & 0.050 & 0.047 \\
$\mathrm{Fe}_{2} \mathrm{O}_{3}$ & 0.193 & 0.194 & 0.183 & 0.169 \\
$\mathrm{Cu}_{2} \mathrm{O}$ & 0.005 & - & 6.24 & 8.01 \\
$\mathrm{Br}_{\mathrm{ZrO}}$ & - & 0.342 & 0.006 & 0.005 \\
$\mathrm{LOI}$ & 0.007 & 0.005 & 0.007 & 0.005 \\
$\mathrm{SiO}_{2} / \mathrm{Al}_{2} \mathrm{O}_{3}$ & 14.46 & 14.68 & 20.14 & 24.25 \\
\hline
\end{tabular}

\subsection{XRD Analysis}

The XRD patterns of the starting $\mathrm{Cu}_{2} \mathrm{O}, \mathrm{CTAB}$-modified geopolymer and corresponding $\mathrm{Cu}_{2} \mathrm{O}$ composites (Figure 6.1) show that the modified geopolymer matrix is typically X-ray amorphous and similar to the unmodified matrix (chapters 4 and 5). The $\mathrm{Cu}_{2} \mathrm{O}$ reflections and the absence of peaks of $\mathrm{CuO}$ or $\mathrm{Cu}$ confirm the successful synthesis of the $\mathrm{Cu}_{2} \mathrm{O}$. 


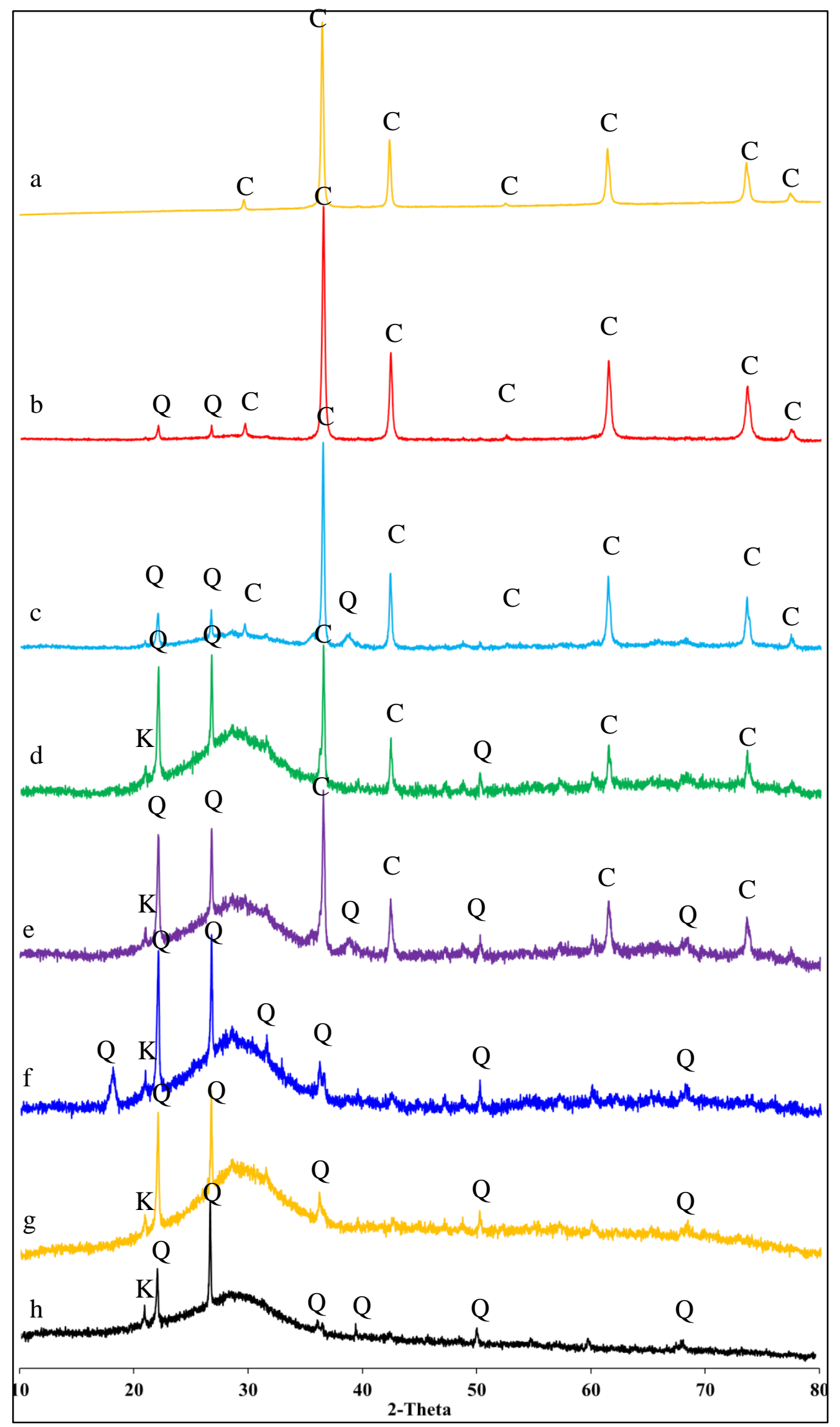

Figure 6.1. XRD patterns of (a) $\mathrm{Cu}_{2} \mathrm{O}$, (b) M-GP-50 wt $\% \mathrm{Cu}_{2} \mathrm{O}$, (c) M-GP-30 wt $\% \mathrm{Cu}_{2} \mathrm{O}$, (d) M-GP-15 wt\% $\mathrm{Cu}_{2} \mathrm{O}$, (e) M-GP-10 wt\% Cu $2 \mathrm{O}$, (f) M-GP-5 wt\% $\mathrm{Cu}_{2} \mathrm{O}$, (g) M-GP, (h) GP. Q = quartz, $\mathrm{K}=$ cristobalite, $\mathrm{C}=$ cuprous oxide. 


\subsection{Scanning electron microscopy}

Figure 6.2a shows a BSE image of the CTAB-modified geopolymer. EDS mapping and point analysis (Figure $6.2 \mathrm{~b}$-c) confirm the presence of sodium $(\mathrm{Na})$, silicon $(\mathrm{Si})$, aluminum ( $\mathrm{Al}$ ) without any other impurities.
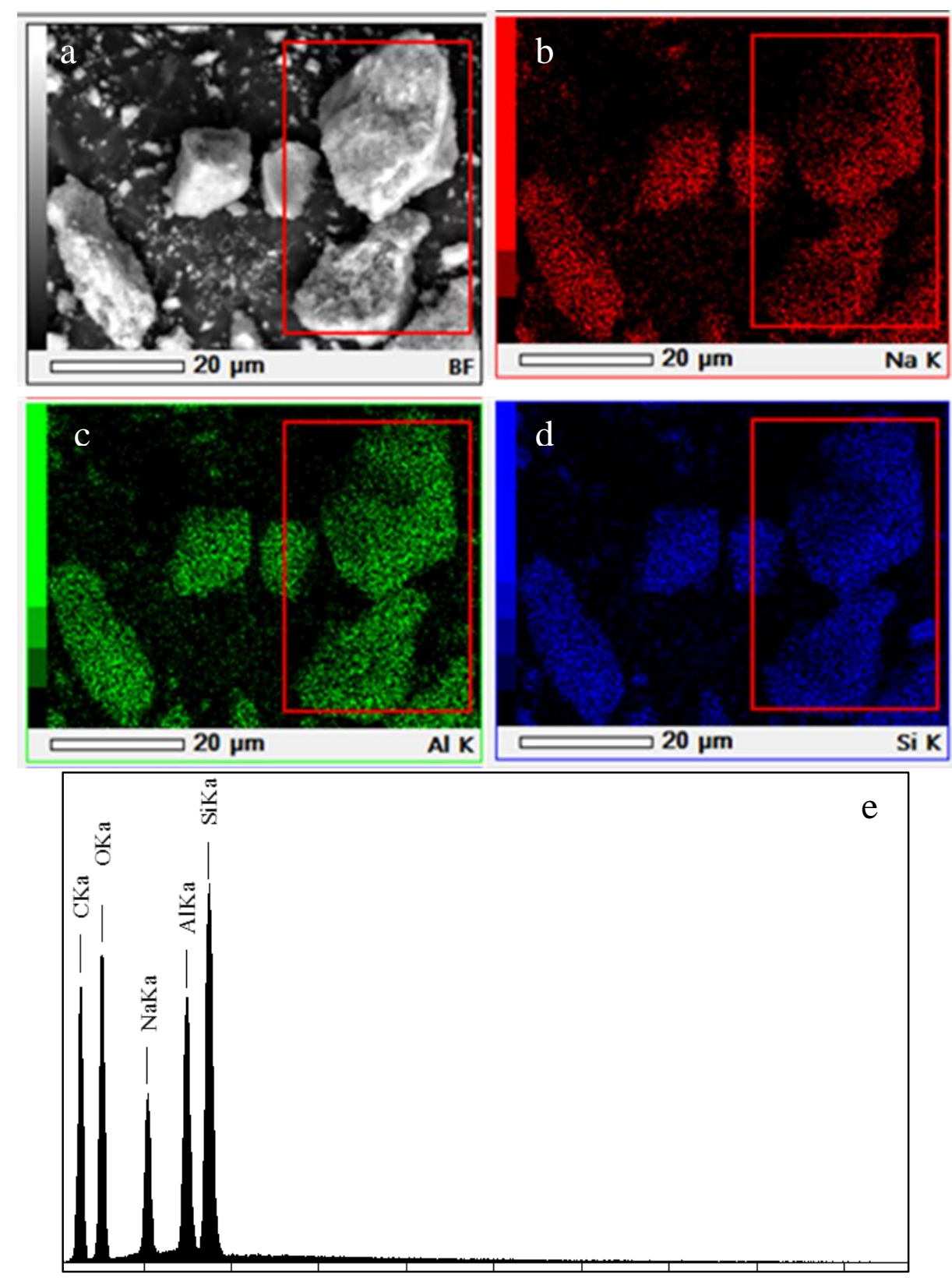

Figure 6.2. (a) Backscattered SEM image of M-GP and elemental maps of (b) $\mathrm{Na}$, (c) Al, (d) si, (e) EDS element spectrum. Red rectangular areas in the elemental maps correspond to the EDS spectrum (e) 


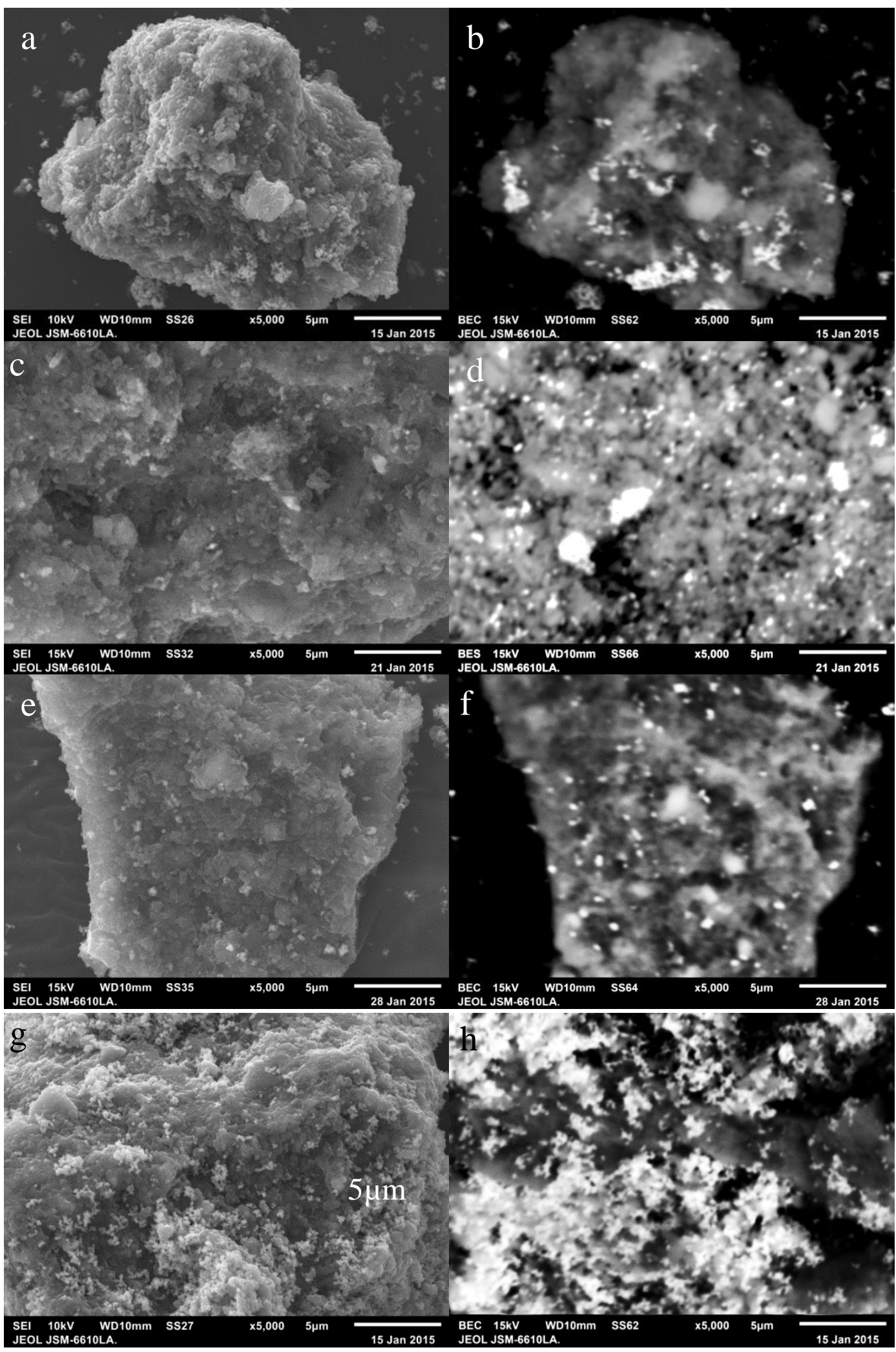

Figure 6.3. (a,b) M-GP- 5 wt $\% \mathrm{Cu}_{2} \mathrm{O}$ composite, (c,d) M-GP-10 wt $\% \mathrm{Cu}_{2} \mathrm{O}$ composite, (e,f) M-GP-15 wt $\% \mathrm{Cu}_{2} \mathrm{O}$ composite, (g,h) M-GP-50 wt\% $\mathrm{Cu}_{2} \mathrm{O}$ composite. Micrographs b,d,f,h are BSE images, micrographs a,c,e,g are SE images. 
Figure 6.3 is a series of SE and BSE micrographs of CTAB-GP with 5, 10, 15, 50 wt \% $\mathrm{Cu}_{2} \mathrm{O}$. The left hand micrographs are SE micrographs and the right hand micrographs are the

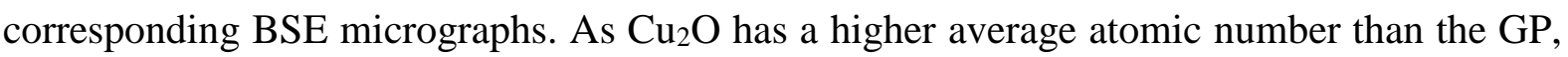
the $\mathrm{Cu}_{2} \mathrm{O}$ particles appear bright in comparison to the GP matrix.

Figure $6.4 \mathrm{a}$ is a BSE micrograph of the CTAB-GP- $50 \mathrm{wt} \% \mathrm{Cu}_{2} \mathrm{O}$ sample. Very bright regions are observed in the $\mathrm{BSE}$ image, suggesting $\mathrm{Cu}_{2} \mathrm{O}$ phase aggregation. This is confirmed from the EDS mapping, where strong $\mathrm{Cu}$-rich regions (Figure 6.4e) are seen. The $\mathrm{Na}, \mathrm{Al}$ and Si elemental maps (Figure 6.4 (b-d)), show no strong phase segregation. From EDS elemental analysis no impurity phases are observed (Figure 6.4 f).
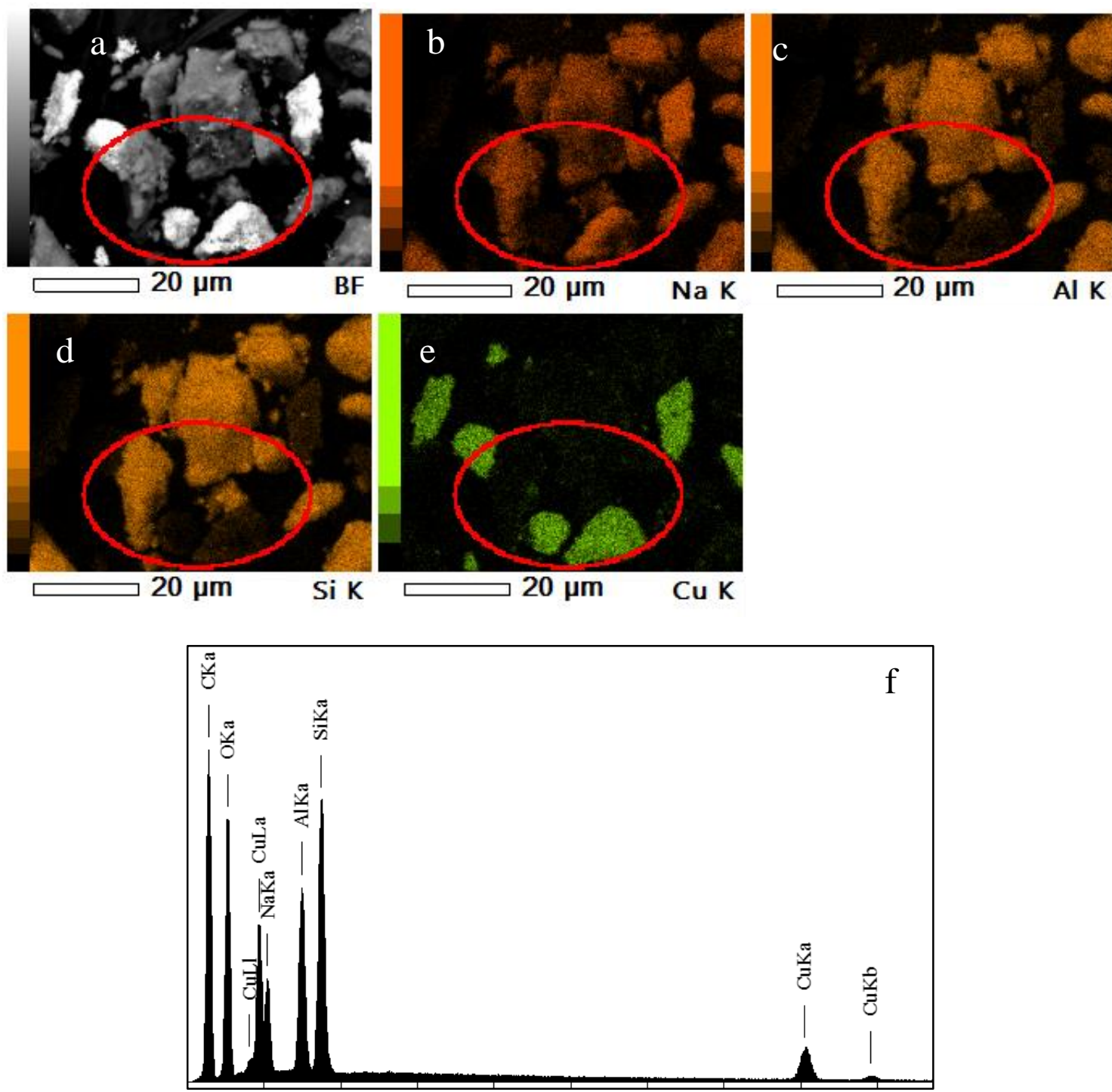

Figure 6.4. (a) Backscattered SEM image of ground M-GP-50\% $\mathrm{Cu}_{2} \mathrm{O}$ and elemental maps of (b) $\mathrm{Na}$, (c) $\mathrm{Al}$, (d) $\mathrm{Si}$, (e) $\mathrm{Cu}$, (f) EDS element spectrum of M-GP-50 wt\% $\mathrm{Cu}_{2} \mathrm{O}$. 


\subsection{High-Resolution Transmission Electron Microscopy}

The TEM image of the geopolymer-CTAB $10 \%-\mathrm{Cu}_{2} \mathrm{O}$ composite (Figure 6.5a) shows the presence of dark nanocubes corresponding to $\mathrm{Cu}_{2} \mathrm{O}$ nanoparticles. That the dark black dots represent the $\mathrm{Cu}_{2} \mathrm{O}$ nanoparticles is confirmed by measurement of the lattice fringes in the HRTEM images (Figure 6.5).

Figure $6.5 \mathrm{a}$ is a low magnification TEM micrograph of the GP-CTAB10\%- $\mathrm{Cu}_{2} \mathrm{O}$ sample. The image is characterised by dark cubic regions in a lighter GP matrix. From HRTEM work these cubic regions are confirmed to be $\mathrm{Cu}_{2} \mathrm{O}$ (Figure 6.5c and inset). The inset in Figure 6.5c is an inverse Fourier transform (IFFT) with a d-spacing of $0.24 \mathrm{~nm}$ which corresponds to the $\mathrm{Cu}_{2} \mathrm{O}$ (111) plane. The $\mathrm{Cu}_{2} \mathrm{O}$ are approximately $100 \mathrm{~nm}$ in size which agrees with the initial synthesis work described in Section 4.2. The smaller spherical grains observed in Figure 6.5b are $\mathrm{Cu}_{2} \mathrm{O}$.

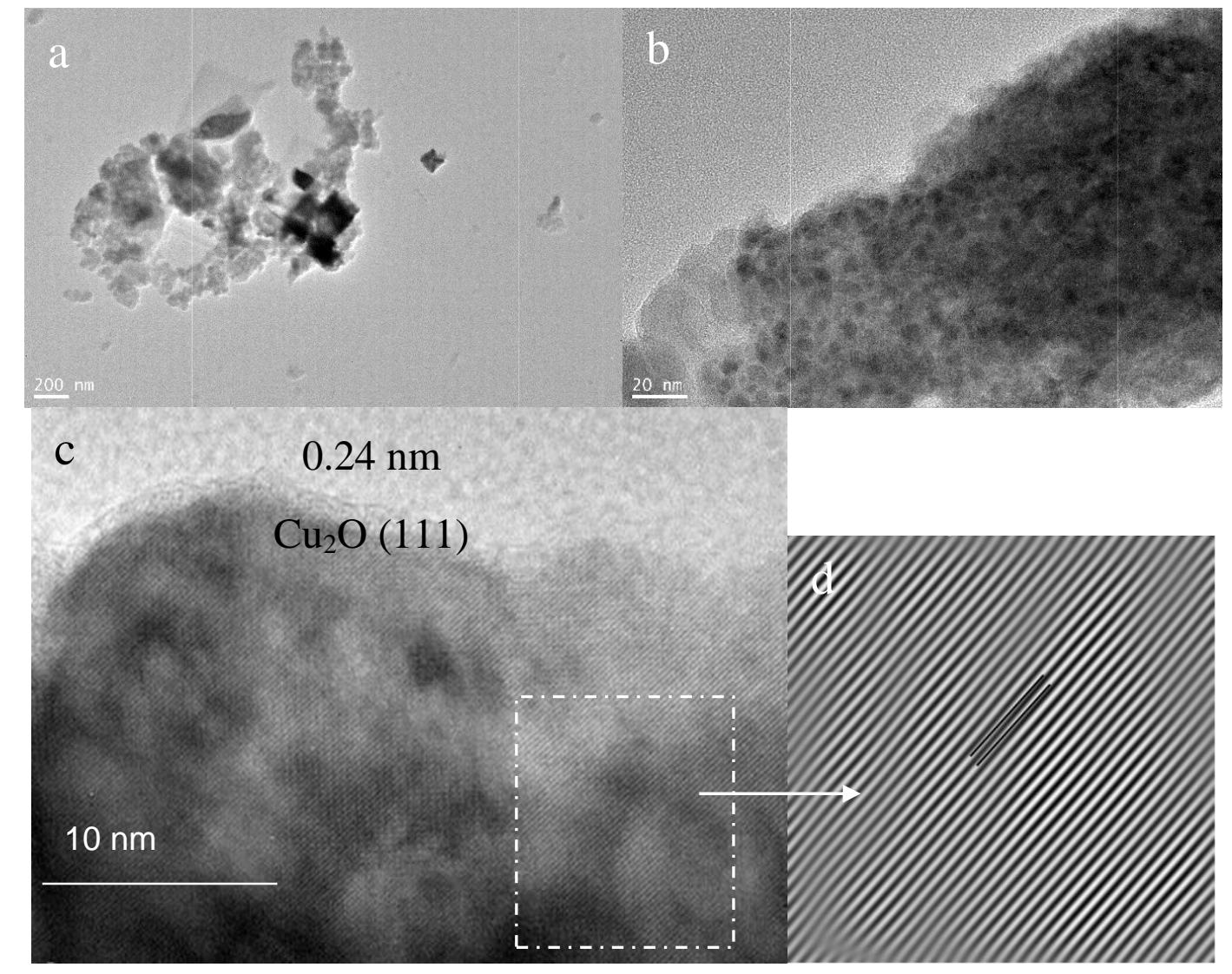

Figure 6.5. (a-c) TEM images of GP-CTAB10\%-Cu $\mathrm{Cu}_{2} \mathrm{O}$ composite, (d) HTREM of selected area in (c).

The aligned lattice fringes of the $\mathrm{Cu}_{2} \mathrm{O}$ nanoparticles are clearly illustrated in Figure 6.5. which shows adjacent fringe spacings of about $0.21 \mathrm{~nm}$, measured by digital micrograph 
software by calculating the average parameters between 10 lattice fringes. These lattice spacings are in agreement with the (cubic) structure of $\mathrm{Cu}_{2} \mathrm{O}$ (JCPDS file 01-073-6237) and the HRTEM analysis thus provides a reliable confirmation of the XRD analysis.

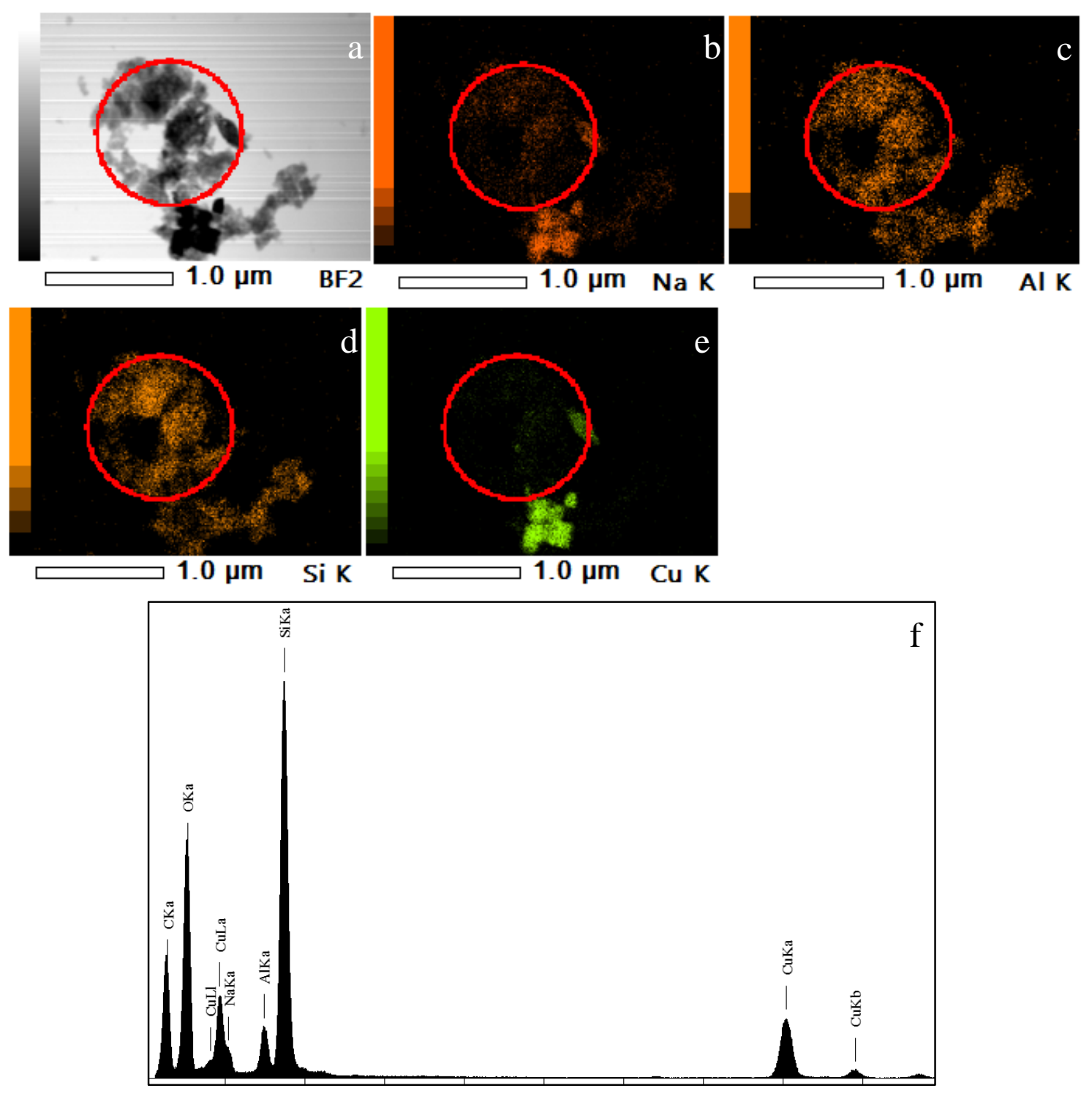

Figure 6.6. STEM and EDX elemental mapping images of M-GP-10 wt $\%-\mathrm{Cu}_{2} \mathrm{O}$ composite. Red circled areas in the elemental maps correspond to the EDS spectrum (f)

\subsection{FTIR spectra of these samples}

Figure 6.7 shows the FTIR spectra of unmodified geopolymer, CTAB-modified geopolymer and $\mathrm{Cu}_{2} \mathrm{O}$ composites with $\mathrm{CTAB}$-modified geopolymer (5-50 wt $\% \mathrm{Cu}_{2} \mathrm{O}$ ). The band in the unmodified geopolymer at $1644 \mathrm{~cm}^{-1}$ is related to the $\mathrm{H}-\mathrm{O}-\mathrm{H}$ bending vibration of water molecules adsorbed on the geopolymer ${ }^{10}$. This vibration band is shifted to the higher number due to the presence of CTAB. The frequency shift trend indicates the hydrophobicity of the 
resultant material by the surfactant loading. ${ }^{10}$ However, all the FTIR frequencies of the composites decrease with increasing $\mathrm{Cu}_{2} \mathrm{O}$ content, suggesting a reduction in the hydrophobicity of the $\mathrm{Cu}_{2} \mathrm{O}$ composites by replacement of some surfactant. The adsorption band for the $\mathrm{O}-\mathrm{H}$ stretching vibration of $\mathrm{H}$-bonded water ${ }^{10}$ appears in all the samples. This band occurs at $3439 \mathrm{~cm}^{-1}$ in the unmodified geopolymer and is shifted to higher frequencies for the composites containing $\mathrm{CTAB}$ and $\mathrm{Cu}_{2} \mathrm{O}$. The presence of the surfactant causes a decrease in the hydrogen bonding strength of the composite. ${ }^{10}$

Table 6.2. Positions and assignments of the IR vibration bands observed in the range of 400-4000 $\mathrm{cm}^{-1}$

\begin{tabular}{|c|c|c|c|c|c|c|c|}
\hline $\begin{array}{c}\text { Unmodified } \\
\mathrm{GP}\end{array}$ & $\begin{array}{c}\mathrm{GP}- \\
\mathrm{CTAB}\end{array}$ & $\begin{array}{c}\mathrm{GP}- \\
\mathrm{CTAB}- \\
5 \% \mathrm{Cu}_{2} \mathrm{O}\end{array}$ & $\begin{array}{c}\mathrm{GP}- \\
\mathrm{CTAB}- \\
10 \% \mathrm{Cu}_{2} \mathrm{O}\end{array}$ & $\begin{array}{c}\mathrm{GP}- \\
\mathrm{CTAB}- \\
15 \% \mathrm{Cu}_{2} \mathrm{O}\end{array}$ & $\begin{array}{c}\mathrm{GP}- \\
\mathrm{CTAB}- \\
50 \% \mathrm{Cu}_{2} \mathrm{O}\end{array}$ & $\mathrm{Cu}_{2} \mathrm{O}$ & $\mathrm{CTAB}$ \\
\hline $\mathbf{3 8 3 4}$ & & 3772 & 3774 & & 3778 & 3560 & \\
\hline $\mathbf{3 4 3 9}$ & 3444 & 3479 & 3466 & 3464 & 3448 & 3433 & \\
\hline $\mathbf{3 0 1 5}$ & & & & & & & 3016 \\
\hline $\mathbf{2 9 6 7}$ & 2964 & 2966 & 2968 & 2968 & 2968 & & \\
\hline & 2929 & & & & & & 2919 \\
\hline $\mathbf{1 6 4 4}$ & 1652 & 1653 & 1651 & 1649 & 1649 & & 2848 \\
\hline $\mathbf{1 3 8 4}$ & 1384 & 1460 & & & 1462 & & 1475 \\
\hline $\mathbf{1 0 0 2}$ & 1003 & 1009 & 1007 & 1007 & 1007 & & 962 \\
\hline & 872 & 874 & 874 & 874 & & & 910 \\
\hline $\mathbf{6 9 4}$ & 700 & 700 & 698 & 698 & 698 & & 725 \\
\hline & & & 617 & 621 & 627 & 627 & \\
\hline $\mathbf{5 7 8}$ & 588 & 586 & & & & & \\
\hline & & & & & & 521 & \\
\hline & & & & & & 482 & \\
\hline $\mathbf{4 3 7}$ & 440 & 434 & 442 & 444 & 444 & 422 & \\
\hline
\end{tabular}

$-\mathrm{OH}: 3700-3600,-\mathrm{OH}, \mathrm{HOH}: 3600-2200, \mathrm{HOH}: 1700-1600$, Si-O-Si \&Al-O-Si: 1200-950

The CTAB surfactant replaces the hydrated cations and causes a reduction of the $\mathrm{H}_{2} \mathrm{O}$ content, so the H-bonding is strongly reduced, and the surface of the composite is changed from hydrophilic to hydrophobic ${ }^{10}$. Furthermore, the pore structure of the geopolymer may be altered, allowing nano oxides such as $\mathrm{Cu}_{2} \mathrm{O}$ greater access to the cavities. The CTAB cation can be coordinated to the oxygen of the geopolymer from one side and the water molecules on the other side, decreasing the polarising ability and weakening the $\mathrm{H}$-bonds in the isolated hydrated species, ${ }^{10}$ so the $\mathrm{O}-\mathrm{H}$ stretching band is shifted to higher wavenumbers. The vibration corresponding to the $\mathrm{CH}_{2}$ stretching mode of the amine is located at 2918 and 2929 
$\mathrm{cm}^{-1}$ in CTAB and the M-GP respectively. The presence of this band indicates the presence of $\mathrm{CTAB}$ at the surface or inside the geopolymer matrix. The $-\mathrm{CH}-$ stretching vibration disappears in the M-GP- $-\mathrm{Cu}_{2} \mathrm{O}$ composites, due to the interaction between the surfactant and $\mathrm{Cu}_{2} \mathrm{O}$.

The most significant peak which confirms the formation of the geopolymer is related to the $\mathrm{Al}-\mathrm{O}$ and $\mathrm{Si}-\mathrm{O}$ asymmetric stretching vibration ${ }^{11}$ at about $1000 \mathrm{~cm}^{-1}$ is located in the matrix and all the composites. This band is shifted to higher numbers by the addition of $\mathrm{Cu}_{2} \mathrm{O}$ to the modified geopolymer composite, evidencing a small change in the geopolymer structure. The vibration associated with the $\mathrm{Cu}-\mathrm{O}$ stretch is situated at $627 \mathrm{~cm}^{-1}$ in the reference $\mathrm{Cu}_{2} \mathrm{O}$. This vibration appears at almost the same position in the composites containing 10, 15 and $50 \mathrm{wt} \%$ $\mathrm{Cu}_{2} \mathrm{O}$. 


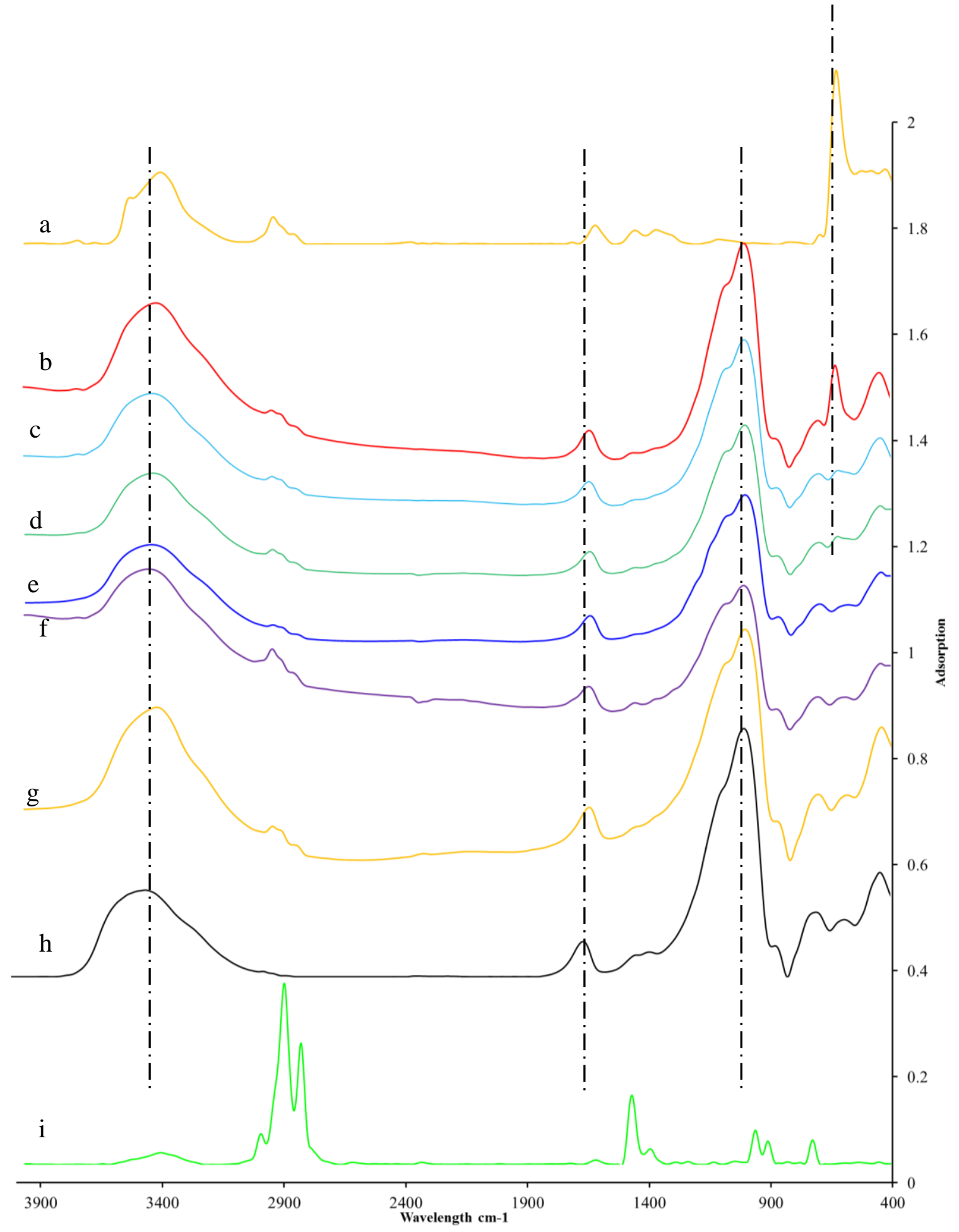

Figure 6.7. FTIR spectra of unmodified $\mathrm{GP}, \mathrm{M}-\mathrm{GP}, \mathrm{Cu}_{2} \mathrm{O}$ and $\mathrm{Cu}_{2} \mathrm{O}$ supported by $\mathrm{GP}$ matrix with different loading contents; (a) $\mathrm{Cu}_{2} \mathrm{O}$, (b) M-GP-50 wt $\% \mathrm{Cu}_{2} \mathrm{O}$, (c) M-GP-30 wt\% $\mathrm{Cu}_{2} \mathrm{O}$, (d) M-GP-15 wt\% $\mathrm{Cu}_{2} \mathrm{O}$, (e) M-GP-10 wt $\% \mathrm{Cu}_{2} \mathrm{O}$, (f) M-GP-5 wt $\% \mathrm{Cu}_{2} \mathrm{O}$, (g) M-GP, (h) GP, (i) $\mathrm{CTAB}$. 


\section{$6.6{ }^{29} \mathrm{Si}$ and ${ }^{27} \mathrm{Al}$ solid state MAS NMR}

The ${ }^{29} \mathrm{Si}$ MAS NMR spectra of the geopolymer and geopolymer composites are shown in Figure 6.8. All the samples contain a principal resonance at about $-87 \mathrm{ppm}$, confirming the considerable saturation of the framework structure in $\mathrm{Al}$, but this peak is broadened due to the presence of several slightly different Si-O-Al environments. ${ }^{121}$ This peak remains essentially unchanged after adding different percentages of $\mathrm{Cu}_{2} \mathrm{O}$ nanoparticles. As was found for the $\mathrm{Cu}_{2} \mathrm{O}$ composites in a unmodified geopolymer matrix (chapter 4), the general characteristics of these ${ }^{29}$ Si MAS NMR spectra are similar, as are the ${ }^{27} \mathrm{Al}$ MAS NMR spectra of the CTABmodified geopolymer composites (Figure 6.9). The ${ }^{27} \mathrm{Al}$ MAS NMR spectrum of the unmodified geopolymer matrix is noticeably narrower than those of the CTAB-modified matrix and corresponding composites; this probably reflects a progressive disruption of the structure by the insertion of the CTAB.

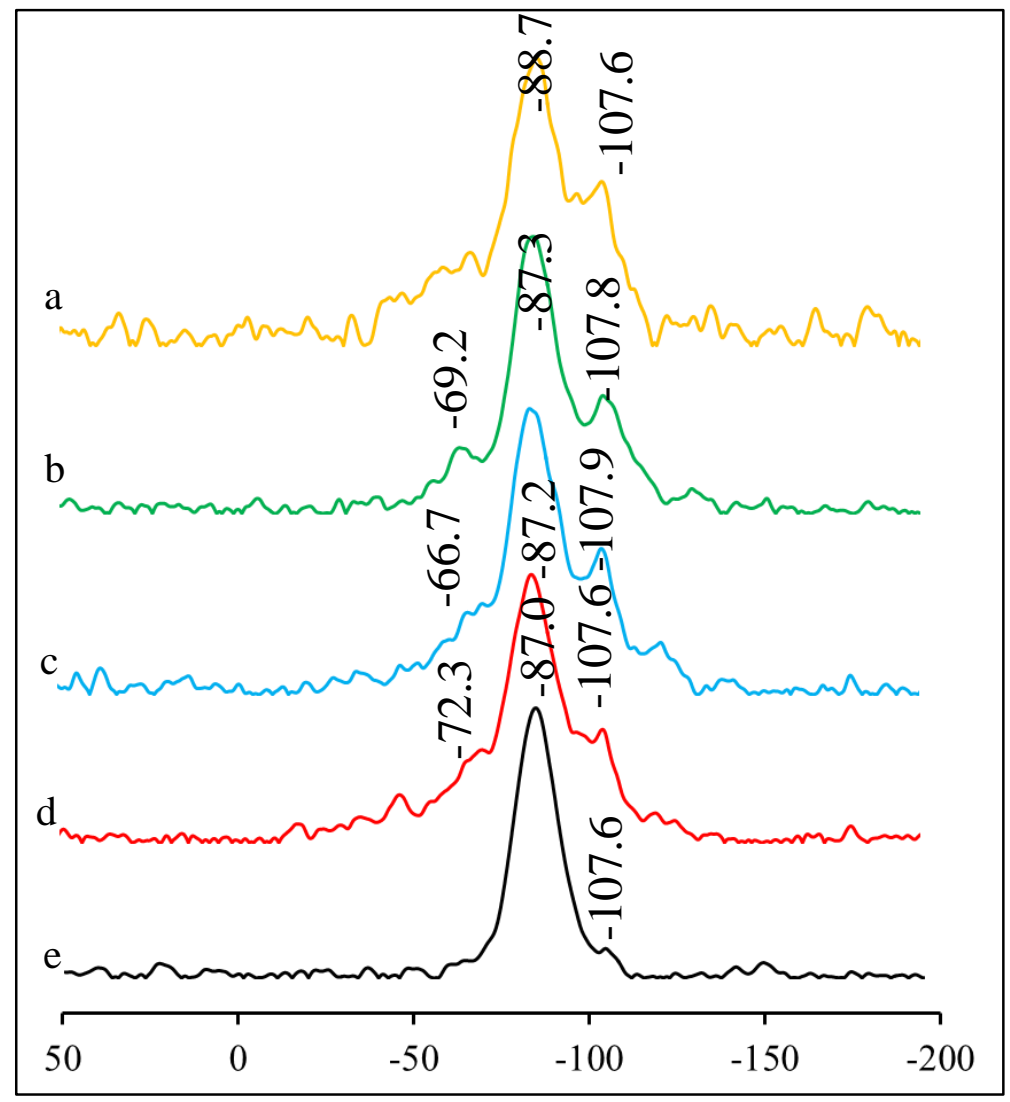

Figure 6.8. 11.7 $\mathrm{T}^{29} \mathrm{Si}$ MAS NMR spectra (a) GP, (b) M-GP, (c) M-GP-10 wt $\% \mathrm{Cu}_{2} \mathrm{O}$, (d) $\mathrm{M}$ GP-30 wt $\% \mathrm{Cu}_{2} \mathrm{O}$, (e) M-GP-50 wt $\% \mathrm{Cu}_{2} \mathrm{O}$ 
Thus, these spectra confirm the successful formation of aluminosilicate geopolymer composites in the presence of the CTAB surfactant.

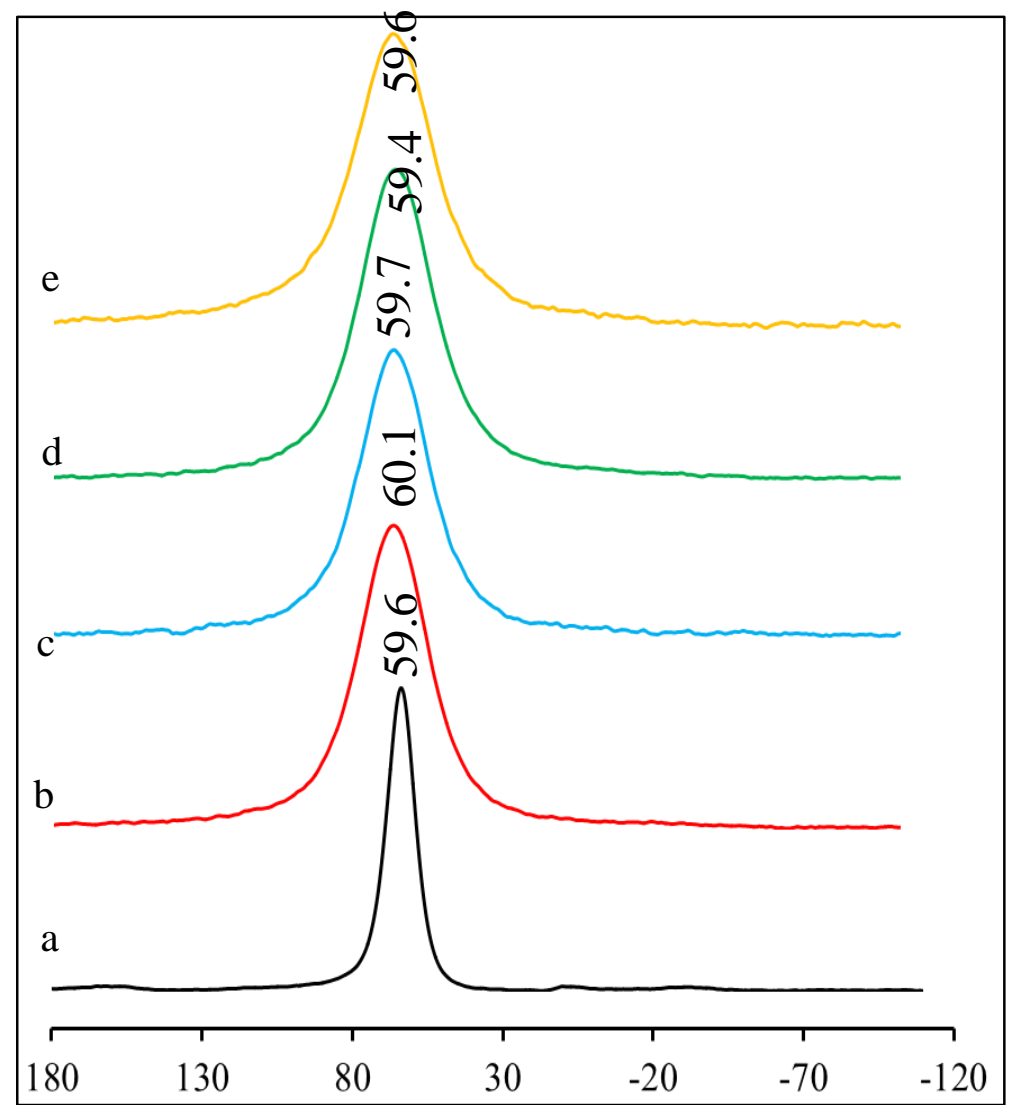

Figure 6.9. $11.7 \mathrm{~T}{ }^{27} \mathrm{Al}$ MAS NMR spectra (a) GP, (b) M-GP, (c) M-GP-10 wt\% $\mathrm{Cu}_{2} \mathrm{O}$, (d) MGP-30 wt $\% \mathrm{Cu}_{2} \mathrm{O}$, (e) M-GP-50 wt $\% \mathrm{Cu}_{2} \mathrm{O}$.

\subsection{Adsorption of MB}

\subsubsection{Reactions under dark conditions}

As with the composites formed with the unmodified geopolymer matrix discussed in chapter 4, a corresponding set of experiments was conducted on the composites formed with the CTAB-modified geopolymer matrix. The CTAB-modified composites are expected to decolorize the MB dye by a combination of adsorption on the geopolymer matrix (in the dark), and by photodegradation (under UV irradiation). For this reason, the adsorption characteristics of these composites were first investigated in the dark. Figure 6.10 shows the change in the relative concentration $\left(\mathrm{C} / \mathrm{C}_{0}\right)$ of $\mathrm{MB}$ dye solution with time in the dark for the CTAB-modified geopolymer matrix and the corresponding composites with 5, 10, 15 and 50 wt $\% \mathrm{Cu}_{2} \mathrm{O}$. By contrast with the experiments using the unmodified geopolymer matrix which 
did not reach equilibrium, but adsorbed the dye continuously (Chapter 4), the CTAB-matrix samples reached equilibrium after 12 hour. The most rapid decrease in MB colour and greatest degree of adsorption reached at equilibrium was observed in the composites containing 5-10 wt\% $\mathrm{Cu}_{2} \mathrm{O}$. The slower adsorption rates and lower degree of adsorption at equilibrium in the samples containing higher concentrations of $\mathrm{Cu}_{2} \mathrm{O}$ may be due to blocking of the active adsorption sites by the presence of the additional oxide and is particularly noticeable in the sample containing $50 \mathrm{wt} \% \mathrm{Cu}_{2} \mathrm{O}$.

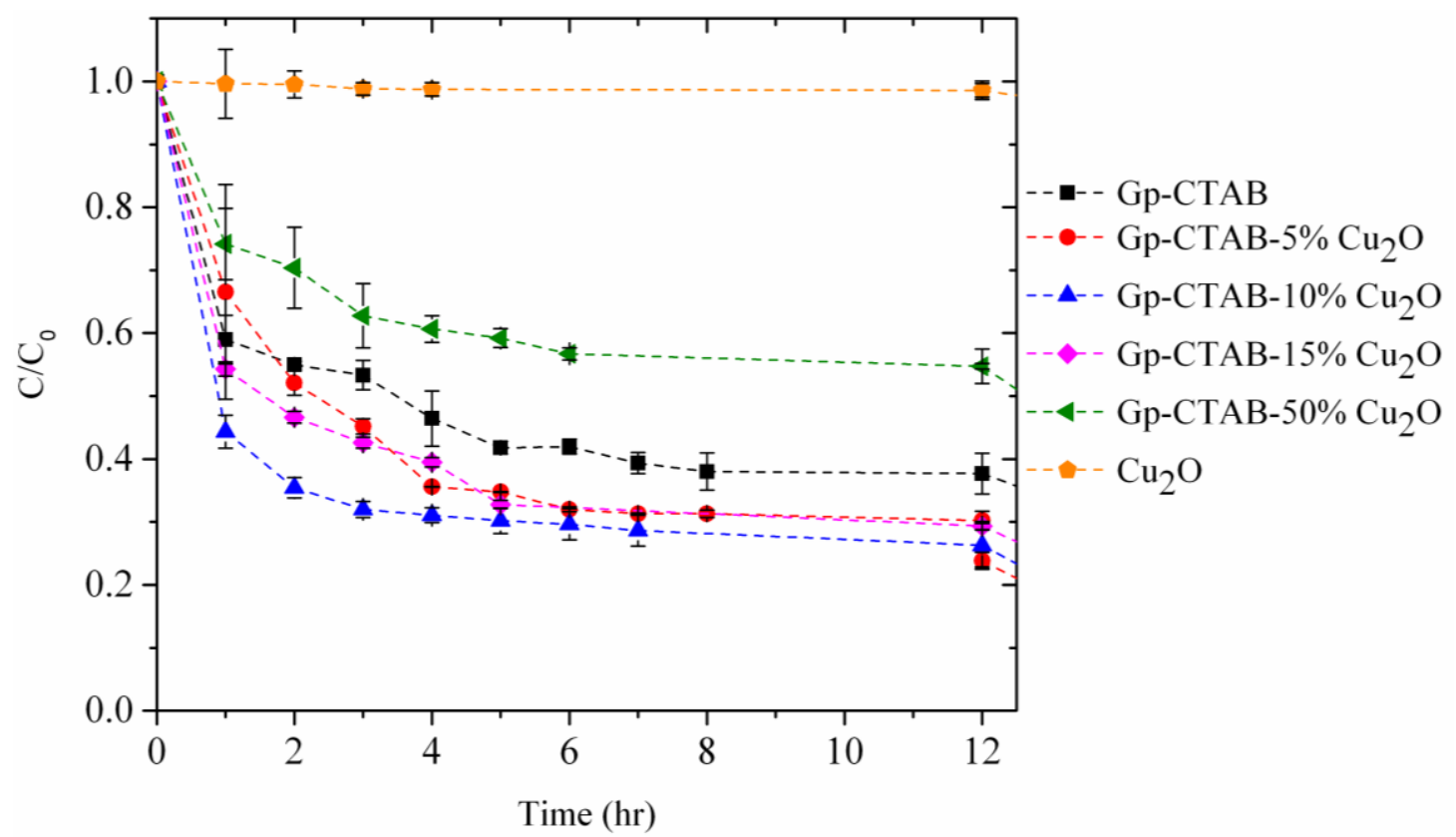

Figure 6.10. Plots of the residual concentration $\left(\mathrm{C} / \mathrm{C}_{0}\right)$ vs. time $(\mathrm{t})$ onto the GP matrix, M-GP 5, 10, 15 and $50 \mathrm{wt} \% \mathrm{Cu}_{2} \mathrm{O}$ (monitored at $664 \mathrm{~nm}$ in dark)

As with the composites of unmodified geopolymer, the adsorption data were fitted to both pseudo-first order and pseudo-second order kinetic equations, ${ }^{181}, 182$ but the fits to the pseudofirst-order model were poorer, as suggested by comparison of the experimental values $\mathrm{q}_{\exp }$ with the $\mathrm{q}_{\mathrm{e}}$ values and the correlation coefficients $\mathrm{R}^{2}$ (Table 6.3). In addition, the correlation coefficients for the second order kinetic model are $>0.99$ (Table 6.3) confirming the superior fit to the second order kinetic model. (see Figure 6.11.)

The difference between the adsorption kinetic model followed by the composites based on the unmodified geopolymer matrix (pseudo first-order) and the present CTAB-modified matrix is interesting, and arises from differences in the matrix itself. This is not unexpected; the kinetic order of adsorption is known to depend on the nature of the matrix since in the case of dye adsorption on a fly ash geopolymer matrix, second order kinetics were followed, reflecting the presence of impurities in the fly ash. ${ }^{195}$ 

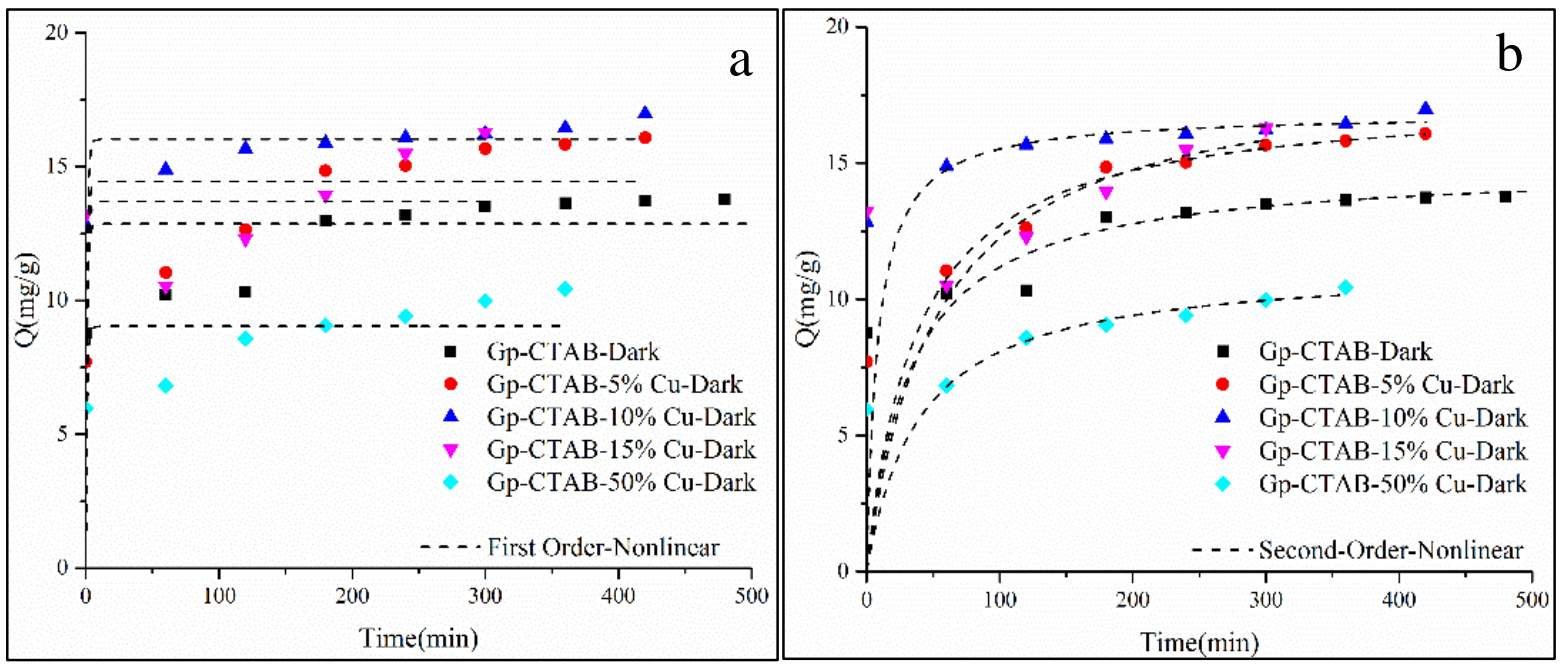

Figure 6.11. (a) Pseudo first-order kinetics, (b) Pseudo second-order kinetics by the nonlinear method and experimental kinetics for the adsorption of MB onto M-GP and GP composites.

Table 6.3. Parameters for kinetic models of MB adsorption on CTAB-based samples

\begin{tabular}{|c|c|c|c|c|c|}
\hline Sample & $\begin{array}{l}\text { Kinetic } \\
\text { model }\end{array}$ & $\mathrm{q}_{\exp (\mathrm{mg} / \mathrm{g})}$ & $\mathrm{q}_{\mathrm{e}(\mathrm{mg} / \mathrm{g})}$ & $\mathrm{k}$ & $\mathrm{R}^{2}$ \\
\hline M-GP & $1^{\text {st }}$-order & 14.40 & 12.86 & 240.78 & 0.97 \\
\hline$"$ & $2^{\text {nd }}$-order & “ & 14.91 & 0.52 & 0.97 \\
\hline M-GP-5 wt $\% \mathrm{Cu}_{2} \mathrm{O}$ & $1^{\text {st }}$-order & 16.08 & 14.45 & 163.43 & 0.92 \\
\hline " $" 1$ & $2^{\text {nd }}$-order & “ & 17.50 & 99.56 & 0.99 \\
\hline $\mathrm{M}-\mathrm{GP}-10 \mathrm{wt} \% \mathrm{Cu}_{2} \mathrm{O}$ & $1^{\text {st }}$-order & 16.98 & 16.02 & 704.05 & 0.99 \\
\hline$"$ & $2^{\text {nd }}-$ order & $"$ & 16.84 & 3.39 & 0.92 \\
\hline M-GP-15 wt $\% \mathrm{Cu}_{2} \mathrm{O}$ & $1^{\text {st }}$-order & 16.28 & 13.71 & 984.54 & 0.96 \\
\hline " " $"$ & $2^{\text {nd }}$-order & " & 18.59 & 80.49 & 0.97 \\
\hline $\mathrm{M}-\mathrm{GP}-50 \mathrm{wt} \% \mathrm{Cu}_{2} \mathrm{O}$ & $1^{\text {st }}$-order & 10.43 & 9.049 & 337.56 & 0.95 \\
\hline " " & 2nd-order & " & 11.28 & 1.38 & 0.99 \\
\hline
\end{tabular}




\subsubsection{MB dye adsorption isotherms under dark conditions}

As for the previous composites (chapter 4) the equilibrium adsorption data were fitted to the three isotherms (Langmuir, Freundlich and Langmuir-Freundlich, eqs. 31-33) ${ }^{17,} 178$ The results of the three models are displayed in Figure 6.12. The adsorption of MB dye in the dark on the CTAB-modified geopolymer matrix is well fitted by both the Langmuir and Freundlich models, with a high $\mathrm{R}^{2}$ value (0.99). The CTAB-modified geopolymer composites containing 5, 10 and $50 \mathrm{wt} \% \mathrm{Cu}_{2} \mathrm{O}$ are fitted by the Langmuir-Freundlich model which gives the highest $\mathrm{R}^{2}$ values (1.0, 0.99 and 0.99 respectively) but the $15 \%-\mathrm{Cu}_{2} \mathrm{O}-\mathrm{CTAB}$-modified geopolymer is better fitted to the Freundlich model $\left(R^{2}=0.97\right)$. The similarity of all these fits as reflected by their $\mathrm{R}^{2}$ values militates against distinguishing any one isotherm as being the most appropriate to describe the $\mathrm{MB}$ adsorption on these composite, but visual inspection of the plots of the isotherm data (Figure 6.12) suggests that the Langmuir-Freundlich may be the more appropriate description for all samples.
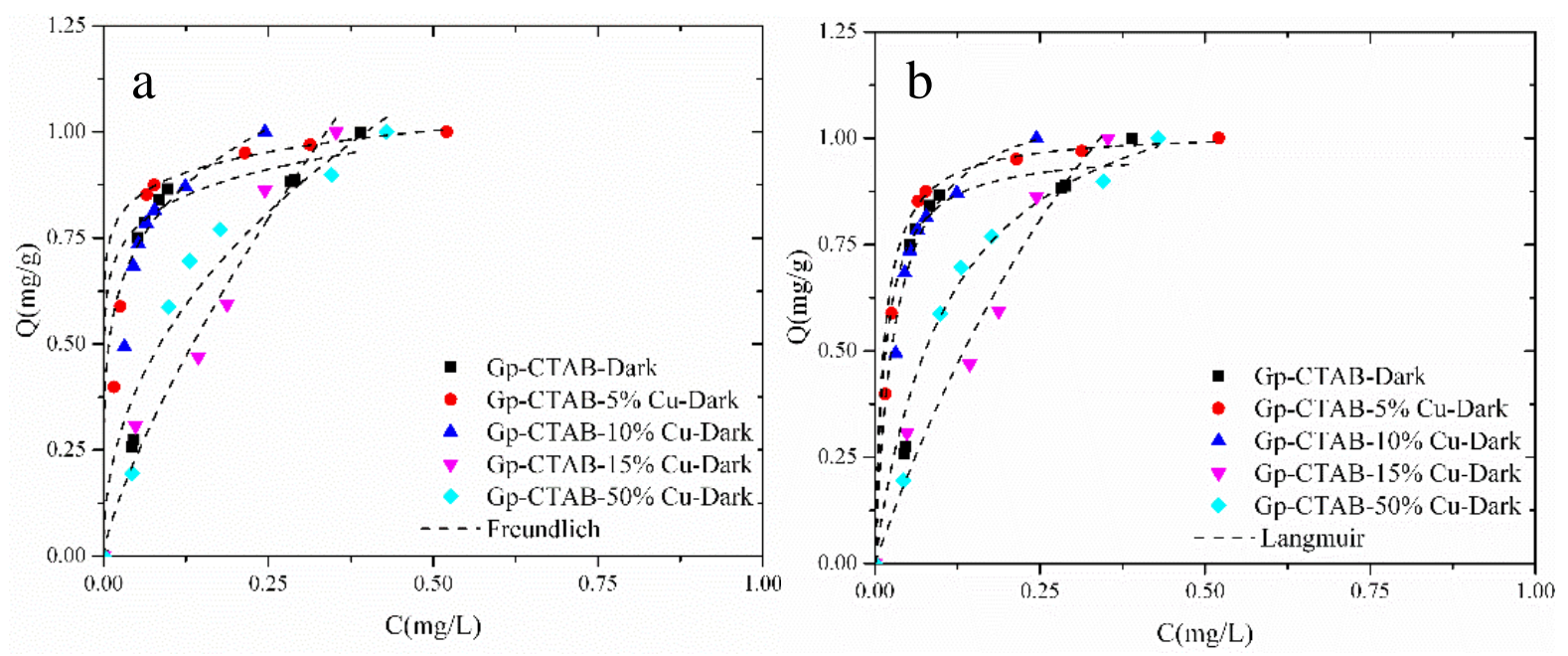

Figure 6.12. (a,b) adsorption isotherms for MB adsorption and the corresponding Freundlich and Langmuir models fit (dashed lines). 


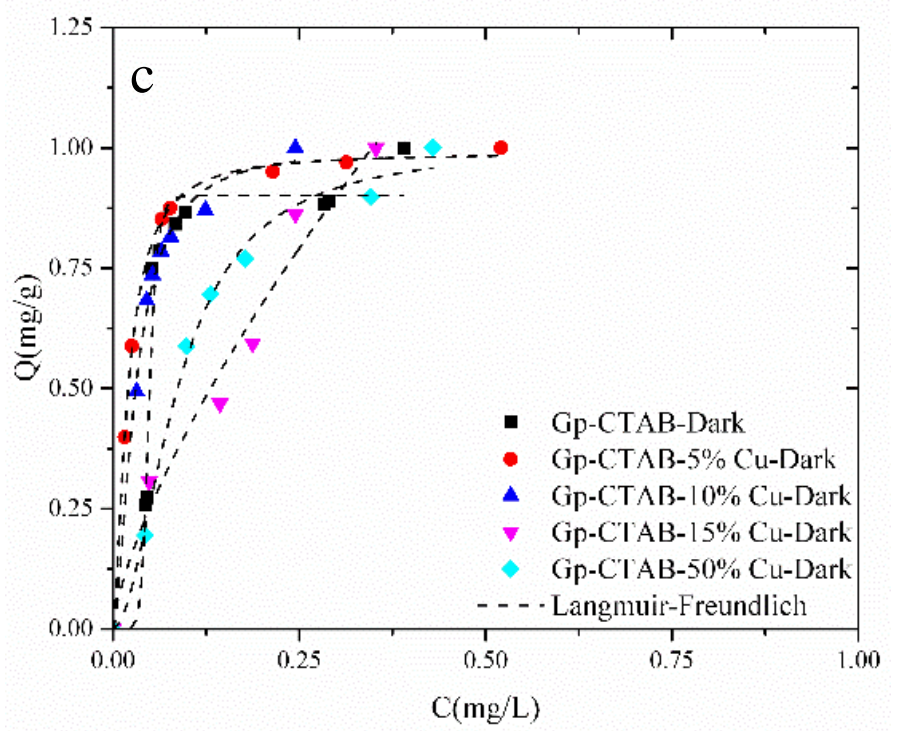

Figure 6.12. (Continued) (c) adsorption isotherms for MB adsorption and the corresponding Langmuir-Freundlich models fit (dashed lines).

\subsubsection{Reactions under UV radiation}

By contrast with the behaviour of composites based on the unmodified geopolymer matrix (Chapter 4) in which adsorption occurred continuously and never reached equilibrium, the composites based on $\mathrm{CTAB}$-modified geopolymer matrices reached equilibrium under dark conditions, as demonstrated in section 6.7.1. This property of the matrix results from modification of the pore surfaces by the $\mathrm{CTAB}$, producing a stable $\mathrm{pH}$ matrix which may act as a $\mathrm{pH}$ buffer and allow the two dye removal processes to be separated. The degradation of $\mathrm{MB}$ by the photocatalyst composites at room temperature was therefore determined in a separate set of experiments in which the fresh catalyst/dye solution was allowed to equilibrate in the dark for 12 hour to determine the amount of MB adsorbed onto the composites before photodegradation. After equilibration, the system was subjected to UV irradiation and the further change in $\mathrm{MB}$ concentration resulting from the photodegradation step was monitored by removing aliquots, centrifuging and measuring their absorbance. Each experiment was repeated a minimum of three times.

Figure 6.13 shows the results of MB degradation by these samples under both dark and UV conditions as a function of time. Under dark conditions, none of the metal oxide samples removes $\mathrm{MB}$ from solution, indicating that the nano structure and surface properties of these oxides is not effective in absorbing the dye.

Incorporation of 10 and $15 \mathrm{wt} \% \mathrm{Cu}_{2} \mathrm{O}$ nanoparticles into the CTAB-modified geopolymer produced much better photocatalytic activity than other samples, suggesting that the CTAB is 
acting to open the geopolymer matrix structure, facilitating access of the dye to the internal adsorption sites. In addition, by being able to separate the two processes of adsorption and photodegradation, these results confirm the $\mathrm{Cu}_{2} \mathrm{O}$-geopolymer nano composites have significantly improved photocatalytic activity under UV irradiation compared with the $\mathrm{Cu}_{2} \mathrm{O}$ nanoparticles alone.

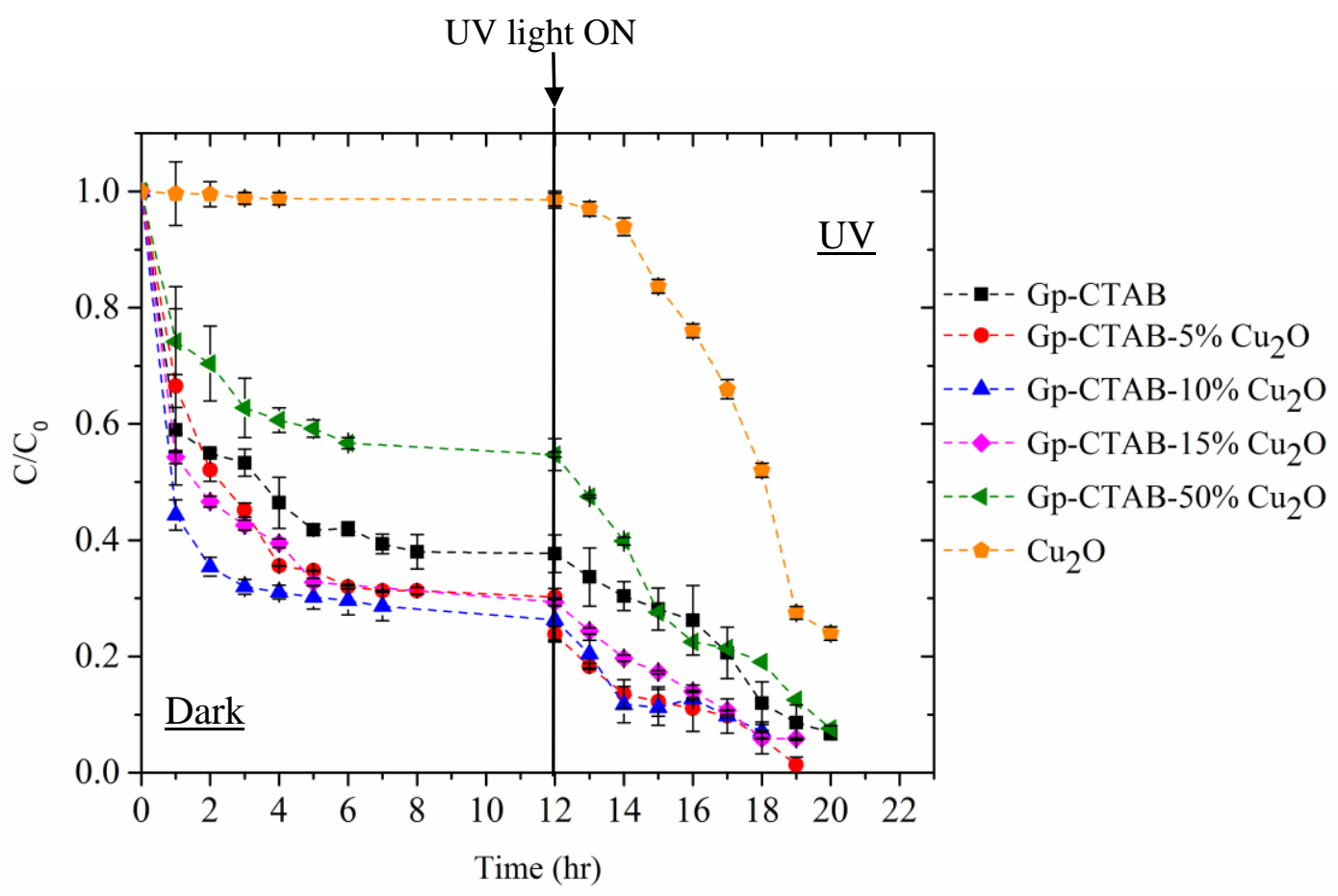

Figure 6.13. Plots of the residual concentration $\left(\mathrm{C} / \mathrm{C}_{0}\right)$ vs. time $(\mathrm{t})$ onto the $\mathrm{M}-\mathrm{GP}, \mathrm{Cu}_{2} \mathrm{O}$ and M-GP-5, 10, 15, $50 \mathrm{wt} \% \mathrm{Cu}_{2} \mathrm{O}$ (monitored at $664 \mathrm{~nm}$ ) under different conditions.

Figure 6.14 compares the removal of $\mathrm{MB}$ by the CTAB-modified geopolymer, the CTABmodified geopolymer composite containing different amounts of $\mathrm{Cu}_{2} \mathrm{O}$, and $\mathrm{Cu}_{2} \mathrm{O}$ itself after $60 \mathrm{~min}$. in the dark and under UV irradiation. This figure shows that the elimination of MB from aqueous solution under UV irradiation by the composites of the CTAB-modified geopolymer with $\mathrm{Cu}_{2} \mathrm{O}$ is more effective than by $\mathrm{Cu}_{2} \mathrm{O}$ alone. It can be seen that only about $10 \% \mathrm{MB}$ is removed in the dark by $\mathrm{Cu}_{2} \mathrm{O}$ alone while in the geopolymer composites more than half the MB is removed by adsorption on the geopolymer. The adsorption process is more efficient in the composites containing lower $\mathrm{Cu}_{2} \mathrm{O}$ contents (5-10 wt\%) and decreases with increasing $\mathrm{Cu}_{2} \mathrm{O}$ content. The highest degree of $\mathrm{MB}$ removal by both the adsorption and photodegradation processes occurs in the CTAB-modified geopolymer containing $10 \% \mathrm{Cu}_{2} \mathrm{O}$. The poorer performance of the compounds containing higher $\mathrm{Cu} 2 \mathrm{O}$ contents is probably due 
to the blocking of the active sites for adsorption and photodegradation by the oxide nanoparticles.

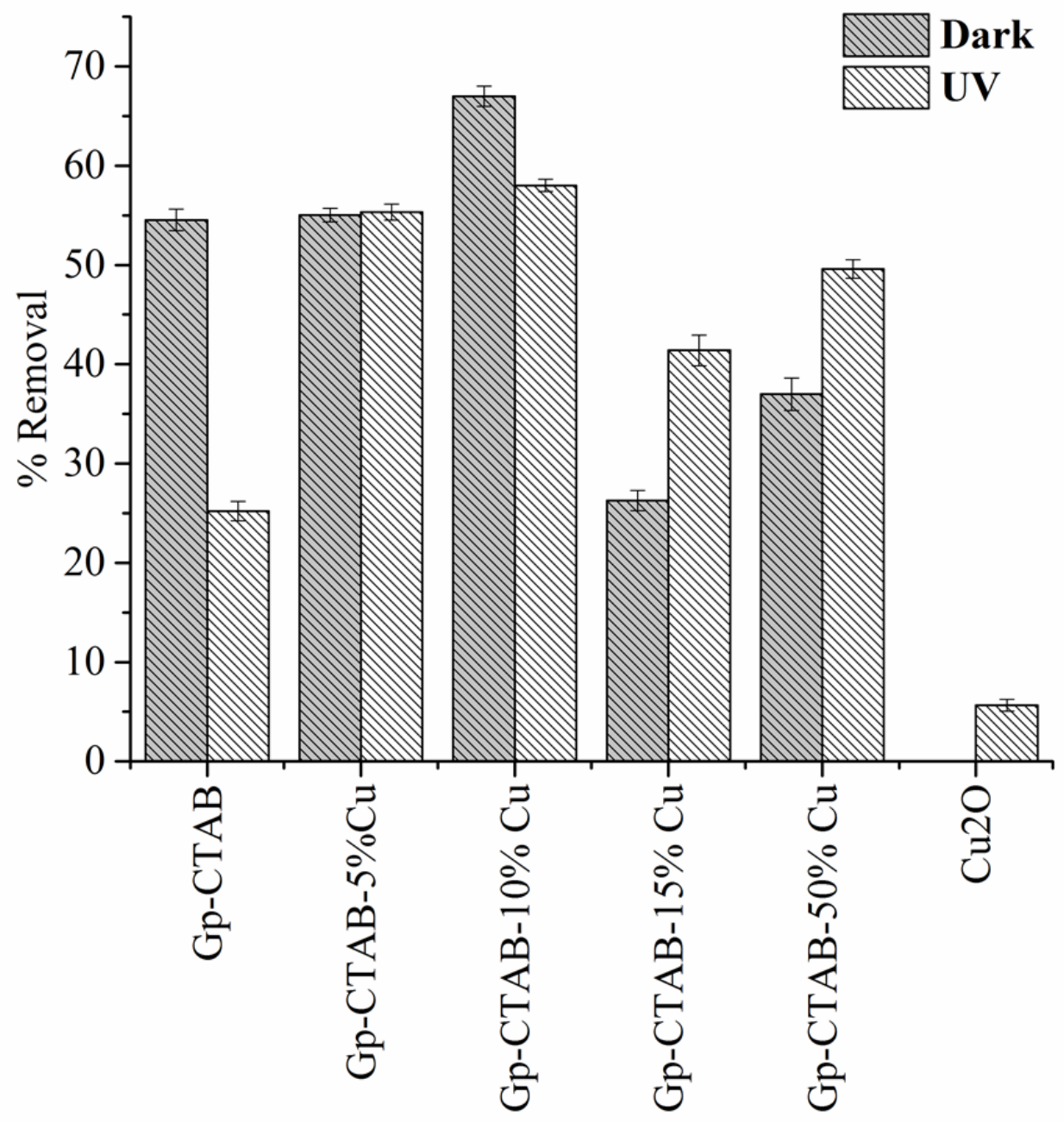

Figure 6.14. MB removal by the M-GP matrix, M-GP composites containing 5, 10, 15 and 50 wt\% $\mathrm{Cu}_{2} \mathrm{O}$ and $\mathrm{Cu}_{2} \mathrm{O}$ alone after 60 min.

\subsubsection{Nitrogen Adsorption/Desorption Isotherms}

Possible explanations for the improved behaviour of the CTAB-modified geopolymer matrix were sought by making measurements of the surface area and porosity of the unmodified and CTAB-modified geopolymers and their $\mathrm{Cu}_{2} \mathrm{O}$-containing composites by determining their $\mathrm{N}_{2}$ adsorption-desorption isotherms (Table 6.5). 
The specific surface areas derived from these adsorption/desorption isotherms (Figure 6.15) indicate that these are relatively similar in the unmodified and CTAB-modified geopolymer matrices, whereas the inclusion of $\mathrm{CTAB}$ results in a decrease in the pore volume and pore size (Table 6.5). Incorporation of 10 and $15 \mathrm{wt} \% \mathrm{Cu}_{2} \mathrm{O}$ results in an increase in the BET surface area from $17.02 \mathrm{~m}^{2} / \mathrm{g}$ in the CTAB-modified geopolymer matrix to $27.27 \mathrm{~m}^{2} / \mathrm{g}$ and $23.73 \mathrm{~m}^{2} / \mathrm{g}$ in the composites containing 10 and $15 \mathrm{wt} \% \mathrm{Cu}_{2} \mathrm{O}$ respectively. Similar trends are seen in the Langmuir surface areas and the cumulative surface areas of the pores calculated by the BJH method (Table 6.5). This is accompanied by a corresponding decrease in the pore size from $43.09 \mathrm{~nm}$ in the CTAB-modified geopolymer matrix to $31.56 \mathrm{~nm}$ in the composite containing $10 \mathrm{wt} \% \mathrm{Cu}_{2} \mathrm{O}$, remaining approximately constant at $32.67 \mathrm{~nm}$ in the composite containing $15 \mathrm{wt} \% \mathrm{Cu}_{2} \mathrm{O}$. Thus, the superior performance of the composite containing 10 wt $\% \mathrm{Cu}_{2} \mathrm{O}$ under both dark and UV conditions, appears to be due to the improved ability ability of the oxide to enter the matrix pore structure, without causing too much constriction of the pore volume, as occurs at higher oxide concentrations.

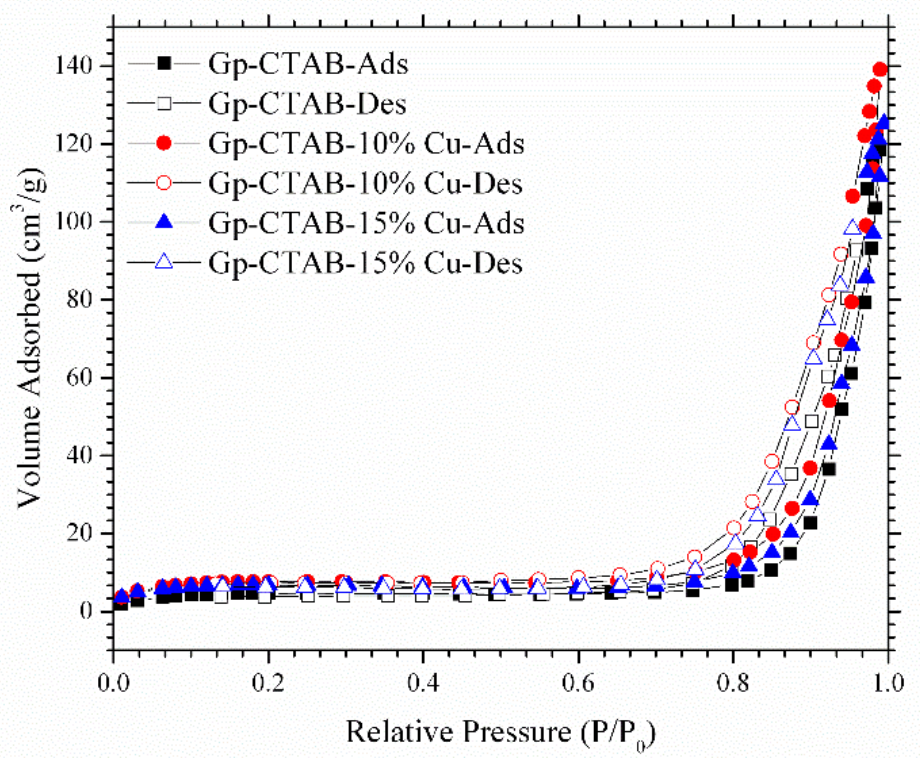

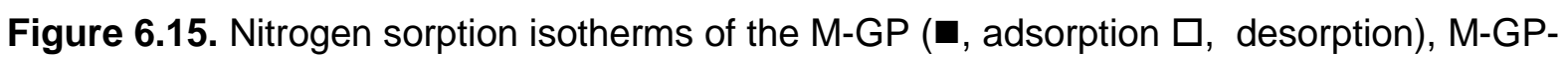
$10 \mathrm{wt} \% \mathrm{Cu}_{2} \mathrm{O}(\boldsymbol{O}$, adsorption $\bigcirc$, desorption $)$ and $\mathrm{M}-\mathrm{GP}-15 \mathrm{wt} \% \mathrm{Cu}_{2} \mathrm{O}(\boldsymbol{\Delta}$, adsorption $\triangle$, desorption) 
Table 6.4. Specific surface areas and pore parameters of geopolymer and geopolymer composites

\begin{tabular}{|c|c|c|c|c|}
\hline & GP & M-GP & $\begin{array}{c}\text { M-GP-10 wt\%- } \\
\mathrm{Cu}_{2} \mathrm{O}\end{array}$ & $\begin{array}{c}\text { M-GP-15 wt\%- } \\
\mathrm{Cu}_{2} \mathrm{O}\end{array}$ \\
\hline Single Point Surface Area & $18.44 \mathrm{~m}^{2} / \mathrm{g}$ & $16.14 \mathrm{~m}^{2} / \mathrm{g}$ & $26.59 \mathrm{~m}^{2} / \mathrm{g}$ & $23.52 \mathrm{~m}^{2} / \mathrm{g}$ \\
\hline $\mathrm{S}_{\text {BET }}$ & $17.23 \mathrm{~m}^{2} / \mathrm{g}$ & $17.025 \mathrm{~m}^{2} / \mathrm{g}$ & $27.27 \mathrm{~m}^{2} / \mathrm{g}$ & $23.73 \mathrm{~m}^{2} / \mathrm{g}$ \\
\hline $\mathrm{S}_{\text {Langmuir }}$ & $21.92 \mathrm{~m}^{2} / \mathrm{g}$ & $23.44 \mathrm{~m}^{2} / \mathrm{g}$ & $37.07 \mathrm{~m}^{2} / \mathrm{g}$ & $31.95 \mathrm{~m}^{2} / \mathrm{g}$ \\
\hline $\mathrm{S}_{\text {BJH Adsorption Cumulative }}$ & $23.06 \mathrm{~m}^{2} / \mathrm{g}$ & $21.41 \mathrm{~m}^{2} / \mathrm{g}$ & $28.72 \mathrm{~m}^{2} / \mathrm{g}$ & $23.96 \mathrm{~m}^{2} / \mathrm{g}$ \\
\hline $\mathrm{S}$ BJH Desorption Cumulative & $38.94 \mathrm{~m}^{2} / \mathrm{g}$ & $33.63 \mathrm{~m}^{2} / \mathrm{g}$ & $43.60 \mathrm{~m}^{2} / \mathrm{g}$ & $39.70 \mathrm{~m}^{2} / \mathrm{g}$ \\
\hline \multicolumn{5}{|l|}{ Volume } \\
\hline Single Point Adsorption & $0.24 \mathrm{~cm}^{3} / \mathrm{g}$ & $0.18 \mathrm{~cm}^{3} / \mathrm{g}$ & $0.22 \mathrm{~cm}^{3} / \mathrm{g}$ & $0.19 \mathrm{~cm}^{3} / \mathrm{g}$ \\
\hline $\mathrm{V}_{\text {pore }} \mathrm{BJH}$ Adsorption Cumulative & $0.24 \mathrm{~cm}^{3} / \mathrm{g}$ & $0.18 \mathrm{~cm}^{3} / \mathrm{g}$ & $0.22 \mathrm{~cm}^{3} / \mathrm{g}$ & $0.19 \mathrm{~cm}^{3} / \mathrm{g}$ \\
\hline $\mathrm{V}_{\text {pore BJH Desorption Cumulative }}$ & $0.24 \mathrm{~cm}^{3} / \mathrm{g}$ & $0.18 \mathrm{~cm}^{3} / \mathrm{g}$ & $0.22 \mathrm{~cm}^{3} / \mathrm{g}$ & $0.19 \mathrm{~cm}^{3} / \mathrm{g}$ \\
\hline \multicolumn{5}{|l|}{ Pore Size } \\
\hline D Adsorption & $55 \mathrm{~nm}$ & $43 \mathrm{~nm}$ & $32 \mathrm{~nm}$ & $33 \mathrm{~nm}$ \\
\hline D BJH Adsorption & $41 \mathrm{~nm}$ & $34 \mathrm{~nm}$ & $30 \mathrm{~nm}$ & $32 \mathrm{~nm}$ \\
\hline D BJH Desorption & $24 \mathrm{~nm}$ & $22 \mathrm{~nm}$ & $20 \mathrm{~nm}$ & $20 \mathrm{~nm}$ \\
\hline
\end{tabular}

\section{Conclusions}

This chapter confirms the successful preparation of a new geopolymer matrix with a pore structure expanded by the inclusion of the large quaternary ammonium ion CTAB. Composites of $\mathrm{Cu}_{2} \mathrm{O}$ nanoparticles with this expanded matrix have an increased surface area facilitating the entry of $\mathrm{Cu}_{2} \mathrm{O}$ nanoparticles into the internal pores of the geopolymer matrix. This phenomenon is also reflected by a decrease in the pore diameter after the addition of the nanoparticles. The uniform dispersion of the oxide nanoparticles in the composites was demonstrated by SEM/EDS and TEM. One major benefit of the use of this CTAB-modified matrix in $\mathrm{MB}$ dye removal experiments is its maintenance of a stable $\mathrm{pH}$, enabling it to separate the two processes of adsorption and photodegradation in these composites. Unlike composites of unmodified geopolymers, the adsorption of MB dye on composites with CTAB-modified geopolymer matrices in the dark follow pseudo second-order kinetics, but are similar to composites with unmodified matrices in being described by Freundlich- 
Langmuir type isotherms. Incorporation of $10 \mathrm{wt} \% \mathrm{Cu}_{2} \mathrm{O}$ into the geopolymer composites removes the highest percentage of $\mathrm{MB}$ under UV irradiation, and this is achieved by a combination of adsorption and photodegradation. 


\section{Chapter 7}

\section{Composites of CTAB-modified geopolymer matrices containing $\mathrm{Cu}_{2} \mathrm{O} / \mathrm{TiO}_{2}$ nano-heterostructures and P25 titania}

\section{Introduction}

The previous chapter demonstrated the previously unexplored possibility of producing a geopolymer matrix in which the pore structure is modified by the insertion of the large quaternary ammonium cation $\mathrm{CTAB}$. Composites of this matrix with $\mathrm{Cu}_{2} \mathrm{O}$ nanoparticles were synthesised and their structures and photoactive properties were investigated. A particular advantage of composites based on this modified matrix was shown to be its ability to act as a $\mathrm{pH}$ buffer, allowing the dual processes of $\mathrm{MB}$ dye adsorption and photodegradation to be distinguished. This chapter brings together the advantage of this new matrix with the improved photoactivity obtained by combining $\mathrm{Cu}_{2} \mathrm{O}$ with $\mathrm{P} 25 \mathrm{TiO}_{2}$ into a $\mathrm{Cu}_{2} \mathrm{O} / \mathrm{TiO}_{2}$ nano-heterostructure, as demonstrated in chapter 5 . The spherical nanocrystalline $\mathrm{Cu}_{2} \mathrm{O} / \mathrm{TiO}_{2}$ heterostructures were synthesized as described in chapter 3 , section 3.3 and the structural characteristics of the resulting composites were determined as previously by XRD, FTIR, SEM/EDS and HRTEM. The photocatalytic properties of the composites in the degradation of MB were determined as in chapter 6 by bringing the adsorption step to equilibrium in the dark, then initiating the photodegradation step by exposing the samples to UV radiation. For comparison, a corresponding set of samples containing P25 titania alone were prepared and studied.

\section{Results and Discussion}

\subsection{Elemental Analysis}

The chemical composition of all samples obtained by X-ray fluorescence (Table 7.1), confirmed the incorporation of $\mathrm{Cu}$ and $\mathrm{Ti}$ in different amounts in each composite. The $\mathrm{Na}$ content was dramatically decreased due to exchange by $\mathrm{Cu}^{+}$and $\mathrm{Ti}^{4+}$ ions. The increase in the $\mathrm{Ti} / \mathrm{Si}$ and $\mathrm{Cu} / \mathrm{Si}$ ratio confirmed the increase in the oxide elements and the presence of $\mathrm{Cu}-\mathrm{Ti}$ oxides within the geopolymer matrix. The percentage of bromide decreased after addition of the nano oxide particles and confirmed the removal of bromide ions in the washing step accompanying the insertion of the metal oxide nanoparticles. 
Table 7.1. XRF analysis (wt \%) of the major elements in the geopolymer samples of different composition

\begin{tabular}{|c|c|c|c|c|c|}
\hline & $\begin{array}{l}\text { Halloysite } \\
\text { clay }\end{array}$ & $\begin{array}{c}\text { GP } \\
\text { unmodified }\end{array}$ & M-GP & $\begin{array}{c}\text { M-GP- } \\
10 \mathrm{wt} \% \mathrm{Cu} / \mathrm{Ti}\end{array}$ & $\begin{array}{c}\text { M-GP- } \\
15 \mathrm{wt} \% \mathrm{Cu} / \mathrm{Ti}\end{array}$ \\
\hline $\mathrm{Na}_{2} \mathrm{O}$ & 0.04 & 15.2 & 16.8 & 11.6 & 10.2 \\
\hline $\mathbf{A l}_{2} \mathbf{O}_{3}$ & 35.5 & 23.7 & 23.0 & 22.0 & 20.0 \\
\hline $\mathrm{SiO}_{2}$ & 49.5 & 46.2 & 44.8 & 42.5 & 38.8 \\
\hline $\mathrm{TiO}_{2}$ & 0.09 & 0.043 & 0.048 & 3.97 & 5.45 \\
\hline $\mathrm{Fe}_{2} \mathrm{O}_{3}$ & 0.29 & 0.193 & 0.194 & 0.194 & 0.192 \\
\hline $\mathrm{Cu}_{2} \mathrm{O}$ & - & 0.005 & - & 2.52 & 3.69 \\
\hline Br & - & - & 0.342 & 0.014 & 0.007 \\
\hline $\mathbf{Z r O}_{2}$ & & 0.007 & 0.005 & 0.008 & 0.007 \\
\hline LOI & 13.8 & 14.46 & 14.68 & 17.05 & 21.5 \\
\hline $\mathrm{SiO}_{2} / \mathrm{Al}_{2} \mathrm{O}_{3}$ & 1.39 & 1.95 & 1.95 & 1.93 & 1.93 \\
\hline $\mathrm{TiO}_{2} \mathrm{SiO}_{2}$ & - & - & - & 0.09 & 0.14 \\
\hline $\mathrm{Cu}_{2} \mathrm{O} / \mathrm{SiO}_{2}$ & - & - & - & 0.06 & 0.09 \\
\hline
\end{tabular}

\subsection{XRD Analysis}

Figure 7.1 shows the XRD patterns of the CTAB-modified geopolymer composites with different $\mathrm{Cu}_{2} \mathrm{O} / \mathrm{TiO}_{2}$ contents. As found for the $\mathrm{CTAB}$-modified geopolymer containing $\mathrm{Cu}_{2} \mathrm{O}$ (chapter 6), the XRD traces of the composites show that the modified geopolymer matrix is typically X-ray amorphous and similar to the unmodified matrix (chapters 4 and 5). The characteristic diffraction peaks for anatase at $2 \theta=25.29,(111), \mathrm{Cu}_{2} \mathrm{O}$ at $2 \theta=36.50$ and the (310) reflection of rutile at $2 \theta=64.00$ are present in the XRD patterns of the composites containing the $\mathrm{Cu}_{2} \mathrm{O} / \mathrm{TiO}_{2}$. However for the $\mathrm{M}-\mathrm{GP}-\mathrm{Cu}_{2} \mathrm{O} / \mathrm{TiO}_{2}$ composites containing 5 and $10 \mathrm{wt} \% \mathrm{Cu}_{2} \mathrm{O} / \mathrm{TiO}_{2}$, there is insufficient nano-heterostructure present for these reflections to be observed by XRD. 


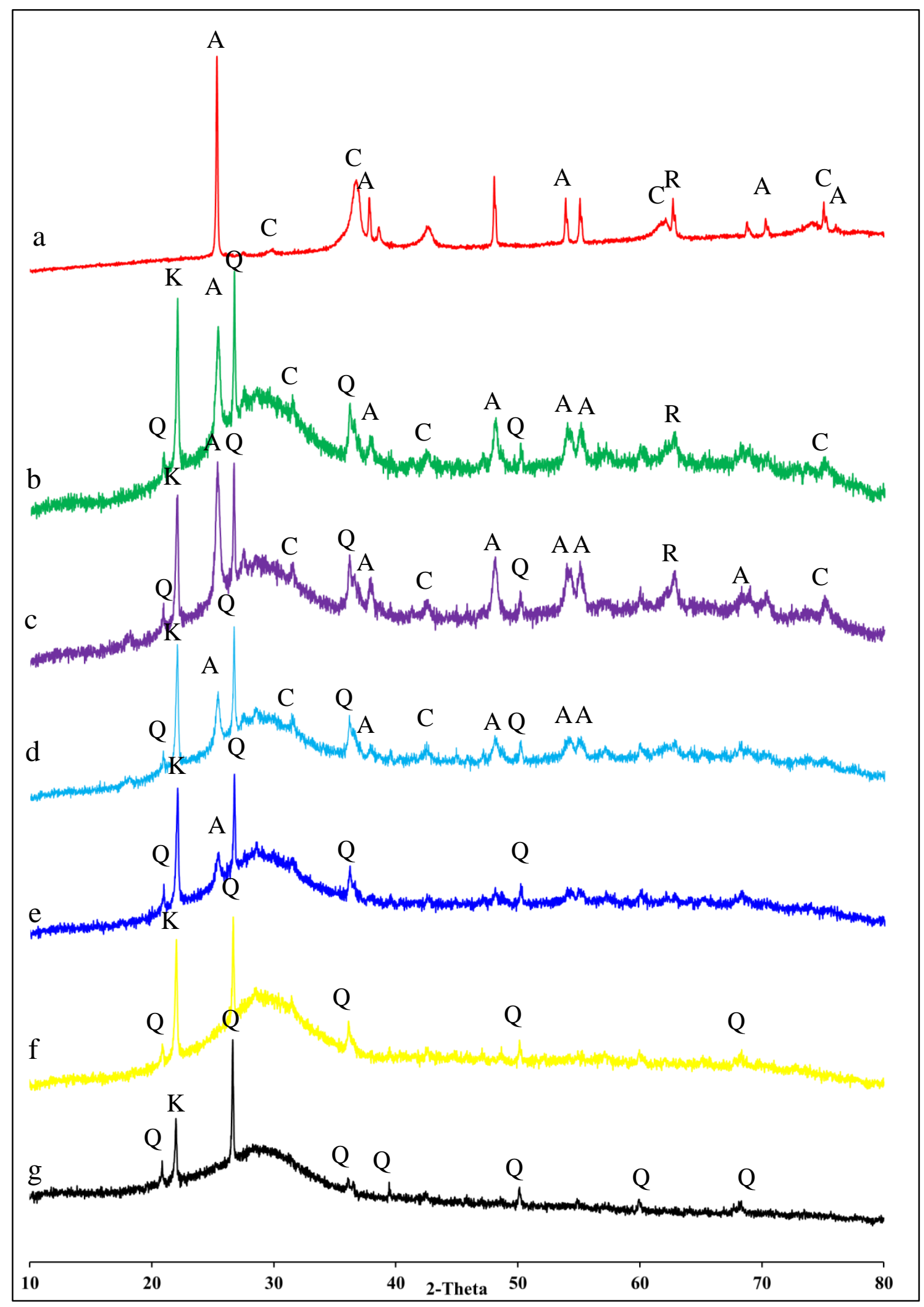

Figure 7.1. $\mathrm{XRD}$ patterns of $\mathrm{M}-\mathrm{GP}, \mathrm{Cu}_{2} \mathrm{O} / \mathrm{TiO}_{2}$ and $\mathrm{Cu}_{2} \mathrm{O} / \mathrm{TiO}_{2}$ supported by M-GP matrix with different loading contents; (a) $\mathrm{Cu}_{2} \mathrm{O} / \mathrm{TiO}_{2}$, (b) M-GP-50 wt\% $\mathrm{Cu}_{2} \mathrm{O} / \mathrm{TiO}$, (c) M-GP-15 wt $\% \mathrm{Cu}_{2} \mathrm{O} / \mathrm{TiO}_{2}$, (d) M-GP-10 wt $\% \mathrm{Cu}_{2} \mathrm{O} / \mathrm{TiO}_{2}$ (e) M-GP-5 wt $\% \mathrm{Cu}_{2} \mathrm{O} / \mathrm{TiO}_{2}$, (f) M-GP, (g) GP. $\mathrm{Q}=$ quartz, $\mathrm{K}=$ cristobalite, $\mathrm{C}=$ cuprous oxide, $\mathrm{A}=$ anatase, $\mathrm{R}=$ rutile. 


\subsection{Scanning electron microscopy}

Figure 7.2a is a BSE micrograph showing bright regions on a light grey background in sample M-GP-10 wt $\% \mathrm{Cu}_{2} \mathrm{O} / \mathrm{TiO}_{2}$. The lighter regions are from the higher atomic number $\mathrm{TiO}_{2}$ and $\mathrm{Cu}_{2} \mathrm{O}$, which is confirmed by EDS elemental mapping (Figure 7.2e and f). The particles are homogenously dispersed on the GP surface with no obvious $\mathrm{Cu}$ or $\mathrm{Ti}$ aggregation. No additional impurities are found in the sample. As observed previously the $\mathrm{Cu}_{2} \mathrm{O}$ grains $(200-300 \mathrm{~nm})$ are considerably larger than the $\mathrm{TiO}_{2}$ grains (ca. $25 \mathrm{~nm}$ ).

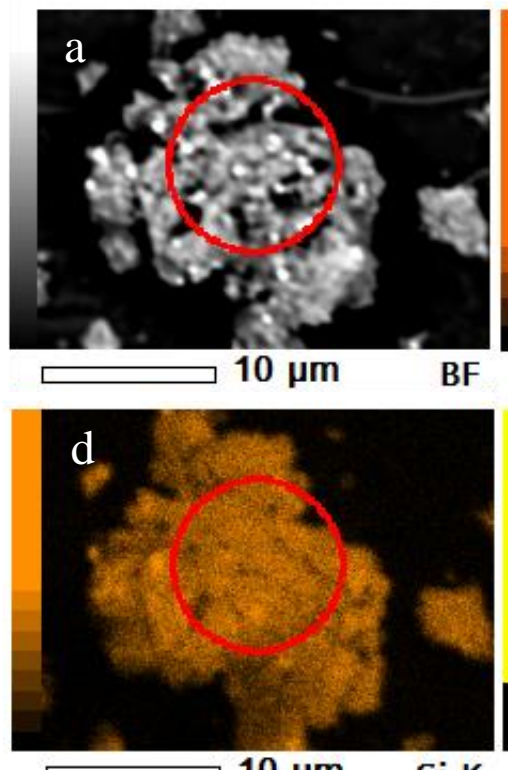

$10 \mu \mathrm{m}$
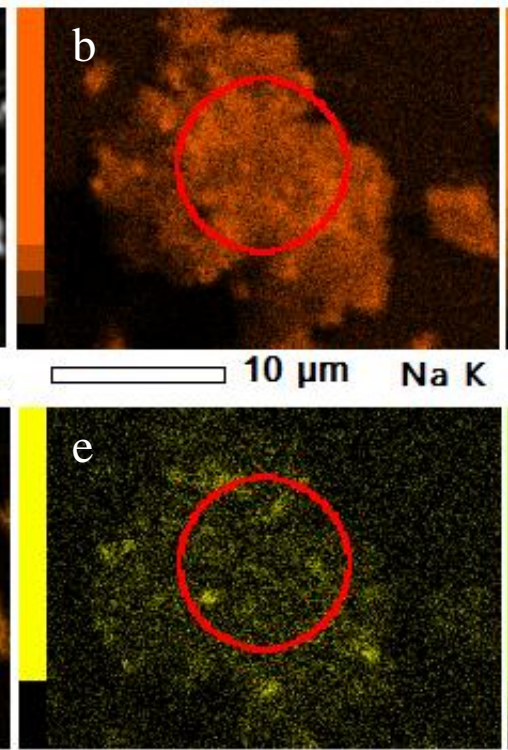

$10 \mu \mathrm{m} \quad \mathrm{Ti} \mathrm{K}$
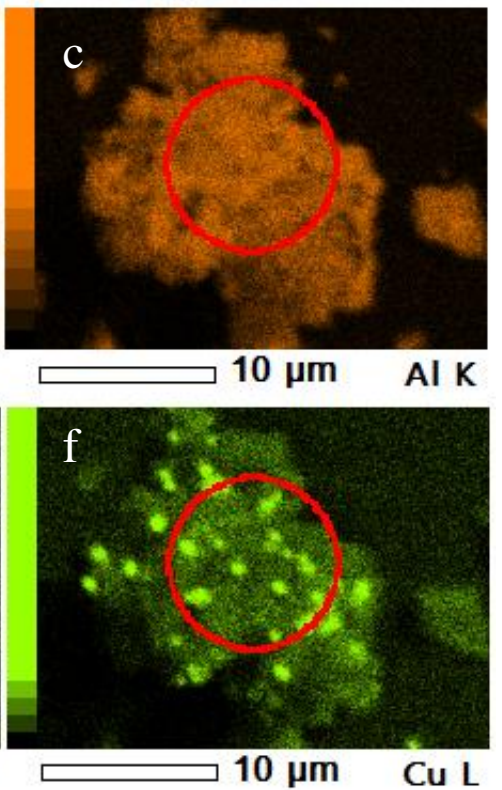

Figure 7.2. (a) BSE image of powdered M-GP-10 wt\% $\mathrm{Cu}_{2} \mathrm{O} / \mathrm{TiO}{ }_{2}$, (b) $\mathrm{Na}$, (c) $\mathrm{Al}$, (d) $\mathrm{Si}$, (e) $\mathrm{Ti}$, (f) $\mathrm{Cu}$.

Figure 7.3 is a series of SE and BSE micrographs of M-GP with 5, 10, 15, 50 wt \% $\mathrm{Cu}_{2} \mathrm{O} / \mathrm{TiO}_{2}$. The left hand micrographs are $\mathrm{SE}$ micrographs and the right hand micrographs are the corresponding BSE micrographs. $\mathrm{As} \mathrm{Cu}_{2} \mathrm{O}$ and $\mathrm{TiO}_{2}$ have a higher average atomic number than the GP, these particles appear bright in comparison to the GP matrix. The surface morphology (Figure 7.3, SE micrographs) show a spongy-like structure. 

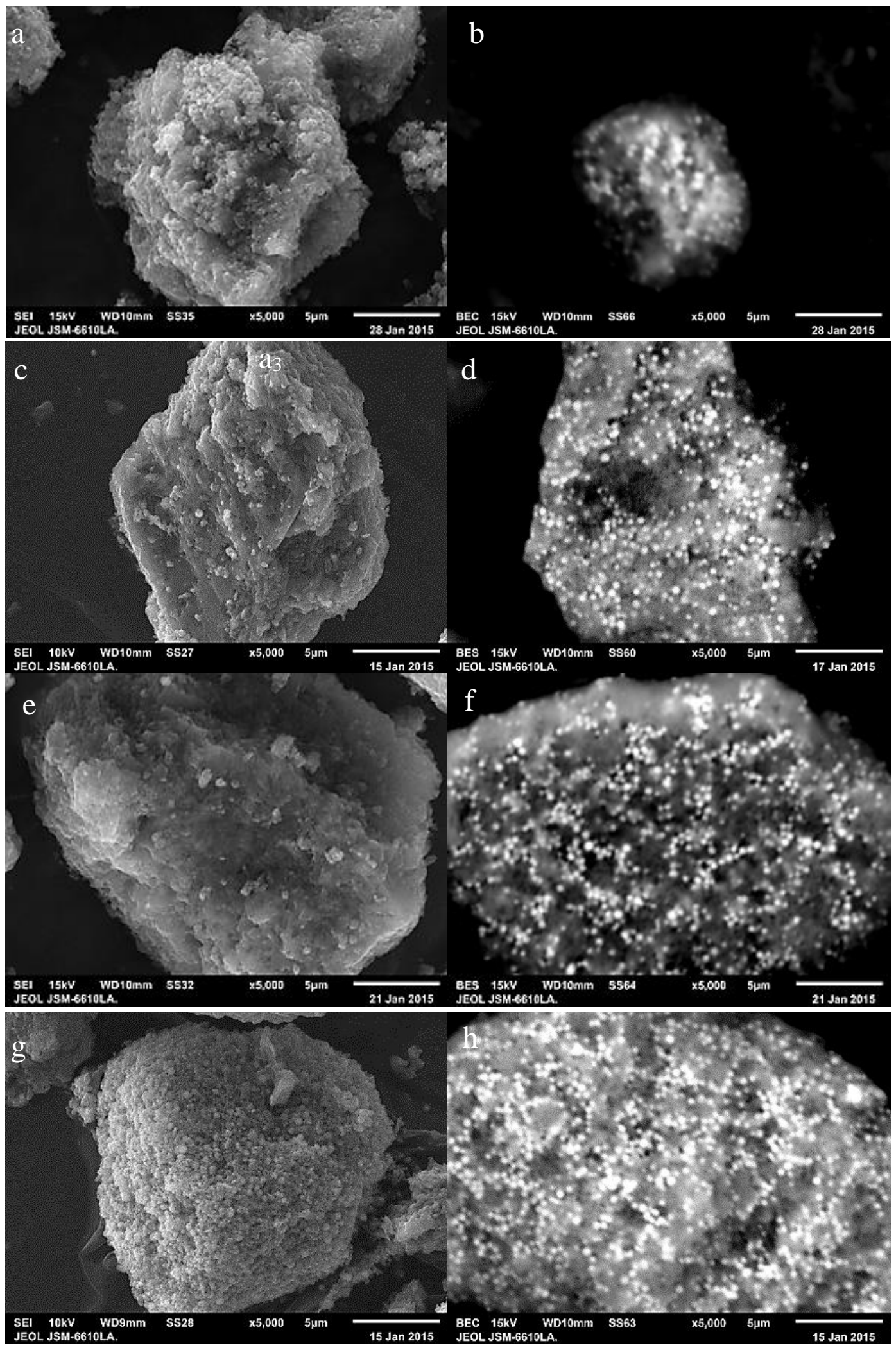

Figure 7.3. SEM micrographs of (a,b) M-GP-5 wt $\% \mathrm{Cu}_{2} \mathrm{O} / \mathrm{TiO}_{2}$, (c,d) M-GP-10 wt $\%$ $\mathrm{Cu}_{2} \mathrm{O} / \mathrm{TiO}_{2}$, (e,f) M-GP-15 wt\% $\mathrm{Cu}_{2} \mathrm{O} / \mathrm{TiO}_{2}$, (g,h) M-GP-50 wt\% $\mathrm{Cu}_{2} \mathrm{O} / \mathrm{TiO}$. Micrographs on left-hand side of figure are SEM, those on the right hand side are BSE. 


\subsection{High Resolution Transmission Electron Microscopy}

TEM images of the $10 \% \mathrm{Cu}_{2} \mathrm{O} / \mathrm{TiO}_{2}$-modified geopolymer composite are shown in Figure $7.4(a, b)$. These images show the penetration of the photoactive nano-hetrostructures into the geopolymer matrix, confirming that the preparation method achieved the desired photocatalyst morphology. The lattice fringes were measured by digital micrograph software by calculating the average parameters between 10 lattice fringes, resulting in lattice fringe spacings of $0.22 \mathrm{~nm}$ for the $\mathrm{Cu}_{2} \mathrm{O}$ area and $0.18 \mathrm{~nm}$ for the $\mathrm{TiO}_{2}$ area. These spacings correspond to the (312) lattice plane of $\mathrm{TiO}_{2}$ and the (200) plane of $\mathrm{Cu}_{2} \mathrm{O}$. This HRTEM analysis provides a reliable confirmation of the XRD analysis. These lattice spacings are in agreement with the cubic structure of $\mathrm{Cu}_{2} \mathrm{O}$ (JCPDS file no. 01-073-6237) and the tetragonal structure of the anatase and rutile phases of $\mathrm{TiO}_{2}$ (JCPDS file no. 00-021-1272 and 04-0061919 respectively). 


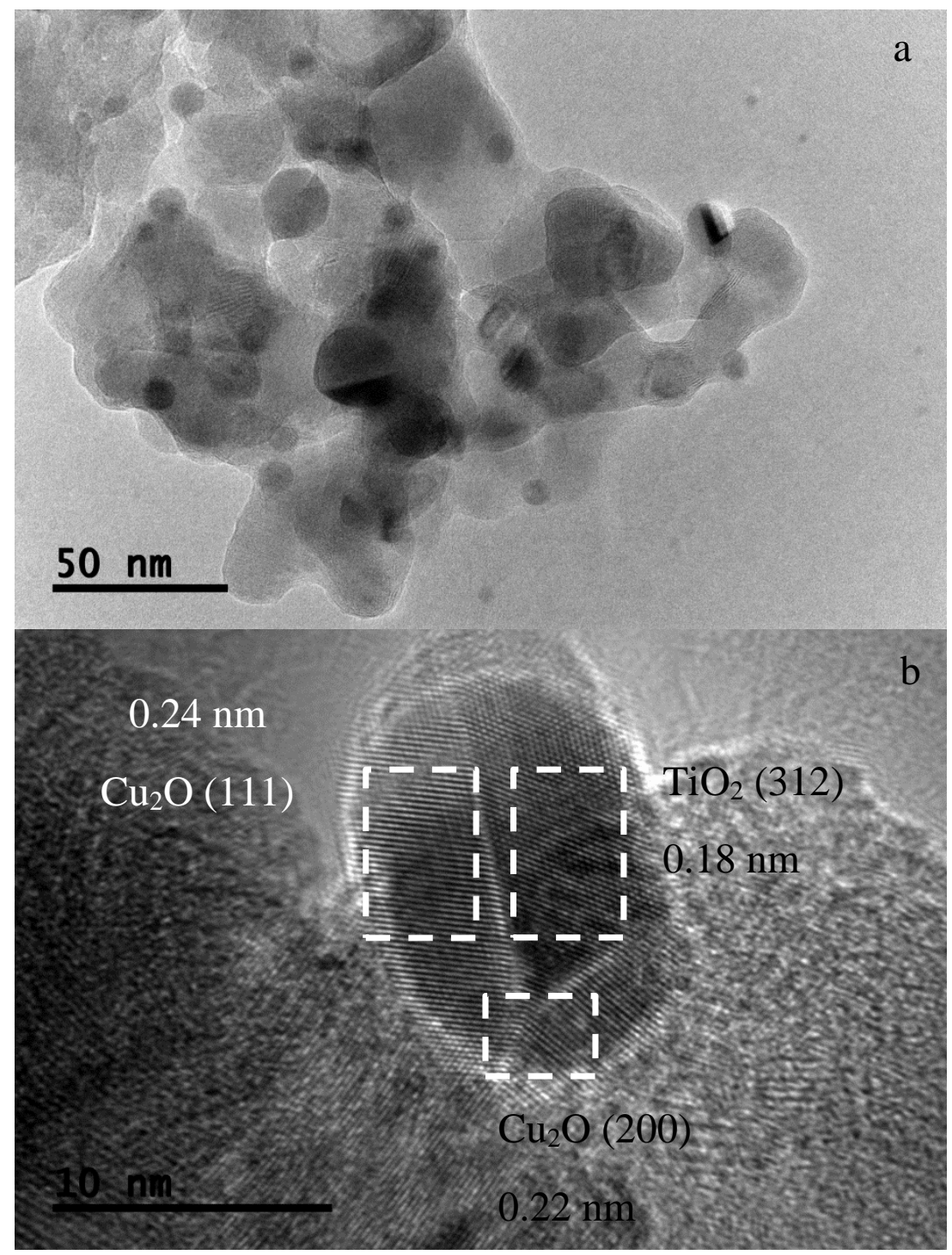

Figure 7.4. $(a, b)$ TEM images of $\mathrm{M}-\mathrm{GP}-10$ wt $\% \mathrm{Cu}_{2} \mathrm{O} / \mathrm{TiO}_{2}$ composite

Further evidence for the successful synthesis of the $\mathrm{Cu}_{2} \mathrm{O} / \mathrm{TiO}_{2}$ heterostructures is provided by STEM imaging in conjugation with EDS mapping (Fig. 7.5) which clearly shows that the composite contains a high concentration of $\mathrm{Cu}_{2} \mathrm{O} / \mathrm{TiO}_{2}$ nanoparticles. EDX element mapping of the sample further shows the spatial distributions of $\mathrm{Si}, \mathrm{Al}, \mathrm{Na}, \mathrm{Cu}$ and $\mathrm{Ti}$ in the composite. The $\mathrm{Ti}$ and $\mathrm{Cu}$ atoms are distributed within the geopolymer composite, but the $\mathrm{Ti}$ appears to be more closely associated with the Si elements of the geopolymer matrix, whereas the $\mathrm{Cu}$ is more homogeneously distributed over the complete matrix. The Si map suggests the presence of regions of the sample that are richer in $\mathrm{Si}$, which are also associated with the Ti component, but there is no obvious explanation for this interesting observation. 

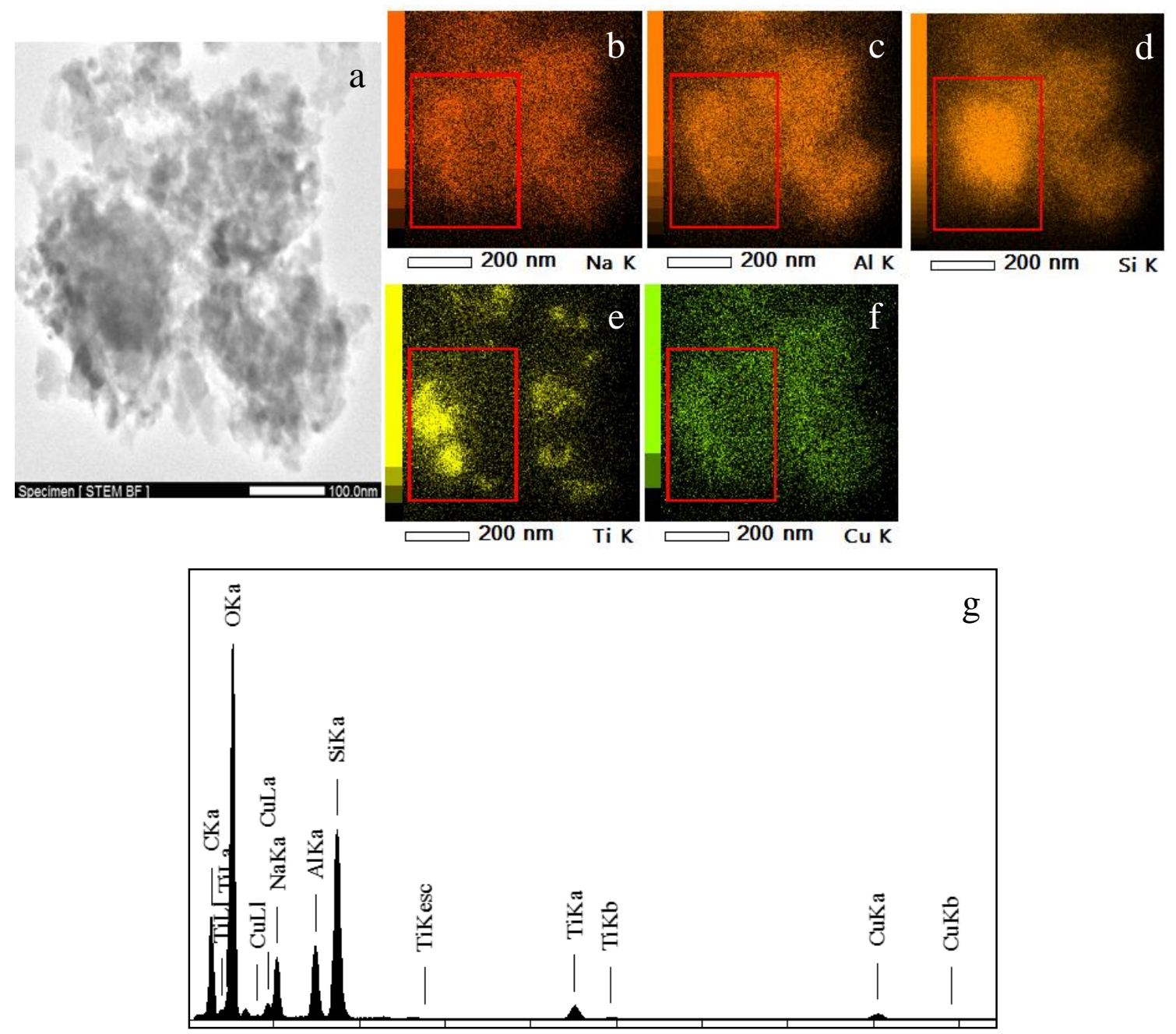

Figure 7.5. (a) STEM image of M-GP-10 wt $\%-\mathrm{Cu}_{2} \mathrm{O} / \mathrm{TiO}{ }_{2}$ composite, (b-f) corresponding EDX elemental maps and (g) EDX spectrum of the area indicated in red.

\subsection{FTIR spectroscopy}

FTIR spectra of the unmodified geopolymer, CTAB-modified geopolymer and $\mathrm{Cu}_{2} \mathrm{O}-\mathrm{TiO}_{2}$ M-GP composites (5-50 wt\% $\mathrm{Cu}_{2} \mathrm{O}$ ) are presented in Figure 7.6. As with the previous samples prepared with CTAB-modified matrices, the FTIR spectra show three principal bands in the region (a) $3439-3463 \mathrm{~cm}^{-1}$, (b) $1644-1652 \mathrm{~cm}^{-1}$ and (c) $1002-1008 \mathrm{~cm}^{-1}$ (Table 7.2). Region (a) arises from the $(\mathrm{OH})$ stretching vibration of $\mathrm{H}$-bonded water ${ }^{193}$ and appears in all composites. This band is shifted to higher frequencies in most of the samples containing $\mathrm{CTAB}$ and $\mathrm{Cu}_{2} \mathrm{O} / \mathrm{TiO}_{2}$. Loading with the surfactant causes a decrease of hydrogen bonding strength in the composite. ${ }^{185,193}$ 


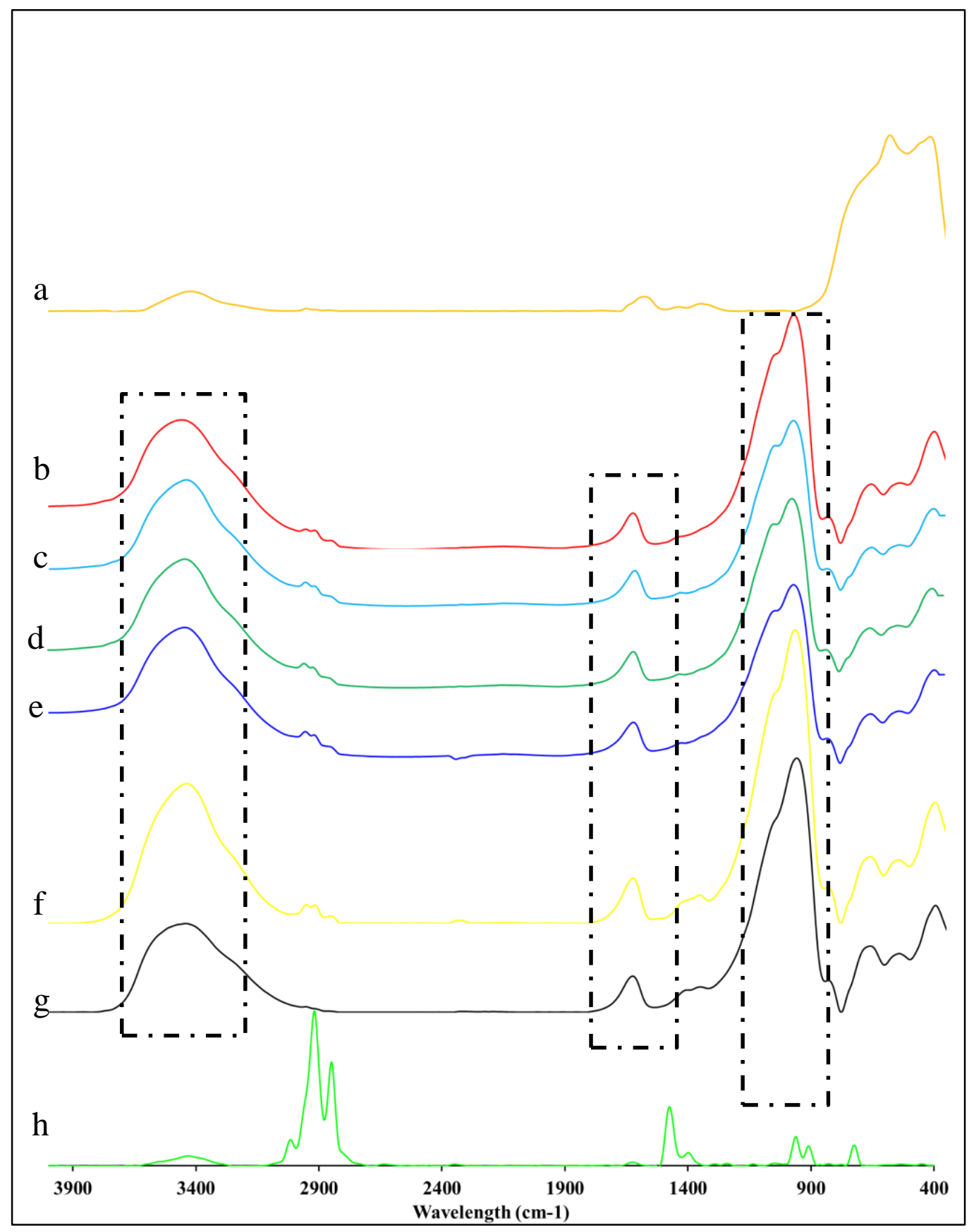

Figure 7.6. FTIR spectra of $\mathrm{GP}, \mathrm{M}-\mathrm{GP}, \mathrm{Cu}_{2} \mathrm{O} / \mathrm{TiO}_{2}$ and $\mathrm{Cu}_{2} \mathrm{O} / \mathrm{TiO}_{2}$ supported by $\mathrm{GP}$ matrix with different loading contents; (a) $\mathrm{Cu}_{2} \mathrm{O}$, (b) M-GP 50 wt\% $\mathrm{Cu}_{2} \mathrm{O}$, (c) M-GP 30 wt\% $\mathrm{Cu}_{2} \mathrm{O}$, (d) M-GP 15 wt $\% \mathrm{Cu}_{2} \mathrm{O}$, (e) M-GP 10 wt\% $\mathrm{Cu}_{2} \mathrm{O}$, (f) M-GP 5 wt\% $\mathrm{Cu}_{2} \mathrm{O}$, (g) M- GP, (h) CTAB. 
The surfactant changes the composite surface from hydrophilic to hydrophobic by replacing the hydrated cations which are the cause of the reduction of H-bonding. ${ }^{185}$ As previously noted in chapter 6 , the photoactive constituents $\mathrm{Cu}_{2} \mathrm{O}$ and $\mathrm{TiO}_{2}$ can enter the cavities in geopolymer matrix and coordinate to the surface of the oxygen from one side and the water molecules on the other side, decreasing the polarising ability and weakening the H-bonds in the isolated hydrated band, ${ }^{194}$ so that the $\mathrm{O}-\mathrm{H}$ stretching band is shifted to higher wavenumbers.

Table 7.2. Positions and assignments of the IR vibration bands observed in the range of 400 $4000 \mathrm{~cm}^{-1}$

\begin{tabular}{|c|c|c|c|c|c|c|c|}
\hline GP & M-GP & $\begin{array}{c}\mathrm{M}-\mathrm{GP} \\
5 \mathrm{wt} \% \\
\mathrm{Cu}_{2} \mathrm{O} / \mathrm{TiO}_{2}\end{array}$ & $\begin{array}{c}\mathrm{M}-\mathrm{GP} \\
10 \mathrm{wt} \% \\
\mathrm{Cu}_{2} \mathrm{O} / \mathrm{TiO}_{2}\end{array}$ & $\begin{array}{c}\mathrm{M}-\mathrm{GP} \\
15 \mathrm{wt} \% \\
\mathrm{Cu}_{2} \mathrm{O} / \mathrm{TiO}_{2}\end{array}$ & $\begin{array}{c}\mathrm{M}-\mathrm{GP} \\
50 \mathrm{wt} \% \\
\mathrm{Cu}_{2} \mathrm{O} / \mathrm{TiO}_{2}\end{array}$ & $\mathrm{Cu}_{2} \mathrm{O} / \mathrm{TiO}_{2}$ & $\mathrm{CTAB}$ \\
\hline 3834 & & & & & & & \\
\hline 3439 & 3445 & 3450 & 3456 & 3447 & 3464 & 3429 & \\
\hline 3015 & & & & & & & 3016 \\
\hline 2967 & 2964 & 2968 & 2968 & 2968 & 29682 & 2964 & \\
\hline & 2930 & 2932 & & 2933 & 2932 & 2930 & 2918 \\
\hline 1644 & 1653 & 1649 & 1651 & 1645 & 1653 & 1605 & 2849 \\
\hline 1384 & 1385 & 1456 & & & & 1381 & 1475 \\
\hline 1002 & 1003 & 1007 & 1007 & 1009 & 1007 & & 962 \\
\hline & 872 & 872 & 870 & 874 & 870 & & 910 \\
\hline 694 & 700 & 696 & 694 & 694 & 696 & & 725 \\
\hline & & & & & & 621 & \\
\hline 578 & 588 & 582 & 581 & 582 & 581 & & \\
\hline & & & & & & & \\
\hline 437 & 440 & 442 & 445 & 445 & 444 & 459 & \\
\hline
\end{tabular}

$-\mathrm{OH}: 3700-3600,-\mathrm{OH}, \mathrm{HOH}: 3600-2200, \mathrm{HOH}: 1700-1600$, Si-O-Si \&Al-O-Si: 1200-950

Area (b) (Figure 7.6) arises from $\mathrm{H}-\mathrm{O}-\mathrm{H}$ bending vibrations and indicates that the geopolymer retains absorbed water following polycondensation of the $(\mathrm{OH})$ groups. ${ }^{185}$ This vibration band is shifted to higher wave numbers due to the presence of CTAB. This frequency shift trend indicates the hydrophobicity of the materials resulting from the CTAB surfactant loading. ${ }^{185}$

Region (c) (Figure 7.6) arises from the $\mathrm{Si}-\mathrm{O}-\mathrm{Si}$ and $\mathrm{Si}-\mathrm{O}-\mathrm{Al}$ asymmetric stretching vibrations. ${ }^{123,184}$ The addition of $\mathrm{Cu}_{2} \mathrm{O} / \mathrm{TiO}_{2}$ to the geopolymer produces a small shift in the position of the asymmetric $\mathrm{Si}-\mathrm{O}-\mathrm{Si}$ stretching vibration at $1000 \mathrm{~cm}^{-1}$ and a reduction in the intensity of this band. This fact is evidence of a small change in the geopolymer structure. As previously observed (chapter 6), the vibration corresponding to the $\mathrm{CH}_{2}$ stretching mode of 
the amine is located at 2918 and $2929 \mathrm{~cm}^{-1}$ in the reference CTAB and CTAB-modified geopolymer respectively. The presence of this band confirms the presence of CTAB at the surface or inside the geopolymer matrix.

At lower wave numbers, the Si-O-Si bands of the geopolymer matrix are observed at $437 \mathrm{~cm}^{-}$ ${ }^{1}$ and $694 \mathrm{~cm}^{-1}$ (Si-O-Si symmetric stretching mode) with slight shift to the higher wave number, probably due to the superposition of $\mathrm{Cu} / \mathrm{Ti}-\mathrm{O}-\mathrm{Cu} / \mathrm{Ti}$.

\section{6 ${ }^{29} \mathrm{Si}$ and ${ }^{27} \mathrm{Al}$ solid state MAS NMR}

The ${ }^{29} \mathrm{Si}$ MAS NMR spectra of the geopolymer and geopolymer composites are presented in Figure 7.7. The spectra of these samples are essentially identical to those shown in chapter 6, showing a principal resonance at about $-87 \mathrm{ppm}$ except the sample containing 50\% $\mathrm{Cu}_{2} \mathrm{O} / \mathrm{TiO}_{2}$ in which the peak is slightly shifted to a less-shielded position of $-89 \mathrm{ppm}$. This peak remains essentially unchanged after the addition of different percentages of the $\mathrm{Cu}_{2} \mathrm{O} / \mathrm{TiO}_{2}$ nano-heterostructure. As discussed in earlier chapters, the small broad peak at about -107 ppm corresponds to $\mathrm{SiO}_{4}$ units, and the presence of CTAB in the geopolymer matrix results in a small peak at about $-72 \mathrm{ppm}$ corresponding to a range of monosilicates of the single tetrahedra type of silicon-oxygen $\left(\mathrm{Q}^{0}\right) .{ }^{16}$ This peak is slightly shifted to -70 and -71 ppm by the shielding effect of additions of 10 and $15 \mathrm{wt} \% \mathrm{Cu}_{2} \mathrm{O} / \mathrm{TiO}_{2}$ nano-heterostructures. The positions of the ${ }^{29} \mathrm{Si} \mathrm{NMR}$ resonances are shown in Table 7.3. With increasing content of $\mathrm{Cu}_{2} \mathrm{O} / \mathrm{TiO}_{2}$, the ${ }^{29} \mathrm{Si}$ spectra become broader, reflecting an increased randomness of the matrix structure; this appears to result in a change in the relative intensities of the peaks at 89 and -107 ppm; this is however an artefact caused by the more poorly resolved spectra of the composites containing the higher $\mathrm{Cu} / \mathrm{Ti}$ contents. 


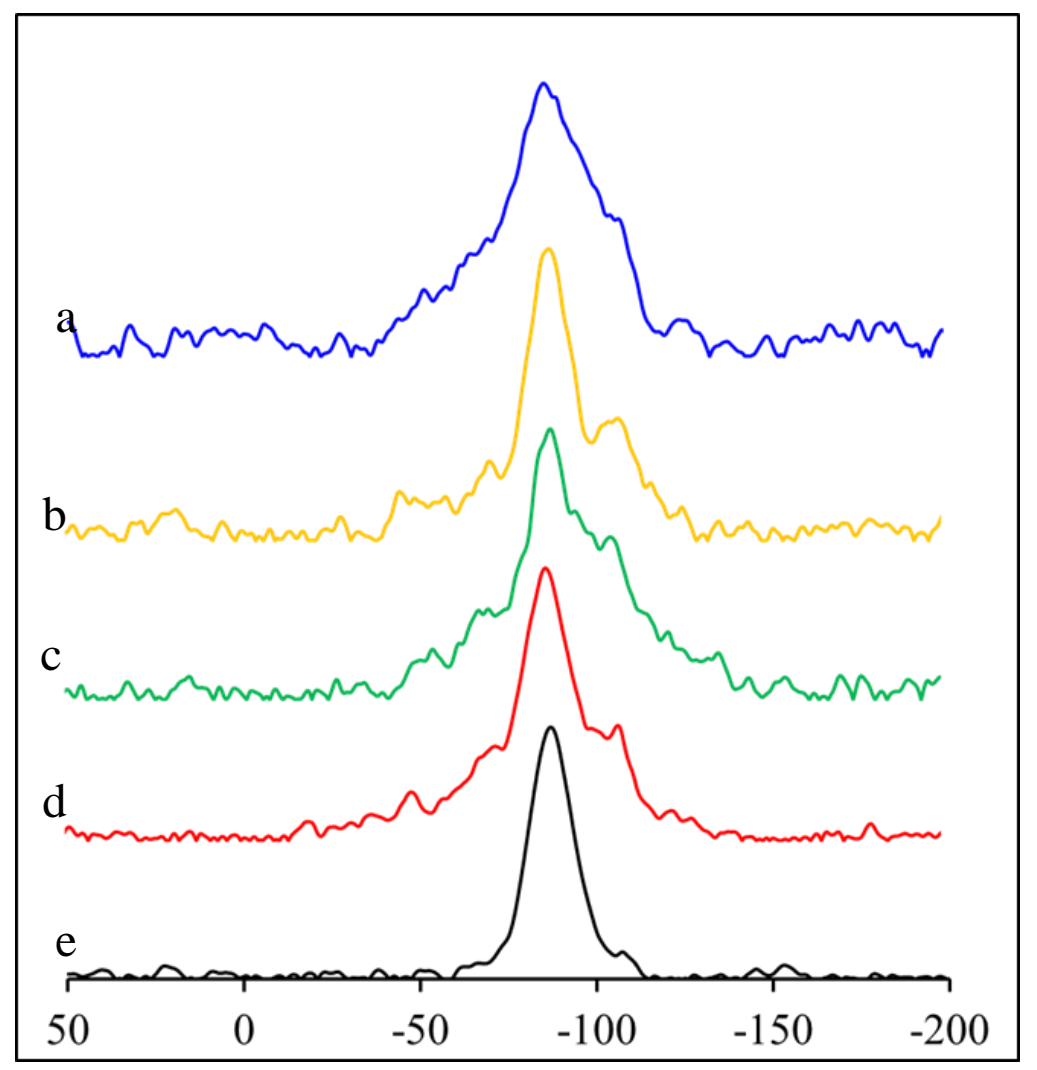

Figure 7.7. 11.7 $\mathrm{T}^{29} \mathrm{Si}$ MAS NMR spectra (a) M-GP $50 \mathrm{wt} \% \mathrm{Cu}_{2} \mathrm{O} / \mathrm{TiO}_{2}$ (b) $\mathrm{M}-\mathrm{GP} 15 \mathrm{wt} \%$ $\mathrm{Cu}_{2} \mathrm{O} / \mathrm{TiO}_{2}$, (c) M-GP 10 wt\% $\mathrm{Cu}_{2} \mathrm{O} / \mathrm{TiO}_{2}$, (d) M-GP, (e) GP.

Table 7.3. Peaks related to the 11.7 T 29Si MAS NMR spectra

\begin{tabular}{ccccc}
\hline GP & M-GP & $\begin{array}{c}\text { M-GP 10 wt \% } \\
\mathrm{Cu}_{2} \mathbf{O} / \mathrm{TiO}_{2}\end{array}$ & $\begin{array}{c}\text { M-GP 15 wt\% } \\
\mathrm{Cu}_{2} \mathbf{O} / \mathbf{T i O}_{2}\end{array}$ & $\begin{array}{c}\text { M-GP 50 wt\% } \\
\mathrm{Cu}_{2} \mathbf{O} / \mathbf{T i O}_{2}\end{array}$ \\
\hline-87 & -87.2 & -87.4 & -87.8 & -85.9 \\
& & & & -89.2 \\
\hline- & -72.3 & -70.4 & -71.3 & -106.3 \\
107.6 & & -105.5 & -107.9 & \\
\hline
\end{tabular}

The corresponding ${ }^{27} \mathrm{Al}$ MAS NMR spectra (Figure 7.8) are identical to the spectra already discussed in previous chapters, the principal sharp resonance at about $59 \mathrm{ppm}$ corresponding to tetrahedral $\mathrm{AlO}_{4}$ units of a well-developed geopolymer structure ${ }^{188,194}$. The positions of this resonance in the various samples are shown in Table 7.4. The small broad feature in some of the samples arises from Al-O in octahedral coordination, ${ }^{120}$ from a trace of unreacted metakaolin. ${ }^{141}$ These spectra confirm the successful formation of aluminosilicate 
geopolymer composites in the presence of the CTAB surfactant and are unchanged by the presence of homogeneously distributed nanosized $\mathrm{Cu}_{2} \mathrm{O} / \mathrm{TiO}_{2}$ particles.

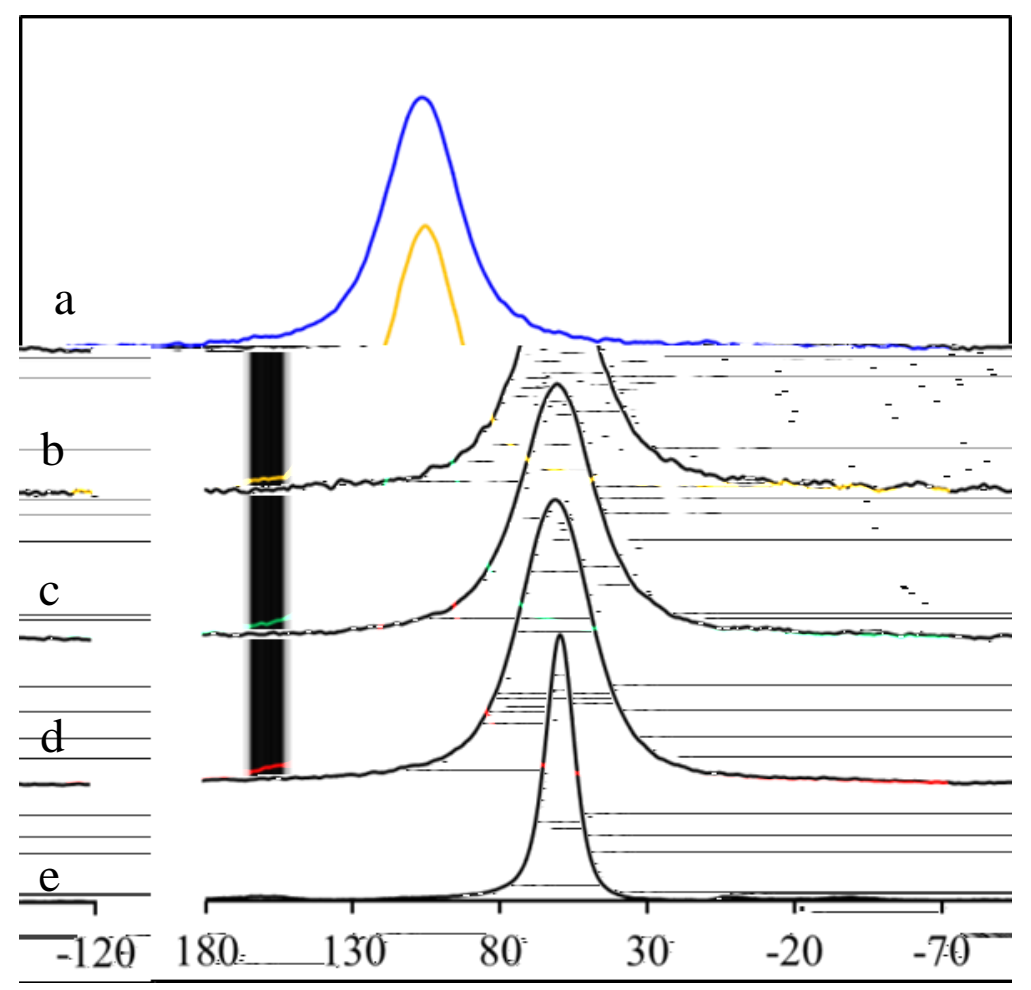

Figure 7.8. $11.7 \mathrm{~T}^{27} \mathrm{Al}$ MAS NMR spectra (a) M-GP $50 \mathrm{wt} \% \mathrm{Cu}_{2} \mathrm{O} / \mathrm{TiO}_{2}$ (b) $\mathrm{M}-\mathrm{GP} 15 \mathrm{wt} \%$ $\mathrm{Cu}_{2} \mathrm{O} / \mathrm{TiO}_{2}$, (c) M-GP $10 \mathrm{wt} \% \mathrm{Cu}_{2} \mathrm{O} / \mathrm{TiO}_{2}$, (d) M-GP, (e) GP.

Table 7.4. Peaks related to the $11.7 \mathrm{~T}^{27} \mathrm{AI}$ MAS NMR spectra

$\begin{array}{lr}\text { GP } & 59.6 \\ \text { M-GP } & 59.65 \\ \text { M-GP } 10 \text { wt\% Cu2O/TiO2 } & 59.18 \\ \text { M-GP } 15 w t \% \mathrm{Cu}_{2} \mathrm{O} / \mathrm{TiO}_{2} & 58.65 \\ \text { M-GP } 50 \text { wt\% Cu} \mathbf{C u}_{2} \mathrm{O} / \mathrm{TiO}_{2} & 59.24\end{array}$

\subsection{Nuclear quadrupole resonance $\left({ }^{63} \mathrm{Cu} \mathrm{NQR}\right)$}

${ }^{63} \mathrm{Cu}$ NQR spectra of the $\mathrm{Cu}_{2} \mathrm{O}$ and CTAB-modified geopolymer/Cu $/ \mathrm{Cu}_{2} \mathrm{O}$ and $\mathrm{CTAB}$-modified geopolymer/ $\mathrm{Cu}_{2} \mathrm{O} / \mathrm{TiO}_{2}$ composites (Figure 7.9) show the expected single line for pure $\mathrm{Cu}_{2} \mathrm{O}$ (Figure 7.9a) and the $\mathrm{Cu}_{2} \mathrm{O}$ component of the composite containing $\mathrm{Cu}_{2} \mathrm{O}$ before $\mathrm{UV}$ irradiation (Figure 7.9b). However, by contrast with the ${ }^{63} \mathrm{Cu} \mathrm{NQR}$ spectra of the composites formed with the unmodified geopolymer matrix (chapter 4), UV irradiation of these samples 
results in the loss of the NQR spectrum (Figure $7.9 \mathrm{c}, \mathrm{e}$ ). There are three possible explanations for this behaviour: (i) it may be due to a change of the copper valence upon UV irradiation, thus transforming the original $\mathrm{Cu}_{2} \mathrm{O}$ to an entity that is sufficiently structurally different to produce a different quadrupole frequency and be obscured by paramagnetic broadening (i.e. $\mathrm{CuO}$ ), (ii) complete destruction of the $\mathrm{Cu}_{2} \mathrm{O}$ due to the presence of an increased concentration of residual acid sites and/or $\mathrm{OH}$ concentration by virtue of the different synthesis route (i.e. the inclusion of $\mathrm{TiO}_{2}$ resulting in a different $\mathrm{OH} / \mathrm{Al} / \mathrm{Si}$ ratio) or (iii) dilution of the $\mathrm{Cu}_{2} \mathrm{O}$ content by its inclusion in the geopolymer/ $\mathrm{Cu}_{2} \mathrm{O} / \mathrm{TiO}_{2}$ composite is the reason why it is not detected in these samples. In view of the fact that the presence of $\mathrm{Cu}_{2} \mathrm{O}$ is suggested by XRD in all the samples, both unirradiated and UV irradiated, explanation (iii) may be the most likely. It is worth noting however that these samples appear to be darker in colour, raising the possibility that the $\mathrm{Ti}^{4+}$ is being reduced to paramagnetic $\mathrm{Ti}^{3+}$; since the $\mathrm{Ti}$ and $\mathrm{Cu}$ species are in reasonable proximity to each other in the pore spaces of the matrix, $\mathrm{Ti}^{4+}-\mathrm{Ti}^{3+}$ reduction could be triggered by the more energetically favourable $\mathrm{Cu}^{+}-\mathrm{Cu}^{2+}$ oxidation in these dark samples, producing paramagnetic species (both $\mathrm{Ti}^{3+}$ and $\mathrm{Cu}^{2+}$ ) and removing the NQR signal. 


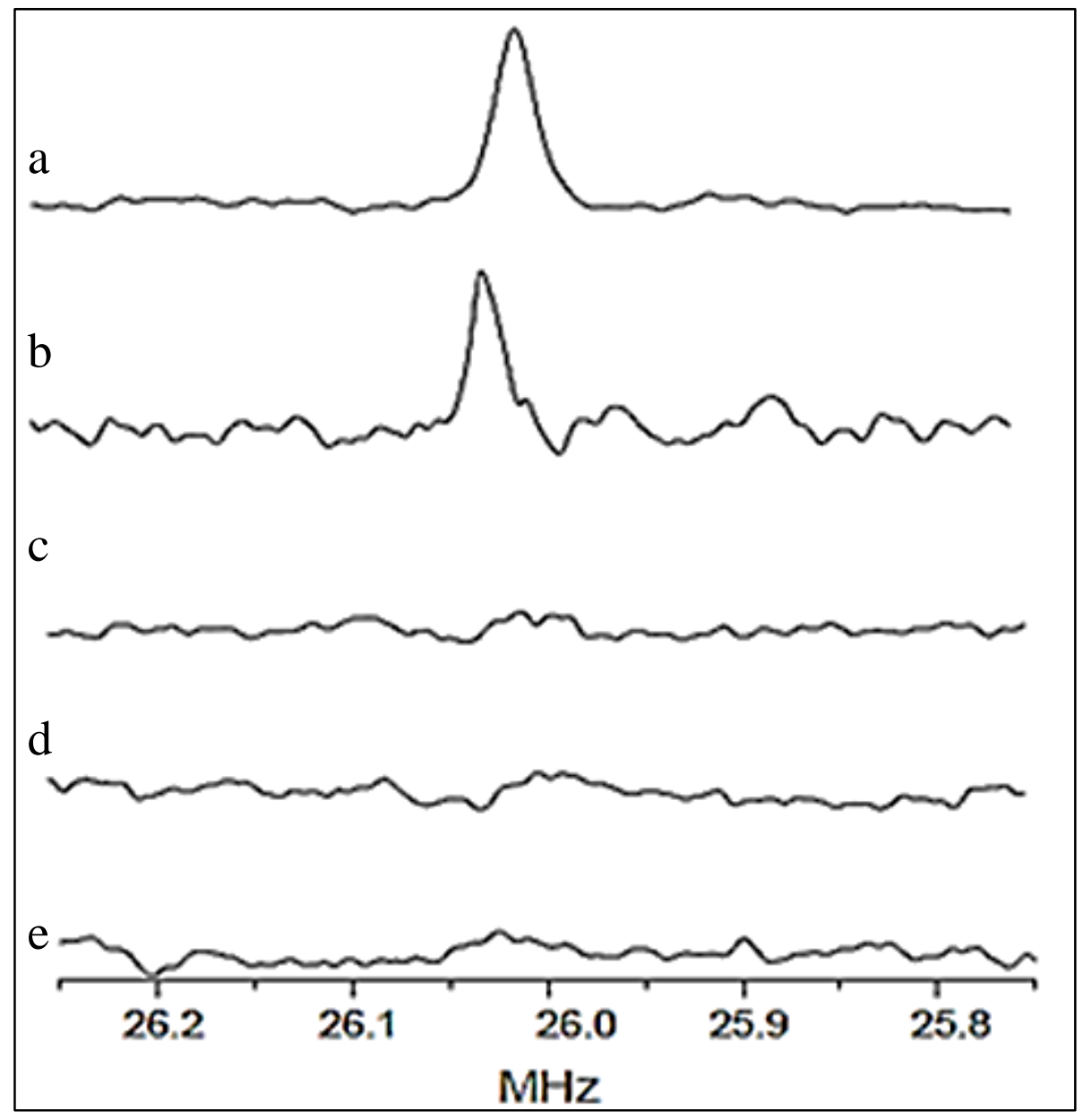

Figure 7.9. ${ }^{63} \mathrm{Cu}$ NQR spectra of nanoparticle $\mathrm{Cu}_{2} \mathrm{O}$ and M-GP composites. (a) assynthesized $\mathrm{Cu}_{2} \mathrm{O}$, (b) M-GP- $\mathrm{Cu}_{2} \mathrm{O}$ before UV irradiation, (c) M-GP-Cu${ }_{2} \mathrm{O}$ after UV irradiation, (d) $\mathrm{M}-\mathrm{GP}-\mathrm{Cu}_{2} \mathrm{O} / \mathrm{TiO}_{2}$ before UV irradiation, (e) $\mathrm{M}-\mathrm{GP}-\mathrm{Cu}_{2} \mathrm{O} / \mathrm{TiO}_{2}$ after UV irradiation

\subsection{Adsorption of MB}

\subsubsection{Reactions under dark conditions}

As described in the previous chapter, composites based on geopolymer matrices modified with CTAB removed MB dye from solution by a combination of adsorption (in the dark) and photodegradation (under UV illumination), but unlike the composites based on the unmodified geopolymer matrix, these two processes could be distinguished in the same experiment in the CTAB-matrix composites. Therefore, a series of experiments similar to those outlined in Chapter 6 were carried out on the $\mathrm{CTAB}$-modified $\mathrm{Cu}_{2} \mathrm{O} / \mathrm{TiO}_{2}$ composites, in which the composite was initially exposed to $\mathrm{MB}$ dye in the dark, and the system was allowed to equilibrate. Measurements of MB dye removal made in this step correspond to adsorption but not photodecomposition. 
As found in the previous chapter, the metal oxide particles alone cannot adsorb MB from solution in the dark, but when combined with the CTAB-modified geopolymer matrix, they show substantial dye adsorption abilities (Figure 7.10). The CTAB-modified geopolymers composite containing 5-15 wt $\%$ of the $\mathrm{Cu}_{2} \mathrm{O} / \mathrm{TiO}_{2}$ heterostructure show the greatest degree of MB removal after 12 hour, but at higher heterostructure loadings, the adsorption process becomes more hindered (Figure 7.10).

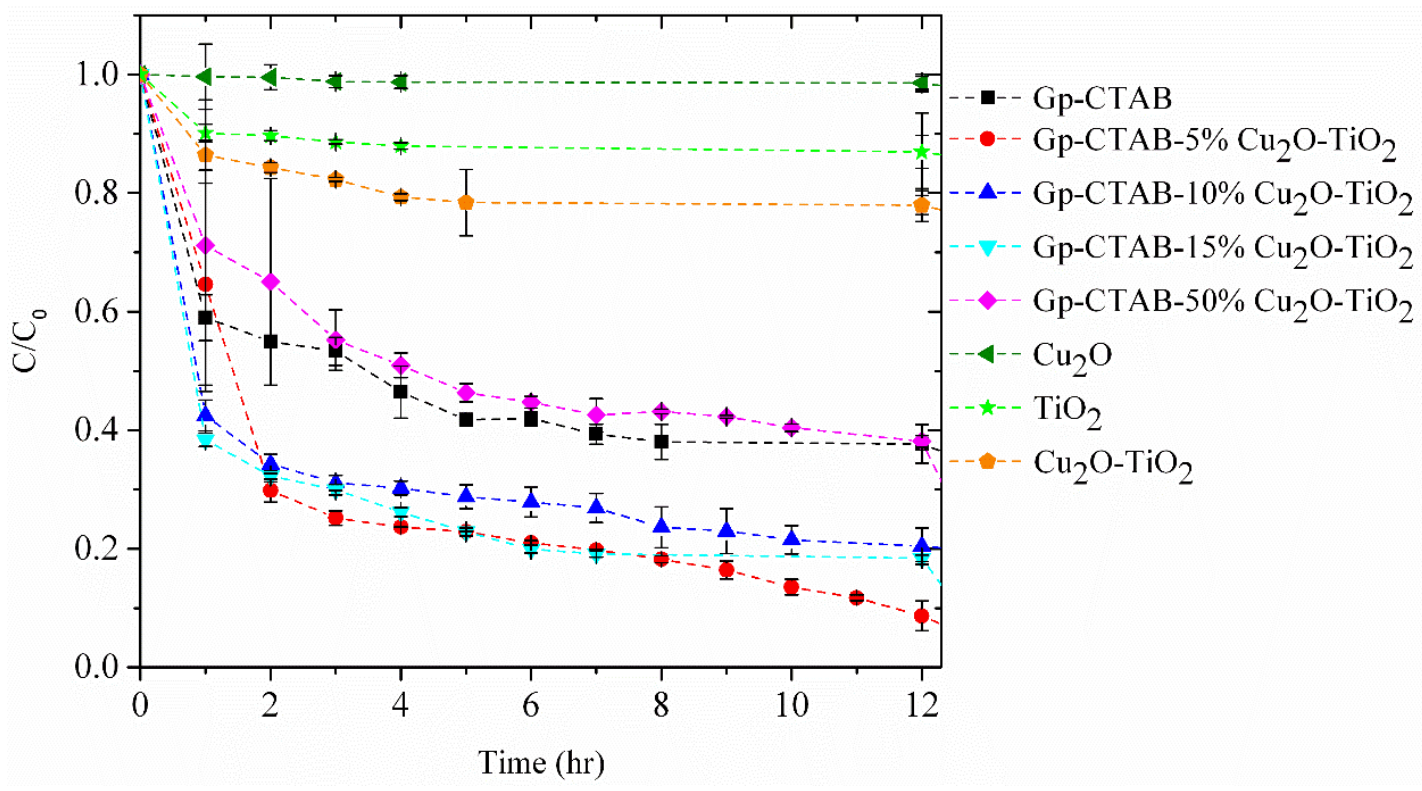

Figure 7.10. Plots of the residual concentration $\left(\mathrm{C} / \mathrm{C}_{0}\right)$ vs. time $(\mathrm{t})$ onto the $\mathrm{M}-\mathrm{GP}$ matrix, $\mathrm{M}$ GP 5,10, 15, and $50 \mathrm{wt} \% \mathrm{Cu}_{2} \mathrm{O}$ (monitored at $664 \mathrm{~nm}$ in dark)

Figure 7.11 shows the results of fitting the experimental data for MB adsorption on the CTAB-modified geopolymer matrix and geopolymer composites by pseudo-first-order and pseudo-second-order kinetic models (eqs. 27 and 28). ${ }^{182,} 196$ The resulting plots of the data (Figure $7.11 \mathrm{a}, \mathrm{b}$ ) are only poorly fitted by the pseudo-first-order model but very good fits are obtained to the pseudo-second-order model. The amount of MB adsorbed at equilibrium $\left(\mathrm{q}_{\mathrm{e}}\right)$ obtained from the pseudo-first and second-order model and the correlation coefficients $\mathrm{R}^{2}$ are presented in Table 7.5, showing that the $\mathrm{R}^{2}$ values of the pseudo-second-order kinetic model are all $>0.90$ except for the composite containing $15 \% \mathrm{Cu}_{2} \mathrm{O} / \mathrm{TiO}_{2}$. Moreover, comparison of the experimental values $\mathrm{q}_{\exp }$ with the $\mathrm{q}_{\mathrm{e}}$ values calculated from equations (eq. 27-28) (Table 7.5) indicates that pseudo-second-order model delivers a better fit to the experimental data under dark conditions, as was found to be the case with CTAB-modified composites containing $\mathrm{Cu}_{2} \mathrm{O}$ (Chapter 6). 
Table 7.5. Parameters for kinetic models of MB adsorption on samples

\begin{tabular}{|c|c|c|c|c|c|}
\hline Sample & $\begin{array}{l}\text { Kinetic } \\
\text { model }\end{array}$ & $\mathrm{q}_{\exp (\mathrm{mg} / \mathrm{g})}$ & $\mathrm{q}_{\mathrm{e}(\mathrm{mg} / \mathrm{g})}$ & $\mathrm{k}$ & $\mathrm{R}^{2}$ \\
\hline M-GP & $1^{\text {st }}$-order & 14.40 & 12.86 & 240.78 & 0.97 \\
\hline " & $2^{\text {nd }}$-order & " & 14.91 & 0.52 & 0.97 \\
\hline $\begin{array}{c}\text { M-GP-5 wt } \% \\
\mathrm{Cu}_{2} \mathrm{O} / \mathrm{TiO}_{2}\end{array}$ & $1^{\text {st }}$-order & 19.70 & 18.54 & 87.30 & 0.79 \\
\hline " & $2^{\text {nd }}$-order & " & 20.11 & 0.002 & 0.98 \\
\hline $\begin{array}{c}\text { M-GP-10 wt } \% \\
\mathrm{Cu}_{2} \mathrm{O} / \mathrm{TiO}_{2}\end{array}$ & $1^{\text {st }}$-order & 18.12 & 16.92 & 0.02 & 0.91 \\
\hline " & $2^{\text {nd }}$-order & " & 18.38 & 0.002 & 0.96 \\
\hline $\begin{array}{c}\text { M-GP-15 wt } \% \\
\mathrm{Cu}_{2} \mathrm{O} / \mathrm{TiO}_{2}\end{array}$ & $1^{\text {st }}$-order & 8.66 & 3.53 & 120.94 & 0.96 \\
\hline " & $2^{\text {nd }}-$ order & " & 6.55 & $2.49^{\mathrm{e}-07}$ & 0.70 \\
\hline $\begin{array}{c}\text { M-GP-50 wt } \% \\
\mathrm{Cu}_{2} \mathrm{O} / \mathrm{TiO}_{2}\end{array}$ & $1^{\text {st }}$-order & 14.34 & 11.88 & 44.68 & 0.90 \\
\hline " " & 2nd-order & $"$ & 16.70 & $5.96^{\mathrm{e}-04}$ & 0.92 \\
\hline
\end{tabular}



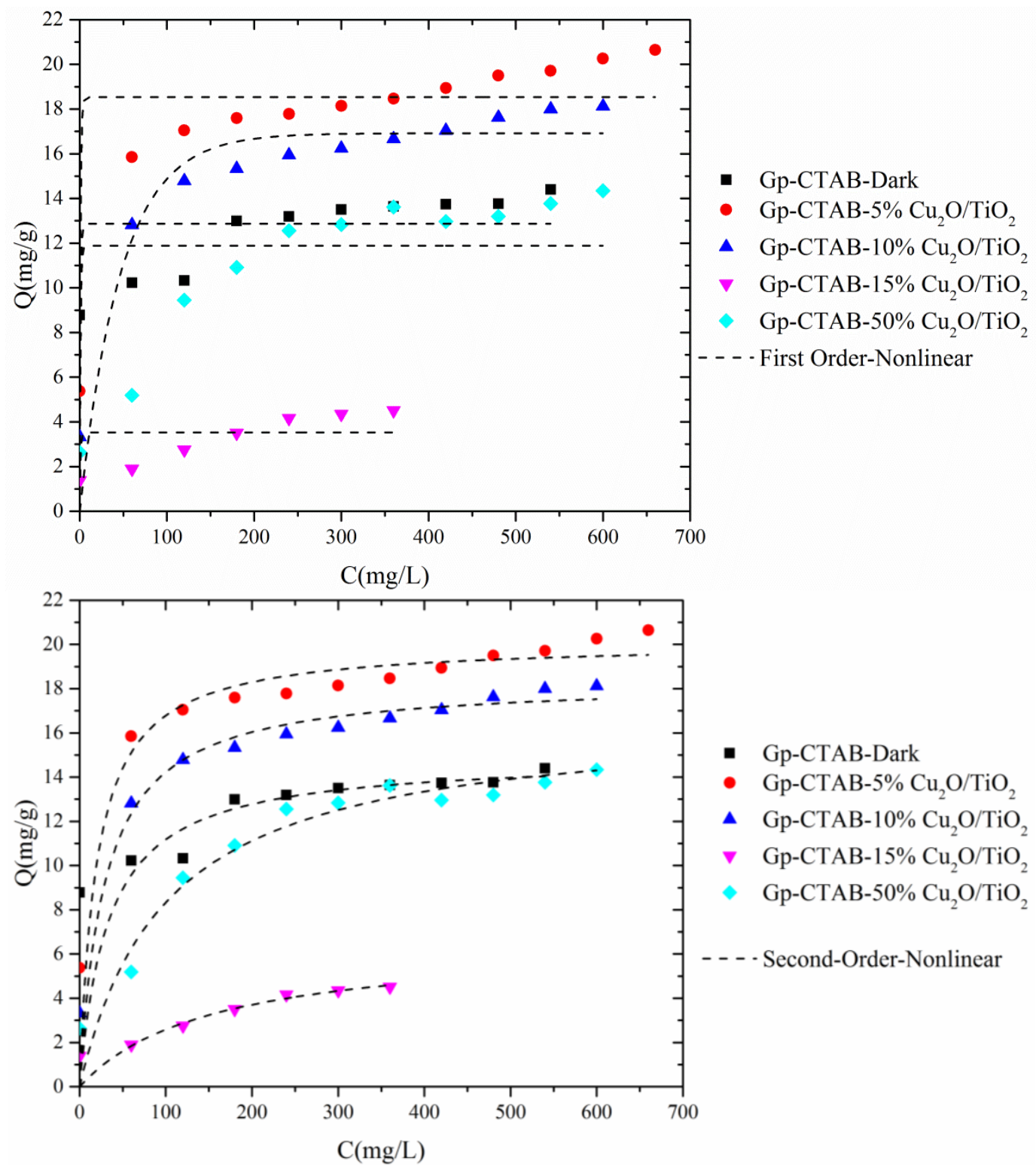

Figure 7.11. Experimental data for the adsorption of $M B$ dye in the dark on to the M-GP matrix and the M-GP-Cu $2 \mathrm{O} / \mathrm{TiO}_{2}$ composites fitted to (a) pseudo first-order kinetic model, (b) pseudo second-order kinetic model.

\subsubsection{MB dye adsorption isotherms under dark conditions}

As outlined in previous chapters, the adsorption isotherms of the CTAB-modified geopolymer and geopolymer composites were determined using the Langmuir, Freundlich and Langmuir-Freundlich equations (eqs. 29-31) ${ }^{17,178}$ (Figure 7.12 (a-c)). The resulting adsorption parameters and correlation coefficients from these three equations are shown in Table 7.6. 

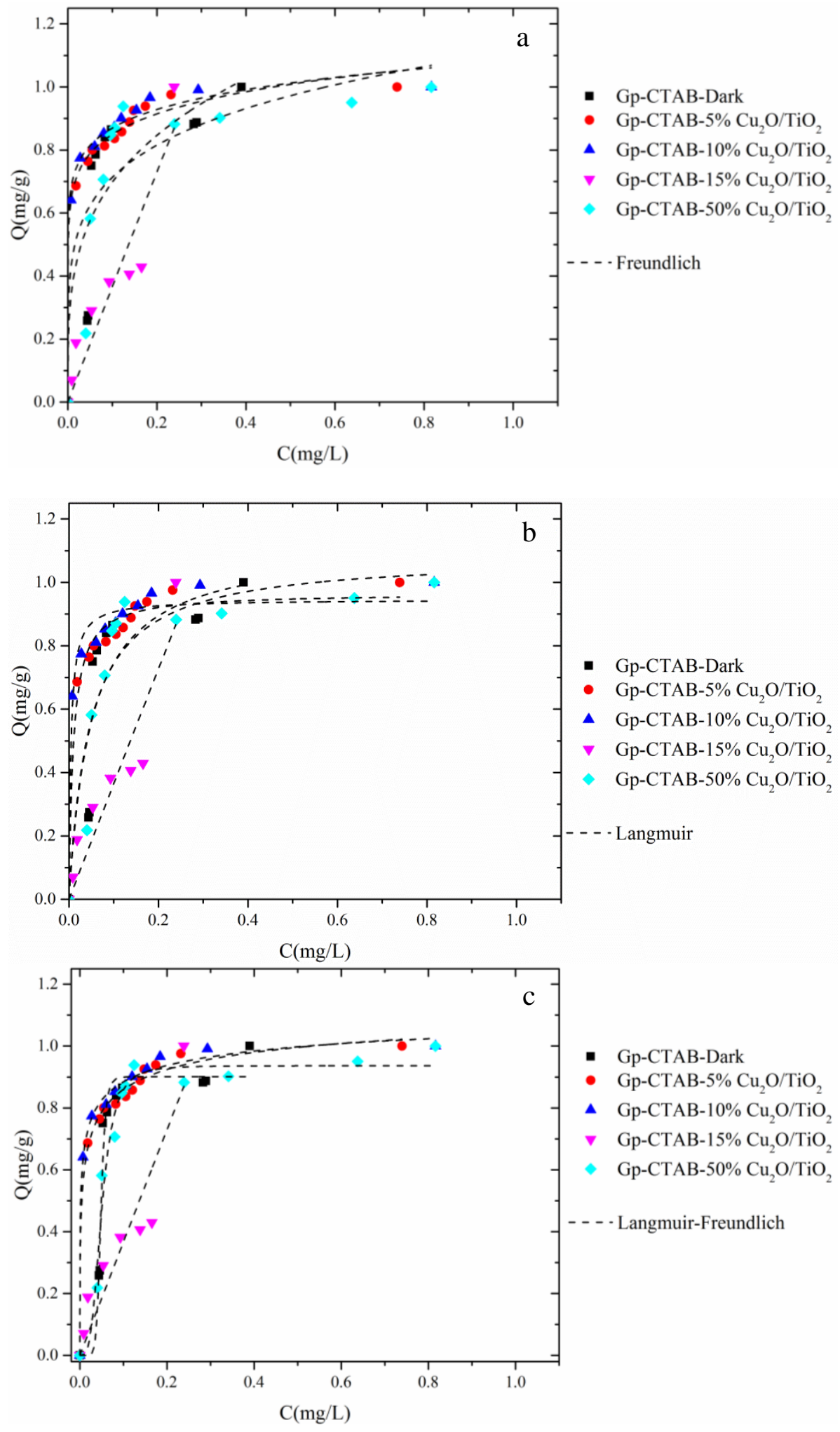

Figure 7.12. (a-c) Adsorption isotherms for MB adsorption fitted to Freundlich, Langmuir and Langmuir-Freundlich models (dashed lines).

Adsorption by the CTAB-modified geopolymer is fitted well by the Langmuir and Freundlich models which have $\mathrm{R}^{2}$ values $>0.99$. The $\mathrm{Cu}_{2} \mathrm{O} / \mathrm{TiO}_{2}$-geopolymer 
composites (5, 10 and $50 \mathrm{wt} \%)$ are fitted best by the three-parameter Langmuir-Freundlich model, giving higher $\mathrm{R}^{2}$ values (0.99, 0.99 and 0.96 respectively). The Langmuir and Langmuir-Freundlich constants provide an indication of the actual adsorption mechanisms and indicate the favourable adsorption of $\mathrm{MB}$ on the geopolymer composites.

\subsubsection{Reactions under UV irradiation}

As described in the previous chapter, the photodegradation of MB under UV irradiation by the CTAB-modified composites was determined at ambient temperature after allowing the system to equilibrate in the dark for 12 hour Figure 7.13 shows the MB degradation under both dark and UV conditions as a function of elapsed time. As previously found, under dark conditions neither of the metal oxides or their mixture is particularly effective in removing MB from solution but in combination with the geopolymer matrix, adsorption occurs on the geopolymer by a pseudo-second order kinetic model (see section 7.2.1 above). Under UV illumination, significant photodegradation occurs in all the samples (Figure 7.13), particularly at a concentration of $15 \mathrm{wt} \% \mathrm{Cu}_{2} \mathrm{O} / \mathrm{TiO}_{2}$, but this sample has already proved to be one of the most efficient composites in removing MB in the previous adsorption step. Considering the photodegradation step alone, the sample containing $50 \mathrm{wt} \% \mathrm{Cu}_{2} \mathrm{O} / \mathrm{TiO}_{2}$ is the most efficient, which is not unexpected in view of its highest content of photoactive components. These results show enhanced photocatalytic behaviour of the $\mathrm{Cu}_{2} \mathrm{O} / \mathrm{TiO}_{2}-\mathrm{CTAB}$-modified geopolymer composites compared with nanoparticle $\mathrm{Cu}_{2} \mathrm{O} / \mathrm{TiO}_{2}$ heterostructures alone and also with $\mathrm{Cu}_{2} \mathrm{O} / \mathrm{TiO}_{2}$ composites synthesised with an unmodified geopolymer matrix. 


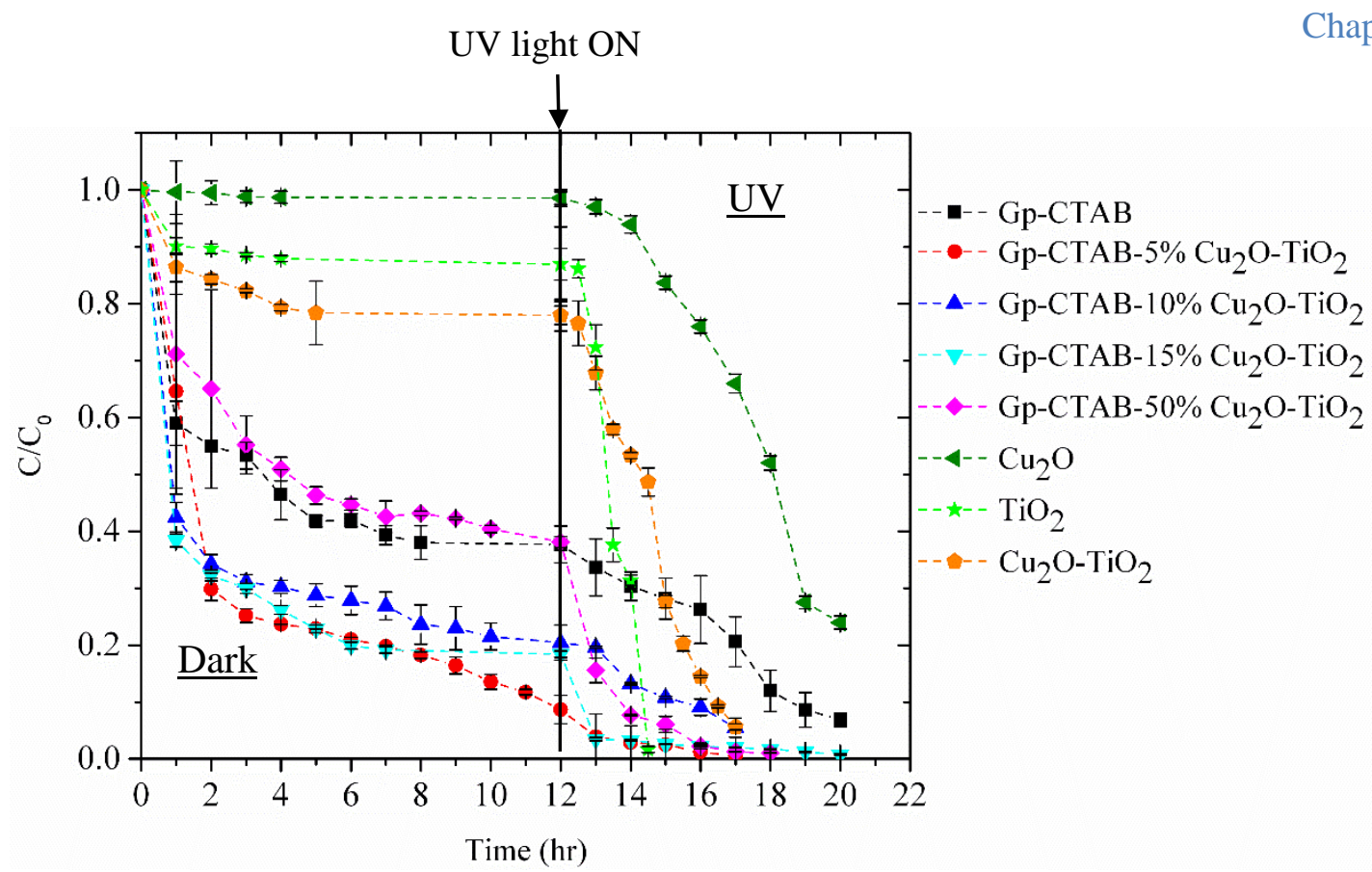

Figure 7.13. Plots of the residual concentration $\left(C / C_{0}\right)$ vs. time $(t)$ onto the $M-G P, M-G P-5$, 10, 15 and 50 wt\% $\mathrm{Cu}_{2} \mathrm{O}, \mathrm{Cu}_{2} \mathrm{O}, \mathrm{TiO}_{2}, \mathrm{Cu}_{2} \mathrm{O} / \mathrm{TiO}_{2}$ (monitored at $664 \mathrm{~nm}$ ).

These points are illustrated more clearly in Figure 7.14 which compares the removal of MB after $60 \mathrm{~min}$. by the CTAB-modified geopolymer composites containing different percentages of $\mathrm{Cu}_{2} \mathrm{O} / \mathrm{TiO}_{2}$ and the metal oxide components alone, in the dark and under UV irradiation. This figure confirms the result that after $60 \mathrm{~min}$. the adsorption step of $\mathrm{MB}$ removal is most eficient in the composites containing 5-15 wt $\% \mathrm{Cu}_{2} \mathrm{O} / \mathrm{TiO}_{2}$, by comparison wih the CTAB-modified geopolymer matrix alone, and the $\mathrm{Cu}_{2} \mathrm{O}, \mathrm{TiO}_{2}$ and $\mathrm{Cu}_{2} \mathrm{O} / \mathrm{TiO}_{2}$ photoactive elements alone. The removal of MB dye by photodegradation is equally efficient in the geopolymers containing 5-15 wt $\% \mathrm{Cu}_{2} \mathrm{O} / \mathrm{TiO}_{2}$ (Figure 7.14), and all these composites are more efficient than $\mathrm{TiO}_{2}$ alone. Thus, the performance of all these composites, in both the adsorption and photodegradation steps, is superior to that of the oxides when they are not combined with the geopolymer matrix. 


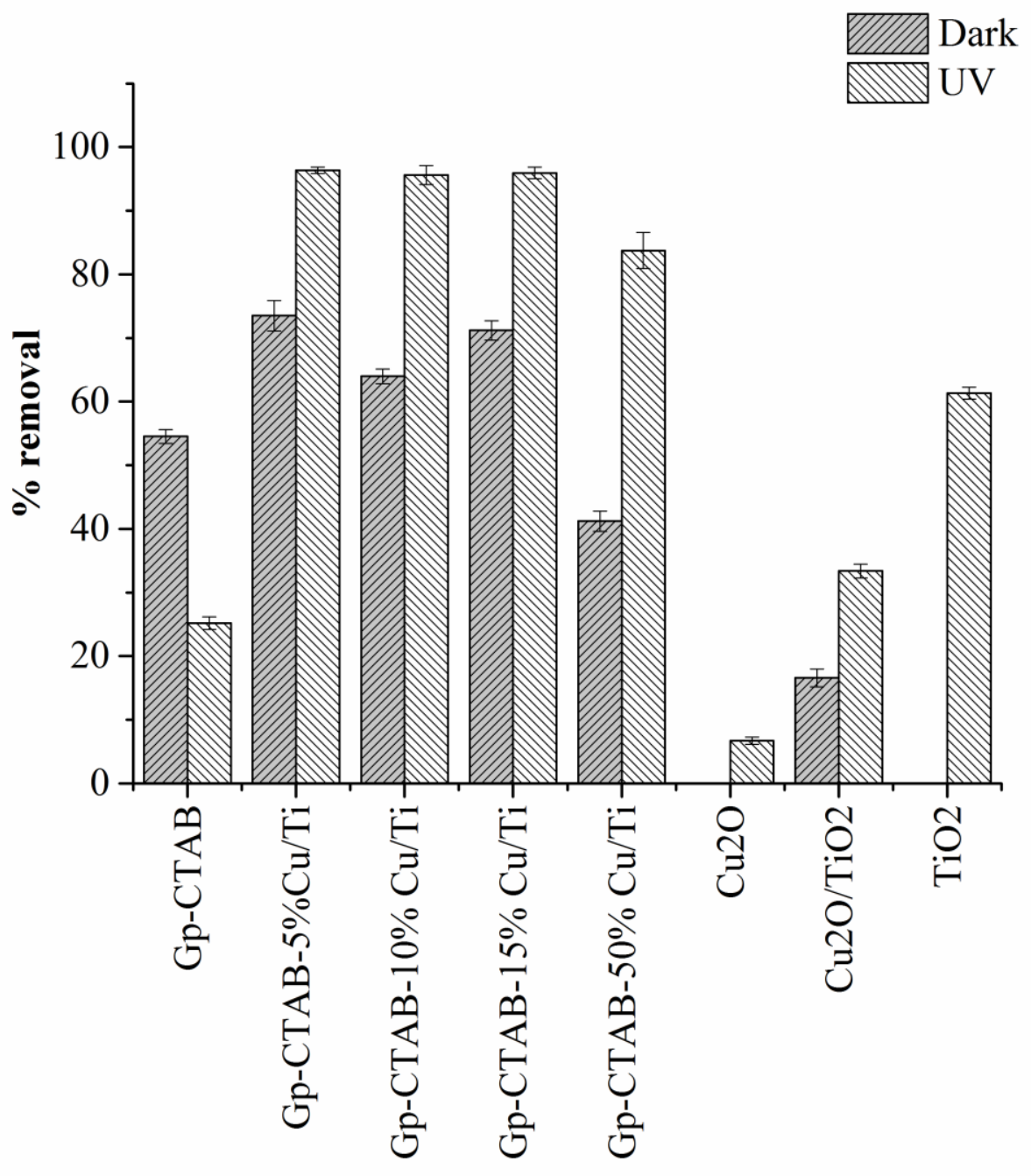

Figure 7.14. $\mathrm{MB}$ removal by the M-GP matrix, M-GP composites containing $5,10,15$ and 50 wt $\% \mathrm{Cu}_{2} \mathrm{O} / \mathrm{TiO}_{2}, \mathrm{Cu}_{2} \mathrm{O}, \mathrm{TiO}_{2}$, and $\mathrm{Cu}_{2} \mathrm{O} / \mathrm{TiO}_{2}$ alone after $60 \mathrm{~min}$.

\subsubsection{Nitrogen Adsorption/Desorption Isotherms}

$\mathrm{N}_{2}$ adsorption-desorption isotherms of the composites formed using the CTAB-modified geopolymer matrix are presented in Figure 7.15. The specific surface areas resulting from the adsorption/desorption isotherms (Table 7.6) indicate an increase in the surface area from 17.0 $\mathrm{m}^{2} / \mathrm{g}$ in the CTAB-modified geopolymer matrix to $34.8 \mathrm{~m}^{2} / \mathrm{g}$ and $33.6 \mathrm{~m}^{2} / \mathrm{g}$ in the composites containing 10 and $15 \mathrm{wt} \% \mathrm{Cu}_{2} \mathrm{O} / \mathrm{TiO}_{2}$ respectively. Similar trends are seen in the Langmuir surface areas and the cumulative surface areas of the pores calculated by the BJH method. Increasing specific surface areas confirm the dispersion of $\mathrm{Cu}_{2} \mathrm{O} / \mathrm{TiO}_{2}$ inside the geopolymer matrix, but the average pore diameters, calculated by the BET method, decrease from 43.09 
$\mathrm{nm}$ in the CTAB-modified geopolymer matrix to $29.7 \mathrm{~nm}$ in the composite containing 10 wt $\% \mathrm{Cu}_{2} \mathrm{O}$, remaining approximately constant at $27.9 \mathrm{~nm}$ in the composite containing 15 wt $\% \mathrm{Cu}_{2} \mathrm{O}$. Thus, the presence of the oxide nanoparticles in the pore structure of the geopolymer matrix increases the surface area of the pores available for adsorption and decreases the average pore size. Therefore, the greater photoactivity of the composite containing $10 \mathrm{wt} \% \mathrm{Cu}_{2} \mathrm{O}$ under both dark and $\mathrm{UV}$ conditions is related to the dispersion of the oxide in the geopolymer matrix, as confirmed by the decreased the pore diameter and increased surface area.

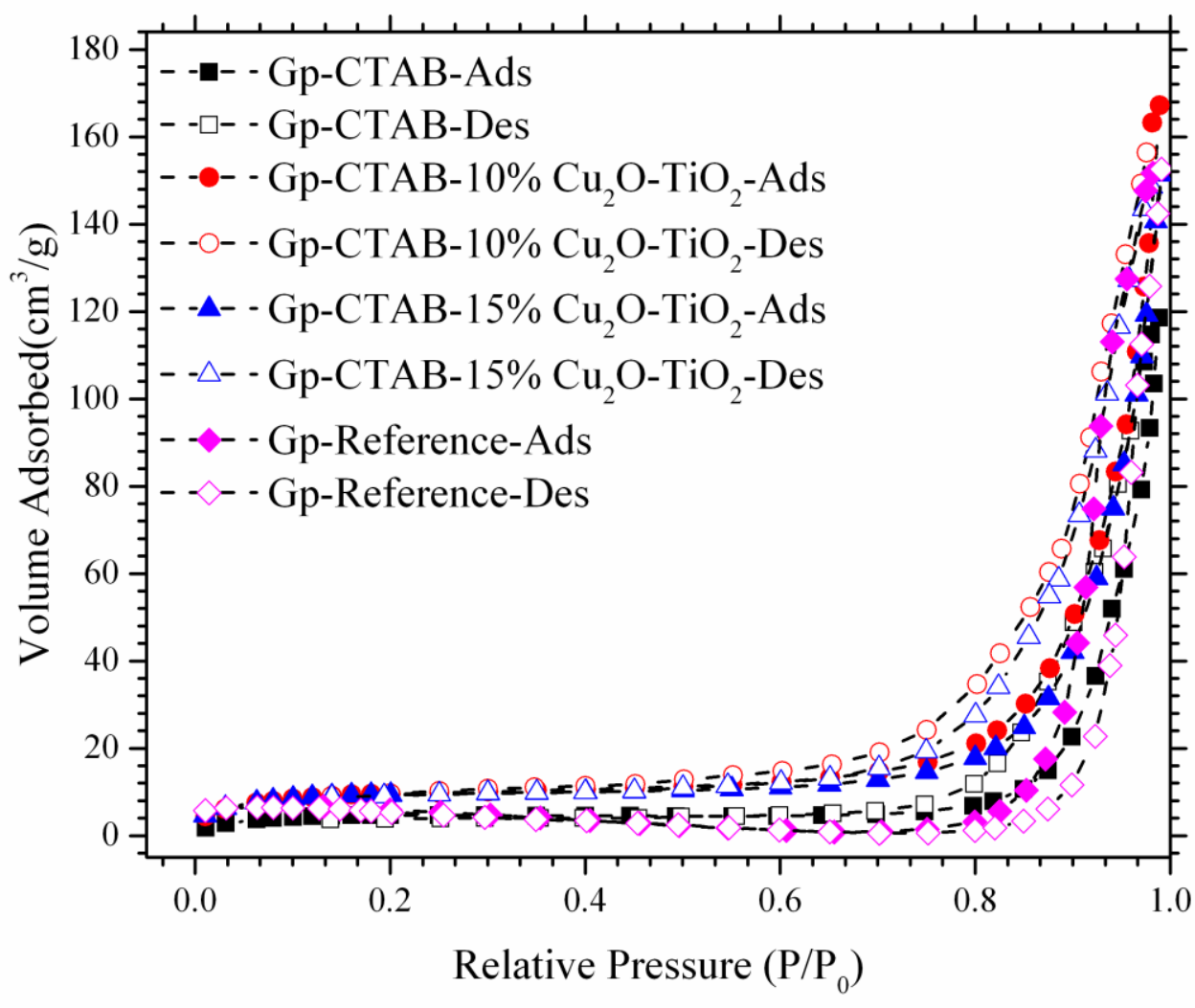

Figure 7.15. Nitrogen sorption isotherms of the M-GP ( $\boldsymbol{\square}$, adsorption $\square$, desorption), M-GP10 wt $\% \mathrm{Cu}_{2} \mathrm{O} / \mathrm{TiO}_{2}\left(\bullet\right.$, adsorption $\bigcirc$, desorption ) and $\mathrm{M}-\mathrm{GP}-15 \mathrm{wt} \% \mathrm{Cu}_{2} \mathrm{O} / \mathrm{TiO}_{2}(\boldsymbol{\Delta}$, adsorption $\triangle$, desorption) GP $(\diamond$, adsorption $\diamond$, desorption) 
Table 7.6. Specific surface areas and pore parameters of CTAB-modified geopolymer matrix and geopolymer composites

\begin{tabular}{|c|c|c|c|c|}
\hline & GP & M-GP & $\begin{array}{l}\text { M-GP-10 wt\% } \\
\mathrm{Cu}_{2} \mathrm{O} / \mathrm{TiO}_{2}\end{array}$ & $\begin{array}{l}\text { M-GP-15 wt\% } \\
\mathrm{Cu}_{2} \mathrm{O} / \mathrm{TiO}_{2}\end{array}$ \\
\hline $\begin{array}{l}\text { Single Point Surface } \\
\text { Area }\end{array}$ & $18.4 \mathrm{~m}^{2} / \mathrm{g}$ & $16.1 \mathrm{~m}^{2} / \mathrm{g}$ & $33.2 \mathrm{~m}^{2} / \mathrm{g}$ & $32.5 \mathrm{~m}^{2} / \mathrm{g}$ \\
\hline $\mathrm{S}_{\text {BET }}$ & $17.2 \mathrm{~m}^{2} / \mathrm{g}$ & $17.0 \mathrm{~m}^{2} / \mathrm{g}$ & $34.8 \mathrm{~m}^{2} / \mathrm{g}$ & $33.6 \mathrm{~m}^{2} / \mathrm{g}$ \\
\hline $\mathrm{S}_{\text {Langmuir }}$ & $21.9 \mathrm{~m}^{2} / \mathrm{g}$ & $23.4 \mathrm{~m}^{2} / \mathrm{g}$ & $48.1 \mathrm{~m}^{2} / \mathrm{g}$ & $45.9 \mathrm{~m}^{2} / \mathrm{g}$ \\
\hline$\overline{\mathrm{S}}$ BJH Adsorption Cumulative & $23.1 \mathrm{~m}^{2} / \mathrm{g}$ & $21.4 \mathrm{~m}^{2} / \mathrm{g}$ & $35.3 \mathrm{~m}^{2} / \mathrm{g}$ & $31.1 \mathrm{~m}^{2} / \mathrm{g}$ \\
\hline$\overline{\mathrm{S}}$ BJH Desorption Cumulative & $38.9 \mathrm{~m}^{2} / \mathrm{g}$ & $33.6 \mathrm{~m}^{2} / \mathrm{g}$ & $53.1 \mathrm{~m}^{2} / \mathrm{g}$ & $47.8 \mathrm{~m}^{2} / \mathrm{g}$ \\
\hline \multicolumn{5}{|l|}{ Volume } \\
\hline $\begin{array}{l}\text { Single Point } \\
\text { Adsorption }\end{array}$ & $0.24 \mathrm{~cm}^{3} / \mathrm{g}$ & $\begin{array}{l}0.18 \\
\mathrm{~cm}^{3} / \mathrm{g}\end{array}$ & $0.26 \mathrm{~cm}^{3} / \mathrm{g}$ & $0.23 \mathrm{~cm}^{3} / \mathrm{g}$ \\
\hline $\begin{array}{l}\mathrm{V} \text { pore BJH Adsorption } \\
\text { Cumulative }\end{array}$ & $0.24 \mathrm{~cm}^{3} / \mathrm{g}$ & $\begin{array}{l}0.18 \\
\mathrm{~cm}^{3} / \mathrm{g}\end{array}$ & $0.26 \mathrm{~cm}^{3} / \mathrm{g}$ & $0.23 \mathrm{~cm}^{3} / \mathrm{g}$ \\
\hline $\begin{array}{l}\mathrm{V} \text { pore BJH Desorption } \\
\text { Cumulative }\end{array}$ & $0.24 \mathrm{~cm}^{3} / \mathrm{g}$ & $\begin{array}{l}0.18 \\
\mathrm{~cm}^{3} / \mathrm{g}\end{array}$ & $0.26 \mathrm{~cm}^{3} / \mathrm{g}$ & $0.23 \mathrm{~cm}^{3} / \mathrm{g}$ \\
\hline \multicolumn{5}{|l|}{ Pore Size } \\
\hline $\mathrm{D}_{\text {Adsorption }}$ & $55 \mathrm{~nm}$ & $43 \mathrm{~nm}$ & $30 \mathrm{~nm}$ & $28 \mathrm{~nm}$ \\
\hline $\mathrm{D}_{\text {BJH Adsorption }}$ & $41 \mathrm{~nm}$ & $34 \mathrm{~nm}$ & $29 \mathrm{~nm}$ & $30 \mathrm{~nm}$ \\
\hline D BJH Desorption & $24 \mathrm{~nm}$ & $22 \mathrm{~nm}$ & $20 \mathrm{~nm}$ & $20 \mathrm{~nm}$ \\
\hline
\end{tabular}

\subsection{CTAB-Modified-geopolymer composites of P25 titania alone}

\subsubsection{XRD Analysis}

Figure 7.16 shows the XRD patterns of CTAB-modified composites containing different percentages of $\mathrm{P} 25 \mathrm{TiO}_{2}$. The specific broad X-ray amorphous feature for geopolymer and the sharp reflections of rutile and anatase of titania are as expected. 


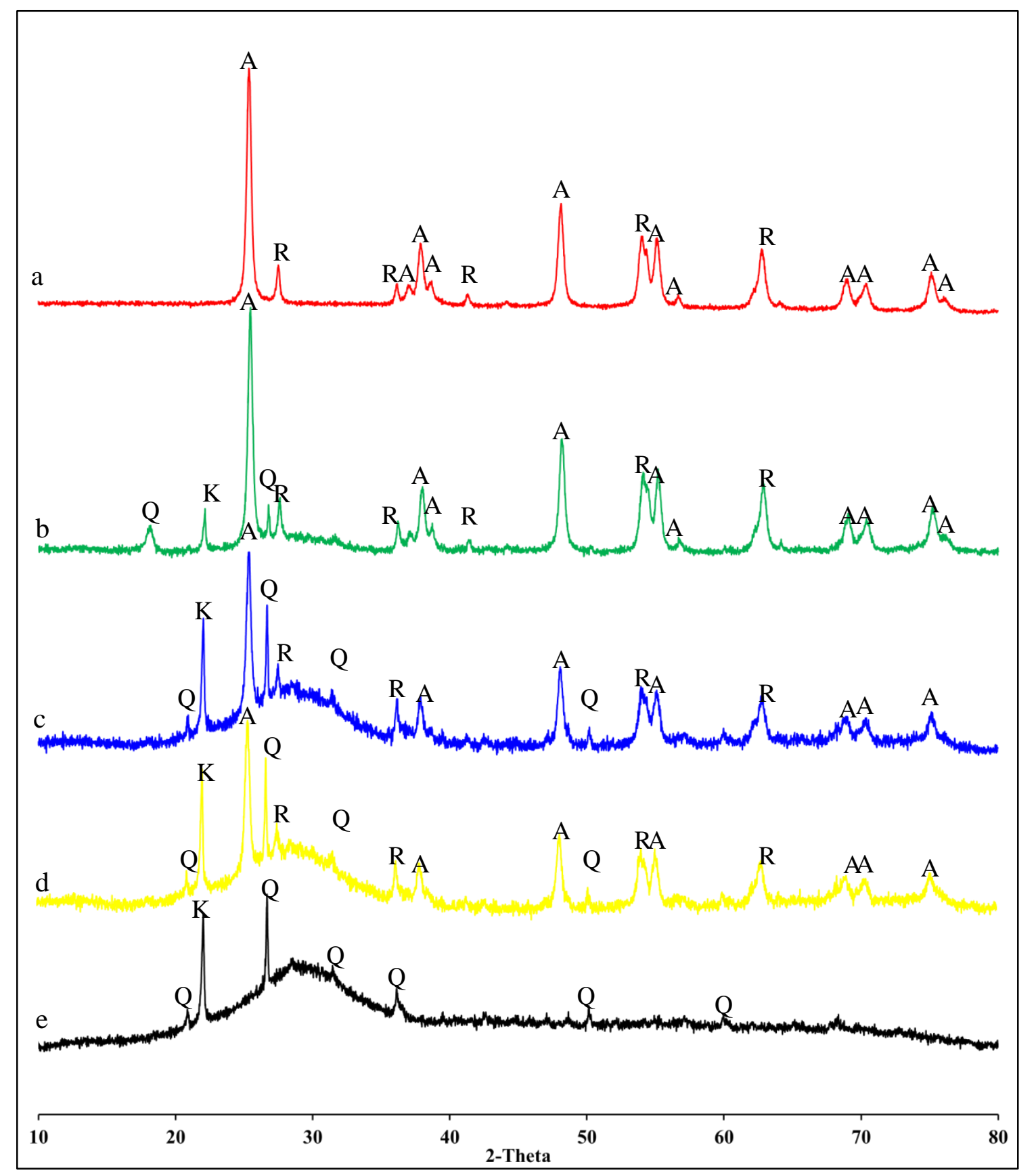

Figure 7.16. XRD patterns of $\mathrm{TiO}_{2}$ and $\mathrm{TiO}_{2}$ supported by M-GP with different loading contents; (a) $\mathrm{TiO}_{2}$, (b-d) M-GP 50, 10 and 5 wt\% $\mathrm{TiO}_{2}$, (e) M- GP.

\subsubsection{Scanning electron microscopy}

The SEM micrographs of Figure 7.17 confirm the dispersion of the $\mathrm{P} 25 \mathrm{TiO}_{2}$ particles over the surface of the CTAB-modified geopolymer composites with no sign of particle aggregation. The backscattered images (Figure7.17 b,d,f) show the increased presence of bright spots corresponding to the $\mathrm{TiO}_{2}$ particles. 


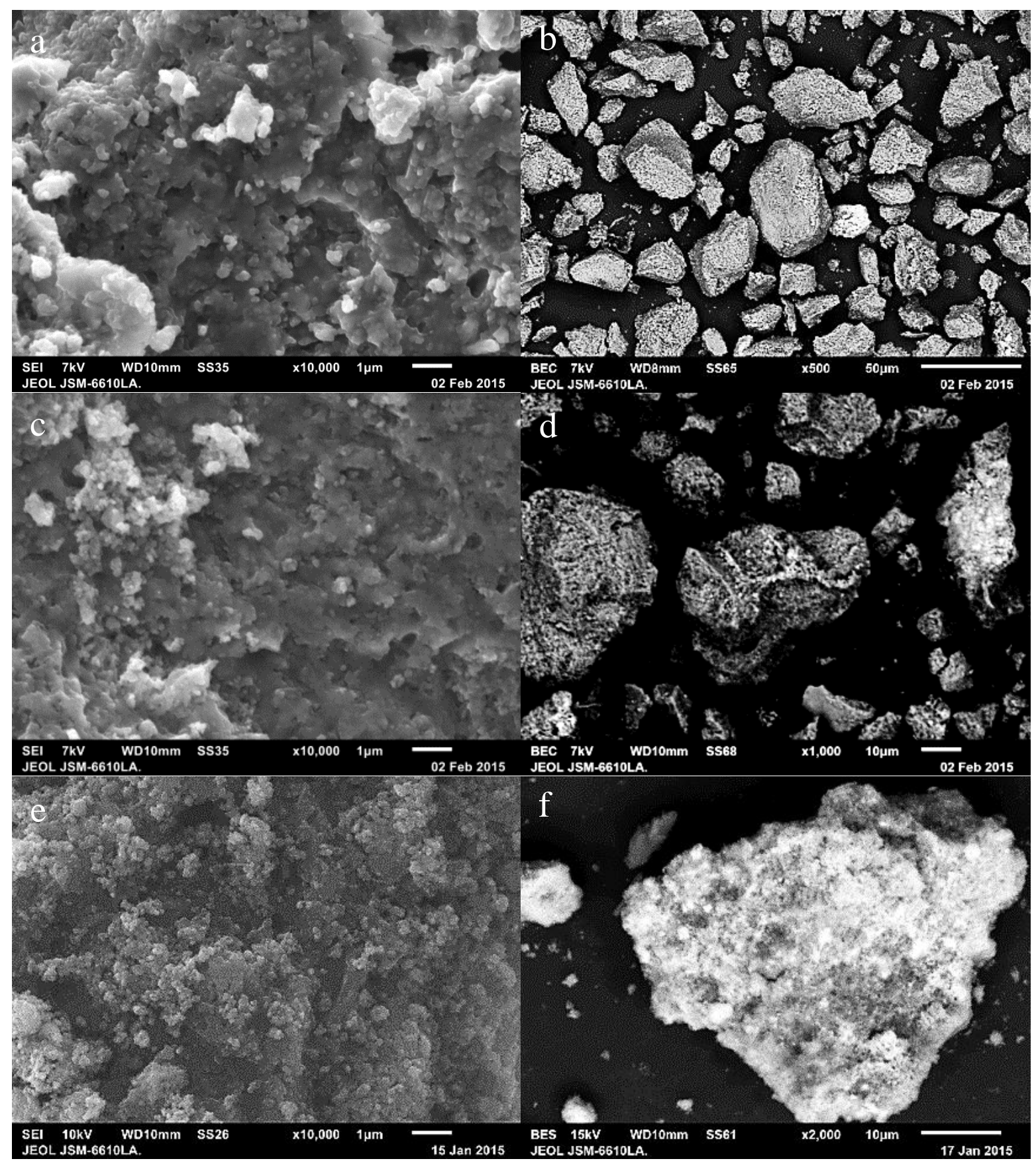

Figure 7.17. SEM micrographs of (a-f) M-GP composite containing 5, 10, 15 wt $\% \mathrm{TiO}_{2}$. Right hand micrographs are BSE, left hand are SE.

The EDS elemental analysis and the Figure 7.18 confirms the presence of all the expected elements ( $\mathrm{Si}, \mathrm{Al}, \mathrm{Na}$, and $\mathrm{Ti}$ ) in the $\mathrm{CTAB}$-modified geopolymer composite and the absence of any additional impurities. 

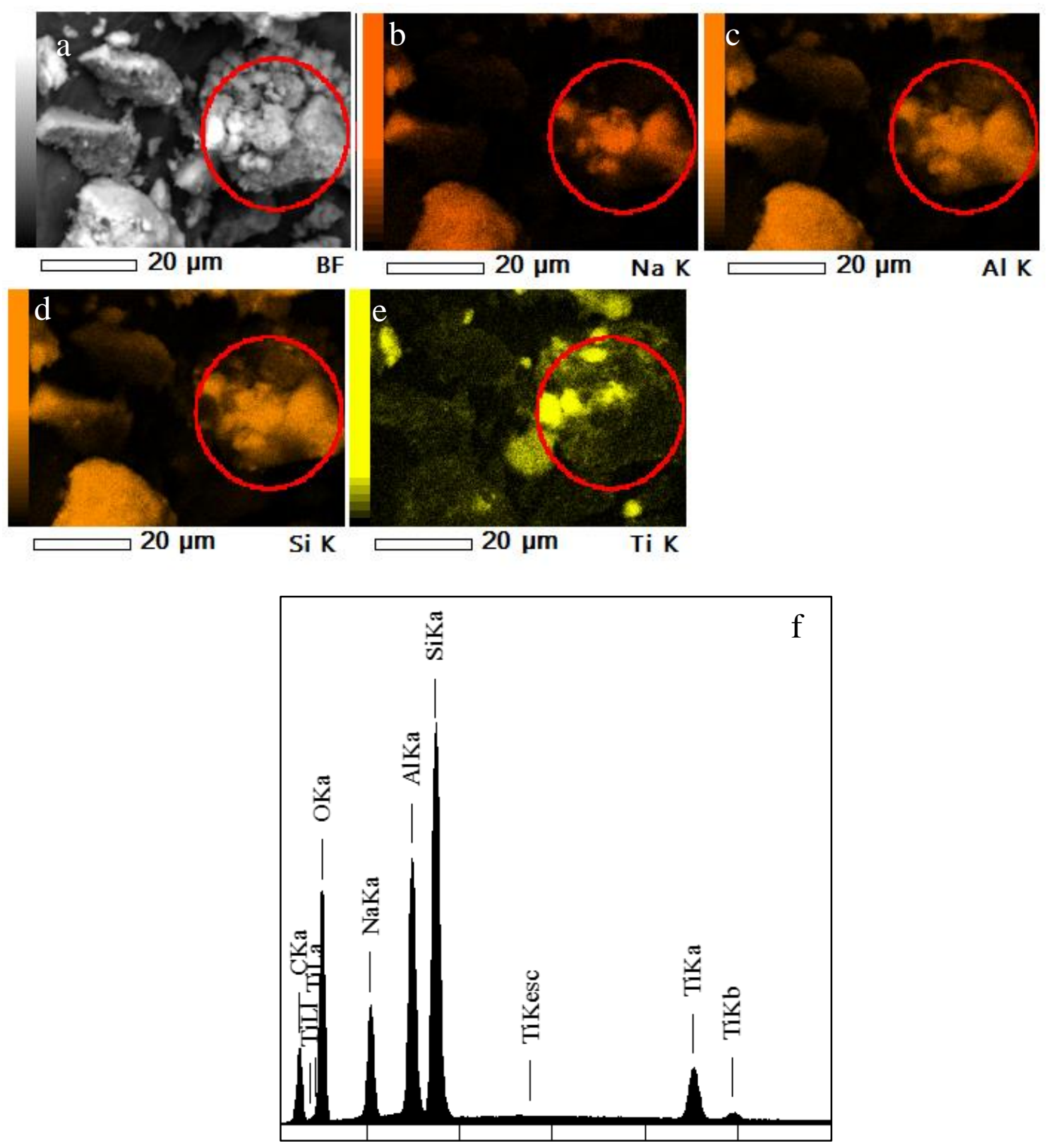

Figure 7.18 (a) Backscattered image, (b) Na, (c) Al, (d) Si, (e) Ti elemental map (f) EDS spectrum of the red-circled area of $\mathrm{M}-\mathrm{GP}-15 \mathrm{wt} \% \mathrm{TiO}_{2}$.

\subsubsection{High-Resolution Transmission Electron Microscopy}

The HRTEM micrographs (Figure 7.19) confirm the entry of the $\mathrm{TiO}_{2}$ particles into the pore structure of the geopolymer matrix. The average lattice fringe spacings measured for 10 lattice fringes show distance of $0.18,0.38$ and $0.37 \mathrm{~nm}$ between them arising from the (201) and (101) plane of the $\mathrm{TiO}_{2}$, consistent with the result obtained for the unmodified geopolymer composite containing $\mathrm{P} 25 \mathrm{TiO}_{2}$. 

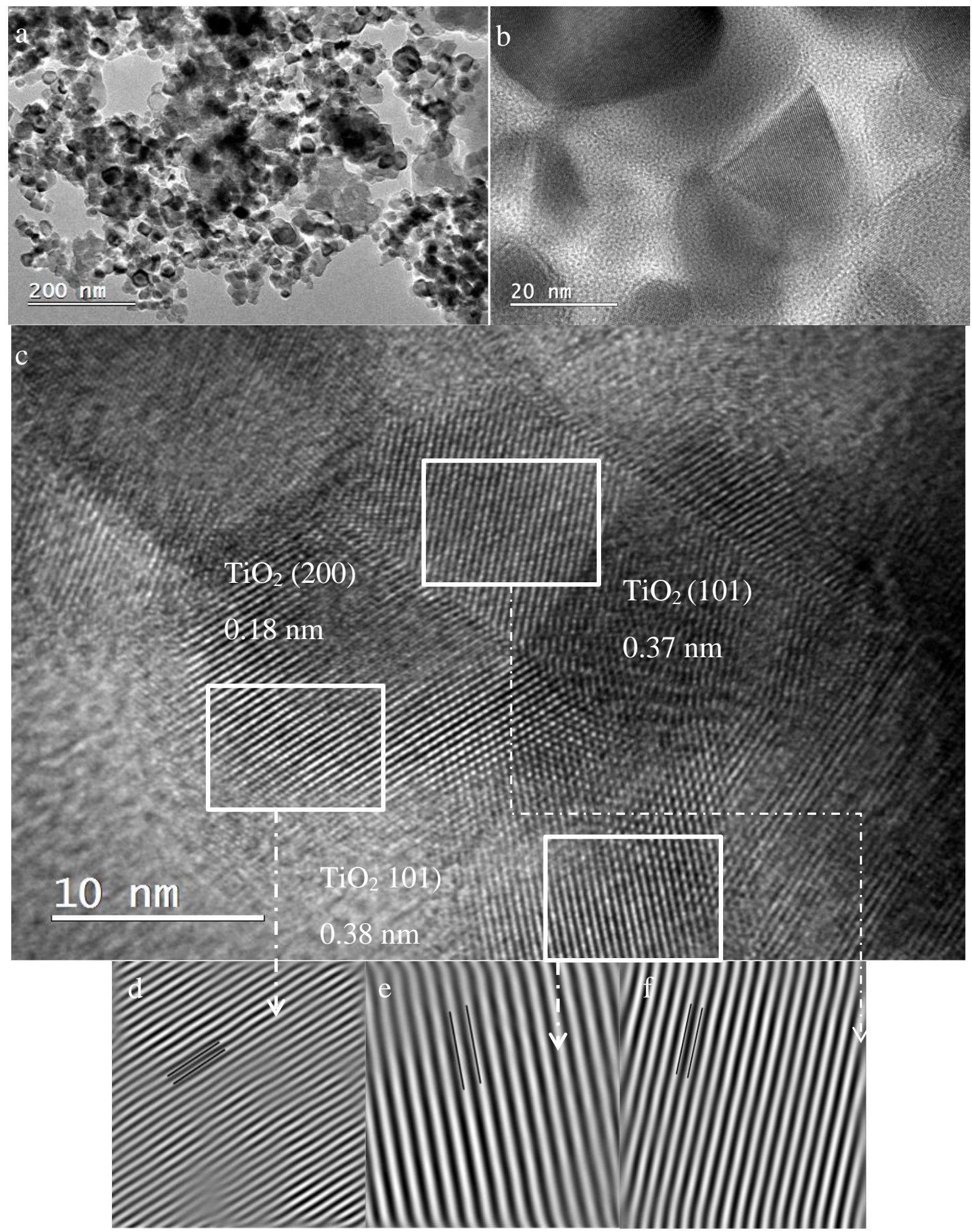

Figure 7.19. (a-c) TEM images of GP-10\%-TiO 2 composite with, (d-f) HRTEM images of selected area in c. 


\subsubsection{Adsorption and degradation of $\mathrm{MB}$ dye by $\mathrm{P} 25$ titania, $\mathrm{Cu}_{2} \mathrm{O}, \mathrm{Cu}_{2} \mathrm{O} / \mathrm{TiO}_{2}$ and their CTAB-modified geopolymer composites}

The behaviour of P25 titania alone and incorporated in the CTAB-modified geopolymer matrix was measured in the both dark and UV condition and compared with the $\mathrm{Cu}_{2} \mathrm{O} / \mathrm{TiO}_{2}$ and $\mathrm{Cu}_{2} \mathrm{O}$ CTAB-modified geopolymer composites (Figure 7.20). The metal oxide nanoparticles themselves do not have the ability to remove MB from solution under dark conditions, but, in combination with the CTAB-modified geopolymer matrix, adsorption occurs by a process that can be described by the pseudo-second order kinetic equation. In addition, these data are well fitted to isotherms of the Langmuir-Freundlich type, as was found to be the case for composites of $\mathrm{Cu}_{2} \mathrm{O}$ with $\mathrm{CTAB}$-modified geopolymer matrices (chapter 6).

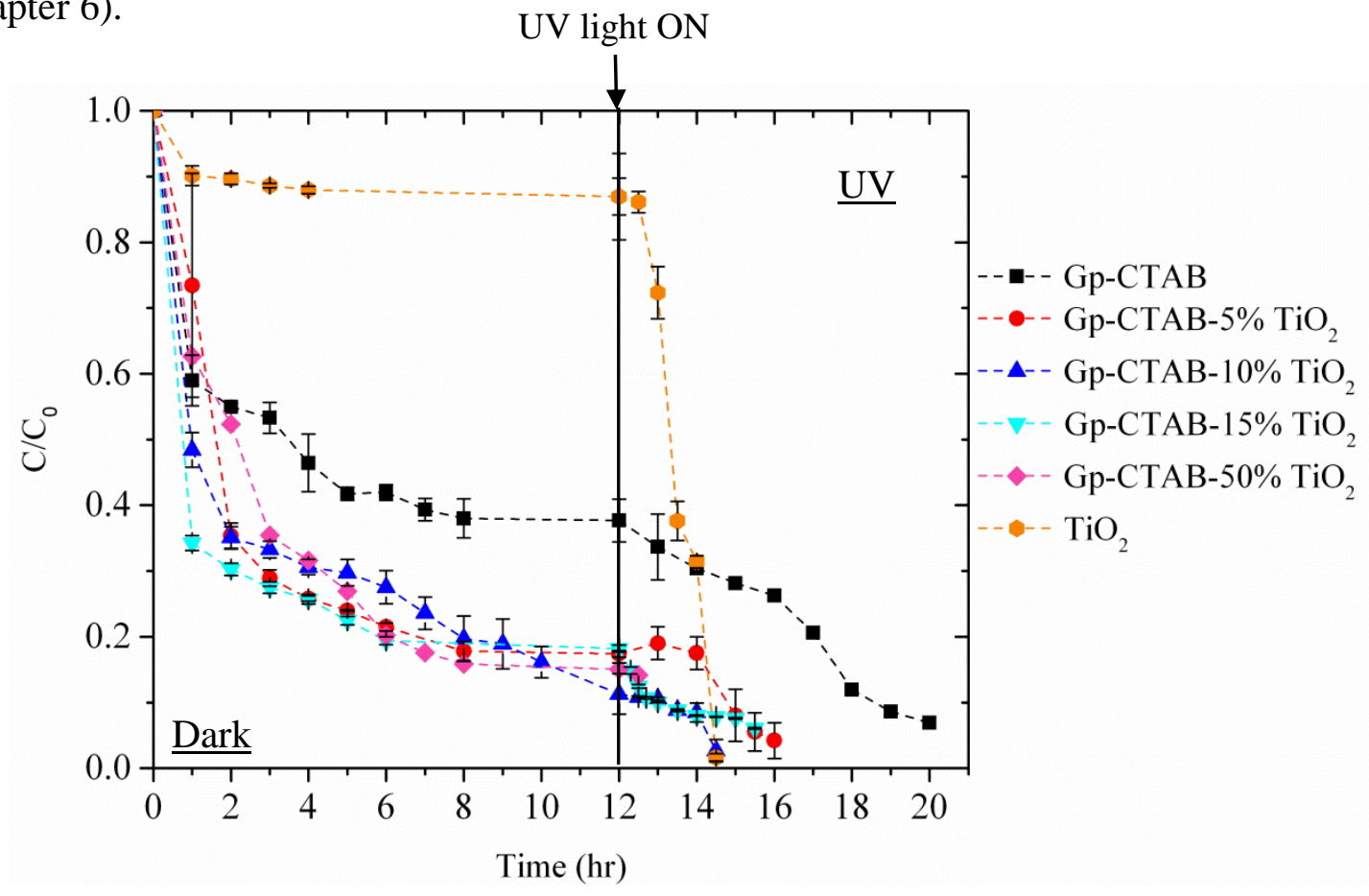

Figure 7.20. Plots of the residual concentration $\left(\mathrm{C} / \mathrm{C}_{0}\right)$ vs. time $(\mathrm{t})$ onto the $\mathrm{M}-\mathrm{GP}, \mathrm{TiO}_{2}$ and M-GP 5, 10, 15 and $50 \mathrm{wt} \% \mathrm{TiO}_{2}$ (monitored at $664 \mathrm{~nm}$ ).

Under the UV irradiation, the most rapid destruction of $\mathrm{MB}$ dye, starting from the equilibrium position, is by the composite containing $10 \mathrm{wt} \% \mathrm{P} 25 \mathrm{TiO}_{2}$ (Figure 7.21), but this composite has the advantage of starting from a vale in which a good deal of the MB has already been adsorbed under dark conditions. Figure 7.21 shows that all the photocatalysts prepared from CTAB-modified geopolymer have very rapid photodegradation properties. 


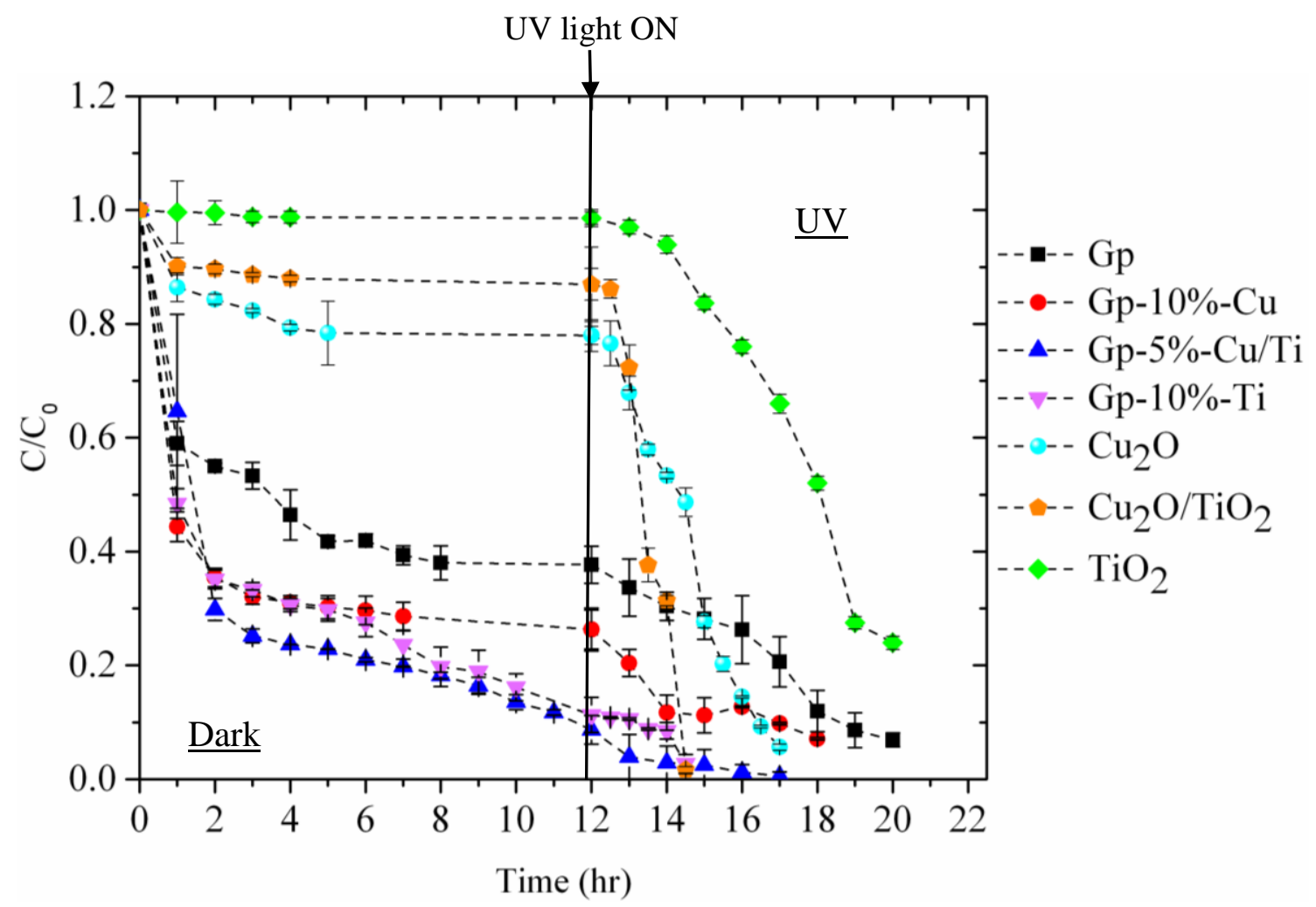

Figure 7.21. Plots of the residual concentration $\left(\mathrm{C} / \mathrm{C}_{0}\right)$ vs. time $(\mathrm{t})$ onto the $\mathrm{M}-\mathrm{GP}, \mathrm{Cu}_{2} \mathrm{O}$, $\mathrm{TiO}_{2}, \mathrm{Cu}_{2} \mathrm{O} / \mathrm{iO}_{2}, \mathrm{M}-\mathrm{GP}-10$ wt $\% \mathrm{Cu}_{2} \mathrm{O}, \mathrm{M}-\mathrm{GP}-5 \mathrm{wt} \% \mathrm{Cu}_{2} \mathrm{O} / \mathrm{TiO} 2, \mathrm{M}-\mathrm{GP}-10 \mathrm{wt} \% \mathrm{TiO}_{2}$ (monitored at $664 \mathrm{~nm}$ ).

Figure 7.22 compares the removal of $\mathrm{MB}$ after $60 \mathrm{~min}$. CTAB-modified geopolymer containing different percentages of $\mathrm{TiO}_{2}$ and $\mathrm{TiO}_{2}$ alone, in the dark and under UV irradiation. This figure confirms the removal of MB dye by photodegradation in the the CTAB-modified geopolymers containing 5-50 wt\% is correspondingly effective and all these composites are more efficient than $\mathrm{TiO}_{2}$ alone (Figure 7.22) The adsorption process is more efficient in the composites containing $15 \mathrm{wt} \% \mathrm{TiO}_{2}$ and the highest degree of $\mathrm{MB}$ removal by both the adsorption and photodegradation processes occurs in the CTAB-modified geopolymer containing $10 \mathrm{wt} \% \mathrm{TiO}_{2}$ contents. 


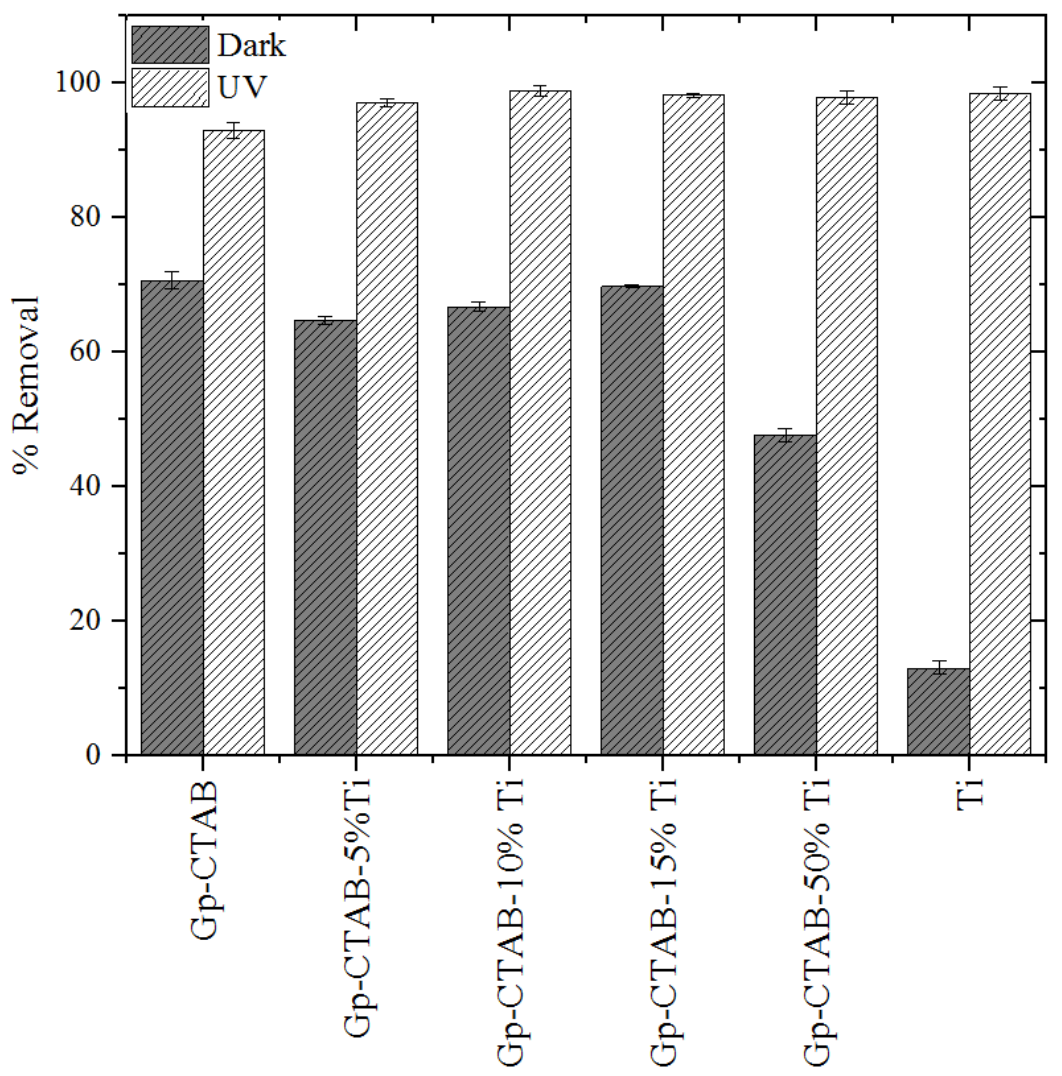

Figure 7.22. $\mathrm{MB}$ removal by the $\mathrm{M}-\mathrm{GP}, \mathrm{M}-\mathrm{GP}-5,10,15$ and $50 \mathrm{wt} \% \mathrm{TiO}_{2}, \mathrm{TiO}_{2}$ alone after 60 $\min$.

\subsubsection{Nitrogen Adsorption/Desorption Isotherms}

The nitrogen adsorption/desorption isotherms of these composites are shown in Figure 7.21. The specific surface areas derived from these isotherms (Table 7.8) show a major decrease from $16.14 \mathrm{~m}^{2} / \mathrm{g}$ in the CTAB-modified geopolymer composite to $0.46 \mathrm{~m}^{2} / \mathrm{g}$ in the composite containing $15 \mathrm{wt} \% \mathrm{TiO}_{2}$. This is possibly due to blocking of the pores by the $\mathrm{TiO}_{2}$ particles, and is in marked contrast to the increase in surface area produced by the inclusion of $15 \mathrm{wt} \%$ $\mathrm{Cu}_{2} \mathrm{O}$ (Table 7.6). The composites containing $\mathrm{TiO}_{2}$ also show anomalous behaviour in their pore size and volume, the former being much larger than in the CTAB-modified matrix and the latter being much smaller than the matrix (Table 7.6). Both these effects may be understood in terms of the ready entry of the titania particles into the matrix, causing the pores to expand but blocking the access of the nitrogen gas to the pore surfaces, as reflected in the decreased BET surface area. 


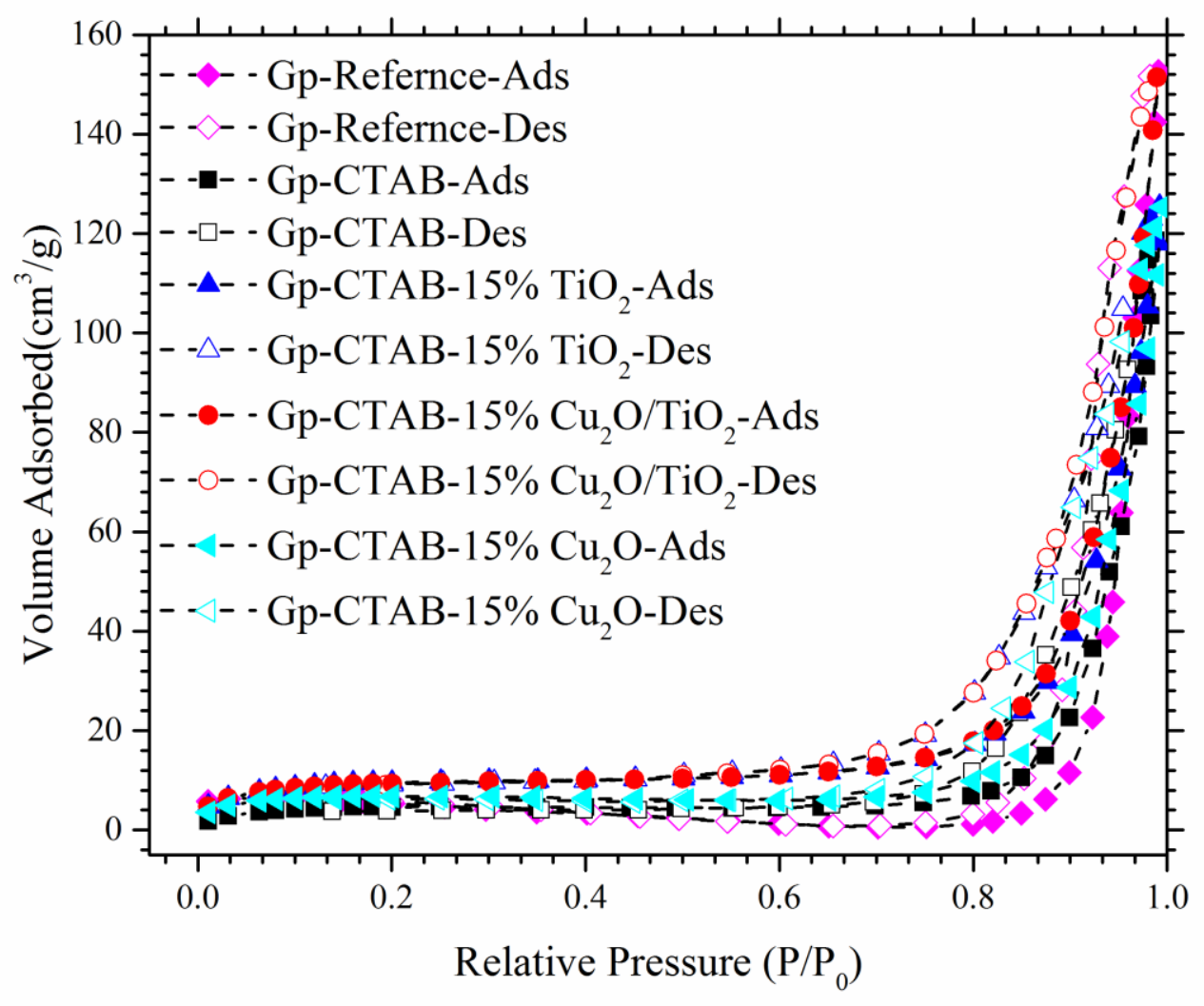

Figure 7.23. Nitrogen sorption isotherms of the GP ( $\diamond$, adsorption $\diamond$, desorption), M-GP $(\boldsymbol{\square}$, adsorption $\square$, desorption), M-GP-15 wt $\% \mathrm{TiO}_{2}$ ( $\boldsymbol{\Delta}$, adsorption $\triangle$, desorption) M-GP-15 wt\% $\mathrm{Cu}_{2} \mathrm{O}(<$, adsorption $\varangle$, desorption) 
Table 7.7. Specific surface areas and pore parameters of GP, M-GP and their composites containing $\mathrm{TiO}_{2}, \mathrm{Cu}_{2} \mathrm{O}$ and $\mathrm{Cu}_{2} \mathrm{O} / \mathrm{TiO}_{2}$

\begin{tabular}{|c|c|c|c|c|c|}
\hline & GP & M-GP & $\begin{array}{c}\text { M-GP- } \\
15 \text { wt\% } \\
\mathrm{Cu}_{2} \mathrm{O} \\
\end{array}$ & $\begin{array}{c}\text { M-GP- } \\
15 \text { wt\% } \\
\mathrm{Cu}_{2} \mathrm{O} / \mathrm{TiO}_{2} \\
\end{array}$ & $\begin{array}{c}\text { M-GP- } \\
15 \text { wt } \% \\
\mathrm{TiO}_{2} \\
\end{array}$ \\
\hline $\begin{array}{l}\text { Single Point Surface } \\
\text { Area }\end{array}$ & $18.44 \mathrm{~m}^{2} / \mathrm{g}$ & $16.14 \mathrm{~m}^{2} / \mathrm{g}$ & $23.52 \mathrm{~m}^{2} / \mathrm{g}$ & $32.54 \mathrm{~m}^{2} / \mathrm{g}$ & $0.46 \mathrm{~m}^{2} / \mathrm{g}$ \\
\hline $\mathrm{S}_{\mathrm{BET}}$ & $17.23 \mathrm{~m}^{2} / \mathrm{g}$ & $17.02 \mathrm{~m}^{2} / \mathrm{g}$ & $23.73 \mathrm{~m}^{2} / \mathrm{g}$ & $33.57 \mathrm{~m}^{2} / \mathrm{g}$ & $0.30 \mathrm{~m}^{2} / \mathrm{g}$ \\
\hline $\mathrm{S}_{\text {Langmuir }}$ & $21.92 \mathrm{~m}^{2} / \mathrm{g}$ & $23.44 \mathrm{~m}^{2} / \mathrm{g}$ & $31.95 \mathrm{~m}^{2} / \mathrm{g}$ & $45.89 \mathrm{~m}^{2} / \mathrm{g}$ & $0.32 \mathrm{~m}^{2} / \mathrm{g}$ \\
\hline $\mathrm{S}_{\text {BJH Adsorption Cumulative }}$ & $23.06 \mathrm{~m}^{2} / \mathrm{g}$ & $21.41 \mathrm{~m}^{2} / \mathrm{g}$ & $23.96 \mathrm{~m}^{2} / \mathrm{g}$ & $31.09 \mathrm{~m}^{2} / \mathrm{g}$ & $0.40 \mathrm{~m}^{2} / \mathrm{g}$ \\
\hline $\mathrm{S}_{\text {BJH Desorption Cumulative }}$ & $38.94 \mathrm{~m}^{2} / \mathrm{g}$ & $33.63 \mathrm{~m}^{2} / \mathrm{g}$ & $39.70 \mathrm{~m}^{2} / \mathrm{g}$ & $47.77 \mathrm{~m}^{2} / \mathrm{g}$ & $1.01 \mathrm{~m}^{2} / \mathrm{g}$ \\
\hline \multicolumn{6}{|l|}{ Volume } \\
\hline $\begin{array}{l}\text { Single Point } \\
\text { Adsorption }\end{array}$ & $0.24 \mathrm{~cm}^{3} / \mathrm{g}$ & $0.18 \mathrm{~cm}^{3} / \mathrm{g}$ & $0.19 \mathrm{~cm}^{3} / \mathrm{g}$ & $0.23 \mathrm{~cm}^{3} / \mathrm{g}$ & $0.019 \mathrm{~cm}^{3} / \mathrm{g}$ \\
\hline $\begin{array}{l}\mathrm{V} \text { pore BJH Adsorption } \\
\text { Cumulative }\end{array}$ & $0.24 \mathrm{~cm}^{3} / \mathrm{g}$ & $0.18 \mathrm{~cm}^{3} / \mathrm{g}$ & $0.19 \mathrm{~cm}^{3} / \mathrm{g}$ & $0.23 \mathrm{~cm}^{3} / \mathrm{g}$ & $0.016 \mathrm{~cm}^{3} / \mathrm{g}$ \\
\hline $\begin{array}{l}\mathrm{V} \text { pore BJH Desorption } \\
\text { Cumulative }\end{array}$ & $0.24 \mathrm{~cm}^{3} / \mathrm{g}$ & $0.18 \mathrm{~cm}^{3} / \mathrm{g}$ & $0.19 \mathrm{~cm}^{3} / \mathrm{g}$ & $0.23 \mathrm{~cm}^{3} / \mathrm{g}$ & $0.018 \mathrm{~cm}^{3} / \mathrm{g}$ \\
\hline \multicolumn{6}{|l|}{ Pore Size } \\
\hline $\mathrm{D}_{\text {Adsorption }}$ & $55 \mathrm{~nm}$ & $43 \mathrm{~nm}$ & $33 \mathrm{~nm}$ & $28 \mathrm{~nm}$ & $27 \mathrm{~nm}$ \\
\hline D BJH Adsorption & $41 \mathrm{~nm}$ & $34 \mathrm{~nm}$ & $32 \mathrm{~nm}$ & $30 \mathrm{~nm}$ & $165 \mathrm{~nm}$ \\
\hline D BJH Desorption & $24 \mathrm{~nm}$ & $22 \mathrm{~nm}$ & $20 \mathrm{~nm}$ & $20 \mathrm{~nm}$ & $71 \mathrm{~nm}$ \\
\hline
\end{tabular}

\section{Conclusions}

This chapter establishes the effective synthesis and structure of composites based on a combination of the most promising materials identified in the previous chapters, namely, a matrix of CTAB-modified geopolymer with a photoactive component of a spherical $\mathrm{Cu}_{2} \mathrm{O} / \mathrm{TiO}_{2}$ nano-heterostructure. As in the previous chapters, SEM/EDS and TEM was used to confirm the homogenous distribution of the nano oxide particles within the geopolymer matrix and on the surface of the composite. The entry of the $\mathrm{Cu}_{2} \mathrm{O} / \mathrm{TiO}_{2}$ nanoparticles into the 
internal pores of the geopolymer matrix was evidenced by an increase of the composite surface area and a decrease of the pore size upon the addition of the oxide nanoparticles. As in the previous chapter, the use of CTAB to modify the pore structure and facilitate the ingress of the nano oxides also has the effect of maintaining a stable $\mathrm{pH}$ during $\mathrm{MB}$ dye removal from solution, and also permits the adsorption and desorption processes to be separately observed. The adsorption of MB by these CTAB-modified composites follows pseudo second-order kinetics and Freundlich-Langmuir type isotherms. The most effective composite in removing $\mathrm{MB}$ dye from solution under UV irradiation contains $5 \mathrm{wt} \%$ $\mathrm{Cu}_{2} \mathrm{O} / \mathrm{TiO}_{2}$, representing the most efficient combination of the adsorption and photodegradation steps. 


\section{Chapter 8}

\section{Overall Conclusions from This Research and Possible Directions for Further Work}

\subsection{Conclusions from This Research}

The initial aim of this research was to develop metakaolin-based geopolymer composites containing $\mathrm{Cu}_{2} \mathrm{O}$ nanoparticles as the photoactive element able to remove organic pollutants from water or the atmosphere. The first part of the project was therefore to determine a suitable synthesis protocol for the $\mathrm{Cu}_{2} \mathrm{O}$ oxide nanoparticles and to characterize their size and shape using electron microscopy. The synthesis method producing nanoparticles of the most suitable size $(\sim 100 \mathrm{~nm})$ was found to be one that produced cubic morphologies. Composites of these cubic nanocrystals were prepared with a geoplymer matrix of standard composition ("unmodified geopolymer") by pre-synthesising the nanoparticles and mechanically mixing them with the geopolymer matrix prior to curing. The homogeneity of the oxide nanoparticle distribution within the geopolymer matrix was confirmed by SEM/EDS and TEM, while XRD, FTIR, ${ }^{27} \mathrm{Al}$ and ${ }^{29} \mathrm{Si}$ MAS NMR and ${ }^{63} \mathrm{Cu}$ NQR spectroscopy showed that the geopolymer matrix was well-reacted geopolymer matrix and was unaffected by the insertion of the $\mathrm{Cu}_{2} \mathrm{O}$ nanoparticles. These composites proved to be very successful in removing from solution a model organic pollutant (MB dye, chosen for its colour stability at the high $\mathrm{pH}$ of the geopolymer matrix). The removal of the dye followed a two-step process, namely, adsorption by the geopolymer matrix (under dark conditions) and photodegradation by the $\mathrm{Cu}_{2} \mathrm{O}$ (under UV illumination) but since these two processes occurred simultaneously, they could not be studied separately. The adsorption process carried out in the dark was shown to follow a pseudo-first order kinetic model and be described by an empirical Langmuir-type isotherm.

As an approach to improving the photocatalytic performance of these composites, a combination of $\mathrm{Cu}_{2} \mathrm{O}$ with $\mathrm{P} 25 \mathrm{TiO}_{2}$ in a 50\% weight ratio as produced in the form of a nanoheterostructure, following a procedure documented in the literature. This $\mathrm{Cu}_{2} \mathrm{O} / \mathrm{TiO}_{2}$ photoactive component was incorporated in varying amounts in the unmodified geopolymer matrix, and the resulting composites proved to have improved photoactivity over composites 
containing either $\mathrm{Cu}_{2} \mathrm{O}$ or $\mathrm{TiO}_{2}$ alone, although the dual processes of dye adsorption and photodegradation were still indistinguishable, being a property of the matrix rather than the photoactive element. As with the composites containing $\mathrm{Cu}_{2} \mathrm{O}$ alone, the pseudo-first-order kinetic model was more appropriate for describing the adsorption data, and they were also best described by a Langmuir-type isotherm.

Attention was then turned to the effect of the geopolymer matrix on the performance of these composites, and a novel approach was adopted to modify the geopolymer structure by the use of the large quaternary ammonium cation CTAB. This had not previously been used with geopolymers, but proved to be successful in acting as a $\mathrm{pH}$ buffer, enabling the two processes of dye adsorption and photodegradation to be distinguished by allowing the adsorption step to reach equilibrium under dark conditions before phototodegradation under UV illumination. By contrast with the composites of unmodified geopolymer matrices, the dye adsorption kinetics on composites with CTAB-modified geopolymer matrices followed a pseudo-second order kinetic model and could be described by Freundlich-Langmuir type isotherms.

$\mathrm{N}_{2}$ adsorption-desorption isotherms of the composites formed using the CTAB-modified geopolymer matrix showed thir specific surface areas to increase significantly with the insertion of the photoactive $\mathrm{Cu}_{2} \mathrm{O} / \mathrm{TiO}_{2}$ nano-heterostructures, suggesting that the modified matrix structure facilitates the entry of the nano oxides into the matrix. On the other hand, the average pore diameters decrease significantly with the entry of the nano oxides, possibly due to blocking of the pores by the oxide nanoparticles.

The photoactive efficiency of these composites was found to depend on a number of factors, including the content of the photactive component, in addition to the nature of the photocatalyst and the matrix, which was capable of removing $>99 \%$ of MB dye under UV irradiation.

Overall, the most effective composite in removing MB dye from solution under UV irradiation contained $5 \mathrm{wt} \% \mathrm{Cu}_{2} \mathrm{O} / \mathrm{TiO}_{2}$, supported on a CTAB-modified geopolymer matrix, which was capable of removing $>98 \%$ of the dye under UV irradiation after 4 hour.

These results demonstrate that composites of nanosized $\mathrm{Cu}_{2} \mathrm{O}$ particles combined with photoreactive $\mathrm{TiO}_{2}$ supported by an aluminosilicate geopolymer matrix modified with CTAB constitute new and novel materials with potential environmental protection applications to efficiently remove organic pollutants from water or the atmosphere. 
To summarise,

Composites of nanoparticle sized $\mathrm{Cu}_{2} \mathrm{O}$ in a geopolymer matrix have successfully been synthesised and their structures characterized before and after their use as photocatalysts, using XRD, SEM, TEM, FTIR, MAS NMR and ${ }^{63} \mathrm{Cu}$ NQR

These composites act to photodegrade a model organic chemical (MB dye) by a dual mechanism of adsorption and photodegradation which cannot be distinguished but the kinetics of dye adsorption on the matrix could be measured under dark conditions.

More efficient removal of MB dye was achieved using a photoactive nano-heterostructure of $\mathrm{Cu}_{2} \mathrm{O}$ and $\mathrm{TiO}_{2}$ in the geopolymer matrix

Modification of the geopolymer matrix with CTAB enables the two processes of adsorption and photodegradation to be distinguished and produces even more efficient removal of $\mathrm{MB}$ from solution.

\subsection{Recommendations for Future Work}

Based on the results and conclusions of this present study, it is recommended that the following possibilities be further investigated in future studies:

Other combinations of small band gap semiconducting oxides could be tried with the CTABmodified geopolymer matrix to improve the photoactivity of the composite.

Experiments could be carried out under solar radiation wavelengths to develop photoactive devices of greater efficiency under real conditions.

Additional modification studies could be carried out to explore other means of modifying the geopolymer matrix to improve its acceptance of oxide nanoparticles and improve the photocatalytic properties of the resulting composites.

The use of CTAB could be investigated to modify the structure of other geopolymer matrices derived from even cheaper materials, e.g. fly ash.

The next major challenge in the development of "green" geopolymer concrete is to incorporate the metal oxides into coatings for building materials and apply the principles developed here to practical situations. 


\section{Bibliography}

1. N. P. Rajamane, N. L., Nataraja M C Geopolymer Concrete - A New Eco-friendly Material of Construction. http://www.nbmcw.com/articles/concrete/10827-geopolymer-concrete-a-new-ecofriendly-material-of-construction.html

2. Smog, S., Concrete that Cleans itself and the Air. Concrete international 2009, 31.

3. Biello, D., Cement from $\mathrm{CO}_{2}$ : a concrete cure for global warming. Scientific American 2008.

4. Hardjito, D.; Pui, N. T., The Use of Fly Ash to Reduce the Environmental Impact of Concrete.

5. Giussani, B. A Concrete Step Toward Cleaner Air.

http://www.businessweek.com/stories/2006-11-08/a-concrete-step-toward-cleaner-airbusinessweekbusiness-news-stock-market-and-financial-advice

6. Cassar, L., Pepe, C., Tognon, G., Guerrini, G.L. and Amadelli, R., White cement for architectural concrete, possessing photocatalytic properties. In Chemistry of Cement, Durban/South Africa, 2012; Vol. 4.

7. Italcementi The Photocatalytic Active Principle.

http://www.italcementigroup.com/NR/rdonlyres/96036B14-4C6D-4E07-9854-

1B1CE1AD6593/0/TXactivetechnicalreport 2009.pdf

8. Elvin, G. Nanotechnology for Green Building Green Technology Forum: Wiley and Princeton Architectural Press, 2007.

9. Chen, D.; Zhu, Q.; Zhou, F.; Deng, X.; Li, F., Synthesis and photocatalytic performances of the TiO 2 pillared montmorillonite. Journal of hazardous materials 2012, 235, 186-193.

10. Kuo, C.-H.; Huang, M. H., Morphologically controlled synthesis of $\mathrm{Cu}_{2} \mathrm{O}$ nanocrystals and their properties. Nano Today 2010, 5, 106-116.

11. Pollack, G.; Trivich, D., Photoelectric properties of cuprous oxide. Journal of Applied Physics 1975, 46, 163-172.

12. Yang, H.; Ouyang, J.; Tang, A.; Xiao, Y.; Li, X.; Dong, X.; Yu, Y., Electrochemical synthesis and photocatalytic property of cuprous oxide nanoparticles. Materials Research Bulletin 2006, 41, 1310-1318.

13. Huang, L.; Peng, F.; Yu, H.; Wang, H., Preparation of cuprous oxides with different sizes and their behaviors of adsorption, visible-light driven photocatalysis and photocorrosion. Solid State Sciences 2009, 11, 129-138.

14. Chang, Y.; Teo, J. J.; Zeng, H. C., Formation of Colloidal CuO Nanocrystallites and Their Spherical Aggregation and Reductive Transformation to Hollow $\mathrm{Cu}_{2} \mathrm{O}$ Nanospheres. Langmuir 2004, 21, 1074-1079.

15. Legrini, O.; Oliveros, E.; Braun, A. M., Photochemical processes for water treatment. Chemical Reviews 1993, 93, 671-698. 
16. Mills, A.; Davies, R. H.; Worsley, D., Water purification by semiconductor photocatalysis. Chemical Society Reviews 1993, 22, 417-425.

17. Robert, D.; Malato, S., Solar photocatalysis: a clean process for water detoxification. Science of the total environment 2002, 291, 85-97.

18. Nick Serpone, E. P., Photocatalysis: Fundamentals and Applications. New York [u.a.]: 1989.

19. Beeldens, A., An environmental friendly solution for air purification and self-cleaning effect: the application of $\mathrm{TiO}_{2}$ as photocatalyst in concrete. In International Conference on Concrete Block Paving, San Francisco, California USA, 2006.

20. S.E Braslavsky, K. N. H., Glossary of Terms used in Photochemstry. Pure Appl. Chem. 1988, 60, 1055-1106.

21. Fujishima, A., Electrochemical photolysis of water at a semiconductor electrode. Nature 1972, 238, 37-38.

22. Zhao, J.; Yang, X., Photocatalytic oxidation for indoor air purification: a literature review. Building and Environment 2003, 38, 645-654.

23. Linsebigler, A. L.; Lu, G. Q.; Yates, J. T., Photocatalysis on $\mathrm{TiO}_{2}$ Surfaces - Principles, Mechanisms, and Selected Results. Chemical Reviews 1995, 95, 735-758.

24. Herrmann, J.-M., Heterogeneous photocatalysis: fundamentals and applications to the removal of various types of aqueous pollutants. Catalysis Today 1999, 53, 115-129.

25. Dr. N . K. Verma, P. S. K. K. D. B. K., Comprehensive Chemistry XII. Laxmi Publications.

26. Farnetti, E.; Di Monte, R.; Kašpar, J., Homogeneous and Heterogeneous Catalysis.

27. S. L. Kakani, K. C. B., Electronics Theory And Applications. New Age International Ltd. Pub: New Delhi, 2005.

28. Kittel, C., Introduction to solid state physics, . 8de ed.; Wiley: Hoboken, NJ 2005.

29. Emeline, A. V.; Ryabchuk, V.; Serpone, N., Factors affecting the efficiency of a photocatalyzed process in aqueous metal-oxide dispersions: Prospect of distinguishing between two kinetic models. Journal of Photochemistry and Photobiology A: Chemistry 2000, 133, 89-97.

30. Yoder, M. N., Wide bandgap semiconductor materials and devices. Ieee Transactions on Electron Devices 1996, 43, 1633-1636.

31. Alfano, O. M.; Bahnemann, D.; Cassano, A. E.; Dillert, R.; Goslich, R., Photocatalysis in water environments using artificial and solar light. Catalysis Today 2000, 58, 199-230.

32. Xu, H.; Van Deventer, J. S. J., The geopolymerisation of alumino-silicate minerals. International Journal of Mineral Processing 2000, 59, 247-266.

33. Litter, M. I.; Navío, J. A., Photocatalytic properties of iron-doped titania semiconductors. Journal of Photochemistry and Photobiology A: Chemistry 1996, 98, 171-181.

34. Hoffmann, M. R.; Martin, S. T.; Choi, W.; Bahnemann, D. W., Environmental Applications of Semiconductor Photocatalysis. Chemical Reviews 1995, 95, 69-96. 
35. Peral, J.; Domènech, X.; Ollis, D. F., Heterogeneous Photocatalysis for Purification, Decontamination and Deodorization of Air. Journal of Chemical Technology \& Biotechnology 1997, $70,117-140$.

36. Litter, M. I., Heterogeneous photocatalysis: Transition metal ions in photocatalytic systems. Applied Catalysis B: Environmental 1999, 23, 89-114.

37. Saien, J.; Soleymani, A. R., Feasibility of using a slurry falling film photo-reactor for individual and hybridized AOPs. Journal of Industrial and Engineering Chemistry 2012, 18, 16831688.

38. Chen, F.; Xie, Y.; Zhao, J.; Lu, G., Photocatalytic degradation of dyes on a magnetically separated photocatalyst under visible and UV irradiation. Chemosphere 2001, 44, 1159-1168.

39. Galindo, C.; Jacques, P.; Kalt, A., Photodegradation of the aminoazobenzene acid orange 52 by three advanced oxidation processes: $\mathrm{UV} / \mathrm{H}_{2} \mathrm{O}_{2}, \mathrm{UV} / \mathrm{TiO}_{2}$ and $\mathrm{VIS} / \mathrm{TiO}_{2}$ : Comparative mechanistic and kinetic investigations. Journal of Photochemistry and Photobiology A: Chemistry 2000, 130, 3547.

40. Peill, N. J.; Hoffmann, M. R., Mathematical Model of a Photocatalytic Fiber-Optic Cable Reactor for Heterogeneous Photocatalysis. Environmental Science \& Technology 1998, 32, 398-404. 41. Zaleska, A., Doped-TiO 2 : a review. Recent Patents on Engineering 2008, 2, 157-164.

42. Konstantinou, I. K.; Albanis, T. A., $\mathrm{TiO}_{2}$ assisted photocatalytic degradation of azo dyes in aqueous solution: kinetic and mechanistic investigations: A review. Applied Catalysis B: Environmental 2004, 49, 1-14.

43. Houas, A.; Lachheb, H.; Ksibi, M.; Elaloui, E.; Guillard, C.; Herrmann, J.-M., Photocatalytic degradation pathway of methylene blue in water. Applied Catalysis B: Environmental 2001, 31, 145157.

44. Rauf, M.; Ashraf, S. S., Fundamental principles and application of heterogeneous photocatalytic degradation of dyes in solution. Chemical Engineering Journal 2009, 151, 10-18.

45. Zhang, J.; Liu, J.; Peng, Q.; Wang, X.; Li, Y., Nearly Monodisperse $\mathrm{Cu}_{2} \mathrm{O}$ and $\mathrm{CuO}$ Nanospheres: Preparation and Applications for Sensitive Gas Sensors. Chemistry of Materials 2006, $18,867-871$.

46. Zhao, Z. Y.; He, X. J.; Yi, J.; Ma, C. S.; Cao, Y. C.; Qiu, J. B., First-principles study on the doping effects of nitrogen on the electronic structure and optical properties of $\mathrm{Cu}_{2} \mathrm{O}$. RSC Advances 2013, 3, 84-90.

47. Poizot, P.; Laruelle, S.; Grugeon, S.; Dupont, L.; Tarascon, J., Nano-sized transition-metal oxides as negative-electrode materials for lithium-ion batteries. Nature 2000, 407, 496-499.

48. Hara, M.; Kondo, T.; Komoda, M.; Ikeda, S.; Shinohara, K.; Tanaka, A.; Kondo, J. N.; Domen, $\mathrm{K}$., $\mathrm{Cu}_{2} \mathrm{O}$ as a photocatalyst for overall water splitting under visible light irradiation. Chemical Communications 1998, 357-358. 
49. Briskman, R. N., A study of electrodeposited cuprous oxide photovoltaic cells. Solar Energy Materials and Solar Cells 1992, 27, 361-368.

50. Martínez-Ruiz, A.; Moreno, M. G.; Takeuchi, N., First principles calculations of the electronic properties of bulk $\mathrm{Cu}_{2} \mathrm{O}$, clean and doped with $\mathrm{Ag}$, Ni, and $\mathrm{Zn}$. Solid State Sciences 2003, 5, 291-295.

51. Yao, X.; Zhang, Z.; Zhu, H.; Chen, Y., Geopolymerization process of alkali-metakaolinite characterized by isothermal calorimetry. Thermochimica Acta 2009, 493, 49-54.

52. Kiaune, L.; Singhasemanon, N., Pesticidal copper (I) oxide: environmental fate and aquatic toxicity. Rev Environ Contam Toxicol 2011, 213, 1-26.

53. Zhang, D. F.; Zhang, H.; Guo, L.; Zheng, K.; Han, X. D.; Zhang, Z., Delicate control of crystallographic facet-oriented $\mathrm{Cu}_{2} \mathrm{O}$ nanocrystals and the correlated adsorption ability. Journal of Materials Chemistry 2009, 19, 5220-5225.

54. Xiong, Y.; Wiley, B. J.; Xia, Y., Nanocrystals with unconventional shapes--a class of promising catalysts. Angew Chem Int Ed Engl 2007, 46, 7157-9.

55. Zhang, Y.; Deng, B.; Zhang, T. R.; Gao, D. M.; Xu, A. W., Shape Effects of $\mathrm{Cu}_{2} \mathrm{O}$ Polyhedral Microcrystals on Photocatalytic Activity. Journal of Physical Chemistry C 2010, 114, 5073-5079.

56. Ho, J. Y.; Huang, M. H., Synthesis of Submicrometer-Sized $\mathrm{Cu}_{2} \mathrm{O}$ Crystals with Morphological Evolution from Cubic to Hexapod Structures and Their Comparative Photocatalytic Activity. Journal of Physical Chemistry C 2009, 113, 14159-14164.

57. Takata, T.; Furumi, Y.; Shinohara, K.; Tanaka, A.; Hara, M.; Kondo, J. N.; Domen, K., Photocatalytic Decomposition of Water on Spontaneously Hydrated Layered Perovskites. Chemistry of Materials 1997, 9, 1063-1064.

58. Domen, K.; Kondo, J. N.; Hara, M.; Takata, T., Photo-and Mechano-Catalytic Overall Water Splitting Reactions to Form Hydrogen and Oxygen on Heterogeneous Catalysts. Bulletin of the Chemical Society of Japan 2000, 73, 1307-1331.

59. Fernando, C. A. N.; Bandara, T. M. W. J.; Wethasingha, S. K., H2 evolution from a photoelectrochemical cell with $\mathrm{n}-\mathrm{Cu}_{2} \mathrm{O}$ photoelectrode under visible light irradiation. Solar Energy Materials and Solar Cells 2001, 70, 121-129.

60. Senevirathna, M.; Pitigala, P.; Tennakone, K., Water photoreduction with $\mathrm{Cu}_{2} \mathrm{O}$ quantum dots on $\mathrm{TiO}_{2}$ nano-particles. Journal of Photochemistry and Photobiology A: Chemistry 2005, 171, 257259.

61. Siripala, W.; Ivanovskaya, A.; Jaramillo, T. F.; Baeck, S. H.; McFarland, E. W., A Cu $\mathrm{A}_{2} \mathrm{O} / \mathrm{TiO}_{2}$ heterojunction thin film cathode for photoelectrocatalysis. Solar Energy Materials and Solar Cells 2003, 77, 229-237.

62. Duxson, P.; Provis, J. L.; Lukey, G. C.; Mallicoat, S. W.; Kriven, W. M.; van Deventer, J. S. J., Understanding the relationship between geopolymer composition, microstructure and mechanical properties. Colloids and Surfaces A: Physicochemical and Engineering Aspects 2005, 269, 47-58. 
63. Lu, C. H.; Qi, L. M.; Yang, J. H.; Wang, X. Y.; Zhang, D. Y.; Xie, J. L.; Ma, J. M., One-pot synthesis of octahedral $\mathrm{Cu}_{2} \mathrm{O}$ nanocages via a catalytic solution route. Advanced Materials 2005, 17, $2562-+$.

64. Luo, F.; Wu, D.; Gao, L.; Lian, S.; Wang, E.; Kang, Z.; Lan, Y.; Xu, L., Shape-controlled synthesis of $\mathrm{Cu}_{2} \mathrm{O}$ nanocrystals assisted by Triton X-100. Journal of Crystal Growth 2005, 285, 534540.

65. Luo, F.; Wu, D.; Gao, L.; Lian, S.; Wang, E.; Kang, Z.; Lan, Y.; Xu, L., Shape-controlled synthesis of $\mathrm{Cu}_{2} \mathrm{O}$ nanocrystals assisted by Triton X-100. Journal of Crystal Growth 2005, 285, 534540.

66. Li, J.; Liu, L.; Yu, Y.; Tang, Y.; Li, H.; Du, F., Preparation of highly photocatalytic active nano-size $\mathrm{TiO}_{2}-\mathrm{Cu}_{2} \mathrm{O}$ particle composites with a novel electrochemical method. Electrochemistry Communications 2004, 6, 940-943.

67. Shi, H.; Yu, K.; Sun, F.; Zhu, Z. Q., Controllable synthesis of novel $\mathrm{Cu}_{2} \mathrm{O}$ micro/nanocrystals and their photoluminescence, photocatalytic and field emission properties. CrystEngComm 2012, 14, 278-285.

68. Gratzel, M., Photoelectrochemical cells. Nature 2001, 414, 338-44.

69. Lu, X.; Xie, S.; Yang, H.; Tong, Y.; Ji, H., Photoelectrochemical hydrogen production from biomass derivatives and water. Chemical Society Reviews 2014, 43, 7581-7593.

70. Xie, S.; Zhai, T.; Li, W.; Yu, M.; Liang, C.; Gan, J.; Lu, X.; Tong, Y., Hydrogen production from solar driven glucose oxidation over $\mathrm{Ni}(\mathrm{OH}) 2$ functionalized electroreduced- $\mathrm{TiO}_{2}$ nanowire arrays. Green Chemistry 2013, 15, 2434-2440.

71. Esposito, D. V.; Forest, R. V.; Chang, Y.; Gaillard, N.; McCandless, B. E.; Hou, S.; Lee, K. H.; Birkmire, R. W.; Chen, J. G., Photoelectrochemical reforming of glucose for hydrogen production using a WO3-based tandem cell device. Energy \& Environmental Science 2012, 5, 9091-9099.

72. Wang, G.; Ling, Y.; Lu, X.; Zhai, T.; Qian, F.; Tong, Y.; Li, Y., A mechanistic study into the catalytic effect of $\mathrm{Ni}(\mathrm{OH})_{2}$ on hematite for photoelectrochemical water oxidation. Nanoscale 2013, 5, 4129-4133.

73. Hoang, S.; Guo, S.; Hahn, N. T.; Bard, A. J.; Mullins, C. B., Visible Light Driven Photoelectrochemical Water Oxidation on Nitrogen-Modified $\mathrm{TiO}_{2}$ Nanowires. Nano Letters 2012, $12,26-32$.

74. Zheng, Z. K.; Huang, B. B.; Wang, Z. Y.; Guo, M.; Qin, X. Y.; Zhang, X. Y.; Wang, P.; Dai, Y., Crystal Faces of $\mathrm{Cu}_{2} \mathrm{O}$ and Their Stabilities in Photocatalytic Reactions. Journal of Physical Chemistry C 2009, 113, 14448-14453.

75. de Jongh, P. E.; Vanmaekelbergh, D.; Kelly, J. J., $\mathrm{Cu}_{2} \mathrm{O}$ : Electrodeposition and Characterization. Chemistry of Materials 1999, 11, 3512-3517. 
76. Dong, J.; Xu, H.; Zhang, F.; Chen, C.; Liu, L.; Wu, G., Synergistic effect over photocatalytic active $\mathrm{Cu}_{2} \mathrm{O}$ thin films and their morphological and orientational transformation under visible light irradiation. Applied Catalysis A: General 2014, 470, 294-302.

77. Aazam, E. S.; Mohamed, R. M., Environmental remediation of Direct Blue dye solutions by photocatalytic oxidation with cuprous oxide. Journal of Alloys and Compounds 2013, 577, 550-555.

78. Fujishima, A.; Rao, T. N.; Tryk, D. A., Titanium dioxide photocatalysis. Journal of Photochemistry and Photobiology C: Photochemistry Reviews 2000, 1, 1-21.

79. Domen, K.; Kondo, J. N.; Hara, M.; Takata, T., Photo- and Mechano-Catalytic Overall Water Splitting Reactions to Form Hydrogen and Oxygen on Heterogeneous Catalysts. Bulletin of the Chemical Society of Japan 2000, 73, 1307-1331.

80. Senevirathna, M. K. I.; Pitigala, P. K. D. D. P.; Tennakone, K., Water photoreduction with Cu $2 \mathrm{O}$ quantum dots on $\mathrm{TiO}_{2}$ nano-particles. Journal of Photochemistry and Photobiology A-chemistry 2005, 171, 257-259.

81. Liu, L.; Yang, W.; Li, Q.; Gao, S.; Shang, J. K., Synthesis of $\mathrm{Cu}_{2} \mathrm{O}$ Nanospheres Decorated with $\mathrm{TiO}_{2}$ Nanoislands, Their Enhanced Photoactivity and Stability under Visible Light Illumination, and Their Post-illumination Catalytic Memory. ACS Appl Mater Interfaces 2014, 6, 5629-5639.

82. Helailli, N.; Bessekhouad, Y.; Bouguelia, A.; Trari, M., Visible light degradation of Orange II using xCuyOz/TiO ${ }_{2}$ heterojunctions. Journal of hazardous materials 2009, 168, 484-492.

83. Han, C.; Li, Z.; Shen, J., Photocatalytic degradation of dodecyl-benzenesulfonate over $\mathrm{TiO}_{2}-$ $\mathrm{Cu}_{2} \mathrm{O}$ under visible irradiation. Journal of hazardous materials 2009, 168, 215-219.

84. Bessekhouad, Y.; Robert, D.; Weber, J. V., Photocatalytic activity of $\mathrm{Cu}_{2} \mathrm{O} / \mathrm{TiO}_{2}, \mathrm{Bi}_{2} \mathrm{O}_{3} / \mathrm{TiO}_{2}$ and $\mathrm{ZnMn}_{2} \mathrm{O}_{4} / \mathrm{TiO}_{2}$ heterojunctions. Catalysis Today 2005, 101, 315-321.

85. Huang, L.; Peng, F.; Wang, H.; Yu, H.; Li, Z., Preparation and characterization of $\mathrm{Cu}_{2} \mathrm{O} / \mathrm{TiO}_{2}$ nano-nano heterostructure photocatalysts. Catalysis Communications 2009, 10, 1839-1843.

86. Xue, J.; Shen, Q.; Liang, W.; Liu, X.; Xu, B., Controlled synthesis of coaxial core-shell $\mathrm{TiO}_{2} / \mathrm{Cu}_{2} \mathrm{O}$ heterostructures by electrochemical method and their photoelectrochemical properties. Materials Letters 2013, 92, 239-242.

87. Du, Y.; Rabani, J., The Measure of $\mathrm{TiO}_{2}$ Photocatalytic Efficiency and the Comparison of Different Photocatalytic Titania. The Journal of Physical Chemistry B 2003, 107, 11970-11978.

88. Mitchell, J. K.; Soga, K., Fundamentals of soil behavior. Wiley, New York 2005.

89. Salvador, S., Pozzolanic Properties of Flash-Calcined Kaolinite - a Comparative-Study with Soak-Calcined Products. Cement and Concrete Research 1995, 25, 102-112.

90. Grim, R. E., Applied clay mineralogy. 1962.

91. Zhang, G.; He, J.; Gambrell, R. P., Synthesis, characterization, and mechanical properties of red mud-based geopolymers. Transportation Research Record: Journal of the Transportation Research Board 2010, 2167, 1-9. 
92. Y. Zhang, W. S., Z. Li, Hydrogen process of potassium polysialate (K-PSDS) geopolymer cement. 2004, 15 .

93. Kriven, W. M., Inorganic polysialates or 'geopolymers'. American Ceramic Society Bulletin 2010, 89, 31-34.

94. Barbosa, V. F. F.; MacKenzie, K. J. D., Synthesis and thermal behaviour of potassium sialate geopolymers. Materials Letters 2003, 57, 1477-1482.

95. Malone, P. G., Kirkpatrick, T., and Randall, C. A., Potential Applications of Alkali-Activated alumino-silicate binders in military applications. US Army Corps of Engineers, 1986.

96. Lyon, R. E., Balaguru, P. N., Foden, A., Sorathia, U., Davidovits, J. and Davidovics, M., Fireresistant Aluminosilicate Composites. Fire and materials 1997, 21, 67-73.

97. Giancaspro, J., Balaguru, P., and Lyon, R., Use of Inorganic Polymer to Improve the Fire Response of Balsa Sandwich Structures. Journal of Materials in Civil Engineering 2006, 18, 390-397.

98. Balaguru, P. Geopolymer for protective coating of transportation infrastructures; 1998.

99. Buchwald, A.; Hohmann, M.; Kaps, C.; Bettzieche, H.; Kuhnert, J. T. In Stabilised Foam Clay Material with High Performance Thermal Insulation Properties, Ceramic Forum International, 2004.

100. Bell, J.; Gordon, M.; Kriven, W., Use of Geopolymeric Cements as a Refractory Adhesive for Metal and Ceramic Joins. In Advances in Ceramic Coatings and Ceramic-Metal Systems: Ceramic Engineering and Science Proceedings, John Wiley \& Sons, Inc.: 2008; pp 407-413.

101. Zhang, S.; Gong, K.; Lu, J., Novel modification method for inorganic geopolymer by using water soluble organic polymers. Materials Letters 2004, 58, 1292-1296.

102. Li, Z.; Zhang, Y.; Zhou, X., Short fiber reinforced geopolymer composites manufactured by extrusion. Journal of Materials in Civil Engineering 2005, 17, 624-631.

103. Allahverdi, A.; Mehrpour, K.; Kani, E. N., Investigating the possibility of utilizing pumicetype natural pozzonal in production of geopolymer cement. Ceramics-Silikaty 2008, 52, 16.

104. Verdolotti, L.; Iannace, S.; Lavorgna, M.; Lamanna, R., Geopolymerization reaction to consolidate incoherent pozzolanic soil. Journal of Materials Science 2008, 43, 865-873.

105. Davidovits, J., Geopolymers - Inorganic polymeric new materials. Journal of Thermal Analysis 1991, 37, 1633-1656.

106. Duxson, P.; Fernández-Jiménez, A.; Provis, J.; Lukey, G.; Palomo, A.; van Deventer, J. S. J., Geopolymer technology: the current state of the art. Journal of Materials Science 2007, 42, 29172933.

107. Van Jaarsveld, J.; Van Deventer, J.; Lukey, G., The effect of composition and temperature on the properties of fly ash-and kaolinite-based geopolymers. Chemical Engineering Journal 2002, 89, 63-73. 
108. Swanepoel, J.; Strydom, C., Utilisation of fly ash in a geopolymeric material. Applied Geochemistry 2002, 17, 1143-1148.

109. Khale, D.; Chaudhary, R., Mechanism of geopolymerization and factors influencing its development: a review. Journal of Materials Science 2007, 42, 729-746.

110. Ramón Gasca-Tirado, J.; Manzano-Ramírez, A.; Villaseñor-Mora, C.; Muñiz-Villarreal, M.; Sampieri-Bulbarela, S.; Rubio-Ávalos, J.; Amigó Borrás, V.; Mendoza, R. N., Incorporation of photoactive $\mathrm{TiO}_{2}$ in an aluminosilicate inorganic polymer by Ion exchange. Microporous and Mesoporous Materials 2011.

111. Lange, J. P.; Klier, K., Uv-Vis-Nir Studies of Fe(Ii)-a-Zeolite. Zeolites 1994, 14, 462-468.

112. Palomo, A.; Grutzeck, M.; Blanco, M., Alkali-activated fly ashes: A cement for the future. Cement and Concrete Research 1999, 29, 1323-1329.

113. Davidovits, J., Geopolymers: Man-Made Rock Geosynthesis and the Resulting Development of Very Early High Strength Cement. Journal of Material Education 1994, 16, 91-137.

114. MacKenzie, K. J. D.; Brew, D.; Fletcher, R.; Nicholson, C.; Vagana, R.; Schmücker, M., Advances in Understanding the Synthesis Mechanisms of New Geopolymeric Materials. In Novel Processing of Ceramics and Composites, John Wiley \& Sons, Inc.: 2006; pp 185-199.

115. Olivia, M.; Nikraz, H. R., Strength and Water Penetrability of Fly Ash Geopolymer Concrete. Parameters 2006, 1,3 .

116. Davidovits, J., Geopolymer Chemistry and Properties. In First European Conference on Soft Mineralurgy, Orlinski, J. D. a. J., Ed. Geopolymer Institute and Technical University, Compiègne, France, 1988; pp 25-48.

117. Davidovits, J., Geopolymers. Journal of Thermal Analysis and Calorimetry 1991, 37, 16331656.

118. Xu, H. Geopolymerization of Aluminosilicate Minerals. University of Melbourne, 2002.

119. Xu, H.; Van Deventer, J., The geopolymerisation of alumino-silicate minerals. International Journal of Mineral Processing 2000, 59, 247-266.

120. Rowles, M. R.; Hanna, J. V.; Pike, K. J.; Smith, M. E.; O'Connor, B. H., Si-29, Al-27, H-1 and Na-23 MAS NMR study of the bonding character in aluminosilicate inorganic polymers. Applied Magnetic Resonance 2007, 32, 663-689.

121. Barbosa, V. F.; MacKenzie, K. J.; Thaumaturgo, C., Synthesis and characterisation of materials based on inorganic polymers of alumina and silica: sodium polysialate polymers. International Journal of Inorganic Materials 2000, 2, 309-317.

122. Barbosa, V. F.; MacKenzie, K. J., Thermal behaviour of inorganic geopolymers and composites derived from sodium polysialate. Materials Research Bulletin 2003, 38, 319-331.

123. Barbosa, V. F. F.; MacKenzie, K. J. D.; Thaumaturgo, C., Synthesis and characterisation of materials based on inorganic polymers of alumina and silica: sodium polysialate polymers. International Journal of Inorganic Materials 2000, 2, 309-317. 
124. MacKenzie, K., Applications of solid state NMR spectroscopy to ceramic research. British ceramic transactions 2000, 99, 231-240.

125. Miao, S.; Liu, Z.; Han, B.; Zhang, J.; Yu, X.; Du, J.; Sun, Z., Synthesis and characterization of $\mathrm{TiO}_{2}$-montmorillonite nanocomposites and their application for removal of methylene blue. Journal of Materials Chemistry 2006, 16, 579-584.

126. Gasca-Tirado, J. R.; Manzano-Ramírez, A.; Villaseñor-Mora, C.; Muñiz-Villarreal, M. S.; Zaldivar-Cadena, A. A.; Rubio-Ávalos, J. C.; Borrás, V. A.; Mendoza, R. N., Incorporation of photoactive $\mathrm{TiO}_{2}$ in an aluminosilicate inorganic polymer by ion exchange. Microporous and Mesoporous Materials 2012, 153, 282-287.

127. Gasca-Tirado, J.; Manzano-Ramírez, A.; Vazquez-Landaverde, P.; Herrera-Díaz, E.; Rodríguez-Ugarte, M.; Rubio-Ávalos, J.; Amigó-Borrás, V.; Chávez-Páez, M., Ion-exchanged geopolymer for photocatalytic degradation of a volatile organic compound. Materials Letters 2014, $134,222-224$.

128. Černý, Z.; Jakubec, I.; Bezdička, P.; Štengl, V., Preparation of Photocatalytic Layers Based on Geopolymer. In Developments in Strategic Materials: Ceramic Engineering and Science Proceedings, Volume 29, Issue 10, John Wiley \& Sons, Inc.: 2009; pp 113-121.

129. Anderson, C.; Bard, A. J., An Improved Photocatalyst of $\mathrm{TiO}_{2} / \mathrm{SiO}_{2}$ Prepared by a Sol-Gel Synthesis. The Journal of Physical Chemistry 1995, 99, 9882-9885.

130. Anpo, M.; Nakaya, H.; Kodama, S.; Kubokawa, Y.; Domen, K.; Onishi, T., Photocatalysis over binary metal oxides. Enhancement of the photocatalytic activity of titanium dioxide in titaniumsilicon oxides. The Journal of Physical Chemistry 1986, 90, 1633-1636.

131. Anderson, C.; Bard, A. J., Improved Photocatalytic Activity and Characterization of Mixed $\mathrm{TiO}_{2} / \mathrm{SiO}_{2}$ and $\mathrm{TiO}_{2} / \mathrm{Al}_{2} \mathrm{O}_{3}$ Materials. The Journal of Physical Chemistry B 1997, 101, 2611-2616.

132. Minero, C.; Catozzo, F.; Pelizzetti, E., Role of adsorption in photocatalyzed reactions of organic molecules in aqueous titania suspensions. Langmuir 1992, 8, 481-486.

133. Yoneyama, H.; Torimoto, T., Titanium dioxide/adsorbent hybrid photocatalysts for photodestruction of organic substances of dilute concentrations. Catalysis Today 2000, 58, 133-140.

134. Yuan, R.; Guan, R.; Shen, W.; Zheng, J., Photocatalytic degradation of methylene blue by a combination of $\mathrm{TiO}_{2}$ and activated carbon fibers. Journal of Colloid and Interface Science 2005, 282, $87-91$.

135. Mogyorósi, K.; Farkas, A.; Dékány, I.; Ilisz, I.; Dombi, A., TiO 2 -Based Photocatalytic Degradation of 2-Chlorophenol Adsorbed on Hydrophobic Clay. Environmental Science \& Technology 2002, 36, 3618-3624.

136. Shimizu, K.-I.; Kaneko, T.; Fujishima, T.; Kodama, T.; Yoshida, H.; Kitayama, Y., Selective oxidation of liquid hydrocarbons over photoirradiated $\mathrm{TiO}_{2}$ pillared clays. Applied Catalysis A: General 2002, 225, 185-191. 
137. Yamashita, H.; Ichihashi, Y.; Anpo, M.; Hashimoto, M.; Louis, C.; Che, M., Photocatalytic Decomposition of $\mathrm{NO}$ at $275 \mathrm{~K}$ on Titanium Oxides Included within Y-Zeolite Cavities: The Structure and Role of the Active Sites. The Journal of Physical Chemistry 1996, 100, 16041-16044.

138. Bhattacharyya, A.; Kawi, S.; Ray, M. B., Photocatalytic degradation of orange II by $\mathrm{TiO}_{2}$ catalysts supported on adsorbents. Catalysis Today 2004, 98, 431-439.

139. Miao, S.; Liu, Z.; Han, B.; Zhang, J.; Yu, X.; Du, J.; Sun, Z., Synthesis and characterization of $\mathrm{TiO} 2$-montmorillonite nanocomposites and their application for removal of methylene blue. Journal of Materials Chemistry 2006, 16, 579-584.

140. Shichi, T.; Takagi, K., Clay minerals as photochemical reaction fields. Journal of Photochemistry and Photobiology C: Photochemistry Reviews 2000, 1, 113-130.

141. MacKenzie, K. J.; Bradley, S.; Hanna, J. V.; Smith, M. E., Magnesium analogues of aluminosilicate inorganic polymers (geopolymers) from magnesium minerals. Journal of Materials Science 2013, 48, 1787-1793.

142. Aranda, P.; Kun, R.; Martín-Luengo, M. A.; Letaïef, S.; Dékány, I.; Ruiz-Hitzky, E., Titaniasepiolite nanocomposites prepared by a surfactant templating colloidal route. Chemistry of Materials 2007, 20, 84-91.

143. de Paiva, L. B.; Morales, A. R.; Valenzuela Díaz, F. R., Organoclays: Properties, preparation and applications. Applied Clay Science 2008, 42, 8-24.

144. Jordan, J. W.; Hook, B. J.; Finlayson, C. M., The Organophilic Bentonites. II. Organic Liquid Gels. The Journal of Physical and Colloid Chemistry 1950, 54, 1196-1208.

145. Wang, L.; Wang, A., Adsorption properties of Congo Red from aqueous solution onto surfactant-modified montmorillonite. Journal of hazardous materials 2008, 160, 173-180.

146. Chen, D.; Du, G.; Zhu, Q.; Zhou, F., Synthesis and characterization of $\mathrm{TiO}_{2}$ pillared montmorillonites: Application for methylene blue degradation. Journal of Colloid and Interface Science 2013, 409, 151-157.

147. Li, Y.; Liu, J. R.; Jia, S. Y.; Guo, J. W.; Zhuo, J.; Na, P., $\mathrm{TiO}_{2}$ pillared montmorillonite as a photoactive adsorbent of arsenic under UV irradiation. Chemical Engineering Journal 2012, 191, 6674.

148. Manova, E.; Aranda, P.; Martín-Luengo, M. A.; Letaïef, S.; Ruiz-Hitzky, E., New titania-clay nanostructured porous materials. Microporous and Mesoporous Materials 2010, 131, 252-260.

149. Dvininov, E.; Popovici, E.; Pode, R.; Cocheci, L.; Barvinschi, P.; Nica, V., Synthesis and characterization of $\mathrm{TiO}_{2}$-pillared Romanian clay and their application for azoic dyes photodegradation. Journal of hazardous materials 2009, 167, 1050-1056.

150. Okada, K.; Yoshizawa, A.; Kameshima, Y.; Isobe, T.; Nakajima, A.; Mackenzie, K. J. D., Adsorption and photocatalytic properties of $\mathrm{TiO}_{2} /$ mesoporous silica composites from two silica sources (acid-leached kaolinite and Si-alkoxide). Journal of Porous Materials 2011, 18, 345-354. 
151. Sterte, J., Synthesis and properties of titanium oxide cross-linked montmorillonite. Clays and Clay Minerals 1986, 34, 658-664.

152. Ooka, C.; Akita, S.; Ohashi, Y.; Horiuchi, T.; Suzuki, K.; Komai, S.-i.; Yoshida, H.; Hattori, T., Crystallization of hydrothermally treated $\mathrm{TiO}_{2}$ pillars in pillared montmorillonite for improvement of the photocatalytic activity. Journal of Materials Chemistry 1999, 9, 2943-2952.

153. Zhu, H. Y.; Ding, Z.; Barry, J. C., Porous Solids from Layered Clays by Combined Pillaring and Templating Approaches. The Journal of Physical Chemistry B 2002, 106, 11420-11429.

154. Yan, L.-G.; Wang, J.; Yu, H.-Q.; Wei, Q.; Du, B.; Shan, X.-Q., Adsorption of benzoic acid by CTAB exchanged montmorillonite. Applied Clay Science 2007, 37, 226-230.

155. Kibanova, D.; Trejo, M.; Destaillats, H.; Cervini-Silva, J., Synthesis of hectorite- $\mathrm{TiO}_{2}$ and kaolinite- $\mathrm{TiO}_{2}$ nanocomposites with photocatalytic activity for the degradation of model air pollutants. Applied Clay Science 2009, 42, 563-568.

156. He, H.; Ding, Z.; Zhu, J.; Yuan, P.; Xi, Y.; Yang, D.; Frost, R. L., Thermal characterization of surfactant-modified montmorillonites. Clays and Clay Minerals 2005, 53, 287-293.

157. Bai, Y.; Yang, T.; Gu, Q.; Cheng, G.; Zheng, R., Shape control mechanism of cuprous oxide nanoparticles in aqueous colloidal solutions. Powder Technology 2012, 227, 35-42.

158. Shah, M. A., Preparation of Copper $(\mathrm{Cu})$ and Copper Oxide $\left(\mathrm{Cu}_{2} \mathrm{O}\right)$ Nanoparticles under Supercritical Conditions. Materials Sciences and Applications 2011, 02, 977-980.

159. Darezereshki, E.; Bakhtiari, F., A novel technique to synthesis of tenorite $(\mathrm{CuO})$ nanoparticles from low concentration $\mathrm{CuSO}_{4}$ solution. Journal of Mining and Metallurgy Section B-Metallurgy 2011, 47, 73-78.

160. Zohra, B.; Aicha, K.; Fatima, S.; Nourredine, B.; Zoubir, D., Adsorption of Direct Red 2 on bentonite modified by cetyltrimethylammonium bromide. Chemical Engineering Journal 2008, 136, 295-305.

161. Stanjek, H.; Häusler, W., Basics of X-ray Diffraction. Hyperfine Interactions 2004, 154, 107119.

162. Atkins, P.; Jones, L., Chemical principles. WH Freeman: 2006.

163. MooreD. M. and Reynolds, R. C., X-Ray Diffraction and the Identification and Analysis of Clay Minerals. Oxford University Press, New York, 1997.

164. Dunlap, M., Introduction to the Scanning Electron Microscope.

165. Petherbridge, J. R. Diagnostics of microwave activated novel gas mixtures for diamond chemical vapour deposition. University of Bristol, 2002.

166. Smith, B. C., Fundamentals of FourierTransform Infrared Spectroscopy. CRC: 2009.

167. Sathyanarayana, D. N., Vibrational spectroscopy: Theory and applications. New Age International: 2007.

168. Sattler, K. D., Handbook of Nanophysics: Functional Nanomaterials. 1 ed.; CRC Press: 2010. 
169. Steehler, J. K., Ewing's Analytical Instrumentation Handbook, 3rd Edition (Cazes, Jack). Journal of Chemical Education 2005, 82, 1315.

170. Akolekar, D.; Chaffee, A.; Howe, R. F., The transformation of kaolin to low-silica X zeolite. Zeolites 1997, 19, 359-365.

171. Panias, D.; Giannopoulou, I. P.; Perraki, T., Effect of synthesis parameters on the mechanical properties of fly ash-based geopolymers. Colloids and Surfaces A: Physicochemical and Engineering Aspects 2007, 301, 246-254.

172. Mackenzie, K.; Smith, M., Chapter 6 17O NMR. In Pergamon Materials Series, Kenneth, J. D. M.; Mark, E. S., Eds. Pergamon: 2002; Vol. Volume 6, pp 333-395.

173. Mackenzie, K.; Smith, M., Chapter 1 Introduction. In Pergamon Materials Series, Kenneth, J. D. M.; Mark, E. S., Eds. Pergamon: 2002; Vol. Volume 6, pp 3-19.

174. Kroeker, S.; Wasylishen, R. E.; Hanna, J. V., The structure of solid copper (I) cyanide: A multinuclear magnetic and quadrupole resonance study. Journal of the American Chemical Society 1999, $121,1582-1590$.

175. Vega, A. J., 63Cu NQR Nutation Spectroscopy and Spin Counting in Copper Oxides. Israel journal of chemistry 1992, 32, 195-204.

176. Kroeker, S.; Hanna, J. V.; Wasylishen, R. E.; Ainscough, E. W.; Brodie, A. M., Anisotropy in the $31 \mathrm{P}, 63 / 65 \mathrm{Cu}$ Indirect Spin-Spin Coupling and $31 \mathrm{P}$ Nuclear Shielding Tensors of Linear Copper (I) Phosphines. Journal of Magnetic Resonance 1998, 135, 208-215.

177. Kroeker, S.; Wasylishen, R. E.; Hanna, J. V., The Structure of Solid Copper(I) Cyanide: A Multinuclear Magnetic and Quadrupole Resonance Study. Journal of the American Chemical Society 1999, 121, 1582-1590.

178. Li, L.; Wang, S.; Zhu, Z., Geopolymeric adsorbents from fly ash for dye removal from aqueous solution. Journal of Colloid and Interface Science 2006, 300, 52-59.

179. Skoog, D. A.; Holler, F. J.; Crouch, S. R., Principles of Instrumental Analysis. Brooks/Cole: 2007.

180. John Crocker, D. B., The Science of Laboratory Diagnosis. 2 ed.; Wiley: 2005.

181. Cardoso, N. F.; Lima, E. C.; Pinto, I. S.; Amavisca, C. V.; Royer, B.; Pinto, R. B.; Alencar, W. S.; Pereira, S. F., Application of cupuassu shell as biosorbent for the removal of textile dyes from aqueous solution. Journal of Environmental Management 2011, 92, 1237-1247.

182. Pujol, J., The solution of nonlinear inverse problems and the Levenberg-Marquardt method. GEOPHYSICS 2007, 72, W1-W16.

183. Zhang, X.; Song, J.; Jiao, J.; Mei, X., Preparation and photocatalytic activity of cuprous oxides. Solid State Sciences 2010, 12, 1215-1219.

184. Phair, J. W.; Van Deventer, J. S. J.; Smith, J. D., Mechanism of Polysialation in the Incorporation of Zirconia into Fly Ash-Based Geopolymers. Industrial \& Engineering Chemistry Research 2000, 39, 2925-2934. 
185. Xue, W.; He, H.; Zhu, J.; Yuan, P., FTIR investigation of CTAB-Al-montmorillonite complexes. Spectrochimica Acta Part A: Molecular and Biomolecular Spectroscopy 2007, 67, 10301036.

186. Madejová, J.; Janek, M.; Komadel, P.; Herbert, H. J.; Moog, H. C., FTIR analyses of water in MX-80 bentonite compacted from high salinary salt solution systems. Applied Clay Science 2002, 20, 255-271.

187. Vega, A. J., 63Cu NQR Nutation Spectroscopy and Spin Counting in Copper Oxides. Israel journal of chemistry 1992, 32, 195-204.

188. MacKenzie, K. J.; Smith, M. E., Multinuclear solid-state nuclear magnetic resonance of inorganic materials. Elsevier: 2002; Vol. 6.

189. Atun, G.; Hisarli, G.; Sheldrick, W. S.; Muhler, M., Adsorptive removal of methylene blue from colored effluents on fuller's earth. Journal of Colloid and Interface Science 2003, 261, 32-39.

190. Bickley, R. I.; Gonzalez-Carreno, T.; Lees, J. S.; Palmisano, L.; Tilley, R. J., A structural investigation of titanium dioxide photocatalysts. Journal of Solid State Chemistry 1991, 92, 178-190. 191. Hurum, D. C.; Agrios, A. G.; Gray, K. A.; Rajh, T.; Thurnauer, M. C., Explaining the enhanced photocatalytic activity of Degussa P25 mixed-phase $\mathrm{TiO}_{2}$ using EPR. The Journal of Physical Chemistry B 2003, 107, 4545-4549.

192. Ohtani, B.; Prieto-Mahaney, O. O.; Li, D.; Abe, R., What is Degussa (Evonik) P25 Crystalline composition analysis, reconstruction from isolated pure particles and photocatalytic activity test. Journal of Photochemistry and Photobiology A: Chemistry 2010, 216, 179-182.

193. Zhou, Q.; He, H. P.; Zhu, J. X.; Shen, W.; Frost, R. L.; Yuan, P., Mechanism of p-nitrophenol adsorption from aqueous solution by HDTMA+-pillared montmorillonite-implications for water purification. Journal of hazardous materials 2008, 154, 1025-1032.

194. Johnston, C.; Sposito, G.; Erickson, C., Vibrational probe studies of water interactions with montmorillonite. Clays and Clay Minerals 1992, 40, 722-730.

195. Mall, I. D.; Srivastava, V. C.; Agarwal, N. K.; Mishra, I. M., Removal of congo red from aqueous solution by bagasse fly ash and activated carbon: Kinetic study and equilibrium isotherm analyses. Chemosphere 2005, 61, 492-501.

196. Cardoso, N. F.; Lima, E. C.; Pinto, I. S.; Amavisca, C. V.; Royer, B.; Pinto, R. B.; Alencar, W. S.; Pereira, S. F., Application of cupuassu shell as biosorbent for the removal of textile dyes from aqueous solution. $J$ Environ Manage 2011, 92, 1237-47. 